\title{
Role of vascular remodeling in atherosclerosis and aortic aneurysm
}

Citation for published version (APA):

Petsophonsakul, P. (2020). Role of vascular remodeling in atherosclerosis and aortic aneurysm: vascular calcification as a hallmark of increased vascular smooth muscle cell oxidative stress. [Doctoral Thesis, Maastricht University]. Maastricht University. https://doi.org/10.26481/dis.20201102pp

Document status and date:

Published: 01/01/2020

DOI:

10.26481/dis.20201102pp

Document Version:

Publisher's PDF, also known as Version of record

\section{Please check the document version of this publication:}

- A submitted manuscript is the version of the article upon submission and before peer-review. There can be important differences between the submitted version and the official published version of record.

People interested in the research are advised to contact the author for the final version of the publication, or visit the DOI to the publisher's website.

- The final author version and the galley proof are versions of the publication after peer review.

- The final published version features the final layout of the paper including the volume, issue and page numbers.

Link to publication

\footnotetext{
General rights rights.

- You may freely distribute the URL identifying the publication in the public portal. please follow below link for the End User Agreement:

www.umlib.nl/taverne-license

Take down policy

If you believe that this document breaches copyright please contact us at:

repository@maastrichtuniversity.nl

providing details and we will investigate your claim.
}

Copyright and moral rights for the publications made accessible in the public portal are retained by the authors and/or other copyright owners and it is a condition of accessing publications that users recognise and abide by the legal requirements associated with these

- Users may download and print one copy of any publication from the public portal for the purpose of private study or research.

- You may not further distribute the material or use it for any profit-making activity or commercial gain

If the publication is distributed under the terms of Article $25 \mathrm{fa}$ of the Dutch Copyright Act, indicated by the "Taverne" license above, 


\section{Role of Vascular Remodeling in Atherosclerosis and Aortic Aneurysm}

Vascular calcification as a hallmark of increased vascular smooth muscle cell oxidative stress

Ploingarm Petsophonsakul 
Cover Design: Petnoi Petsophonsakul

Layout: Ploingarm Petsophonsakul

Printing: ProefschriftMaken

ISBN: 978-94-6423-023-9

\section{Copyright $(\mathcal{C}$ Ploingarm Petsophonsakul 2020}

All rights reserved. No part of this publication may be reproduced, stored in retrieval system or transmitted, in any form or by any means, electronic, mechanical, photocopying, recording or otherwise, without prior permission of the author or the copyright-owning journals for previous published chapters. 


\title{
Role of Vascular Remodeling in Atherosclerosis and Aortic Aneurysm
}

\author{
Vascular calcification as a hallmark of increased \\ vascular smooth muscle cell oxidative stress
}

\section{Dissertation}

To obtain the degree of Doctor at Maastricht University, on the authority of the Rector Magnificus Prof. Dr. Rianne M. Letschert, in accordance with the decision of the Board of Deans, to be defended in public on Monday 2 November 2020 at 13:00 hours

by

Ploingarm Petsophonsakul 


\section{Supervisors}

Prof. Dr. L.J. Schurgers

Prof. Dr. C.P.M. Reutelingsperger

\section{Co-supervisor}

Dr. B.M.E. Mees

\section{Assessment Committee}

Prof. Dr. T.M. Hackeng (Chairman)

Prof. Dr. J. Maessen

Prof. Dr. G.R.M.M. Haenen

Dr. A. Gombert (Uniklinik RWTH Aachen, Aachen, Germany)

Dr. K.K. Yeung (VUmc, Amsterdam, the Netherlands) 


\section{Content}

$\begin{array}{lll}\text { Chapter } 1 \text { General introduction } & 7\end{array}$

$\begin{array}{lll}\text { Chapter } 2 \text { Vitamin K: double bonds beyond coagulation. } & 17\end{array}$

Insights into differences between vitamin $\mathrm{K} 1$ and $\mathrm{K} 2$ in health and disease

Chapter 3 Role of vascular smooth muscle cell phenotypic switching and calcification in aortic aneurysm formation Involvement of vitamin K-dependent processes

Chapter 4 Vascular smooth muscle cells from abdominal aortic aneurysm are characterised by a dysregulated inflammatory phenotype and oxidative stress with increased extracellular vesicle release, accelerated senescence and calcification

Chapter 5 Nicotine promotes vascular calcification via intracellular $\mathrm{Ca}^{2+}$ mediated, Nox5-induced oxidative stress and extracellular vesicle release in vascular smooth muscle cells

Chapter 6 Vitamin K inhibits vascular smooth muscle cell induced calcification via reduced oxidative stress and extracellular vesicle secretion

Chapter 7 General discussion

Chapter 8 Summary

Appendix Valorisation

About the author

Publications

Acknowledgement 

Chapter 1

General introduction 


\section{Aortic aneurysm}

Aortic aneurysm is a localized dilation of the aorta and is defined by an increase of at least $50 \%$ in aortic diameter. ${ }^{1}$ Abdominal aortic aneurysm (AAA) and thoracic aortic aneurysm (TAA) are most commonly observed, with a prevalence of $4-7 \%$ in male above 65 years of age $^{2,3}$ and $0.16-0.34 \%$ in male and female between $45-74$ years of age ${ }^{4,5}$, respectively. Most AAA are asymptomatic until rupture occurs. ${ }^{6}$ Vessel dilation larger than $5 \mathrm{~cm}$ has been shown to increase risk of aneurysm rupture. ${ }^{7}$ Aortic aneurysms resulted in $>151000$ deaths globally in 2013 and are ranked in the top 15 causes of mortality in the United States. ${ }^{8}$

AAA and TAA shared common risk factors such as male gender and smoking. ${ }^{9}$ Smoking increases the risk of aortic aneurysm in a dose-dependent manner and smoking of more than one cigarette pack per day over 35 years showed a 12 -fold increase risk of AAA. ${ }^{10}$ Other risk factors include hypertension and bicuspid aortic valve for TAA, and advance age for AAA. ${ }^{9,11}$ Atherosclerosis is associated with aortic aneurysm, but to a lesser degree ${ }^{11}$. It has been reported that atherosclerosis and aortic aneurysm are distinct diseases with shared risk profiles. ${ }^{12}$ In contrast to lifestyle-associated risk factors of AAA, genetic factors play a bigger role in the pathogenesis of TAA. This is linked to several specific gene mutations that attribute to a disrupted extracellular matrix (ECM) and dysregulation of TGF-beta signaling. ${ }^{13}$

Despite the severity and high mortality rate, it is not clear what causes aortic aneurysm. Thus far, the pathology underlying aortic aneurysm formation is poorly understood. Molecular imaging of degenerated aortic wall in animal models of AAA revealed several pathological events including angiogenesis, ECM disruption, activated macrophages and tissue proteolysis. ${ }^{10,14-17}$ Whereas AAA is considered to be an atherothrombotic disease, presenting with intraluminal thrombus, oxidative stress and adventitial inflammation, the immune response and intraluminal thrombus is not observed in TAA. ${ }^{18}$ TAA is characterized by mucoid degeneration and accumulation of VSMC-like cells and elastin-poor ECM which leads to vascular remodeling. ${ }^{18}$ Moreover, the physical structure of the vessel wall and district embryonic origin of VSMCs contribute to the difference in pathophysiology between TAA and AAA. ${ }^{19,20}$ VSMC apoptosis and reduced VSMC number are among the common features between AAA and TAA. ${ }^{18,19}$ Indeed, increasing evidence suggests that VSMCs play a central role in the development of aortic aneurysm. ${ }^{21-23}$

Because of lack of understanding in the pathology of aneurysm formation, no pharmacotherapy is yet recommended to reduce risk of aortic aneurysm progression and rupture. ${ }^{24}$ Current management relies exclusively on surgical repair in order to prevent rupture of larger aneurysms $(>55 \mathrm{~mm}) .{ }^{10,25}$ Decision for the type of repair requires careful assessment 
of rupture risk, specific feature or anatomy, life-expectancy, and patient's preference. ${ }^{26-28}$ Endovascular aneurysm repair (EVAR) is most advantageous for higher risk and older age patient with hostile abdomen. ${ }^{26}$ It has proven a lower perioperative morbidity and reduction in recovery time in comparison to an open repair. ${ }^{26}$ However, EVAR comes with higher reintervention rate and cost, whereas open repair has shown a superior long-term durability. ${ }^{25,26}$

Aneurysm rupture risk assessment relies mainly on the size of aneurysm. However, several other rupture risk indicators have been proposed in recent years. ${ }^{29}$ Among those, vascular calcification has been validated as one of the predictors for aortic aneurysm rupture. ${ }^{30-}$ ${ }^{32}$ Indeed, cigarette smoking has also been shown to associate with calcification. ${ }^{33,34}$ Increased degree of calcification has been observed in symptomatic and ruptured aortic aneurysm. ${ }^{31}$ Calcification volume and location affect aortic wall stress, thereby contributing to higher rupture risk of the aneurysm once it exceeds the strength of the wall. ${ }^{32}$ Micromechanical modeling has demonstrated that aneurysm strength decreased when calcification is present. ${ }^{35}$ Indeed, it was shown in an experimental model of AAA that segmental aortic stiffening precedes aneurysm dilation. ${ }^{36}$ Moreover, intervention reduction of segmental stiffness has been shown to reduce wall stress and aneurysm progression. ${ }^{36} \mathrm{~A}$ recent study showed that active microcalcification correlates with presence and progression of AAA, as represented by a significant increase in ${ }^{18} \mathrm{~F}-\mathrm{NaF}$ uptake on positron emission tomography-computed tomography. ${ }^{37}$ Altogether, this puts (micro)calcification forward as a promising risk factor amendable for intervention in AAA. ${ }^{37,38}$

\section{Vascular Calcification}

Vascular calcification is an active process of calcium-phosphate crystal deposition in the vessel wall and is associated with cardiovascular diseases. ${ }^{39}$ Calcification can be categorized based on size. Microcalcification is defined as calcification $<50 \mathrm{um}$, and macrocalcification is defined as calcification $>50 u m .{ }^{40}$ Vascular calcification can occur within the intimal, medial, or adventitial layer of the aortic wall. ${ }^{41}$ Whereas intimal calcification is typically present in atherosclerosis, medial calcification, or Monckeberg's sclerosis, occurs without inflammation and lipid infiltration. ${ }^{42,43}$ Medial calcification is most commonly seen in patients with chronic kidney disease, diabetes, and in the aging population. ${ }^{44,45}$ Intimal calcification is mostly amorphous without distinct architecture and has a patchy distribution within the atherosclerosis lesion. ${ }^{46}$ Medial calcification however, starts at the medial elastic fibers with a key role for VSMCs, and is usually concentric and has a diffuse distribution. ${ }^{46}$ 
Vascular calcification in the adventitia occurs less frequent, and has been shown to be associated with phenotypic differentiation of VSMCs, pericytes and fibroblast. ${ }^{47,48}$

Numerous processes have been proposed as pathological mechanism for the initiation of vascular calcification, including loss of calcification inhibitors, induction of vascular bone and cartilage-like cells, apoptosis, calcium/phosphate imbalance, and circulating nucleation complex such as extracellular vesicles (EVs) and calcifying protein particles (CPPs). ${ }^{49,50}$

Mineralization generally takes place in bone and cartilage under physiological conditions. ${ }^{51}$ Under pathological conditions, ectopic calcification may occur in case of lack of mineralization inhibition processes. ${ }^{52}$ Several inhibitors of vascular calcification have been identified, including matrix Gla-protein (MGP), Fetuin A, pyrophosphate, and ANK. ${ }^{52}$ MGP is a vitamin $\mathrm{K}$-dependent protein which binds directly to calcium-phosphate crystals and inhibits BMP2 function by forming a complex. ${ }^{52}$ In particular, MGP is expressed in healthy VSMCs and potently inhibits vascular calcification when it is carboxylated with the aid of vitamin K. ${ }^{53,54}$

VSMCs are the major cell type in the vessel and they elicit a remarkable phenotypic plasticity. ${ }^{55}$ Under physiological conditions, VSMCs regulate vascular tone and support repair of the vessel wall, which is under continues mechanical stress. However, VSMCs are also known to play a key role in vascular calcification. ${ }^{56}$ Osteochondrogenic differentiation of VSMCs has been described in atherogenesis. ${ }^{55}$ An elevated calcium phosphate level and oxidative stress are amongst factors that induce transdifferentiation of VSMCs into an osteo/chondrogenic phenotype. ${ }^{57-59}$ Osteochondrogenic VSMCs are characterized by downregulation of VSMC contractile genes and upregulation of bone related genes, including OCN, OPN, BMP2, BMP4 and RUNX2. ${ }^{60,61}$ Interestingly, recent attention has been given to senescent VSMCs which also showed increased expression of osteochondrogenic genes. ${ }^{62,63}$ Senescent VSMCs are known to execute apoptosis. ${ }^{64}$ Apoptosis is accompanied with generation of apoptotic bodies, which if not cleared by efferocytosis, can initiate calcification. ${ }^{65}$ This has put forward senescence amongst one of the pathological factors contributing to vascular calcification. ${ }^{62,63}$

Differentiation of VSMCs subsequently leads to the secretion of extracellular vesicles which serve as nucleating factors for calcification. ${ }^{58,66,67}$ Indeed, MGP is highly concentrated in VSMC-derived vesicles. ${ }^{58}$ It has shown that vitamin $\mathrm{K}$ antagonist (warfarin) treatment potentiates VSMC calcification and markedly increases the secretion of VSMC-derived extracellular vesicles that are prone to calcify. ${ }^{58}$ Moreover, high dietary intake of vitamin $\mathrm{K}$ has been shown to reduced coronary artery calcification and progression of aortic valve 
calcification. ${ }^{68-70}$ Mechanistically, it has been shown that vitamin K2 increased MGP and decreased OPN expression of inorganic Pi-induced VSMC calcification in vitro. ${ }^{71}$

\section{Outline of the thesis}

The research described in this thesis aims to unravel mechanisms underlying aortic aneurysm formation. We characterized VSMCs from aortic aneurysm tissue with specific focus on the involvement of vascular calcification in the pathogenesis of abdominal aortic aneurysm. Moreover, we studied the effect of smoking, a known risk factor for the development of aneurysm, on VSMCs and explored the role of vitamin K in VSMC pathologies.

Chapter 2 provides a literature review on fundamental knowledge of vitamin $\mathrm{K}$ and vitamin $\mathrm{K}$ dependent proteins. We elaborated on the different functions and implications in diseases of vitamin $\mathrm{K}$ beyond its well-established role in coagulation. Chapter 3 is based on a review describing the role of VSMC phenotypic switching and calcification in aortic aneurysm formation. We extended on current knowledge by providing an insight in the involvement of vitamin K-dependent processes in aortic aneurysm and shed light on potential treatment mechanisms with vitamin $\mathrm{K}$ to prevent vascular calcification induced aortic aneurysm formation and progression. In Chapter 4, we characterized VSMCs from aneurysm patients and compared apparently healthy VSMCs and VSMCs from the abdominal aneurysm of the same patient. In Chapter 5, we investigated the relationship between nicotine and vascular calcification. More specifically, we investigated the direct effect of nicotine on VSMC phenotype and function. In Chapter 6, we used a pre-clinical animal model to study the effects of VKA and vitamin $\mathrm{K}$ treatment on the development of atherosclerosis and vascular calcification. Chapter 7 outlines the key findings of the research described in this thesis and discusses the relevance in relation to the current literature. 


\section{Reference}

1. Johnston KW, Rutherford RB, Tilson MD, Shah DM, Hollier L, Stanley JC. Suggested standards for reporting on arterial aneurysms. Subcommittee on Reporting Standards for Arterial Aneurysms, Ad Hoc Committee on Reporting Standards, Society for Vascular Surgery and North American Chapter, International Society for Cardiovascular Surgery. Journal of vascular surgery. 1991;13(3):452-8.

2. Kostun ZW, Malik RK. Screening for abdominal aortic aneurysms. Clinical Imaging. 2016;40(2):321-324.

3. Svensjö S, Björck M, Wanhainen A. Update on screening for abdominal aortic aneurysm: A topical review. European Journal of Vascular and Endovascular Surgery. 2014;48(6):659-667.

4. Kälsch H, Lehmann N, Möhlenkamp S, Becker A, Moebus S, Schmermund A, Stang A, Mahabadi AA, Mann K, Jöckel KH, Erbel R, Eggebrecht H. Body-surface adjusted aortic reference diameters for improved identification of patients with thoracic aortic aneurysms: Results from the population-based Heinz Nixdorf Recall study. International Journal of Cardiology. 2013;163(1):72-78.

5. Itani Y, Watanabe S, Masuda Y, Hanamura K, Asakura K, Sone S, Sunami Y, Miyamoto T. Measurement of aortic diameters and detection of asymptomatic aortic aneurysms in a mass screening program using a mobile helical computed tomography unit. Heart and Vessels. 2002;16(2):42-45.

6. Sakalihasan N, Limet R, Defawe OD. Abdominal aortic aneurysm. Lancet. 2005;365(9470):1577-1589.

7. Doyle BJ, Molony D, Walsh MT, Mcgloughlin TM. Abdominal aortic aneurysms: New approaches to rupture risk assessment. Nova Science Publishers, Inc.; 2010.

8. GBD 2013 Mortality and Causes of Death Collaborators. Global, regional, and national age-sex specific all-cause and cause-specific mortality for 240 causes of death, 19902013: a systematic analysis for the Global Burden of Disease Study 2013. The Lancet. 2015;385(9963):117-171.

9. Butcovan D, Mocanu V, Haliga R, Ioan B, Danciu M, Tinica G. Sub-classification of non-inflammatory and inflammatory surgical aortic aneurysms and the association of histological characteristics with potential risk factors. Experimental and Therapeutic Medicine. 2019;18(4).

10. Chaikof EL, Dalman RL, Eskandari MK, Jackson BM, Lee WA, Mansour MA, Mastracci TM, Mell M, Murad MH, Nguyen LL, Oderich GS, Patel MS, Schermerhorn ML, Starnes BW. The Society for Vascular Surgery practice guidelines on the care of patients with an abdominal aortic aneurysm. Journal of Vascular Surgery. 2018;67(1):277.e2.

11. Lee CC, Gabriel Lee MT, Chen YS, Lee SH, Chen YS, Chen SC, Chang SC. Risk of aortic dissection and aortic aneurysm in patients taking oral fluoroquinolone. JAMA Internal Medicine. 2015;175(11):1839-1847.

12. Toghill BJ, Saratzis A, Bown MJ. Abdominal aortic aneurysm - an independent disease to atherosclerosis? Cardiovascular Pathology. 2017;27:71-75.

13. Wu L. The pathogenesis of thoracic aortic aneurysm from hereditary perspective. Gene. 2018;677:77-82.

14. Golestani R, Razavian M, Nie L, Zhang J, Jung JJ, Ye Y, De Roo M, Hilgerink K, Liu $\mathrm{C}$, Robinson SP, Sadeghi MM. Imaging vessel wall biology to predict outcome in abdominal aortic aneurysm. Circulation: Cardiovascular Imaging. 2014;8(1).

15. Kitagawa T, Kosuge H, Chang E, James ML, Yamamoto T, Shen B, Chin FT, Gambhir SS, Dalman RL, McConnell M V. Integrin-targeted molecular imaging of experimental 
abdominal aortic aneurysms by (18)F-labeled Arg-Gly-Asp positron-emission tomography. Circulation. Cardiovascular imaging. 2013;6(6):950-6.

16. Kitagawa T, Kosuge H, Uchida M, Dua MM, Iida Y, Dalman RL, Douglas T, McConnell M V. RGD-conjugated human ferritin nanoparticles for imaging vascular inflammation and angiogenesis in experimental carotid and aortic disease. Molecular Imaging and Biology. 2012;14(3):315-324.

17. Tedesco MM, Terashima M, Blankenberg FG, Levashova Z, Spin JM, Backer M V, Backer JM, Sho M, Sho E, McConnell M V, Dalman RL. Analysis of in situ and ex vivo vascular endothelial growth factor receptor expression during experimental aortic aneurysm progression. Arteriosclerosis, thrombosis, and vascular biology. 2009;29(10):1452-7.

18. Michel J-B, Jondeau G, Milewicz DM. From genetics to response to injury: vascular smooth muscle cells in aneurysms and dissections of the ascending aorta. Cardiovascular Research. 2018;114(4):578-589.

19. Kuivaniemi H, Ryer EJ, Elmore JR, Tromp G. Understanding the pathogenesis of abdominal aortic aneurysms. Expert Review of Cardiovascular Therapy. 2015;13(9):975-987.

20. Guo DC, Papke CL, He R, Milewicz DM. Pathogenesis of thoracic and abdominal aortic aneurysms. In: Annals of the New York Academy of Sciences.Vol 1085. Blackwell Publishing Inc.; 2006:339-352.

21. Clément M, Chappell J, Raffort J, Lareyre F, Vandestienne M, Taylor AL, Finigan A, Harrison J, Bennett MR, Bruneval P, Taleb S, Jørgensen HF, Mallat Z. Vascular Smooth Muscle Cell Plasticity and Autophagy in Dissecting Aortic Aneurysms. Arteriosclerosis, Thrombosis, and Vascular Biology. 2019:ATVBAHA118311727.

22. Petsophonsakul P, Furmanik M, Forsythe R, Dweck M, Schurink GW, Natour E, Reutelingsperger C, Jacobs M, Mees B, Schurgers L. Role of Vascular Smooth Muscle Cell Phenotypic Switching and Calcification in Aortic Aneurysm Formation. Arteriosclerosis, Thrombosis, and Vascular Biology. 2019;39(7):1351-1368.

23. Bogunovic N, Meekel JP, Micha D, Blankensteijn JD, Hordijk PL, Yeung KK. Impaired smooth muscle cell contractility as a novel concept of abdominal aortic aneurysm pathophysiology. Scientific Reports. 2019;9(1):1-14.

24. Yoshimura K, Morikage N, Nishino-Fujimoto S, Furutani A, Shirasawa B, Hamano K. Current Status and Perspectives on Pharmacologic Therapy for Abdominal Aortic Aneurysm. Current Drug Targets. 2017;19(11):1265-1275.

25. Lindeman JH, Matsumura JS. Pharmacologic management of aneurysms. Circulation Research. 2019;124(4):631-646.

26. Brewster DC, Cronenwett JL, Hallett JW, Johnston KW, Krupski WC, Matsumura JS. Guidelines for the treatment of abdominal aortic aneurysms: Report of a subcommittee of the Joint Council of the American Association for Vascular Surgery and Society for Vascular Surgery. Journal of Vascular Surgery. 2003;37(5):1106-1117.

27. Moll FL, Powell JT, Fraedrich G, Verzini F, Haulon S, Waltham M, Van Herwaarden JA, Holt PJE, Van Keulen JW, Rantner B, Schlösser FJV, Setacci F, Ricco JB. Management of abdominal aortic aneurysms clinical practice guidelines of the European society for vascular surgery. European Journal of Vascular and Endovascular Surgery. 2011;41(SUPPL. 1):S1-S58.

28. Wanhainen A, Verzini F, Van Herzeele I, Allaire E, Bown M, Cohnert T, Dick F, Van Herwaarden J, Karkos C, Koelemay M, Kölbel T, Loftus I, Mani K, Melissano G, Powell J, et al. Editor's Choice e European Society for Vascular Surgery (ESVS) 2019 Clinical Practice Guidelines on the Management of Abdominal Aorto-iliac Artery Aneurysms. European Journal of Vascular \& Endovascular Surgery. 2019;57:8-93. 
29. Doyle BJ, Molony D, Walsh MT, Mcgloughlin TM. Abdominal aortic aneurysms: New approaches to rupture risk assessment. Nova Science Publishers, Inc.; 2010.

30. O'Leary SA, Mulvihill JJ, Barrett HE, Kavanagh EG, Walsh MT, McGloughlin TM, Doyle BJ. Determining the influence of calcification on the failure properties of abdominal aortic aneurysm (AAA) tissue. Journal of the Mechanical Behavior of Biomedical Materials. 2015;42:154-167.

31. Buijs RVC, Willems TP, Tio RA, Boersma HH, Tielliu IFJ, Slart RHJA, Zeebregts CJ. Calcification as a Risk Factor for Rupture of Abdominal Aortic Aneurysm. European Journal of Vascular and Endovascular Surgery. 2013;46(5):542-548.

32. Speelman L, Bohra A, Bosboom EMH, Schurink GWH, Van De Vosse FN, Makaorun MS, Vorp DA. Effects of wall calcifications in patient-specific wall stress analyses of abdominal aortic aneurysms. Journal of Biomechanical Engineering. 2007;129(1):105109.

33. Hisamatsu T, Miura K, Arima H, Kadota A, Kadowaki S, Torii S, Suzuki S, Miyagawa N, Sato A, Yamazoe M, Fujiyoshi A, Ohkubo T, Yamamoto T, Murata K, Abbott RD, et al. Smoking, Smoking Cessation, and Measures of Subclinical Atherosclerosis in Multiple Vascular Beds in Japanese Men. Journal of the American Heart Association. 2016;5(9).

34. McEvoy JW, Nasir K, Defilippis AP, Lima JAC, Bluemke DA, Hundley WG, Barr RG, Budoff MJ, Szklo M, Navas-Acien A, Polak JF, Blumenthal RS, Post WS, Blaha MJ. Relationship of cigarette smoking with inflammation and subclinical vascular disease: The multi-ethnic study of atherosclerosis. Arteriosclerosis, Thrombosis, and Vascular Biology. 2015;35(4):1002-1010.

35. Volokh KY, Aboudi J. Aneurysm strength can decrease under calcification. Journal of the Mechanical Behavior of Biomedical Materials. 2016;57:164-174.

36. Raaz U, Zöllner AM, Schellinger IN, Toh R, Nakagami F, Brandt M, Emrich FC, Kayama Y, Eken S, Adam M, Maegdefessel L, Hertel T, Deng A, Jagger A, Buerke M, et al. Segmental Aortic Stiffening Contributes to Experimental Abdominal Aortic Aneurysm Development. Circulation. 2015;131(20):1783-1795.

37. Forsythe RO, Dweck MR, McBride OMB, Vesey AT, Semple SI, Shah ASV, Adamson PD, Wallace WA, Kaczynski J, Ho W, van Beek EJR, Gray CD, Fletcher A, Lucatelli C, Marin A, et al. 18 F-Sodium Fluoride Uptake in Abdominal Aortic Aneurysms. Journal of the American College of Cardiology. 2018;71(5):513-523.

38. Reeps C, Essler M, Pelisek J, Seidl S, Eckstein H-H, Krause B-J. Increased 18Ffluorodeoxyglucose uptake in abdominal aortic aneurysms in positron emission/computed tomography is associated with inflammation, aortic wall instability, and acute symptoms. Journal of Vascular Surgery. 2008;48(2):417-423.

39. Kalra SS, Shanahan CM. Vascular calcification and hypertension: Cause and effect. Annals of Medicine. 2012;44(sup1):S85-S92.

40. Kelly-Arnold A, Maldonado N, Laudier D, Aikawa E, Cardoso L, Weinbaum S. Revised microcalcification hypothesis for fibrous cap rupture in human coronary arteries. Proceedings of the National Academy of Sciences. 2013;110(26):10741-10746.

41. Demer LL, Tintut Y. Inflammatory, metabolic, and genetic mechanisms of vascular calcification. Arteriosclerosis, Thrombosis, and Vascular Biology. 2014;34(4):715-723.

42. Doherty TM, Fitzpatrick LA, Inoue D, Qiao JH, Fishbein MC, Detrano RC, Shah PK, Rajavashisth TB. Molecular, Endocrine, and Genetic Mechanisms of Arterial Calcification. Endocrine Reviews. 2004;25(4):629-672.

43. Lehto S, Niskanen L, Suhonen M, Rönnemaa T, Laakso M. Medial artery calcification: A neglected harbinger of cardiovascular complications in non-insulin-dependent diabetes mellitus. Arteriosclerosis, Thrombosis, and Vascular Biology. 1996;16(8):978- 
983.

44. Young MJ, Adams JE, Anderson GF, Boulton AJM, Cavanagh PR. Medial arterial calcification in the feet of diabetic patients and matched non-diabetic control subjects. Diabetologia. 1993;36(7):615-621.

45. Lanzer P, Boehm M, Sorribas V, Thiriet M, Janzen J, Zeller T, St Hilaire C, Shanahan C. Medial vascular calcification revisited: Review and perspectives. European Heart Journal. 2014;35(23):1515-1525.

46. Desai MY, Cremer PC, Schoenhagen P. Thoracic Aortic Calcification: Diagnostic, Prognostic, and Management Considerations. JACC: Cardiovascular Imaging. 2018;11(7):1012-1026.

47. Li N, Cheng W, Huang T, Yuan J, Wang X, Song M. Vascular adventitia calcification and its underlying mechanism. PLoS ONE. 2015;10(7).

48. Sui Y Bin, Chang JR, Chen WJ, Zhao L, Zhang BH, Yu YR, Tang CS, Yin XH, Qi YF. Angiotensin-(1-7) inhibits vascular calcification in rats. Peptides. 2013;42:25-34.

49. Karwowski W, Naumnik B, Szczepański M, Myśliwiec M. The mechanism of vascular calcification - a systematic review. Medical Science Monitor. 2012;18(1).

50. Giachelli CM. Vascular calcification mechanisms. Journal of the American Society of Nephrology. 2004;15(12):2959-2964.

51. Schäfer C, Heiss A, Schwarz A, Westenfeld R, Ketteler M, Floege J, Müller-Esterl W, Schinke T, Jahnen-Dechent W. The serum protein $\alpha 2$-Heremans-Schmid glycoprotein/ fetuin-A is a systemically acting inhibitor of ectopic calcification. Journal of Clinical Investigation. 2003;112(3):357-366.

52. Lee D. Vascular calcification: Inducers and inhibitors. Materials Science and Engineering B: Solid-State Materials for Advanced Technology. 2011;176(15):11331141.

53. Proudfoot D, Shanahan CM, Weissberg PL. Vascular calcification: new insights into an old problem. The Journal of pathology. 1998;185(1):1-3.

54. Price PA, Williamson MK. Primary structure of bovine matrix Gla protein, a new vitamin K-dependent bone protein. Journal of Biological Chemistry. 1985;260(28):14971-14975.

55. Basatemur GL, Jørgensen HF, Clarke MCH, Bennett MR, Mallat Z. Vascular smooth muscle cells in atherosclerosis. Nature Reviews Cardiology. 2019:1-18.

56. Shanahan CM, Crouthamel MH, Kapustin A, Giachelli CM. Arterial Calcification in Chronic Kidney Disease: Key Roles for Calcium and Phosphate. Towler DA, ed. Circulation Research. 2011;109(6):697-711.

57. Yang H, Curinga G, Giachelli CM. Elevated extracellular calcium levels induce smooth muscle cell matrix mineralization in vitro. Kidney International. 2004;66(6):2293-2299.

58. Reynolds JL, Joannides AJ, Skepper JN, Mcnair R, Schurgers LJ, Proudfoot D, JahnenDechent W, Weissberg PL, Shanahan CM. Human vascular smooth muscle cells undergo vesicle-mediated calcification in response to changes in extracellular calcium and phosphate concentrations: A potential mechanism for accelerated vascular calcification in ESRD. Journal of the American Society of Nephrology. 2004;15(11):2857-2867.

59. Voelkl J, Lang F, Eckardt KU, Amann K, Kuro-o M, Pasch A, Pieske B, Alesutan I. Signaling pathways involved in vascular smooth muscle cell calcification during hyperphosphatemia. Cellular and Molecular Life Sciences. 2019;76(11):2077-2091.

60. Dhore CR, Cleutjens JPM, Lutgens E, Cleutjens KBJM, Geusens PPM, Kitslaar PJEHM, Tordoir JHM, Spronk HMH, Vermeer C, Daemen MJAP. Differential expression of bone matrix regulatory proteins in human atherosclerotic plaques. Arteriosclerosis, Thrombosis, and Vascular Biology. 2001;21(12):1998-2003. 
61. Durham AL, Speer MY, Scatena M, Giachelli CM, Shanahan CM. Role of smooth muscle cells in vascular calcification: implications in atherosclerosis and arterial stiffness. Cardiovascular research. 2018;114(4):590-600.

62. Burton DGA, Matsubara H, Ikeda K. Pathophysiology of vascular calcification: Pivotal role of cellular senescence in vascular smooth muscle cells. Experimental Gerontology. 2010;45(11):819-824.

63. Nakano-Kurimoto R, Ikeda K, Uraoka M, Nakagawa Y, Yutaka K, Koide M, Takahashi T, Matoba S, Yamada H, Okigaki M, Matsubara H. Replicative senescence of vascular smooth muscle cells enhances the calcification through initiating the osteoblastic transition. American Journal of Physiology-Heart and Circulatory Physiology. 2009;297(5):H1673-H1684.

64. Thompson RW, Liao S, Curci JA. Vascular smooth muscle cell apoptosis in abdominal aortic aneurysms. Coronary artery disease. 1997;8(10):623-31.

65. Proudfoot D, Skepper JN, Hegyi L, Bennett MR, Shanahan CM, Weissberg PL. Apoptosis regulates human vascular calcification in vitro: evidence for initiation of vascular calcification by apoptotic bodies. Circulation research. 2000;87(11):1055-62.

66. Krohn JB, Hutcheson JD, Martínez-Martínez E, Aikawa E. Extracellular vesicles in cardiovascular calcification: Expanding current paradigms. Journal of Physiology. 2016;594(11):2895-2903.

67. Kapustin AN, Chatrou MLL, Drozdov I, Zheng Y, Davidson SM, Soong D, Furmanik M, Sanchis P, De Rosales RTM, Alvarez-Hernandez D, Shroff R, Yin X, Muller K, Skepper JN, Mayr M, et al. Vascular Smooth Muscle Cell Calcification Is Mediated by Regulated Exosome Secretion. Circulation Research. 2015;116(8):1312-1323.

68. Beulens JWJ, Bots ML, Atsma F, Bartelink M-LEL, Prokop M, Geleijnse JM, Witteman JCM, Grobbee DE, van der Schouw YT. High dietary menaquinone intake is associated with reduced coronary calcification. Atherosclerosis. 2009;203(2):489-93.

69. Geleijnse JM, Vermeer C, Grobbee DE, Schurgers LJ, Knapen MHJ, van der Meer IM, Hofman A, Witteman JCM. Dietary Intake of Menaquinone Is Associated with a Reduced Risk of Coronary Heart Disease: The Rotterdam Study. The Journal of Nutrition. 2004;134(11):3100-3105.

70. Brandenburg VM, Reinartz S, Kaesler N, Krüger T, Dirrichs T, Kramann R, Peeters F, Floege J, Keszei A, Marx N, Schurgers LJ, Koos R. Slower Progress of Aortic Valve Calcification With Vitamin K Supplementation. Circulation. 2017;135(21):2081-2083.

71. Saito E, Wachi H, Sato F, Sugitani H, Seyama Y. Treatment with vitamin k(2) combined with bisphosphonates synergistically inhibits calcification in cultured smooth muscle cells. Journal of atherosclerosis and thrombosis. 2007;14(6):317-24. 


\section{Chapter}

Vitamin K: double bonds beyond coagulation Insights into differences between vitamin $\mathrm{K} 1$ and $\mathrm{K} 2$ in health and disease.

Maurice Halder ${ }^{1 *}$, Ploingarm Petsophonsakul ${ }^{2 *}$, Asim Cengiz Akbulut ${ }^{2 *}$, Angelina Pavlic ${ }^{2 *}$, Frode Bohan ${ }^{3}$, Eric Anderson ${ }^{3}$, Katarzyna Maresz ${ }^{4}$, Rafael Kramann ${ }^{1}$, Leon Schurgers ${ }^{1,2 \# . ~}$

International journal of molecular sciences. 2019;20(4).

1. Division of Nephrology, RWTH Aachen University, Aachen, Germany

2. Department of Biochemistry, Cardiovascular Research Institute Maastricht, Maastricht University, Maastricht, The Netherlands

3. NattoPharma ASA, Oslo, Norway

4. International Science \& Health Foundation, Krakow, Poland

*These authors contributed equally 


\begin{abstract}
Vitamin $\mathrm{K}$ is an essential bioactive compound required for optimal body function. Vitamin $\mathrm{K}$ can be present in various isoforms, distinguishable by two main structures namely phylloquinone (K1) and menaquinones (K2). The difference in structure between $\mathrm{K} 1$ and $\mathrm{K} 2$ is seen in different absorption rates, tissue distribution, and bioavailability. Although differing in structure, both act as cofactor for the enzyme gamma-glutamylcarboxylase encompassing both hepatic and extrahepatic activity. Only carboxylated proteins are active and promote a health profile like hemostasis. Furthermore, vitamin K2 in the form of MK-7 has been shown as a bioactive compound in regulating osteoporosis, atherosclerosis, cancer and inflammatory diseases without risk of negative side effects or overdosing. This review is the first to highlight differences between isoforms vitamin $\mathrm{K} 1$ and $\mathrm{K} 2$ by means of source, function, and extrahepatic activity.
\end{abstract}

\title{
Introduction
}

Vitamin K was first identified in 1936 to be a key factor in blood clotting. When chickens were fed a low-fat diet, they exhibited significant lower coagulation capacity resulting in severe bleedings (1). The lipid fraction of diet was analyzed and a novel antihemorrhagic factor was discovered. This lipid soluble factor was given the first letter in the alphabet available which coincided with the first letter of the German word "Koagulation" and deemed to be only essential for its anti-hemorrhagic trait (1). Since then non-coagulant functions have been discovered and have gained research interests in a number of fields over the world. The vitamin $\mathrm{K}$ family is comprised of multiple similarly structured fat-soluble molecules containing a 2-methyl-1,4-naphthoquinone ring structure called menadione. Menadione (K3) is of synthetic origin, though due to reported adverse effects of hemolysis and liver toxicity will not encompass the scope of this review (2-4). Naturally, vitamin K occurs as two vitamers: vitamin $\mathrm{K} 1$ (also known as phylloquinone) and vitamin K2 (designated also as menaquinones (MKs)). Phylloquinone contains a phytyl side chain which comprises 4 prenyl units (5). Menaquinones contain an unsaturated aliphatic side chain with a variable number of prenyl units. The number of prenyl units indicates the respective type of menaquinone. Vitamin K2 can be divided in subtypes, namely short-chain (i.e. menaquinone-4; MK-4) and long-chain (i.e. MK-7, MK-8, and MK-9). For K2 no official reference daily intake (RDI) exists at present. Nevertheless, the effects of $\mathrm{K} 2$ on improving health in cardiovascular disease (CVD), bone metabolism, chronic kidney disease and particular cancers has been subject to research in the last decades. The aim 
of this review is to signify and elaborate on the differences between $\mathrm{K} 1$ and $\mathrm{K} 2$, by source, and function with an emphasis on non-coagulant mechanisms of vitamin $\mathrm{K}$.

\section{Dietary vitamin K}

Vitamin $\mathrm{K} 1$ is the predominant form of vitamin $\mathrm{K}$ present in the diet $(6,7) . \mathrm{K} 1$ is predominantly found in green vegetables and plant chlorophylls. Whereas K2 menaquinones are synthesized by bacteria (8) and are primarily found in food where bacteria are part of the production process $(5,9)$. Major sources of $\mathrm{K} 1$ include spinach, cabbage, and kale, and absorption of dietary $\mathrm{K} 1$ is increased in presence of butter or oils. Beyond leafy greens, K1 can also be found in fruits like avocado, kiwi and grapes $(10,11)$. Main known sources of K2 are fermented food, meat, and dairy produce (12) (Figure 1). Fermentation of soy beans with Bacillus natto, produces Natto, a Japanese dish that contains the highest content of K2, in particular MK-7 [321 ng/g of K1, and $10985 \mathrm{ng} / \mathrm{g}$ of K2] (13). Dairy products are the second richest source of K2 in the diet. Hard cheeses are considered to have the highest amount of menaquinones (14). Other notable sources of K2 are chicken meat, egg yolks, sauerkraut, beef and salmon (12) (Figure 1).

\section{VITAMIN K1}

VITAMIN

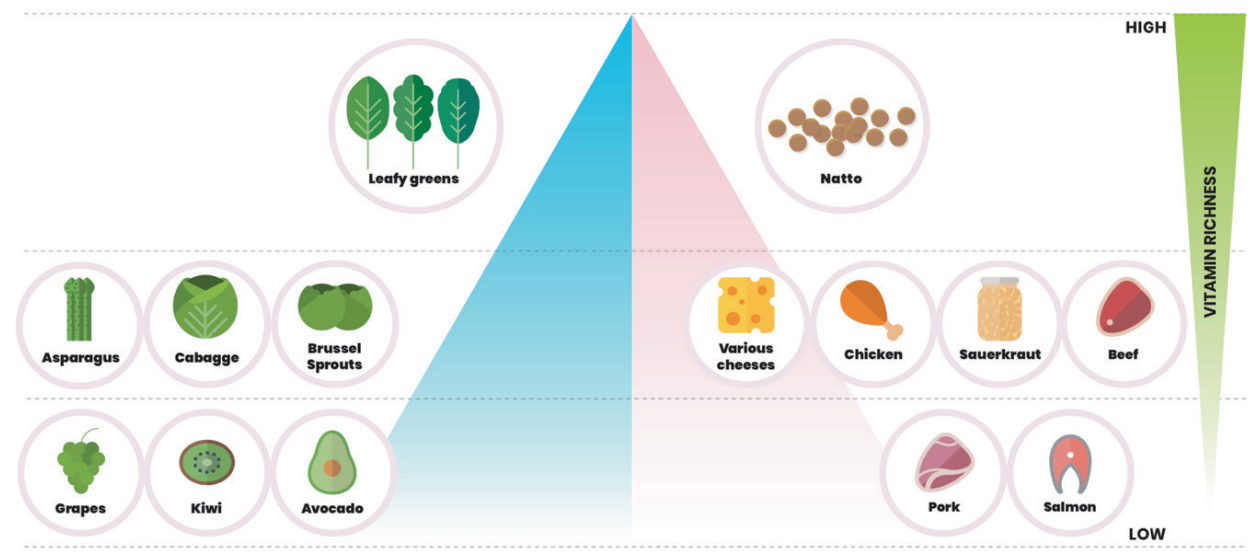

Figure 1. Dietary sources of vitamin K. Left side of pyramid displays K1 content gradient in dietary sources of vitamin K1. Leafy greens include spinach, kale and swiss shards. Right side visualizes K2 content gradient with natto being the most significant source. Various cheeses include hard and soft cheeses with K2 content being dependent on fermentation level. 


\section{Vitamin $K$ in vegetables}

One of the best representatives in this group that contains both forms of vitamin $\mathrm{K}$ is sauerkraut [22.4 $\mu \mathrm{g}$ per $100 \mathrm{~g}$ of K1, and $5.5 \mu \mathrm{g}$ per $100 \mathrm{~g}$ of K2] (14). Leafy green vegetables show highest amount of vitamin K1. Vitamin K1 was present in in collards [706 $\mu \mathrm{g}$ per $100 \mathrm{~g}$ ], in turnip [568 $\mu \mathrm{g}$ per $100 \mathrm{~g}$ ], spinach [96.7 $\mu \mathrm{g}$ per $100 \mathrm{~g}$ ], kale [75.3 $\mu \mathrm{g}$ per $100 \mathrm{~g}$ ], broccoli [146.7 $\mu \mathrm{g}$ per $100 \mathrm{~g}$ ], soybeans roasted [57.3 $\mu \mathrm{g}$ per $100 \mathrm{~g}$ ], and carrot juice [25.5 $\mu \mathrm{g}$ per 100 g] $(7,15,16)$.

\section{Vitamin $\mathrm{K}$ in fruits and nuts}

It has been shown by a US led investigation that generally fruits and nuts do not contain $\mathrm{K} 1$, with the exception of kiwifruit [33.9-50.3 $\mu \mathrm{g}$ per $100 \mathrm{~g}$ ], avocado [15.7-27.0 $\mu \mathrm{g}$ per 100 g], blueberries [14.7-27.2 $\mu \mathrm{g}$ per $100 \mathrm{~g}$ ], blackberries [14.7-25.1 ug per $100 \mathrm{~g}$ ], grapes red and green [13.8-18.1 $\mu \mathrm{g}$ per $100 \mathrm{~g}$ ], dried figs [11.4-20.0 $\mu \mathrm{g}$ per $100 \mathrm{~g}]$ and dried prunes [51.1-68.1 $\mu \mathrm{g}$ per $100 \mathrm{~g}$ ]. K1 was present in several nuts during this study; pine nuts [33.4-73.7 $\mu \mathrm{g}$ per $100 \mathrm{~g}$ ], cashews [19.4-64.3 $\mu \mathrm{g}$ per $100 \mathrm{~g}$ ], and pistachios [10.1-15.1 $\mu \mathrm{g}$ per $100 \mathrm{~g}$ ] (10). Other fruit and nuts reported in the study contain vitamin $\mathrm{K} 1$ in insignificant traces. Further to this, vitamin $\mathrm{K}$ from fruit and nuts in the diet, does not interfere with anticoagulation therapy in patients on warfarin (10).

\section{Vitamin $K$ in cheese}

Vitamin $\mathrm{K}$ cheese content varies depending on a range of factors in production, such as time of ripening and regional differences. These dictate not only the type of cheese but fat and nutrient content. Typically, Dutch hard cheeses contain more K2 compared to softer Mediterranean cheeses. This is most likely influenced by duration of the fermentation process and nature of bacterial strains used (14). Although none of these cheeses can be considered an individual source of vitamin K2, consumption can contribute to total vitamin K levels (17). Vitamin K1 and K2 were assessed in European cheeses and highest amount of K1 was found in Roquefort [6.56 $\mu \mathrm{g}$ per $100 \mathrm{~g}$ ], Pecorino [5.56 $\mu \mathrm{g}$ per $100 \mathrm{~g}$ ], Brie [4.92 $\mu \mathrm{g}$ per $100 \mathrm{~g}$ ], Boursin [4.55 $\mu \mathrm{g}$ per $100 \mathrm{~g}$ ], Norvegia [4.37 $\mu \mathrm{g}$ per $100 \mathrm{~g}$ ], Stilton [3.62 $\mu \mathrm{g}$ per $100 \mathrm{~g}$ ] (14). Other tested cheeses contained less than $3 \mu \mathrm{g}$ per $100 \mathrm{~g}$. Total vitamin K2 was the highest in Münster [80.1 $\mu \mathrm{g}$ per $100 \mathrm{~g}$ ], Camembert [68.1 $\mu \mathrm{g}$ per $100 \mathrm{~g}$ ], Gamalost [54.2 $\mu \mathrm{g}$ per $100 \mathrm{~g}$ ], Stilton [49.4 $\mu \mathrm{g}$ per $100 \mathrm{~g}$ ], Emmenthal [43.3 $\mu \mathrm{g}$ per $100 \mathrm{~g}$ ], Norvegia [41.5 $\mu \mathrm{g}$ per $100 \mathrm{~g}$ ], Roquefort [38.1 $\mu \mathrm{g}$ per $100 \mathrm{~g}$ ], and Raclette [32.3 $\mu \mathrm{g}$ per $100 \mathrm{~g}$ ]. The rest of examined cheeses comprised less than $30 \mu \mathrm{g}$ per $100 \mathrm{~g}$ of vitamin K2 (14). 


\section{Vitamin $\mathrm{K}$ in meat and fish}

Vitamin $\mathrm{K}$ is present in meat and fish, although there are inconsistencies in total content of vitamin $\mathrm{K}$ depending on the origin of the meat (15). For example, the amount of MK-4 differs in chicken meat in the United States [13.6-31.6 $\mu \mathrm{g}$ per $100 \mathrm{~g}$ ], compared to the Netherlands [5.8-11.3 $\mu \mathrm{g}$ per $100 \mathrm{~g}$ ], and Japan [27 $\pm 15 \mu \mathrm{g}$ per $100 \mathrm{~g}$ ] (17). In Europe, vitamin $\mathrm{K} 1$ is found in deer back [24.3 $\mu \mathrm{g}$ per $100 \mathrm{~g}$ ], beef liver [22.9 $\mu \mathrm{g}$ per $100 \mathrm{~g}$ ], and minced meat [10.9 $\mu \mathrm{g}$ per $100 \mathrm{~g}$ ] (14). Values less than $1 \mu \mathrm{g}$ per $100 \mathrm{~g}$ were not deemed noteworthy for this review. The richest $\mathrm{K} 1 \mathrm{fish}$ sources are eel [13 $\mu \mathrm{g}$ per $100 \mathrm{~g}$ ] and mackerel [5.1 $\mu \mathrm{g}$ per $100 \mathrm{~g}$ ] (14).

Total vitamin K2 was present in meaningful concentrations in chicken meat [101 ng per $100 \mathrm{~g}$ ], beef liver [112 ng per $100 \mathrm{~g}$ ], minced meat [76.1 ng per $100 \mathrm{~g}$ ], beef meat [18.9 $\mathrm{ng}$ per $100 \mathrm{~g}$ ], and pork liver [18.4] (14). Only values above $1.5 \mu \mathrm{g}$ per $100 \mathrm{~g}$ for meat were chosen as representatives. Amongst the fish tested in this study, eel [631] had the highest concentration of vitamin K2, followed by plaice [52.8], mackerel [6.2], and salmon [5.7]. Rest of the examined fish species contained less than $0.5 \mu \mathrm{g}$ per $100 \mathrm{~g}$ of vitamin $\mathrm{K} 1$ and total vitamin $\mathrm{K} 2$ (14).

\section{Adequate Intake is an Estimate}

Vitamin $\mathrm{K}$ content can vary depending on approach used for detection, especially in case of K2. The gold standard for measuring vitamin $\mathrm{K}$ is by high-performance liquid chromatography (HPLC) using C-18 reversed phase column and fluorometric detection after post-column zinc reduction. This technique is used frequently to analyze vitamin $\mathrm{K}$ content in food and enables quantification of separate vitamin $\mathrm{K}$ isoforms. For example, a European standard method (EN 14148:2003) was developed to determine vitamin K1 by HPLC, however no official registered method exists for K2. Typical recommended vitamin K intake in North America varies from 50 to as high as $600 \mu \mathrm{g}$ /day for vitamin $\mathrm{K} 1$, and from 5 to $600 \mu \mathrm{g} / \mathrm{day}$ for vitamin K2 (12). The challenge lies in assessing an adequate intake, as current requirement is an estimate based on regional consumption. Currently, daily recommended intake for vitamin $\mathrm{K}$ is based solely on intake of vitamin $\mathrm{K} 1$, blood coagulation and differs by region (18-20). It is defined as a median from daily intake in healthy individuals and differs worldwide. According to National Academy of Medicine (NAM), previously known as Institute of Medicine, required vitamin $\mathrm{K}$ dosage for adult men is $120 \mu \mathrm{g} /$ day and $90 \mu \mathrm{g} / \mathrm{day}$ for women. According to World Health Organization (WHO) and Food and Agriculture Organization (FAO), the dosage is $65 \mu \mathrm{g} / \mathrm{day}$ for men and $55 \mu \mathrm{g} /$ day for women, on the basis of $1 \mu \mathrm{g} / \mathrm{day} / \mathrm{kg}$ 
vitamin K. The Commission of the European Communities sets a RDI for vitamin K of 75 $\mu \mathrm{g} /$ day $(12,21-23)$. In case of vitamin K1, NAM implies that the average intake is currently already higher than adequate (surpassing 100\%) (22). Therefore, daily recommended intake of vitamin $\mathrm{K} 1$ can be reached easily by Western diet, as no deficiency in vitamin K1 has been reported so far in healthy adults (12). However, intake of vitamin K2 from food, corresponds to only $25 \%$ and $5 \%$ of the total vitamin $\mathrm{K}$ intake, respectively (21). Therefore, administration of $\mathrm{K} 2$ via supplements in a high dosage might be advisable to meet the required daily intake for improvement of overall health (12).

\section{Functions of vitamin $\mathrm{K} 1$ and $\mathrm{K} 2$}

The most well-known function of vitamin $\mathrm{K}$ is as cofactor in the activation of vitamin K-dependent coagulations factors $(24,25)$. Through post translational modification of glutamate $(\mathrm{Glu})$ residues in coagulation factors, vitamin $\mathrm{K}$ enables posttranslational carboxylation which allows a high affinity binding with support of calcium to negatively charged phospholipid membrane areas and therefore maintains hemostasis (26-28).

Due to well-established guidelines, vitamin K1 is also administered as a medication. For instance, newborns are given $1 \mathrm{mg} \mathrm{K} 1$ shortly after birth to prevent the potentially lethal vitamin $\mathrm{K}$ deficiency bleeding (VKDB). VKDB occurring within the first 24 hours of life is uncommon and usually caused by prescribed drugs to the mother. These may interfere with fetal vitamin K metabolism (29). Without prophylaxis, VKDB can occur within the first week after birth due to vitamin $\mathrm{K}$ deficiency caused by insufficient placental transfer and low concentrations in breast milk of vitamin K $(30,31)$. Moreover, vitamin K1 is used as an antagonist in patients on vitamin K Antagonist (VKA) treatment prior to elective surgery or when international normalized ratio (INR) values are too high (prolonged bleeding) $(32,33)$. Other functions of vitamin K are mainly ascribed to vitamin K2 (discussed below). Different strains of bacteria synthesize a variety of menaquinones, the exception being MK-4. MK-4 is a product of tissue specific conversion from phylloquinone, and can be found in mammals (34). Nakagawa et al. identified UbiA prenyltransferase containing 1 (UBIAD1), a human homologue of Escherichia coli prenyltransferase, responsible for the conversion of phylloquinone to MK-4 in several tissues such as the cerebrum, liver and pancreas (35). The discovery of a MK-4 biosynthetic enzyme in humans and confirmation that MK-4 originates from phylloquinone, might support the rationale behind a lower efficacy of MK-4 compared to other menaquinones. 


\section{Vitamin K: The vitamin K cycle}

Both vitamin $\mathrm{K} 1$ and $\mathrm{K} 2$ can function as cofactor in the carboxylation process of vitamin $\mathrm{K}$ dependent proteins (VKDPs). That being, vitamin $\mathrm{K}$ serves as a cofactor for $\gamma$ glutamylcarboxylase (GGCX), which catalyzes the Glu residue of VKDPs into $\gamma$ carboxyglutamic acid (Gla). This process is driven by the oxidation of vitamin K-hydroquinone $\left(\mathrm{KH}_{2}\right)$ to vitamin $\mathrm{K}$-epoxide $(\mathrm{KO})$ in the vitamin $\mathrm{K}$ cycle. The vitamin $\mathrm{K}$-oxidoreductase (VKOR) converts $\mathrm{KO}$ to vitamin $\mathrm{K}$ and back to $\mathrm{KH}_{2}$, generating a recycling process of vitamin K $(36,37)$. Consequently, VKAs inhibit VKOR and thereby the recycling of vitamin K resulting in a drug-induced vitamin $\mathrm{K}$ deficiency (38).

VKDPs are categorized as hepatic and extra-hepatic VKDPs. Hepatic VKDPs include coagulation factors II, VII, IX, X, and anticoagulant protein C, protein S, and protein Z, all of which are involved in regulating blood coagulation. Extra-hepatic VKDPs include Matrix Gla protein (MGP), Osteocalcin, and Gla-rich protein (GRP) (36). These VKDPs are primarily involved in maintaining bone homeostasis as well as inhibiting ectopic calcification (39). MGP is primarily expressed in vascular smooth muscle cells and chondrocytes. This protein is known to inhibit extracellular matrix mineralization of vascular lesions and is involved in vascular remodeling (40-42). Osteocalcin can be defined as a bone tissue-specific protein and is involved in regulating mineral deposition $(36,43)$. GRP can be found in calcified cartilage and vasculature, where it directly binds and inhibits crystal formation/maturation and vascular smooth muscle cell calcification $(36,44,45)$.

In addition to the role of vitamin $\mathrm{K}$ in the carboxylation of VKDPs, recent studies suggest a role for vitamin $\mathrm{K}$ as an antioxidant. A paralogue enzyme of VKORC1, named VKORC1-like 1 (VKORC1L1), is expressed in many tissues. VKORC1L1 has been shown to mediate vitamin K-dependent intracellular antioxidant function in the human cellular membrane (46). Indeed, vitamin $\mathrm{KH}_{2}$ exhibits an antioxidative activity of 10 to 100 fold higher than any other known radical scavengers, such as alpha-tocopherol and ubiquinone (47). Vitamin K protects the cellular membrane from lipid peroxidation (48). This antioxidative activity is diminished in the presence of warfarin. Both vitamin K1 and K2 prevent oxidative stress in neuronal cells and primary oligodendrocytes through inhibition of 12-Lipoxygenase $(49,50)$. In addition to antioxidative properties, vitamin $\mathrm{K}$ has been reported to facilitate ATP generation and rescue mitochondrial dysfunction (51). 


\section{Vitamin K: Bioavailability}

Of all the menaquinones, MK-7 is absorbed most efficiently and exhibits greatest bioavailability $(6,13)$. This was shown by a comparative study between K1 and MK-7 following intake of vegetables and $\mathrm{K} 2$ rich food, respectively. Both vitamin $\mathrm{K} 1$ and MK-7 were readily absorbed within 2 hours after ingestion. However, postprandial serum concentrations of K2 (MK-7) were 10-fold higher than K1 (6). K1 showed large interindividual variation in fasting plasma concentrations (52). Vitamin $\mathrm{K} 1$ also showed inferior absorption in comparison to MK-4 as well as longer chain menaquinone food sources (MK-8 and MK-9) (6). Long chain menaquinones, such as MK-7 and MK-9, have longer half-life in circulation in comparison to K1 (Figure 2) (53). Thus, it is available for longer in the circulation to be absorbed by extrahepatic tissue (13). However, not all menaquinones are equally well absorbed. The bioavailability of MK-4 does not reflect an increased serum concentration after administration. However, MK-7 administration is reflected in increased serum MK-7 levels up to several days, thereby contributing to vitamin K status (54). Finally, MK-9 being even more lipophilic has a very long half-life but due to the lipophilicity is poorly absorbed (53).

\section{Vitamin K: Uptake and distribution}

All vitamin $\mathrm{K}$ forms can be taken up by enterocytes in the small intestine and packaged into chylomicrons during absorption. These chylomicrons are then taken up by the liver. Moreover, vitamin K1 has a rapid removal rate from the circulation. This was revealed by giving isotope-labeled phylloquinone to a volunteer, which then showed rapid appearance of radiolabeled excretory metabolites in urine and bile $(55,56)$. Vitamin $\mathrm{K} 1$ is preferentially retained in the liver to assist carboxylation of clotting factors (53). In contrast, vitamin $\mathrm{K} 2$, particularly long chain derivatives, are redistributed to the circulation and are available for extra-hepatic tissues such as bone and vasculature (Figure 2) $(5,53)$. 


\section{BIOAVAILABILITY OF VITAMIN K}

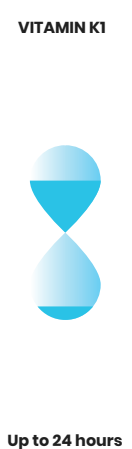

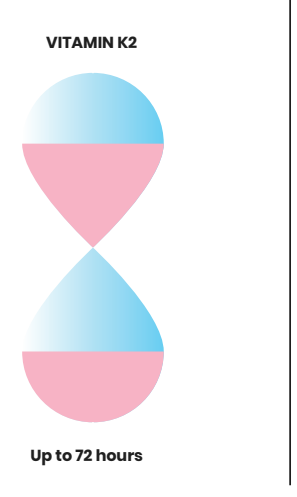

\section{BIODISTRIBUTION OF VITAMIN K}

VITAMIN KI

VITAMIN K2

Figure 2. Bioavailability and biodistribution of vitamin $\mathrm{K}$. Vitamin $\mathrm{K} 2$ has a longer half-life in the circulation than vitamin $\mathrm{K} 1$. While vitamin $\mathrm{K} 1$ is retained and exerts its function in the liver, vitamin $\mathrm{K} 2$ is redistributed to the circulation and (extra-)hepatic tissues.

\section{Vitamin K2: Health and Disease}

Vitamin K2 dependent proteins are expressed in a varying manner in both soft and hard tissues. The role of K1 in coagulation is well established and has been reviewed elsewhere. Whereas vitamin K2's position in health and disease is well recognized within CVD, bone development and fractures, chronic kidney disease and certain cancers.

Additional evidence is demonstrating further roles of vitamin $\mathrm{K} 2$ in liver disease, immune function, neurological diseases and obesity.

\section{Vitamin K2: Cardiovascular disease}

Vascular calcification is an active process that causes CVD, the largest killer in the world (57). It is well known that vitamin K2-dependent proteins activate a protective mechanism preventing the development of vascular calcification (58). Further, vitamin K2, in the form of MK-7, has been proven in numerous trials with healthy and diseased patient cohorts to have a long-term protective effect on the development of calcification (59-62). Additionally, several studies have demonstrated an overall reduction in risk of CVD development (63). Even a regression of arterial stiffening and improvement of vascular elasticity have been observed in healthy population cohorts, following supplementation. Interestingly, in a study investigating all vitamin $\mathrm{K} 1$ and $\mathrm{K} 2$ isoforms, only $\mathrm{K} 2$ was effective and beneficial for CVD health and not K1 (64). Furthermore, the role of K2 in CVD is profound and can be found 
discussed detail elsewhere $(58,59,65)$. At present there are multiple large clinical studies over the world with vitamin K2 supplementation to a variety of cardiovascular patients, the results of which will add further substance to the role of vitamin K2 in CVD (66).

\section{Vitamin K2: Bone fractures and degeneration}

Bone fracture and quality is important in any aged population. Vitamin $\mathrm{K} 2$ is known to improve bone quality, which in turn reduces fracture risk as demonstrated by numerous studies with population groups above the age of 50 (67-70). Further, children are inherently born vitamin $\mathrm{K} 2$ deficient, and there is the implication that should this not be corrected, inadequate bone formation might take place (71). This is substantiated by mutations to vitamin Kdependent enzymes resulting in birth defects that affect development of bone and cartilage (72). Within bone marrow mesenchymal stem cells, vitamin K2 treatment supports osteogenic differentiation (73). Osteocalcin expression in bone is related to proper function, although the precise mechanism is under ongoing research (58). Further to this, there are population studies currently underway that will shed further light on the role of vitamin K2 on bone development, health and maintenance $(74,75)$.

\section{Vitamin K2: Diabetes Mellitus}

Long term supplementation of vitamin $\mathrm{K} 2$ has been shown to reduce the risk of diabetes development. The largest study with 38,000 men and women, aged 20-70 demonstrated that just $10 \mu \mathrm{g} /$ day of K2 decreases diabetes risk by $7 \%$ (76). The mechanism by which this $\mathrm{K} 2$ may act in doing so is beginning to be unraveled. Vitamin K2 activates osteocalcin, which has been shown in vitro to promote proliferation of pancreatic beta cells as well as increasing insulin production and expression of CyclinD1 (77-79). The specific mechanism is currently under research and it is hypothesized that osteocalcin, lectin and adiponectin have an intricate network for glucose metabolism that can be modulated by vitamin K2 (80).

\section{Vitamin K2: Cancer}

Interestingly vitamin $\mathrm{K} 2$ has been explored in a number of clinical interventions to supplement cancer treatments (81). In vitro studies found K2 supplementation alone to prevent growth and metastasis of multiple cancer cell lines (82-84). The mechanisms by which vitamin K2 can inhibit proliferation and metastasis of cancers has been reviewed elsewhere (80). In short, vitamin K2 may act in a number of pathways including protein kinase A, protein kinase $\mathrm{C}$, nuclear factor kappa B and steroid and xenobiotic receptor $(81,85)$. Furthermore, there are 
multiple cases by which K2 supplementation alongside standard treatment subsided cancer development, including multiple cases where patients entered complete remission $(86,87)$. Remarkably vitamin K2's action as an anticancer agent is not limited to a definitive cancer type and instead has been reported in multiple cancer forms (81).

\section{Vitamin K2: Liver Disease}

The role of vitamin $\mathrm{K}$ in the liver has been well established with regards to production of coagulation factors and activation of VKDPs $(88,89)$. While majority of research has focused on K1, K2's has a higher bioactivity, might act in a similar manner to hepatic tissue. Additionally, emerging vitamin $\mathrm{K} 2$ research is demonstrating a regenerative effect on oval cells as well as maturation of hepatic cells from stem cell cultures $(90,91)$. This suggests that there might be a developmental importance of K2 in the liver. Further, within the anticancer effects of vitamin K2 several trials have found MK-4 to be an effective agent against hepatocarcinomas that have arisen from alcoholic and non-alcoholic liver cirrhosis $(85,92)$. Moreover, there is a positive trend in vitamin K2 supplementation to treat liver cirrhosis. Though, further investigation is required to determine whether this is significant and to understand the mechanism by which vitamin $\mathrm{K} 2$ acts in liver disease.

\section{Vitamin K2: Chronic Kidney Disease}

Status of dephosphorylated-uncarboxylated-MGP (dp-ucMGP) is an accepted research marker for vitamin K deficiency first described in patients with chronic kidney disease (93). Dp-ucMGP is associated with progression of CKD, that being later stage CKD patients have higher circulating dp-ucMGP levels (94-97). Vitamin K2 supplementation has been shown to improve renal artery function and prevent further development of renal artery calcification $(62,98)$. This has an overall benefit to renal function. Further to this it has been demonstrated that vitamin K2 supplementation may improve glomerular filtration in a patient cohort (96). The promise of vitamin K2 in CKD research is great and there are multiple large-scale studies underway using vitamin K supplementation to treat patients with CKD (74,99-101).

\section{Vitamin K2: The Immune System}

In recent years, ex vivo studies have demonstrated a previously unknown immunomodulatory role for vitamin K2. First it was demonstrated that MK-7 modulated expression of TNF-Alpha, IL-1Alpha and IL-1Beta (102). Furthering this finding K2 decreases proliferation of T-cells from healthy individuals, whereas vitamin K1 had no such effect (103). 
This has been further substantiated with T-cells from a larger number of children with pediatric atopic dermatitis and healthy controls, as well as a separate study with patients on dialysis $(104,105)$. Both these studies demonstrated that K2 decreased the number of activated T-cells as well as proliferation. Thus, accumulated evidence is showing a novel role of K2 as an immunosuppressive agent. This needs to be further elaborated, until then a novel physiological mechanism by which vitamin K2 can aid immunomodulation can be hypothesized though requires further study.

\section{Vitamin K2: Neurological Disease}

Extrahepatic activity of vitamin $\mathrm{K} 2$ has been elucidated in vivo by varying activity of K2 recycling enzymes in different tissues. Prominently, a subset of vitamin K2 enzymes have been shown to be highly expressed in the brain (106). Protective effect of K2 on neurons in vitro has been documented (107). MK-4 improved energy production and rescued PINK1 mutation found in Parkinson's disease (51). More recently, research identified vitamin K2 protection of neurons via a novel mechanism involving P38 MAP kinase pathway (108). Further to this various $\mathrm{K} 2$ analogous have been found to be decisive in neuronal differentiation (109). The first epidemiological study of K2 in relation to neuronal activity involved a cohort of 45 patients with multiple sclerosis (MS) and 29 healthy volunteers (110). K2 levels were greatly reduced in patients with MS compared to the controls that were gender and age dependent. Also, K2 levels were correlated to neurological spasms and lesions of the optic nerves. These emerging studies suggest a potentially important role of vitamin $\mathrm{K} 2$ in neurological development and disease.

\section{Vitamin K2: Obesity}

The link between osteocalcin and adiponectin has been strongly suggested, however the mode by which any such action takes place remains elusive $(78,111,112)$. Direct elevation of uncarboxylated osteocalcin (ucOC) levels reduced fat mass and improved glucose metabolism in mice $(79,113)$. More recently, supplementation of vitamin K1 and MK-4 to rats reduced total fat and serum triglyceride levels (114). Furthering this, a mechanism has been implicated by Ding et al. by which VKORC1L1 was found to promote adipogenesis (115). Consequently, downregulation of VKORC1L1 increased intracellular K2 levels, and preadipocyte differentiation was inhibited (115). Human cohort studies have shown improvements in body weight, waist circumference, body composition, visceral fat and diabetes mellitus from K2 supplementation (116-119). This all suggests to an overall beneficial 
effect of vitamin $\mathrm{K} 2$ on glucose and fat metabolism that requires further investigation to confirm.

\section{Conclusion and future perspective}

The existence of vitamin $\mathrm{K}$ has been known for over 80 years, namely via the essential role in coagulation. The discovery of different isoforms of vitamin $\mathrm{K}$ is beginning to elucidate a significant role of vitamin $\mathrm{K}$ outside of coagulation. Functions of $\mathrm{K} 2$ are proving to be beneficial with regards to CVD and bone metabolism. There is a growing body of evidence suggesting vitamin $\mathrm{K} 2$ is involved in multiple cellular processes and might have a protective role in various organs throughout the human body (Figure 3). While vitamin K2 has improved outcome in many clinical trials, the exact mechanism of action remains to be unraveled. Major health organizations, such as WHO, European Food Safety Authority (EFSA) and Food and Drug Administration (FDA) have established RDI for vitamin K, that is solely based on the dose of $\mathrm{K} 1$ to retain an appropriate blood clotting function. This review highlights and summarizes differences between vitamin $\mathrm{K} 1$ and $\mathrm{K} 2$ in intake and function. When exploring the non-coagulation, extrahepatic activity of vitamin $\mathrm{K}$ it is clear that $\mathrm{K} 2$ in its various forms is the highlight of such activity. Therefore, although history and nomenclature has classed K1 and K2 into the same category, these molecules can have a very different action in the body. Though a new realm to vitamin $\mathrm{K}$ seems to be on the horizon, whether it opens up new answers into health and disease remains to be seen. Differences between K1 and K2 merit recognition between national and international regulatory organizations and remain open to research.

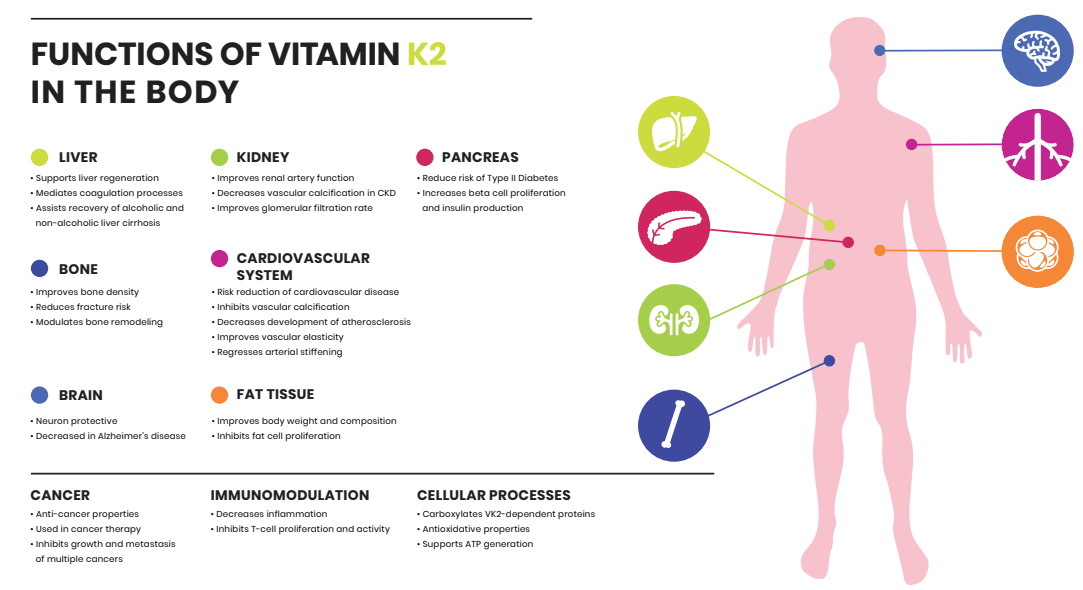

Figure 3. Functions of vitamin $\mathrm{K} 2$ in the body. Vitamin $\mathrm{K} 2$ exerts protective role and is involved in various organ systems throughout the human body (summarized in the figure). 
CHAPTER 2

\section{Acknowledgements}

We thank Nutricon.eu for help with graphics.

\section{Sources of Funding}

Research from MH, ACA, RK and LJS is in part funded via the European Union's Horizon 2020 research and innovation programme under the Marie Skłodowska-Curie grant agreement No 722609. Research from PP, AP, and LJS is in part funded via the European Union's Horizon 2020 research and innovation programme under the Marie Skłodowska-Curie grant agreement No 675111. RK received support from the Germany Research Foundation (DFG), SFB TRR219, TP C05.

\section{Disclosures}

Frode Bohan and Eric Anderson, are employed by NattoPharma ASA, which is industrial partner of the Marie Skłodowska-Curie grants No 722609 and No 675111. 


\section{References}

1. Dam H, Schønheyder F. The occurrence and chemical nature of vitamin K. Biochem J. Portland Press Ltd; 1936 May;30(5):897-901.

2. Shenkin A. Dietary reference values for vitamin A, vitamin K, arsenic, boron, chromium, copper, iodine, iron, manganese, molybdenum, nickel, silicon, vanadium and zinc. Journal of Human Nutrition and Dietetics. Wiley/Blackwell (10.1111); 2003 Jun;16(3):199-200.

3. Schwalfenberg GK. Vitamins K1 and K2: The Emerging Group of Vitamins Required for Human Health. J Nutr Metab. Hindawi; 2017;2017(18):6254836-6.

4. Gröber U, Reichrath J, Holick MF, Kisters K. Vitamin K: an old vitamin in a new perspective. Dermato-Endocrinology. Taylor \& Francis; 2015 Jan 14;6(1):e968490.

5. Shearer MJ, Newman P. Metabolism and cell biology of vitamin K. Thrombosis and Haemostasis. Schattauer GmbH; 2017 Nov 22;100(10):530-47.

6. Schurgers LJ, Vermeer C. Determination of Phylloquinone and Menaquinones in Food. Pathophysiology of Haemostasis and Thrombosis. 2001 Apr 1;30(6):298-307.

7. Gijsbers BLMG, Jie K-SG, Vermeer C. Effect of food composition on vitamin K absorption in human volunteers. British Journal of Nutrition. Cambridge University Press; 2007 Mar 9;76(02):223-9.

8. Bentley R, Meganathan R. Biosynthesis of vitamin K (menaquinone) in bacteria. Microbiol Rev. American Society for Microbiology (ASM); 1982 Sep;46(3):241-80.

9. L Booth S. Vitamin K: food composition and dietary intakes. Food \& Nutrition Research. 2017 Jan 17;56(1):5505.

10. Dismore ML, Haytowitz DB, Gebhardt SE, Peterson JW, Booth SL. Vitamin K content of nuts and fruits in the US diet. Journal of the American Dietetic Association. 2003 Dec;103(12):1650-2.

11. Tarento TDC, McClure DD, Talbot AM, Regtop HL, Biffin JR, Valtchev P, et al. A potential biotechnological process for the sustainable production of vitamin $\mathrm{K} 1$. Critical Reviews in Biotechnology. 19 ed. 2018 May 24;69(12):1-19.

12. Marles RJ, Roe AL, Oketch-Rabah HA. US Pharmacopeial Convention safety evaluation of menaquinone-7, a form of vitamin K. Nutr Rev. 2nd ed. 2017 Jul 1;75(7):553-78.

13. Schurgers LJ, Teunissen KJF, Hamulyák K, Knapen MHJ, Vik H, Vermeer C. Vitamin K-containing dietary supplements: comparison of synthetic vitamin $\mathrm{K} 1$ and nattoderived menaquinone-7. Blood. American Society of Hematology; 2007 Apr 15;109(8):3279-83.

14. Vermeer C, Raes J, van t Hoofd C, Knapen M, Xanthoulea S. Menaquinone Content of Cheese. Nutrients. Multidisciplinary Digital Publishing Institute; 2018 Apr;10(4):446. 
15. Elder SJ, Haytowitz DB, Howe J, Peterson JW, Booth SL. Vitamin K Contents of Meat, Dairy, and Fast Food in the U.S. Diet. Journal of Agricultural and Food Chemistry. 2006 Jan;54(2):463-7.

16. US Department of Agriculture, Agricultural Research Service, Nutrient Data Laboratory. USDA National Nutrient Database for Standard Reference, Release 27. Version Current: May 2015. Internet: http://www.ars.usda.gov/ba/bhnrc/ndl.

17. Walther B, Karl JP, Booth SL, Boyaval P. Menaquinones, Bacteria, and the Food Supply: The Relevance of Dairy and Fermented Food Products to Vitamin K Requirements. Advances in Nutrition. 2013 Jul 8;4(4):463-73.

18. Australian National Health and Medical Research Council, New Zealand Ministry of Health (2005) Vitamin K. Nutrient Reference Values for Australia and New Zealand, pp. 147-151. Canberra: Commonwealth of Australia.

19. FAO Rome Food and Nutrition Division (2001) Vitamin K. Human Vitamin and Mineral Requirements: Report of a Joint FAO/WHO Expert Consultation, Bangkok, Thailand, pp. 133-150. Rome: FAO.

20. National Research Council (2000) Dietary Reference Intakes for Vitamin A, Vitamin $\mathrm{K}$, Arsenic, Boron, Chromium, Copper, Iodine, Iron, Manganese, Molybdenum, Nickel, Silicon, Vanadium, and Zinc. Washington, DC: National Academy Press.

21. Beulens JWJ, Booth SL, van den Heuvel EGHM, Stoecklin E, Baka A, Vermeer C. The role of menaquinones (vitamin K2) in human health. British Journal of Nutrition. Cambridge University Press; 2013 Apr 16;110(08):1357-68.

22. World Health Organization and Food and Agriculture Organization of the United Nations. Vitamin K. In: Vitamin and Mineral Requirements in Human Nutrition. 2nd ed. Geneva, Switzerland: World Health Organization; 2004:108-129.

23. Commission of the European Communities. Commission Directive 2008/100/EC of 28 October 2008 amending Council Directive 90/496/EEC on nutrition labelling for food stuffs as regards recommended daily allowances, energy conversion factors and definitions. $\quad$ http://eur-lex.europa.eu/legal-content/EN/TXT/? uri $1 \frac{1}{4}$ celex\%3A32008L0100.Accessed July26, 2016.

24. Olson R. The Function and Metabolism of Vitamin K. Annual Review of Nutrition. Annual Reviews 4139 El Camino Way, P.O. Box 10139, Palo Alto, CA 94303-0139, USA; 1984 Jan 1;4(1):281-337.

25. Danziger J. Vitamin K-dependent Proteins, Warfarin, and Vascular Calcification. Clinical Journal of the American Society of Nephrology. 2008 Jul 30;3(5):1504-10.

26. Nelsestuen GL, Suttie JW. Mode of action of vitamin K. Calcium binding properties of bovine prothrombin. Biochemistry. American Chemical Society; 2002 May;11(26):4961-4.

27. and EHE, Castellino FJ. Adsorption of Vitamin K-Dependent Blood Coagulation Proteins To Spread Phospholipid Monolayers as Determined from Combined 
Measurements of the Surface Pressure and Surface Protein Concentration $\uparrow$. American Chemical Society; 1998 May 14;37(22):7997-8003.

28. Schurgers L, Spronk H. Differential cellular effects of old and new oral anticoagulants: consequences to the genesis and progression of atherosclerosis. Thrombosis and Haemostasis. Schattauer GmbH; 2017 Nov 20;112(11):909-17.

29. Shearer MJ. Vitamin K deficiency bleeding (VKDB) in early infancy. Blood Reviews. 2009 Mar;23(2):49-59.

30. Burke CW. Vitamin K Deficiency Bleeding: Overview and Considerations. Journal of Pediatric Health Care. 2013 May;27(3):215-21.

31. Greer FR. Vitamin K the basics-What's new? Early Human Development. 2010 Jul;86(1):43-7.

32. Wilson SE, Watson HG, Crowther MA. Low-dose oral vitamin K therapy for the management of asymptomatic patients with elevated international normalized ratios: a brief review. CMAJ. Canadian Medical Association; 2004 Mar 2;170(5):821-4.

33. Burbury KL, Milner A, Snooks B, Jupe D, Westerman DA. Short-term warfarin reversal for elective surgery--using low-dose intravenous vitamin K: safe, reliable and convenient*. British Journal of Haematology. Wiley/Blackwell (10.1111); 2011 Sep;154(5):626-34.

34. Okano T, Shimomura Y, Yamane M, Suhara Y, Kamao M, Sugiura M, et al. Conversion of phylloquinone (Vitamin K1) into menaquinone-4 (Vitamin K2) in mice: two possible routes for menaquinone-4 accumulation in cerebra of mice. Journal of Biological Chemistry. American Society for Biochemistry and Molecular Biology; 2008 Apr 25;283(17):11270-9.

35. Nakagawa K, Hirota Y, Sawada N, Yuge N, Watanabe M, Uchino Y, et al. Identification of UBIAD1 as a novel human menaquinone-4 biosynthetic enzyme. Nature. Nature Publishing Group; 2010 Nov 4;468(7320):117-21.

36. Willems BAG, Vermeer C, Reutelingsperger CPM, Schurgers LJ. The realm of vitamin $\mathrm{K}$ dependent proteins: shifting from coagulation toward calcification. Traber MG, editor. Mol Nutr Food Res. 2014 Aug;58(8):1620-35.

37. van Gorp R, Schurgers L. New Insights into the Pros and Cons of the Clinical Use of Vitamin K Antagonists (VKAs) Versus Direct Oral Anticoagulants (DOACs). Nutrients. Multidisciplinary Digital Publishing Institute; 2015 Nov;7(11):9538-57.

38. STAFFORD DW. The vitamin K cycle. Journal of Thrombosis and Haemostasis. Wiley/Blackwell (10.1111); 2005 Aug;3(8):1873-8.

39. Hauschka PV, Lian JB, Gallop PM. Direct identification of the calcium-binding amino acid, gamma-carboxyglutamate, in mineralized tissue. Proc Natl Acad Sci USA. National Academy of Sciences; 1975 Oct;72(10):3925-9. 
40. Luo G, Ducy P, McKee MD, Pinero GJ, Loyer E, Behringer RR, et al. Spontaneous calcification of arteries and cartilage in mice lacking matrix GLA protein. Nature. 1997 Oct 28;386(6620):78-81.

41. Murshed M, Schinke T, McKee MD, Karsenty G. Extracellular matrix mineralization is regulated locally; different roles of two gla-containing proteins. The Journal of Cell Biology. 2004 Jun 7;165(5):625-30.

42. Schurgers LJ, Teunissen KJF, Knapen MHJ, Kwaijtaal M, van Diest R, Appels A, et al. Novel conformation-specific antibodies against matrix gamma-carboxyglutamic acid (Gla) protein: undercarboxylated matrix Gla protein as marker for vascular calcification. Arterioscler Thromb Vasc Biol. Lippincott Williams \& Wilkins; 2005 Aug;25(8):1629-33.

43. Neve A, Corrado A, Cantatore FP. Osteoblast physiology in normal and pathological conditions. Cell and Tissue Research. 2010 Dec 1;343(2):289-302.

44. Viegas CSB, Rafael MS, Enriquez JL, Teixeira A, Vitorino R, Luis IM, et al. Gla-Rich Protein Acts as a Calcification Inhibitor in the Human Cardiovascular System. Arterioscler Thromb Vasc Biol. Lippincott Williams \& Wilkins Hagerstown, MD; 2015 Jan 21;35(2):399-408.

45. Willems BA, Furmanik M, Caron MMJ, Chatrou MLL, Kusters DHM, Welting TJM, et al. Ucma/GRP inhibits phosphate-induced vascular smooth muscle cell calcification via SMAD-dependent BMP signalling. Sci Rep. Nature Publishing Group; 2018 Mar $21 ; 8(1): 4961$.

46. Westhofen P, Watzka M, Marinova M, Hass M, Kirfel G, Müller J, et al. Human Vitamin K 2,3-Epoxide Reductase Complex Subunit 1-like 1 (VKORC1L1) Mediates Vitamin K-dependent Intracellular Antioxidant Function. Journal of Biological Chemistry. 2011 Apr 22;286(17):15085-94.

47. Mukai K, Morimoto H, Kikuchi S, Nagaoka S-I. Kinetic study of free-radicalscavenging action of biological hydroquinones (reduced forms of ubiquinone, vitamin $\mathrm{K}$ and tocopherol quinone) in solution. Biochimica et Biophysica Acta (BBA) General Subjects. 1993 Jun;1157(2):313-7.

48. Vervoort LM, Ronden JE, Thijssen HH. The potent antioxidant activity of the vitamin $\mathrm{K}$ cycle in microsomal lipid peroxidation. Biochem Pharmacol. 1997 Oct $15 ; 54(8): 871-6$.

49. Wang H, Li J, Follett PL, Zhang Y, Cotanche DA, Jensen FE, et al. 12-Lipoxygenase plays a key role in cell death caused by glutathione depletion and arachidonic acid in rat oligodendrocytes. European Journal of Neuroscience. Wiley/Blackwell (10.1111); 2004 Oct;20(8):2049-58.

50. Li J, Wang H, Rosenberg PA. Vitamin K prevents oxidative cell death by inhibiting activation of 12-lipoxygenase in developing oligodendrocytes. Journal of Neuroscience Research. 2009 Jul;87(9):1997-2005. 
51. Vos M, Esposito G, Edirisinghe JN, Vilain S, Haddad DM, Slabbaert JR, et al. Vitamin K2 Is a Mitochondrial Electron Carrier That Rescues Pink1 Deficiency. Science. 2012 Jun 7;336(6086):1306-10.

52. Booth SL, Tucker KL, McKeown NM, Davidson KW, Dallal GE, Sadowski JA. Relationships between Dietary Intakes and Fasting Plasma Concentrations of FatSoluble Vitamins in Humans. The Journal of Nutrition. 10 ed. 1997 Apr 1;127(4):58792.

53. Schurgers LJ, Vermeer C. Differential lipoprotein transport pathways of K-vitamins in healthy subjects. Biochimica et Biophysica Acta (BBA) - General Subjects. 2002 Feb;1570(1):27-32.

54. Sato T, Schurgers LJ, Uenishi K. Comparison of menaquinone-4 and menaquinone-7 bioavailability in healthy women. Nutrition Journal. BioMed Central; 2012 Nov $12 ; 11(1): 120$.

55. Shearer MJ, Mallinson CN, Webster GR, Barkhan P. Clearance from Plasma and Excretion in Urine, Faeces and Bile of an Intravenous Dose of Tritiated Vitamin K 1 in Man. British Journal of Haematology. Wiley/Blackwell (10.1111); 1972 May;22(5):579-88.

56. SHEARER M, Barkhan P. Studies on the metabolites of phylloquinone (vitamin K1) in the urine of man. Biochimica et Biophysica Acta (BBA) - General Subjects. 1973 Feb 28;297(2):300-12.

57. Schurgers LJ, Akbulut AC, Kaczor DM, Halder M, Koenen RR, Kramann R. Initiation and Propagation of Vascular Calcification Is Regulated by a Concert of Platelet- and Smooth Muscle Cell-Derived Extracellular Vesicles. Frontiers in Cardiovascular Medicine. 2018 Apr 6;5:14391.

58. Wen L, Chen J, Duan L, Li S. Vitamin K-dependent proteins involved in bone and cardiovascular health (Review). Molecular Medicine Reports. 2018 Apr 27.

59. Barrett H, O'Keeffe M, Kavanagh E, Walsh M, O'Connor E. Is Matrix Gla Protein Associated with Vascular Calcification? A Systematic Review. Nutrients. Multidisciplinary Digital Publishing Institute; 2018 Apr;10(4):415.

60. Knapen MHJ, Braam LAJLM, Drummen NE, Bekers O, Hoeks APG, Vermeer C. Menaquinone-7 supplementation improves arterial stiffness in healthy postmenopausal women. A double-blind randomised clinical trial. Thrombosis and Haemostasis. Schattauer GmbH; 2015 May;113(5):1135-44.

61. Knapen MHJ, Drummen NE, Smit E, Vermeer C, Theuwissen E. Three-year low-dose menaquinone-7 supplementation helps decrease bone loss in healthy postmenopausal women. Osteoporosis International. Springer London; 2013 Mar 23;24(9):2499-507.

62. Westenfeld R, Krueger T, Schlieper G, Cranenburg ECM, Magdeleyns EJ, Heidenreich S, et al. Effect of Vitamin K2 Supplementation on Functional Vitamin K Deficiency in Hemodialysis Patients: A Randomized Trial. American Journal of Kidney Diseases. 2012 Feb;59(2):186-95. 
63. Gast GCM, de Roos NM, Sluijs I, Bots ML, Beulens JWJ, Geleijnse JM, et al. A high menaquinone intake reduces the incidence of coronary heart disease. Nutrition, Metabolism and Cardiovascular Diseases. 2009 Sep;19(7):504-10.

64. Geleijnse JM, Vermeer C, Grobbee DE, Schurgers LJ, Knapen MHJ, van der Meer IM, et al. Dietary intake of menaquinone is associated with a reduced risk of coronary heart disease: the Rotterdam Study. The Journal of Nutrition. 2004 Nov;134(11):3100-5.

65. DiNicolantonio JJ, Bhutani J, O'Keefe JH. The health benefits of vitamin K. Open Heart. 2015 Feb 9;2(1):e000300.

66. Brandenburg VM, Schurgers LJ, Kaesler N, Püsche K, van Gorp RH, Lefthériotis G, et al. Prevention of vasculopathy by vitamin K supplementation: can we turn fiction into fact? Atherosclerosis. 2015 May;240(1):10-6.

67. Iwamoto J, Sato Y, Takeda T, Matsumoto H. High-dose vitamin K supplementation reduces fracture incidence in postmenopausal women: a review of the literature. Nutrition Research. 2009 Apr;29(4):221-8.

68. Bulló M, Estruch R, Salas-Salvadó J. Dietary vitamin K intake is associated with bone quantitative ultrasound measurements but not with bone peripheral biochemical markers in elderly men and women. Bone. 2011 Jun;48(6):1313-8.

69. Evatt ML. High Prevalence of Hypovitaminosis D Status in Patients With Early Parkinson Disease. Archives of Neurology. American Medical Association; 2011 Mar 14;68(3):314-9.

70. Apalset EM, Gjesdal CG, Eide GE, Tell GS. Intake of vitamin K1 and K2 and risk of hip fractures: The Hordaland Health Study. Bone. 2011 Nov;49(5):990-5.

71. Prynne CJ, Thane CW, Prentice A, Wadsworth $\mathrm{M}$. Intake and sources of phylloquinone (vitamin K1) in 4-year-old British children: comparison between 1950 and the 1990s. Public Health Nutrition. 2007 Jan 2;8(02):389.

72. Rashdan NA, Rutsch F, Kempf H, Váradi A, Lefthériotis G, MacRae VE. New perspectives on rare connective tissue calcifying diseases. Current Opinion in Pharmacology. 2016 Jun;28:14-23.

73. Zhang Y, Weng S, Yin J, Ding H, Zhang C, Gao Y. Vitamin K2 promotes mesenchymal stem cell differentiation by inhibiting miR-133a expression. Molecular Medicine Reports. Spandidos Publications; 2017 Mar 9;15(5):2473-80.

74. Effect of Vitamin K2 (MK7) on Cardiovascular and Bone Disease in Dialysis Patients, https://ClinicalTrials.gov/show/NCT02976246.

75. Vitamin $\mathrm{K}$ as Additive Treatment in Osteoporosis, https://ClinicalTrials.gov/show/NCT01232647.

76. Beulens JWJ, van der A DL, Grobbee DE, Sluijs I, Spijkerman AMW, van der Schouw YT. Dietary Phylloquinone and Menaquinones Intakes and Risk of Type 2 Diabetes. Diabetes Care. 2010 Jul 28;33(8):1699-705. 
77. Booth SL, Centi A, Smith SR, Gundberg C. The role of osteocalcin in human glucose metabolism: marker or mediator? Nature Reviews Endocrinology. Nature Publishing Group; 2012 Nov 13;9(1):43-55.

78. Lee NK, Sowa H, Hinoi E, Ferron M, Ahn JD, Confavreux C, et al. Endocrine Regulation of Energy Metabolism by the Skeleton. Cell. 2007 Aug;130(3):456-69.

79. Ferron M, Hinoi E, Karsenty G, Ducy P. Osteocalcin differentially regulates $\beta$ cell and adipocyte gene expression and affects the development of metabolic diseases in wildtype mice. Proc Natl Acad Sci USA. 2008 Apr 1;105(13):5266-70.

80. Li Y, Chen JP, Duan L, Li S. Effect of vitamin K2 on type 2 diabetes mellitus: A review. Diabetes Research and Clinical Practice. 2018 Feb;136:39-51.

81. Xv F, Chen J, Duan L, Li S. Research progress on the anticancer effects of vitamin K2 (Review). Oncology Letters. Spandidos Publications; 2018 Apr 16;15(6):8926-34.

82. Xia J, Matsuhashi S, Hamajima H, Iwane S, Takahashi H, Eguchi Y, et al. The role of $\mathrm{PKC}$ isoforms in the inhibition of NF- $\mathrm{BB}$ activation by vitamin $\mathrm{K} 2$ in human hepatocellular carcinoma cells. The Journal of Nutritional Biochemistry. 2012 Dec;23(12):1668-75.

83. Showalter SL, Wang Z, Costantino CL, Witkiewicz AK, Yeo CJ, Brody JR, et al. Naturally occurring $K$ vitamins inhibit pancreatic cancer cell survival through a caspase-dependent pathway. Journal of Gastroenterology and Hepatology. Wiley/Blackwell (10.1111); 2010 Apr;25(4):738-44.

84. Enomoto M, Tsuchida A, Miyazawa K, Yokoyama T, Kawakita H, Tokita H, et al. Vitamin K2-induced cell growth inhibition via autophagy formation in cholangiocellular carcinoma cell lines. International Journal of Molecular Medicine. Spandidos Publications; 2007 Dec 1;20(6):801-8.

85. Jinghe $\mathrm{X}$. Vitamin $\mathrm{K}$ and hepatocellular carcinoma: The basic and clinic. World Journal of Clinical Cases. Baishideng Publishing Group Inc; 2015;3(9):757-64.

86. Sada E, Abe Y, Ohba R, Tachikawa Y, Nagasawa E, Shiratsuchi M, et al. Vitamin K2 modulates differentiation and apoptosis of both myeloid and erythroid lineages. European Journal of Haematology. Wiley/Blackwell (10.1111); 2010 Nov $11 ; 85(6): 538-48$.

87. Yaguchi M, Miyazawa K, Katagiri T, Nishimaki J, Kizaki M, Tohyama K, et al. Vitamin K2 and its derivatives induce apoptosis in leukemia cells and enhance the effect of all-trans retinoic acid. Leukemia. Nature Publishing Group; 1997 Dec 18;11(6):779-87.

88. Lisman T, Porte RJ. Pathogenesis, prevention, and management of bleeding and thrombosis in patients with liver diseases. Research and Practice in Thrombosis and Haemostasis. Wiley-Blackwell; 2017 Aug 5;1(2):150-61.

89. Shah NL, Intagliata NM, Northup PG, Argo CK, Caldwell SH. Procoagulant therapeutics in liver disease: a critique and clinical rationale. Nature Reviews 
Gastroenterology \& Hepatology. Nature Publishing Group; 2014 Jul 15;11(11):67582.

90. Lin M, Sun P, Zhang G, Xu X, Liu G, Miao H, et al. Vitamin K2-Enhanced Liver Regeneration is Associated with Oval Cell Expansion and Up-Regulation of Matrilin2 Expression in 2- AAF/PH Rat Model. Current Molecular Medicine. 2014 Mar 31;14(3):361-9.

91. Avior Y, Levy G, Zimerman M, Kitsberg D, Schwartz R, Sadeh R, et al. Microbialderived lithocholic acid and vitamin $\mathrm{K} 2$ drive the metabolic maturation of pluripotent stem cells-derived and fetal hepatocytes. Hepatology. 2015 Apr 22;62(1):265-78.

92. Zhong J-H, Mo X-S, Xiang B-D, Yuan W-P, Jiang J-F, Xie G-S, et al. Postoperative Use of the Chemopreventive Vitamin K2 Analog in Patients with Hepatocellular Carcinoma. Ahn S-H, editor. PLoS ONE. Public Library of Science; 2013 Mar 7;8(3):e58082.

93. Kurnatowska I, Grzelak P, Masajtis-Zagajewska A, Kaczmarska M, Stefańczyk L, Vermeer C, et al. Plasma Desphospho-Uncarboxylated Matrix Gla Protein as a Marker of Kidney Damage and Cardiovascular Risk in Advanced Stage of Chronic Kidney Disease. Kidney and Blood Pressure Research. Karger Publishers; 2016;41(3):231-9.

94. Puzantian H, Akers SR, Oldland G, Javaid K, Miller R, Ge Y, et al. Circulating Dephospho-Uncarboxylated Matrix Gla-Protein Is Associated With Kidney Dysfunction and Arterial Stiffness. American Journal of Hypertension. 2018 May 17;31(9):988-94.

95. Wei F-F, Drummen NEA, Schutte AE, Thijs L, Jacobs L, Petit T, et al. Vitamin K Dependent Protection of Renal Function in Multi-ethnic Population Studies. EBioMedicine. 2016 Feb;4:162-9.

96. Wei F-F, Trenson S, Thijs L, Huang Q-F, Zhang Z-Y, Yang W-Y, et al. Desphosphouncarboxylated matrix Gla protein is a novel circulating biomarker predicting deterioration of renal function in the general population. Nephrology Dialysis Transplantation. 2017 Aug 25;33(7):1122-8.

97. Aoun M, Makki M, Azar H, Matta H, Chelala DN. High DephosphorylatedUncarboxylated MGP in Hemodialysis patients: risk factors and response to vitamin K2, A pre-post intervention clinical trial. BMC Nephrology. BioMed Central; 2017 Jun 7;18(1):948.

98. Caluwe R, Vandecasteele S, Van Vlem B, Vermeer C, De Vriese AS. Vitamin K2 supplementation in haemodialysis patients: a randomized dose-finding study. Nephrology Dialysis Transplantation. 2014 Jun 25;29(7):1385-90.

99. Vitamin $\mathrm{K}$ to Attenuate Coronary Artery Calcification in Hemodialysis Patients, https://ClinicalTrials.gov/show/NCT01528800.

100. Vitamin K1 to Slow Progression of Vascular Calcification in HD Patients, https://ClinicalTrials.gov/show/NCT01742273. 
101. Effect on Vascular Calcification of Replacing Warfarin by Rivaroxaban With or Without in Hemodialysis Patients, https://ClinicalTrials.gov/show/NCT02610933.

102. Pan M-H, Maresz K, Lee P-S, Wu J-C, Ho C-T, Popko J, et al. Inhibition of TNF- $\alpha$, IL-1 $\alpha$, and IL- $1 \beta$ by Pretreatment of Human Monocyte-Derived Macrophages with Menaquinone-7 and Cell Activation with TLR Agonists In Vitro. Journal of Medicinal Food. Mary Ann Liebert, Inc. 140 Huguenot Street, 3rd Floor New Rochelle, NY 10801 USA; 2016 Jul;19(7):663-9.

103. Myneni VD, Mezey E. Immunomodulatory effect of vitamin K2: Implications for bone health. Oral Diseases. 2018 Feb 26;24(1-2):67-71.

104. Kusano J, Tanaka S, Matsuda H, Hara Y, Fujii Y, Suzuki S, et al. Vitamin K1 and Vitamin K2 immunopharmacological effects on the peripheral lymphocytes of healthy subjects and dialysis patients, as estimated by the lymphocyte immunosuppressant sensitivity test. Journal of Clinical Pharmacy and Therapeutics. 2018 Jul 16;18(593170):590.

105. Meng K, Xu W, Miura T, Suzuki S, Chiyotanda M, Tanaka S, et al. The effects of vitamin $\mathrm{K} 1$ and vitamin $\mathrm{K} 2$ on the proliferation, cytokine production and regulatory T-cell frequency in peripheral blood mononuclear cells of paediatric atopic dermatitis patients. Experimental Dermatology. 2018 Aug 3;114:6.

106. Caspers M, Czogalla KJ, Liphardt K, Müller J, Westhofen P, Watzka M, et al. Two enzymes catalyze vitamin $\mathrm{K}$ 2,3-epoxide reductase activity in mouse: VKORC1 is highly expressed in exocrine tissues while VKORC1L1 is highly expressed in brain. Thrombosis Research. 2015 May;135(5):977-83.

107. Sakaue M, Mori N, Okazaki M, Kadowaki E, Kaneko T, Hemmi N, et al. Vitamin K has the potential to protect neurons from methylmercury-induced cell death In Vitro. Journal of Neuroscience Research. Wiley-Blackwell; 2011 Apr 12;89(7):1052-8.

108. Hadipour E, Tayarani-Najaran Z, Fereidoni M. Vitamin K2 protects PC12 cells against $\mathrm{A} \beta$ (1-42)and $\mathrm{H} 2 \mathrm{O}$ 2-induced apoptosis via p38 MAP kinase pathway. Nutritional Neuroscience. 2018 Jul 30;1(1):1-10.

109. Kimura K, Hirota Y, Kuwahara S, Takeuchi A, Tode C, Wada A, et al. Synthesis of Novel Synthetic Vitamin K Analogues Prepared by Introduction of a Heteroatom and a Phenyl Group That Induce Highly Selective Neuronal Differentiation of Neuronal Progenitor Cells. Journal of Medicinal Chemistry. American Chemical Society; 2017 Feb 28;60(6):2591-6.

110. Lasemi R, Kundi M, Moghadam NB, Moshammer H, Hainfellner JA. Vitamin K2 in multiple sclerosis patients. Wiener klinische Wochenschrift. 4 ed. Springer Vienna; 2018 Mar 2;130(9-10):307-13.

111. Shiba S, Ikeda K, Azuma K, Hasegawa T, Amizuka N, Horie-Inoue K, et al. $\gamma$ Glutamyl carboxylase in osteoblasts regulates glucose metabolism in mice. Biochemical and Biophysical Research Communications. 2014 Oct;453(3):350-5. 
112. Ferron M, Lacombe J, Germain A, Oury F, Karsenty G. GGCX and VKORC1 inhibit osteocalcin endocrine functions. The Journal of Cell Biology. 2015 Mar 16;208(6):761-76.

113. Ferron M, McKee MD, Levine RL, Ducy P, Karsenty G. Intermittent injections of osteocalcin improve glucose metabolism and prevent type 2 diabetes in mice. Bone. 2012 Feb;50(2):568-75.

114. Sogabe N, Maruyama R, Baba O, Hosoi T, Goseki-Sone M. Effects of long-term vitamin K1 (phylloquinone) or vitamin K2 (menaquinone-4) supplementation on body composition and serum parameters in rats. Bone. 2011 May;48(5):1036-42.

115. Ding Y, Cui J, Wang Q, Shen S, Xu T, Tang H, et al. The Vitamin K Epoxide Reductase Vkorc111 Promotes Preadipocyte Differentiation in Mice. Obesity (Silver Spring). 2018 Jul 2;87:377.

116. Juanola-Falgarona M, Salas-Salvadó J, Estruch R, Portillo MP, Casas R, Miranda J, et al. Association between dietary phylloquinone intake and peripheral metabolic risk markers related to insulin resistance and diabetes in elderly subjects at high cardiovascular risk. Cardiovascular Diabetology. BioMed Central; 2013;12(1):7.

117. Shea MK, Booth SL, Gundberg CM, Peterson JW, Waddell C, Dawson-Hughes B, et al. Adulthood Obesity Is Positively Associated with Adipose Tissue Concentrations of Vitamin K and Inversely Associated with Circulating Indicators of Vitamin K Status in Men and Women. The Journal of Nutrition. 2010 Mar 17;140(5):1029-34.

118. Knapen MHJ, Jardon KM, Vermeer C. Vitamin K-induced effects on body fat and weight: results from a 3-year vitamin K2 intervention study. European Journal of Clinical Nutrition. Nature Publishing Group; 2017 Sep 27;72(1):136-41.

119. Tamura T, Yoneda M, Yamane K, Nakanishi S, Nakashima R, Okubo M, et al. Serum leptin and adiponectin are positively associated with bone mineral density at the distal radius in patients with type 2 diabetes mellitus. Metabolism. 2007 May;56(5):623-8. 


\section{Chapter}

\section{Role of vascular smooth muscle cell phenotypic switching and calcification in aortic aneurysm formation \\ Involvement of vitamin K-dependent processes}

Ploingarm Petsophonsakul ${ }^{1}$, Malgorzata Furmanik ${ }^{1}$, Rachael Forsythe ${ }^{2}$, Marc Dweck ${ }^{2}$, Geert

Willem Schurink ${ }^{3}$, Ehsan Natour ${ }^{4,5}$, Chris Reutelingsperger ${ }^{1}$, Michael Jacobs ${ }^{3,4}$, Barend Mees $^{3,4}$, and Leon Schurgers ${ }^{1 *}$.

Arteriosclerosis, Thrombosis, and Vascular Biology. 2019;39(7):1351-1368.

1. Department of Biochemistry, Cardiovascular Research Institute Maastricht, Maastricht University, Maastricht, The Netherlands

2. Centre for Cardiovascular Science, University of Edinburgh, Edinburgh, United Kingdom

3. Department of Vascular Surgery, MUMC, Maastricht, The Netherlands

4. European Vascular Center, Aachen-Maastricht, Germany \& The Netherlands

5. Department of cardiovascular surgery, MUMC, Maastricht, The Netherlands 


\begin{abstract}
Aortic aneurysm is a vascular disease whereby the extracellular matrix (ECM) of a blood vessel degenerates, leading to dilation and eventually vessel wall rupture. Recently, it was shown that calcification of the vessel wall is involved in both initiation and progression of aneurysms. Changes in aortic wall structure that lead to aneurysm formation and vascular calcification are actively mediated by vascular smooth muscle cells (VSMCs). VSMCs in a healthy vessel wall are termed contractile as they maintain vascular tone and remain quiescent. However, in pathological conditions they can de-differentiate into a synthetic phenotype, whereby they secrete extracellular vesicles (EVs), proliferate and migrate to repair injury. This process is called phenotypic switching and is often the first step in vascular pathology. Additionally, healthy VSMCs synthesize vitamin K-dependent proteins (VKDPs), which are involved in inhibition of vascular calcification. The metabolism of these proteins is known to be disrupted in vascular pathologies. In this review we summarize the current literature on VSMC phenotypic switching and vascular calcification in relation to aneurysm. Moreover, we address the role of vitamin $\mathrm{K}$ and VKDPs that are involved in vascular calcification and aneurysm.
\end{abstract}

\title{
Highlights section:
}

1. Vascular smooth muscle cell phenotypic switching and extracellular vesicle release contribute to microcalcification driven aortic aneurysm formation.

2. Calcification is involved in both AAA and TAA formation. Early detection of microcalcification may help to hold aortic aneurysm progression.

3. Vitamin K-dependent processes are involved in the inhibition of calcification and vitamin $\mathrm{K}$ might be a potential treatment option for aortic aneurysm. 
Nonstandard Abbreviations and Acronyms:

$\mathrm{ECM}=$ Extracellular matrix

VSMC $=$ Vascular smooth muscle cell

MMP $=$ Matrix metalloproteinase

$\mathrm{EVs}=$ Extracellular vesicles

MGP $=$ Matrix Gla protein

dp-ucMGP $=$ dephospho-uncarboxylated MGP

AAA $=$ Abdominal aortic aneurysm

TAA $=$ Thoracic aortic aneurysm

PDGF $=$ Platelet derived growth factor

TGF- $\beta=$ Transforming growth factor beta

$\mathrm{SMMHC}=\mathrm{SM}$ myosin heavy chain

$\mathrm{CNN}=\mathrm{SM}$-calponin

MYH11 = Myosin heavy chain 11

SIRT $1=$ Sirtuin 1

TAAD $=$ Thoracic aortic aneurysm and/or aortic dissection

$\mathrm{ER}=$ Endoplasmic reticulum

$\mathrm{XBP} 1 \mathrm{u}=$ Unspliced $\mathrm{X}$ box protein 1

ROS $=$ Reactive oxygen species

$\mathrm{CHOP}=\mathrm{C} / \mathrm{EBP}$ homologous protein

$\mathrm{NADPH}=$ Nicotinamide adenine dinucleotide phosphate

$\mathrm{NOX}=\mathrm{NADPH}$ oxidase

VKDPs $=$ Vitamin K-dependent proteins

$\mathrm{KO}=$ Vitamin K-epoxide

$\mathrm{KH}_{2}=$ Vitamin $\mathrm{K}$-hydroquinone

$\mathrm{KH}=$ Semiquinone

GGCX $=\gamma$-glutamylcarboxylase

VKOR $=$ Vitamin K-oxidoreductase

VKORC1= Vitamin K-oxidoreductase complex subunit 1

$\mathrm{VKA}=$ Vitamin $\mathrm{K}$ antagonist

$\mathrm{CAC}=$ Coronary artery calcification

$\mathrm{BMP}=$ Bone morphogenetic protein

ATP $=$ Adenosine triphosphate

$\mathrm{PDI}=$ Protein disulfide isomerase 
CHAPTER 3

TRX $=$ Thioredoxin

Gas $6=$ Growth arrest specific gene 6 


\section{Introduction}

Aortic aneurysm is a matrix degenerative disease defined by a dilated blood vessel. Aneurysms weaken the arterial vessel wall increasing risk of rupture, which results in massive, and often fatal, internal bleeding. Aortic aneurysms are the result of environmental and genetic risk factors, which lead to shear stress, inflammation, positive vascular remodeling and extracellular matrix (ECM) degradation. ${ }^{1-4}$ Aortic aneurysms resulted in more than 151,000 deaths globally in 2013 and are ranked in the top 15 causes of mortality in the United States. ${ }^{5}$ However, there are no efficient interventions to prevent aneurysm progression.

The sequential pathophysiology of aneurysm formation is unclear, but it is believed that vascular smooth muscle cells (VSMCs) play a central role. Most VSMCs in the vessel wall display a contractile phenotype, which allows them to maintain vascular tone. However, VSMCs have the ability to differentiate into a synthetic phenotype. This process is termed phenotypic switching and is considered to be a key mechanism in arterial remodelling. ${ }^{6,7}$ Synthetic VSMCs are characterised by decreased contractile protein expression and increased production of elastolytic enzymes (matrix metalloproteinases; MMPs), which degrade the ECM and facilitate migration by detaching cells from the basement membrane and ECM. ${ }^{8}$ Additionally, synthetic VSMCs can secrete extracellular vesicles (EVs) that enhance local inflammation and promote vascular calcification. ${ }^{9,10}$ Vascular calcification, an extreme form of arterial remodeling mediated by VSMCs, is characterized by deposition of calcium phosphate crystals in the vessel wall. ${ }^{11}$ Calcification of the medial layer of the vessel wall is associated with arterial stiffening ${ }^{12}$ and has been observed in aneurysm. ${ }^{13-16}$ Vascular calcification is in part regulated by vitamin K-dependent mineralization-inhibiting proteins, such as matrix Gla protein (MGP).

Vitamin $\mathrm{K}$ is a fat-soluble vitamin, whose main function is to facilitate carboxylation of vitamin K-dependent proteins (VKDPs). High dietary intake of vitamin $\mathrm{K}$ has been shown to be associated with reduced coronary artery calcification (CAC) and all-cause mortality ${ }^{17,18}$, but the potential influence of vitamin K on VSMC-mediated mechanisms of aortic aneurysm formation has not been analyzed.

In this review we summarize current knowledge on mechanisms regulating VSMC phenotypic switching and calcification in the context of aortic aneurysm formation. Additionally, we explore the role of vascular vitamin $\mathrm{K}$ in these processes to offer insight into therapeutic implications. 


\section{Aneurysm formation}

The word aneurysm comes from the Greek word 'Aneurysma', which means 'dilation'. Clinically, an aneurysm is defined by a dilated blood vessel with an enlargement of $50 \%$ greater than the normal diameter. ${ }^{19}$ The arterial wall subjected to an aneurysm is vulnerable to pressure. Increased blood pressure results in a continuing enlargement of the vessel wall which may eventually lead to rupture and hemorrhage.

Aneurysms predominantly occur in the aorta and are clinically termed according to the location: 1. Ascending Aortic Aneurysm, 2. Aortic Arch Aneurysm, 3. Descending Thoracic Aortic Aneurysm (DTAA), 4. Thoracoabdominal Aortic Aneurysm (TAAA), and 5. Abdominal Aortic Aneurysm (AAA), the most common type. AAA is the $13^{\text {th }}$ most commonly found cardiovascular disorder ${ }^{20}$, and most frequently seen in men, older than 60 years and with one or more risk factors, including family history, high blood pressure, high cholesterol, obesity, and smoking.

Aortic aneurysms are characterized by a disrupted vessel wall structure with degraded elastic laminae and disappearance of organized VSMC layers. ${ }^{21,22}$ For a long time, biomechanical factors were thought to be the main cause of aneurysm formation and rupture. Currently, aneurysm pathophysiology is regarded as a complex biological process involving cellular-driven remodeling of the vessel wall. ${ }^{23}$ Active and dynamic remodeling, rather than degeneration of the vessel wall, is the cause of AAA development. ${ }^{24}$ In support of this, AAA is characterized histologically by inflammation, oxidative stress, VSMC apoptosis, and ECM degradation. ${ }^{4}$ Moreover, a major difference between the healthy vessel wall and the aneurysm wall is the reduced number of VSMCs. ${ }^{25}$

Aortic aneurysms that develop above the diaphragm in the upper aortic segment are generally termed thoracic aortic aneurysms (TAAs). TAAs are predominantly a result of genetic and connective tissue disorders such as Marfan syndrome caused by mutations in fibrilin-1, which assists proper elastic fiber formation and elastin deposition. ${ }^{26}$ Other TAArelated diseases are Ehlers-Danlos syndrome type IV and Loeys-Dietz syndrome (LDS), caused by mutations in type III collagen (COL3A) and transforming growth factor beta (TGF- $\beta$ ) receptor (TGF- $\beta$ R1 or TGF- $\beta$ R2) genes, respectively. ${ }^{27}$ Moreover, TAA may develop in individuals harboring genetic predispositions without syndromic disorders, termed familial TAA and/or aortic dissection (TAAD). ${ }^{28}$ Increased risk for TAAD is also found in patients with bicuspid aortic valve and mutations in VSMC contractile proteins. ${ }^{29-31}$

TAAs and AAAs share common features such as dilation and rupture of the aorta, proteolysis of ECM and depletion of VSMCs. ${ }^{22}$ While the AAA is seen as an atherothrombotic origin 
presenting with intraluminal thrombus (ILT), oxidative stress, and adventitial inflammation, ILT and immune response are not usually observed in the TAA. ${ }^{22}$ However, infiltration of inflammatory cells in the aortic wall of TAA patients has been documented. ${ }^{32,33}$ Pathological observation in a mouse model suggests that non-inflammatory accumulation of SMC-like cells and elastin-poor ECM, which leads to vascular remodelling, is involved in development of TAAs. ${ }^{34}$ Mucoid degeneration, characterized by accumulation glycosaminoglycans and observed during aging of the human aorta, is also specific to TAA. ${ }^{22,35}$

\section{Vitamin $\mathrm{K}$}

Vitamin $\mathrm{K}$ is a fat-soluble vitamin. Naturally occurring vitamin $\mathrm{K}$ includes vitamin $\mathrm{K} 1$ (phylloquinone) and vitamin K2 (menaquinones). Phylloquinone is mainly found in leafy green vegetables, while menaquinones can be found in fermented food. ${ }^{36}$ Menaquinones have an unsaturated aliphatic side chain with a variable number of prenyl units. The number of prenyl units indicates the respective type of menaquinone. It has been shown that menaquinone-7 (MK-7) is absorbed most efficiently and has the best bioavailability. ${ }^{37,38}$ During absorption, vitamin $\mathrm{K}$ is taken up by enterocytes in the small intestine where it is packaged into chylomicrons, which are taken up by the liver. Vitamin K2, specifically the long chain menaquinones, is redistributed into the circulation and available for extrahepatic tissues such as the vasculature. ${ }^{39,40}$

\subsection{Vitamin K cycle}

The main function of both vitamin $\mathrm{K} 1$ and $\mathrm{K} 2$ is acting as cofactors in carboxylation of VKDPs (Figure 1). Vitamin K serves as a cofactor for the enzyme $\gamma$-glutamylcarboxylase (GGCX), which catalyzes the conversion of glutamic acid (Glu) in VKDP to $\gamma$ carboxyglutamic acid (Gla). This reaction is driven by oxidation of vitamin K-hydroquinone $\left(\mathrm{KH}_{2}\right)$ to vitamin $\mathrm{K}$-epoxide (KO). KO can be recycled by vitamin K-oxidoreductase (VKOR), which converts $\mathrm{KO}$ to vitamin $\mathrm{K}$ and back to $\mathrm{KH}_{2}{ }^{41,42}$ 


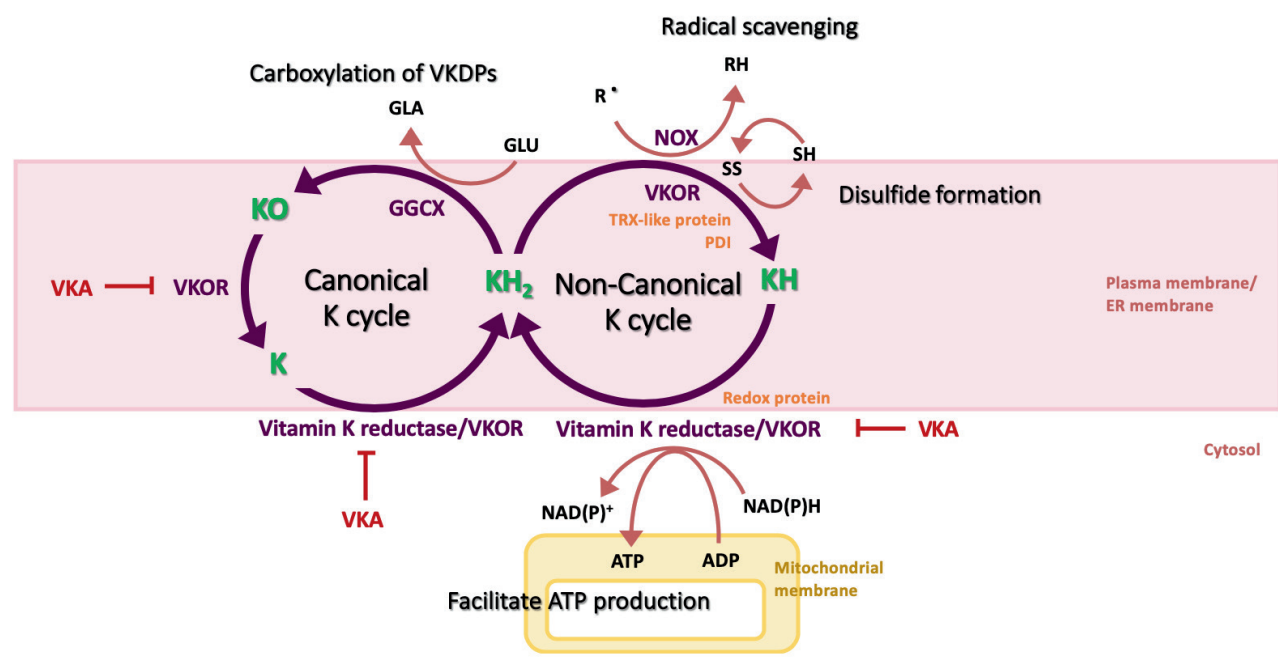

Figure 1. The canonical and non-canonical vitamin $\mathrm{K}$ cycle. In the canonical vitamin $\mathrm{K}$ cycle, vitamin $\mathrm{K}$ is a cofactor in the carboxylation of VKDPs, which then become activated. The oxidation from $\mathrm{KH}_{2}$ to $\mathrm{KO}$ is driven by GGCX. VKOR and vitamin K-reductase enable the recycling process of vitamin $\mathrm{K}$ through conversion of $\mathrm{KO}$ to $\mathrm{K}$ and $\mathrm{KH}_{2}$, respectively. Imbalanced equilibrium of vitamin $\mathrm{K}$ forms may allow an alternative vitamin $\mathrm{K}$ cycle, whose reduction steps to semiquinone $(\mathrm{KH})$ are also driven by VKOR. Through this non-canonical $\mathrm{K}$ cycle, VKOR and a redox protein (DTT or TRX) facilitate $\mathrm{KH}_{2}$ conversion to $\mathrm{KH}$, thereby exerting antioxidant properties such as preventing NADPH-dependent lipid peroxidation and protecting the plasma membrane against ROS by regulating NOX activity. $\mathrm{KH}_{2}$ is involved in protein disulfide-thiol interchange of NOX. Moreover, VKOR, together with PDI or TRX-like protein, contribute to disulfide formation and protein synthesis within the ER membrane. Vitamin $\mathrm{K}$ also improves mitochondrial oxygen consumption and is involved in ATP generation. In all cases, the presence of a VKA inhibits the recycling process of vitamin $\mathrm{K}$ and its subsequent functions.

\subsection{VKOR polymorphisms vs aneurysm risk}

VKOR is expressed in various vascular cells and heart tissue. The first evidence of a role for vitamin $\mathrm{K}$ in aneurysm formation comes from a study showing increased expression of VKOR in vascular endothelial cells and ventricular aneurysm tissue of human heart. ${ }^{43}$ Additionally, in a study of 253 cases of aortic dissection, of which $11.5 \%$ had Marfan syndrome, and 416 controls, VKOR complex subunit 1 (VKORC1) polymorphisms were shown to be associated with an almost two-fold higher risk of aortic dissection, independent of conventional vascular risk factors. ${ }^{44}$ In the same study, a similar observation was made in patients with stroke and coronary heart disease, suggesting VKORC1 variation as a common genetic risk factor for all vascular diseases. ${ }^{44}$ Indeed, the role of VKORC1 was highlighted as an emerging genetic marker of TAA and acute aortic dissection in haemostasis patients. ${ }^{45}$ 
Identifying the genetic polymorphism such as VKORC1 in haemostasis patients may give more specificity in identifying patients at risk of TAA than the currently used protein markers such as plasma D-dimer. ${ }^{45}$ Another study detecting the frequency of VKORC1 polymorphisms was carried out in 189 patients with an aneurysm of the ascending aorta, excluding those with genetic disease, and 188 controls with matching age, sex, body mass index (BMI), and smoking status. ${ }^{46}$ VKORC1 polymorphism rs9923231 was significantly associated with aneurysms of the ascending aorta, suggesting that carboxylation of VKDPs might be involved in TAA formation. $^{46}$

\section{Role of vascular smooth muscle cells in aortic aneurysm formation}

\subsection{VSMC phenotypic plasticity}

The vessel wall of large arteries consists of different cells, including endothelial cells, fibroblasts, and VSMCs. VSMCs reside in the tunica media and comprise the majority of cells in arteries. ${ }^{47}$ The main function of VSMCs is to regulate vascular tone and diameter through contraction and dilatation, thereby controlling blood pressure and blood flow distribution. ${ }^{48}$ VSMCs are not terminally differentiated, which distinguishes them from skeletal muscle cells and cardiomyocytes. Indeed, VSMCs retain remarkably high plasticity, which allows them to modulate and switch phenotype upon stress signals. ${ }^{7}$ VSMC phenotypic switching is triggered by inflammation and/or injury. ${ }^{49}$ Atherosclerosis, hypertension and post-angioplasty restenosis as well as aneurysms are all associated with VSMC phenotypic switching. ${ }^{50-52}$

VSMC phenotypic modulation can be characterized by changes in morphology, protein expression, proliferation and migration (Figure 2). In vitro, contractile VSMCs are elongated and display spindle-shape morphology, while synthetic VSMCs are rhomboidal and display cobblestone morphology. ${ }^{53,54}$ Synthetic VSMCs express lower levels of proteins involved in contraction, such as $\alpha$-smooth muscle actin ( $\alpha$-SMA), SM myosin heavy chain (SMMHC), SM22 $\alpha$, SM-calponin $(\mathrm{CNN})$ and smoothelin-B. ${ }^{55}$ Additionally, synthetic VSMCs are characterized by increased proliferation and migration. ${ }^{55,56}$ VSMCs can also give rise to other cells in the vessel wall, such as osteo/chondrogenic-like and macrophage-like cells, which has been reviewed by others. ${ }^{57-59}$ 


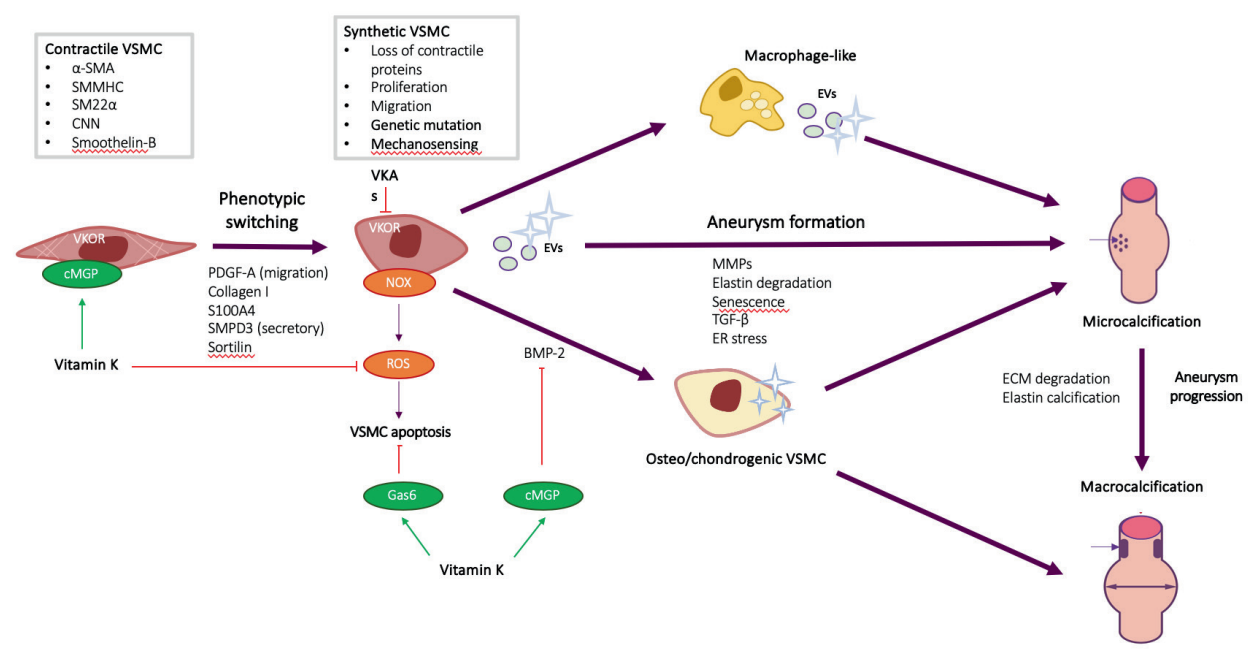

Figure 2: VSMC plasticity in aneurysm formation. VSMC phenotypic switching between contractile and synthetic is essential for vascular remodeling and maintaining a healthy vasculature. In the presence of stimuli (such as PDGF), a contractile VSMC can acquire a synthetic phenotype which is characterized by downregulation of contractile proteins and increase in proliferation and migration. VSMC phenotypic switching precedes aneurysm formation and differentiation of VSMCs into osteo/chondrogenic and macrophage-like phenotypes, which promote further remodeling and calcification. VSMCs fail to maintain contractility in the presence of inactive VKDPs and secrete calcifying vesicles. Oxidative stress drives VSMC proliferation, VSMC apoptosis, and initiates microcalcification. This in turn causes destructive changes in the surrounding matrix and leads to weakening of the vessel wall. Macrocalcification develops over time and further aggravates the dilation of the vessel.

The local environmental factors that modulate VSMC phenotype include: growth factors, such as platelet derived growth factor (PDGF) ${ }^{56,60}$ and TGF- $\beta^{56,61}$, angiotensin $\mathrm{II}^{62}$, nitric oxide ${ }^{56}$, reactive oxygen species (ROS) ${ }^{63}$ and the components of the ECM. Moreover, other factors such as hyaluronan and heparin are also known to influence VSMCs. ${ }^{64-66}$

\subsection{Phenotypic switching of VSMCs is key in aneurysm formation}

In this section, we discuss how mechanisms regulating VSMC phenotype are involved in aneurysm formation and how they could potentially be modulated by vitamin $\mathrm{K}$.

\subsubsection{Mutations in genes encoding contractile proteins and TGF- $\beta$}

In line with that loss of contractile function promotes aneurysm formation, ${ }^{67,68}$ TAAs may arise from a variety of gene mutations encoding structural components of ECM, cytoskeletal/smooth muscle contraction proteins, and proteins associated with TGF- $\beta$ pathway such as TGF- $\beta$ receptors and SMAD proteins. ${ }^{69}$ For example, mutations in MYH11 cause familial TAAD, aortic stiffness, alteration in aortic compliance and arterial degeneration. ${ }^{70}$ 
Mutations in $\alpha$-SMA, a target of TGF- $\beta$-signaling, also cause TAAD ${ }^{71}$, as a result of impaired VSMC contractility, ability to maintain $\mathrm{ECM}^{72}$, differentiation, and proliferation. ${ }^{69}$ Apart from genetic mutations, alteration in vascular tone and interstitial pressure may induce interstitial edema, generate aortic wall stress, and initiate intraparietal dissection. ${ }^{73}$ Pharmacological induction of VSMC contractility in a mouse model, which predisposed to aortic dissection, showed great protection against intramural delamination, an initiator of dissection. ${ }^{74}$ These findings emphasize the importance of VSMC contractility in maintaining the structural integrity of the aorta.

TGF- $\beta$ is another factor implicated in regulating VSMC contractility. ${ }^{26}$ Stimulation of VSMCs with TGF- $\beta 1$ increases $\alpha$-SMA, SMMHC, and CNN mRNA expression ${ }^{61}$ and reduces proliferation. ${ }^{75}$ However, since reduced proliferation results in fewer VSMCs in the vessel wall, leading to AAA formation, ${ }^{76}$ the exact effect of TGF- $\beta 1$ signaling on VSMCs in aneurysm formation is likely dependent on the context and other mechanisms at play. Increased TGF- $\beta$ expression is observed in human AAA and TAA tissue ${ }^{76,77}$ and in TAAs related to Marfan syndrome. ${ }^{26,78}$ Increased TGF- $\beta$ activity has been shown to play a role in the pathology of TAAD in Marfan syndrome. ${ }^{79,80}$ In line with that, a loss-of-function mutation in TGF- $\beta 2$ was sufficient to cause aortic root dilation in a mouse model of Marfan syndrome. ${ }^{81}$ Paradoxically, these mice showed an upregulation of TGF- $\beta$ signaling and TGF- $\beta 1$ expression. ${ }^{81}$ Milewicz et al. suggested that over-activity of TGF- $\beta$ may be a secondary response to tissue injury in thoracic aortic diseases, rather than the primary cause. ${ }^{68}$ Indeed, aortic dilation and medial elastin damage in young Marfan mice developed in the absence of elevated VSMC TGF- $\beta$ signaling. ${ }^{82}$ Furthermore, LDS mice (TGF- $\beta$ receptor knock-in; TGF- $\beta$ R2 ${ }^{\mathrm{G} 357 \mathrm{~W} /+}$ ) showed increased TGF- $\beta$ signaling only in later stages of TAA development. ${ }^{83}$ Conditional disruption of VSMC TGF- $\beta$ R2 in postnatal mice impaired VSMC contractile apparatus, induced a proliferative response and rapidly result in TAAD. ${ }^{84}$ Moreover, TGF- $\beta$ neutralization in these mice exacerbated aortic disease, suggesting that basal TGF- $\beta$ is required to maintain structural integrity of VSMCs. ${ }^{84}$ These studies highlight the fact that TGF- $\beta$ signaling contributes to aneurysm formation regardless of the presence of the fibrillin-1 mutation. Indeed a growing body of evidence suggests emerging concepts such as mechanosensing and vascular tone regulation may better explain how aneurysms are formed in the context of TAAD. ${ }^{85}$

Interestingly, TGF- $\beta$ neutralization was shown to enhance angiotensin II-induced aortic rupture and aneurysm in mice, both at the thoracic and abdominal regions. ${ }^{86}$ In a similar mouse model, TGF- $\beta$ was shown to protect against inflammatory aortic aneurysm progression and complications. ${ }^{34}$ Whereas VSMC-extrinsic TGF- $\beta$ signaling protects against AAA, VSMC- 
intrinsic TGF- $\beta$ signaling protects the thoracic aorta in the angiotensin II-induced mice. ${ }^{87} \mathrm{~A}$ recent study revealed that TGF- $\beta 1$ suppressed a broad array of proinflammatory genes in cultured human VSMCs, partially through the signal transducer and activator of transcription 3 (STAT3) and nuclear factor $\kappa \mathrm{B}(\mathrm{NF}-\kappa \mathrm{B})$ pathway. ${ }^{88}$ In parallel, TGF- $\beta 1$ potently induced the expression of VSMC contractile genes. ${ }^{88}$ Observation from this study suggests that the two events are independent, and suppression of the proinflammatory genes is not the consequence of the induced contractile VSMC phenotype. ${ }^{88}$

The interaction of vitamin K and TGF- $\beta$ has not been studied in the context of aneurysm and VSMC biology. A study in osteoblast-like cell derived from osteosarcoma showed that vitamin K promoted TGF- $\beta$ mRNA expression. ${ }^{89}$ However, a study in cancer cells showed no alteration in the expression of TGF- $\beta 1 .{ }^{90}$ Conversely, TGF- $\beta$ was found to induce expression of VKDPs, such as MGP, in embryonic lung cell culture and growth arrest specific gene 6 (Gas6) protein in VSMCs. ${ }^{91,92}$

Even though mutational defects may not be easily amended, vitamin $\mathrm{K}$ may alleviate their downstream effects, pathologies, and vessel integrity in aortic aneurysm such as elastin degradation, VSMC apoptosis, oxidative stress and calcification, which we discuss in the following sections.

\subsubsection{Elastin degradation}

Phenotypic switching of VSMCs underlies the destructive changes that lead to aneurysm formation in animal models of TAA. ${ }^{67,93}$ Investigating genetic diseases, in this case Marfan syndrome, provided a better understanding of this process. ${ }^{6}$ The defective elastin lamellae impair VSMC attachment, which leads to switching of VSMCs towards a synthetic, pro-elastolytic phenotype. ${ }^{6,93}$ The pro-elastolytic phenotype of VSMCs isolated from human AAA tissue is characterized by increased production of MMPs. ${ }^{94}$ MMPs are a family of endopeptidases that exert proteolytic activity towards elastin and collagen. Increased MMPs, in particular MMP-2 and MMP-9, degrade the ECM thereby weakening the vascular wall and leading to AAA formation. TAA and AAA were found in ApoE mice with tissue inhibitor of MMPs (TIMP)-1 deficiency. ${ }^{95}$ Moreover, VSMC migration is inhibited by inhibition of MMPs. ${ }^{96}$ End-stage AAA usually features a destruction of elastin which is compensated by an increased synthesis of collagen. ${ }^{97,98}$

Although the effect of vitamin $\mathrm{K}$ on elastin degradation has not been studied in the context of aneurysm, a study in cancer cells showed that vitamin K2 inhibits production of MMPs by suppressing NF- $\mathrm{B}$ and mitogen-activated protein kinase (MAPK) activity. ${ }^{99}$ Vitamin K2 (45 mg/day) was shown to reduce serum MMP-3 in rheumatoid arthritis patients 
in a cross-sectional $(\mathrm{n}=158)$ and a longitudinal study $(\mathrm{n}=52) \cdot{ }^{100}$ However, vitamin K1 (10 $\mathrm{mg} /$ day) does not altered serum MMP-3 of rheumatoid arthritis patients as revealed by a randomized control trial study $(\mathrm{n}=64) .{ }^{101}$

\subsubsection{Apoptosis of VSMCs}

AAAs have a reduced number of $\mathrm{VSMCs}^{25}$, leading to limited capacity to produce connective tissue and to repair elastin breaks. The reduced number of VSMCs is likely the consequence of apoptosis, since apoptotic VSMCs have been observed in the medial layer of AAAs. ${ }^{102}$ VSMC apoptosis can result from proteolytic degradation of the $\mathrm{ECM}^{103}$ and also from oxidative stress. ${ }^{104}$ Other factors that may contribute to a pro-apoptotic milieu include inflammatory mediators, proliferative triggers such as PDGF and cell stretch, hypoxia and DNA damage. ${ }^{103}$ Also, mechanical stress can contribute by enhancing ER stress-induced apoptosis. $^{105}$ In addition, VSMC senescence can ultimately progress into apoptosis. ${ }^{103}$ Apoptosis is accompanied by the generation of apoptotic bodies, which, if not cleared by phagocytosis, can stimulate calcification. ${ }^{106}$ Calcium deposits in turn can aggravate inflammation and mechanical stress ${ }^{107,108}$ indicating the fueling of an amplification loop spiraling down towards a mechanically compromised vessel wall.

Vitamin K may be associated with VSMC apoptosis through activation of Gas6, which is a VKDP containing $\gamma$-carboxyglutamic acid. ${ }^{109}$ Gas6 inhibits VSMC apoptosis by binding to Axl, a tyrosine kinase receptor, thereby activating Akt. ${ }^{110}$ Vitamin K2 was shown to inhibit rat VSMC calcification in culture through restoration of the Gas6/Ax1/Akt anti-apoptotic pathway. ${ }^{111}$ Downregulation of the Gas6-Axl interaction is associated with inorganic phosphate (Pi)-induced human VSMC apoptosis and addition of human recombinant Gas6 inhibits Pi-induced apoptosis and calcification. ${ }^{112}$ Additionally, Axl was found to be upregulated in cultured rat VSMCs after vascular injury and may mediate migration and proliferation of VSMCs. ${ }^{113}$ Circulating Gas6 and soluble Axl in plasma has been measured in healthy controls $(n=141)$ and patients with large $(n=123)$ or small $(n=122)$ AAA. ${ }^{114}$ Gas6 concentration was found to positively correlate with AAA size, and the correlation was stronger with Gas6/Axl ratio. ${ }^{114}$ While the authors of this study suggest that the higher Gas6 concentration in plasma may reflect the higher Gas6 gene expression and Gas6/Axl plasma ratio might be a useful marker for AAA, ${ }^{114}$ the mechanisms of action were not demonstrated. All of these studies point to the possibility that vitamin $\mathrm{K}$ could protect from aneurysm via Gas6/Axl and inhibition of apoptosis. 


\subsubsection{Endoplasmic reticulum stress}

Recently, aortic aneurysm formation has been shown to correlate with increased endoplasmic reticulum (ER) stress. ${ }^{115}$ In line with this, transcription factor unspliced $\mathrm{X}$ box protein 1 (XBP1u), which is expressed in the absence of ER stress, has been shown to maintain VSMC contractile phenotype. XBP1u deficiency causes VSMC dedifferentiation, enhances proinflammatory and proteolytic VSMC phenotype, thus aggravating TAA and AAA in vivo. ${ }^{116}$ ER stress also promotes $\mathrm{TAAD}$ formation through $\mathrm{C} / \mathrm{EBP}$ homologous protein (CHOP), an effector of the ER stress-induced unfolded protein response which regulates ER stress-induced apoptosis. ${ }^{117,118}$ CHOP deletion prevents VSMC apoptosis and TAAD development, without affecting VSMC proliferation. ${ }^{118}$ Moreover, ER stress inhibition was able to attenuate AAA in angiotensin II-induced $\mathrm{ApoE}^{-/-}$mice. ${ }^{119}$

The effect of vitamin K on ER stress has not been studied in the context of aneurysm. However, it is known that VKOR is associated with the ER disulphide forming pathway, ${ }^{120,121}$ and ER transcription factors, such as XBP1, may affect the expression of VKORC1 gene. ${ }^{122}$

\subsubsection{Oxidative stress}

Oxidative stress is a well-established factor promoting the development of aortic aneurysm and it has been implicated in regulating features of VSMC phenotype. Both VSMCs and infiltrating inflammatory cells can contribute to the increase in ROS in the vessel wall. ${ }^{123}$ Several sources of ROS exist (nicotinamide adenine dinucleotide phosphate (NADPH) oxidases (NOX), lipoxygenases, cyclo-oxygenase, and nitric oxide synthase), however NOX enzymes have been predominantly implicated in AAA pathology thus far. ${ }^{124}$ NOX enzymes form a family involved in the production of superoxide anion, and NOX1, NOX2, NOX4, and NOX5 are expressed in human VSMCs. ${ }^{125,126}$ Genetic deletion of p47 ${ }^{\text {phox }}$, a cytosolic subunit that associates with NOX1-4, reduced the incidence of AAA in an angiotensin II-induced mouse model of aneurysm. ${ }^{127}$ Interestingly, systemic NOX2 deficiency reduced ROS in AAA lesion, however, it exacerbated angiotensin II-induced AAAs in mice by increasing vascular inflammation. ${ }^{128}$ This was due to disruption of macrophage function, the main source of increased NOX2 expression in the AAAs. ${ }^{128}$ NOX4-mediated oxidative stress has been shown to be implicated in VSMC apoptosis ${ }^{125}$, while increased NOX2 and NOX5 activity have been shown to induce VSMC proliferation. ${ }^{129-131}$ Moreover, NOX2 and NOX5 are most prominently expressed NOX isoforms in the aorta of AAA patients. ${ }^{132}$ NOX1-mediated ROS generation has been shown to decrease contractile protein expression in cerebral aneurysms. ${ }^{133}$ 
More generally, scavenging ROS attenuated the formation of AAA in mice and protected against aortic aneurysm development. ${ }^{134}$ In another mouse model of AAA, aneurysm formation and rupture were decreased by vitamin $\mathrm{E}$, a well-known antioxidant. ${ }^{136}$ Flow loading and systemic antioxidant therapy lowered oxidative stress and early aortic dilation in a rat model of AAA. ${ }^{135}$ Antioxidant treatment not only reduced macrophage infiltration into the abdominal aorta, but also delayed AAA formation and reduced aortic rupture. ${ }^{136}$ Additionally, in human subjects, increased circulating level of thioredoxin (TRX), a protein released from cells in response to oxidative stress, and release of TRX in the luminal part of AAA patients positively correlated with AAA size and expansion. ${ }^{137}$ Correspondingly, proteomic analysis showed that TRX protein in the human AAA wall sample is negatively correlates with the growth rate, which is in line with hypothesis that upregulation of TRX in defense against ROS may slow down the aneurysm expansion rate. ${ }^{138}$ A similar dependency of TAA on increased ROS has been observed, as in vitro and ex vivo studies on human TAA tissue revealed that oxidative stress mediates VSMC phenotypic switching towards synthetic phenotype through connective tissue growth factor. ${ }^{139}$ These results was further validated in a mouse model of TAA which showed similar pathology as observed in human tissue. ${ }^{139}$ Taken together, these studies suggest that decreasing oxidative stress attenuates aneurysm formation; however, the underlying mechanisms have not been studied in detail.

Recent findings suggest a role for vitamin $\mathrm{K}$ as an antioxidant. Human VKORC1-like 1 (VKORC1L1), a paralogue enzyme of VKORC1 found in the ER, was found to regulate vitamin $\mathrm{K}$-dependent intracellular antioxidant function in the cell membrane. ${ }^{140}$ Both vitamin $\mathrm{K} 1$ and $\mathrm{K} 2$ were shown to mediate a VKORC1L1-dependent increase in cell viability. Genome-wide expression studies showed that VKORC1L1 is expressed throughout many tissues, and may serves as a potential target for the regulation of intracellular redox homeostasis. ${ }^{140}$

Additionally, Mukai et al., showed that $\mathrm{KH}_{2}$ is a potent free radical scavenger. Kinetic studies showed $\mathrm{KH}_{2}$ has 10 to 100 -fold higher antioxidant activity than other radical scavengers such as alpha-tocopherol and ubiquinone. ${ }^{141}$ In another study, menadione (a synthetic form of vitamin $\mathrm{K}$ without a side chain) and vitamin $\mathrm{K} 1$ and $\mathrm{K} 2$ inhibited NADPH-dependent microsomal lipid peroxidation in the presence of dithiothreitol, a non-physiological redox protein which drives VKOR. ${ }^{142}$ This antioxidant effect was abolished when a VKA, namely warfarin, was added into the reaction. Vitamin $\mathrm{K} 1$ and $\mathrm{K} 2$ were shown to protect against oxidative stress in primary oligodendrocytes and immature cortical neurons. ${ }^{143}$ Additionally, vitamin $\mathrm{K} 1$ and $\mathrm{K} 2$ prevented oxidative stress-induced cell death by inhibiting activation of 
12-Lipoxygenase in primary oligodendrocytes. ${ }^{144}$ This vitamin $\mathrm{K}$ action was independent of the GGCX, though facilitated by the VKOR redox cycle.

Vitamin $\mathrm{K}$ has also been shown to directly modulate NOX activity. Bridge et al. have shown that reduced phylloquinone $\left(\mathrm{K}_{1} \mathrm{H}_{2}\right)$ serves as a natural electron donor for NOX in the soybean plant and might protect the plasma membrane against ROS. ${ }^{145}$ In addition, $\mathrm{K}_{1} \mathrm{H}_{2}$ is also involved in protein disulfide-thiol interchange of NOX. ${ }^{145}$ Electron transfer via hydroquinone was proposed as a mechanism sensing the redox changes across plasma membrane that occur during aging and senescence. ${ }^{145-147}$ Additionally, the VKOR recycling requires redox partners such as protein disulfide isomerase (PDI) and TRX-like protein to deliver reducing equivalence. ${ }^{148} \mathrm{PDI}$ is known to regulate the activity of NOX in various cell types and is essential for redox-mediated VSMC migration via PDGF, which is associated with NOX activation. ${ }^{149}$ Intracellular PDI regulates expression and activity of the NOX which contributes to ROS generation. ${ }^{150}$ Further to that, VKOR significantly contributes to disulfide formation and redox homeostasis within the ER. ${ }^{151}$ Reduction of VKOR activity by warfarin, in combination with other disulfide bond formation proteins, resulted in cell death. ${ }^{151}$

All these studies show that oxidative stress is an important factor promoting both AAA and TAA formation, and that vitamin $\mathrm{K}$, as an antioxidant, has great potential in this field. However, as the antioxidant mechanisms of vitamin K have not been analyzed in VSMCs in the context of aneurysm, this warrants further study.

\subsubsection{Senescence of VSMCs}

Many hallmarks of cellular senescence have been reported in aneurysms and aneurysmderived VSMCs. Stress signals such as uremic toxins and ROS induce a cellular senescence response, which is characterized by a quiescent state and secretion of proinflammatory cytokines. ${ }^{152}$ Senescent VSMC releases factors which drive differentiation of local VSMCs to become osteo/chondrogenic. ${ }^{153}$ An in vitro study by Liao et al. indicated that VSMCs derived from human AAA exhibited a distinct phenotype resembling accelerated replicative senescence. These VSMCs displayed distortion in morphology and limited proliferation capacity in comparison to VSMCs derived from inferior mesenteric artery. ${ }^{154}$ Additionally, a genome wide association study revealed a common variant, rs10757278, found in human AAA. ${ }^{155}$ Rs1075728 is adjacent to CDKN2A/CDKN2B (genes encode the cell cycle regulators), which is expressed in senescent VSMCs. ${ }^{156-158}$

Another senescence mechanism is related to lamin A. Persistent DNA damage and accumulation of prelamin $\mathrm{A}$, the precursor to the component of nuclear membrane lamin $\mathrm{A}$, is a key mediator that links premature senescence and accelerated vascular calcification. ${ }^{159}$ 
Increased expression of lamin A was observed in the region of high wall-stress and not in the non-aneurysmal vascular beds of AAA patients. ${ }^{160}$ Furthermore, physiological pulsatile stretch of VSMC in vitro caused a time-dependent elevation of prelamin A and lamin A expression. ${ }^{160}$ Lamin A is also a direct activator of Sirtuin 1 (SIRT1). ${ }^{161}$ SIRT1 is a nicotinamide adenine dinucleotide-dependent protein deacetylase, highly expressed in the vasculature. ${ }^{162}$ SIRT1 is known for its protective function in vascular aging and is involved in variety of cellular processes including the inhibition of apoptosis. ${ }^{163,164}$ Inhibition of SIRT1 in VSMCs results in DNA damage, early senescence and apoptosis. ${ }^{164}$ In addition, reduction of SIRT1 in animal models induces medial degeneration, AAA formation, and aortic dissection providing a potential molecular basis for aneurysm formation in patients. ${ }^{164}$ Concurrently, human AAA wall showed significantly lower SIRT1 immunoreactivity in comparison to non-aneurysmal aortic sections. ${ }^{165}$ In addition, overexpression of VSMC-specific SIRT1 was able to suppress AAA formation in an animal model. ${ }^{165}$ VSMCs cultured from end-stage human AAA expressed elevated levels of differentiation marker (microRNA 145; MiR-145), lower expression of SIRT1, and exhibited higher level of DNA damage compared to non-aneurysmal human saphenous vein. ${ }^{166}$ These features did not correlate with patients' chronological age. ${ }^{166}$ Telomeres, which are DNA repeats at the end of chromosomes, have a protective role against age-associated diseases. ${ }^{167}$ Telomere attrition (shortening) is one of the hallmarks of cellular aging and one of the causes of cellular senescence. ${ }^{168}$ Shortening of telomeres has been documented in biopsies of AAA of aortic tissue. ${ }^{169}$

Senescence has been shown to accompany not only AAAs, but also TAAs. VSMCs derived from bicuspid and tricuspid aortic valve-associated aneurysms of TAA patients displayed reduced proliferation and migration capacity. In addition, telomere length analyses showed that these VSMCs had significantly shorter telomeres compared to VSMCs derived from healthy tissue. ${ }^{170}$ Aschacher et al. showed that telomere shortening was associated with reduced activity of telomerase, which in turn is involved in VSMC proliferation. ${ }^{171}$ It was concluded that VSMCs in TAAs undergo premature senescence. The cause-consequence relationship of VSMC senescence and TAA formation and the role of telomere shortening remains to be unraveled. ${ }^{171}$

Mitochondrial dysfunction is another hallmark of cellular senescence and it has been implicated in vascular aging and cardiovascular diseases. ${ }^{172}$ Mitochondrial respiratory chain dysfunction causes reduction of adenosine triphosphate (ATP) synthesis and increased ROS generation. ${ }^{172,173}$ The bioenergetic profiling of proliferating human VSMCs revealed that they rely on mitochondrial oxidative phosphorylation and have a high respiratory reserve capacity 
at rest, while aging cells have lower resting oxidative phosphorylation and reduced reserve capacity. ${ }^{174}$ Bioinformatic analyzes suggest the importance of mitochondria and oxidative phosphorylation in AAA. ${ }^{175}$ Indeed, mitochondrial dysfunction was observed in synthetic VSMCs of human AAA tissue and of AAA mouse model. ${ }^{176}$ A recent study demonstrated that VSMC mitochondrial respiration is reduced in TAAs of Fibulin-4 mutant mice; this was coupled with increased ROS and dysregulated expression of genes involved in energy metabolism. ${ }^{177}$ The reduction of mitochondrial respiration in VSMC was also observed in VSMCs of LDS mice and human fibroblasts of Marfan and LDS patients, suggesting that altered mitochondrial respiration may contribute to TAA formation. ${ }^{177}$

However, direct effects of vitamin K on VSMC senescence have not been studied, with one exception. Vitamin K2 has been reported to be involved in ATP generation. A study in Drosophila mitochondria revealed that vitamin K2 acts as an electron carrier that can rescue deficiency of PINK1, ${ }^{178}$ a mitochondrial regulator of autophagy that determines VSMC fate. ${ }^{179,180}$ In this study vitamin K2 was shown to rescue mitochondrial dysfunction, improve mitochondrial oxygen consumption and facilitate the production of ATP. ${ }^{178}$

Taken together, the studies of non-canonical roles of vitamin $\mathrm{K}$ at the background of our current understanding of aneurysm biology suggest that vitamin $\mathrm{K}$ antioxidative property seems to be the most promising effects on the pathogenesis of aneurysms (Figure 1). In the following parts, we discuss how the canonical function of vitamin $\mathrm{K}$ might play a role in the mechanisms of aneurysm formation through inhibition of VSMC phenotypic switching towards osteo/chondrogenic and VSMC calcification.

\section{Vascular smooth muscle cell calcification in aneurysm formation}

Calcification, the process of deposition of calcium phosphate crystals of the medial layer of the vessel wall, is associated with arterial stiffening and causes isolated systolic hypertension. ${ }^{181}$ VSMCs are key players in vascular calcification. ${ }^{182}$ Phenotypic switching of contractile VSMCs into osteo/chondrogenic VSMCs is accompanied by expression of bonespecific proteins that regulate ECM mineralization (Figure 2). ${ }^{183,184}$ Bone morphogenetic protein 2 (BMP-2), the main regulator of osteogenesis, binds the BMP receptor and activates SMAD signaling, which leads to expression and increased activity of osteo/chondrogenic transcription factors such as Runx2, Osterix, and Sox9.59,185 These transcription factors control expression of mineralization regulators such as alkaline phosphatase, osteocalcin, osteopontin $(\mathrm{OPN})$, osteoprotegerin, and bone sialoprotein. ${ }^{59}$ In response to a variety of stress signals 
VSMCs can cause and enhance calcification via several mechanisms including increased apoptosis $^{106}, \mathrm{EV}$ release ${ }^{186}$ and loss of natural calcification inhibitors, such as MGP. ${ }^{187}$

Calcification of bovine VSMCs suppressed the expression of elastic fiber protein, tropoelastin (elastin monomer), and fibrillin-1. ${ }^{188}$ Conversely, the addition of recombinant tropoelastin was able to inhibit VSMC calcification. ${ }^{189}$ Study in bovine VSMC culture shows that Vitamin K2 inhibits calcium deposition in a dose-dependent manner, and the addition of vitamin $\mathrm{K}$ to bisphosphonate treatment enhances the expression of tropoelastin. ${ }^{190}$ Moreover, Vitamin K2 and bisphosphate inhibit bovine VSMC differentiation to osteo/chondrogenic phenotype. ${ }^{190}$ Vitamin K alone increased MGP and decrease OPN expression of inorganic Pi-induced bovine VSMC calcification in culture. ${ }^{190}$

Apart from VSMCs, macrophages are now recognized as important contributors to the progression of calcification and pro-inflammatory macrophages release microcalcificationinducing EVs. ${ }^{191,192}$ Cholesterol loading converts VSMCs into a macrophage-like foam cells. ${ }^{193,194}$ Interestingly, recent findings show that macrophage-like human VSMCs, which were induced by enzyme-modified non-oxidized LDL, have a genetic profile associated with calcification including upregulation of BMP and downregulation of MGP and had a higher propensity to calcify. ${ }^{195}$ Taken together, these studies suggest that differentiation of VSMCs in to macrophage-like cells may contribute to vascular calcification (Figure 2).

\subsection{Calcification of aneurysms}

Vascular calcification has been shown to be increased in symptomatic AAA and contribute to rupture risk in AAA, as it induces changes in mechanical properties of the aneurysm (Figure 2). ${ }^{196,197}$ However, when categorized based on size as microcalcification $(<$ $50 \mu \mathrm{m})$ and macrocalcification $(>50 \mu \mathrm{m}),{ }^{198}$ calcification has been suggested to promote different outcomes with respect to aneurysms.

Microcalcification, which precedes macrocalcification, is unequivocally considered detrimental and is present during a biologically active fast-dilating aneurysm. ${ }^{13}$ Microcalcification co-localized with elastin degradation in the aorta of Marfan patients. ${ }^{15}$ In Marfan mice, microcalcification was abundant in the ascending aorta and strongly correlated with the aortic root diameter. ${ }^{15}$ In the same study, macrocalcification was found to be prominent in the aortic root of Marfan mice and correlated with aortic dilation to a lesser extent. ${ }^{15}$ The data on macrocalcification is more complex. Recently, a prospective case-control and observational cohort study of 72 patients with asymptomatic AAA revealed that macrocalcification was not associated with aneurysm expansion or AAA events ${ }^{13}$, and it was suggested that macrocalcification of the aneurysm segment might stabilize the degenerated 
vascular wall. ${ }^{13}$ However, research is conflicting and recently published data on the role of calcium scoring in aneurysmal aortic disease revealed macrocalcification of TAAs and AAAs was associated with significantly higher overall and cardiovascular mortality. ${ }^{16}$ This was a retrospective, observational, single center study performed on 319 patients (TAA=123, AAA =196), underwent computed tomography (CT). Aortic aneurysm calcification scores were derived from $\mathrm{CT}$ and multivariate regression analysis was performed after correcting for potential confounders (age and blood pressure). ${ }^{16}$ Although the study reflects clinical practice, renal function, a known cause for vascular calcification, was not analyzed. ${ }^{16}$

While macrocalcification may be less detrimental to the aneurysmal vessel wall than microcalcification, it does start as microcalcification. Therefore, detection of microcalcification could be useful to measure biological activity in the aneurysmal wall, thus identifying risk for AAA events. ${ }^{199}$ Recently, it was shown that active mineralization in AAA, represented by a marked increase in ${ }^{18} \mathrm{~F}-\mathrm{NaF}$ uptake on positron emission tomographycomputed tomography (PET-CT) (see Figure 3 as a visual example), correlates with presence and progression of AAA. ${ }^{13}{ }^{18} \mathrm{~F}-\mathrm{NaF}$ specifically detects active calcification and puts forward microcalcification as a promising risk factor amendable for intervention in AAA. ${ }^{13,200}$

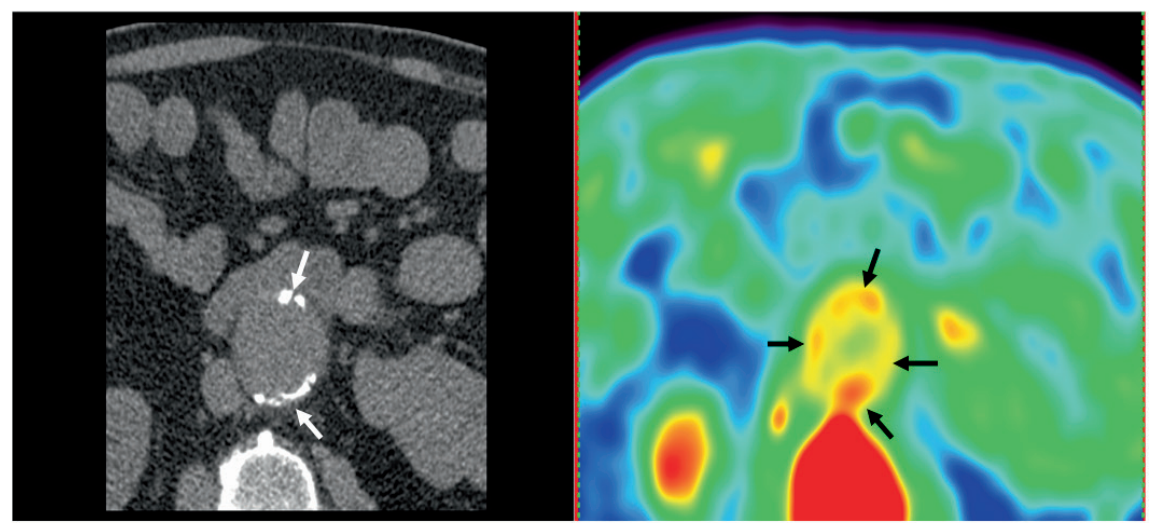

Figure 3: Example of an aneurysm with areas of ${ }^{18} \mathrm{~F}-\mathrm{NaF}$ uptake (PET-CT, right) that do not correlate with calcification visible on $\mathbf{C T}$ (left). On the $\mathrm{CT}$ scan calcification is visible at the anterior and posterior wall of the aorta (white arrows), however there is almost circumferential ${ }^{18} \mathrm{~F}-\mathrm{NaF}$ uptake (black arrows). This shows that there are areas where the PET-CT tracers detect active mineralization, where none is detected by $\mathrm{CT}$ scan. The signal intensity of ${ }^{18} \mathrm{~F}-\mathrm{NaF}$ uptake visualized by PET-CT requires a careful quantitative analysis, which includes calculation of tissue-to-background ratios using background blood pool activity in the right atrium. Moreover, manual adjustment of regions of interest is important when analyzing ${ }^{18} \mathrm{~F}-\mathrm{NaF}$ uptake in structures adjacent to the bone to ensure that any signal attributed to bone is discarded. 


\subsection{Vitamin K-dependent calcification inhibitors}

For many decades, it was thought that calcification of the vasculature was a passive process. The discovery of inhibitors actively preventing vascular calcification revealed that this process is highly regulated by cells and proteins. Of specific interest are VKDPs, whose activity can be modulated by vitamin K or vitamin K antagonists (VKAs). ${ }^{42,201}$ VKDPs can be found in hepatic and extrahepatic tissues (summarized in Table 1). In all cases, VKDPs only exhibit their function when being carboxylated with the aid of its unequivocal cofactor vitamin $\mathrm{K}$.

Table 1. Hepatic and extrahepatic VKDPs. These VKDPs have a high affinity for calcium ions because of their negatively charged Gla residues and are involved in inhibiting ectopic calcification.

\begin{tabular}{|c|c|c|}
\hline $\begin{array}{l}\text { Vitamin K-dependent } \\
\text { proteins }\end{array}$ & function & reference \\
\hline \multicolumn{3}{|l|}{ Hepatic } \\
\hline Coagulation factor VII, IX, X & $\begin{array}{l}\text { Procoagulant. Aid in the coagulation } \\
\text { cascade. }\end{array}$ & $(\text { Danziger } 2008)^{249}$ \\
\hline $\begin{array}{l}\text { Prothrombin (coagulation } \\
\text { factor II) }\end{array}$ & $\begin{array}{l}\text { Inhibits vascular calcification through } \\
\text { binding of phosphatidylserine on EVs, thus } \\
\text { activates coagulation. Loading of EVs with } \\
\text { prothrombin reduces both their pro-calcific } \\
\text { and pro-coagulant properties. }\end{array}$ & $\begin{array}{l}\text { (Kapustin et al. } \\
2017)^{250}\end{array}$ \\
\hline $\begin{array}{l}\text { Activated coagulation factor } \\
\text { (FIIa, FVIIa, FXa) }\end{array}$ & $\begin{array}{l}\text { Activates cellular protease-activated } \\
\text { receptors (PAR), thereby inducing cellular } \\
\text { processes such as inflammation, apoptosis, } \\
\text { migration, fibrosis and calcification. }\end{array}$ & $\begin{array}{l}\text { (Borissoff, Spronk } \\
\text { and ten Cate, 2011) } \\
\text { (Schurgers and } \\
\text { Spronk 2014) }\end{array}$ \\
\hline Protein $\mathrm{C}$ & $\begin{array}{l}\text { Coagulation inhibitor. Assembles } \\
\text { anticoagulant complex on cell surface. }\end{array}$ & $\begin{array}{l}\text { (Danziger 2008) } \\
\text { (Matsuzaka et al. } \\
\text { 1993) (Esmon et al. } \\
1987)^{249,253,254}\end{array}$ \\
\hline Protein S & $\begin{array}{l}\text { Coagulation inhibitor. Cofactor for } \\
\text { activated protein } \mathrm{C} \text {. }\end{array}$ & $\begin{array}{l}\text { (Danziger 2008) } \\
\text { (Matsuzaka et al. } \\
1993)^{249,253}\end{array}$ \\
\hline Protein Z & $\begin{array}{l}\text { Coagulation inhibitor. Cofactor for the } \\
\text { inactivation of FXa. }\end{array}$ & $\begin{array}{l}\text { (Danziger 2008) } \\
\text { (Han et al. } \\
1998)^{249,255}\end{array}$ \\
\hline \multicolumn{3}{|l|}{ Extrahepatic } \\
\hline Osteocalcin (OC) & $\begin{array}{l}\text { Bone tissue-specific protein which is also } \\
\text { expressed in osteo/chondrogenic VSMCs. } \\
\text { Regulates mineral deposition. }\end{array}$ & $\begin{array}{l}\text { (Willems et al. } \\
\text { 2014)(Neve, } \\
\text { Corrado and } \\
\text { Cantatore } 2013) \\
\text { (Steitz et al. } \\
\text { 2001)(Iyemere et al. } \\
\text { 2006) } \\
42,203,256,257\end{array}$ \\
\hline Matrix Gla protein (MGP) & $\begin{array}{l}\text { Regulates VSMC phenotypic switching } \\
\text { through BMP signaling. } \\
\text { Locally, MGP inhibits ECM mineralization } \\
\text { in vascular lesions. }\end{array}$ & $\begin{array}{l}\text { (Luo et al. 1997) } \\
\text { (Wallin et al. 2000) } \\
\text { (Murshed et al. } \\
\text { 2004) (Schurgers et } \\
\text { al. 2005)(Rensen, } \\
\text { Doevendans and van }\end{array}$ \\
\hline
\end{tabular}




\begin{tabular}{|c|c|c|}
\hline & $\begin{array}{l}\text { Prevents calcification when loaded into EVs } \\
\text { that are secreted during the process of } \\
\text { vascular remodeling. }\end{array}$ & $\begin{array}{l}\text { Eys 2007) } \\
\text { (Schurgers et al. } \\
\text { 2008) (Kapustin et } \\
\text { al. 2011) (Willems } \\
\text { et al. 2014) } \\
\text { (Malhotra et al. } \\
\text { 2015) } \\
42,55,202,205,207,210-212\end{array}$ \\
\hline $\begin{array}{l}\text { Gla-rich protein } \\
\text { (GRP; also called Ucma) }\end{array}$ & $\begin{array}{l}\text { Inhibits vascular calcification through direct } \\
\text { binding at calcification sites, thus inhibiting } \\
\text { crystal formation/maturation, and via } \\
\text { loading into EVs and calcifying protein } \\
\text { particles (CPPs). Binds and inhibits BMP-2. }\end{array}$ & $\begin{array}{l}\text { (Viegas et al. 2009) } \\
\text { (Willems et al. } \\
\text { 2014) (Viegas et al. } \\
\text { 2015) (Willems et } \\
\text { al. 2018)(Viegas et } \\
\text { al. 2018) }\end{array}$ \\
\hline $\begin{array}{l}\text { Growth arrest specific gene } 6 \\
\text { (Gas6) }\end{array}$ & $\begin{array}{l}\text { Involved in vascular homeostasis. } \\
\text { In VSMCs, Gas } 6 \text { inhibits apoptosis, induces } \\
\text { migration, and promotes cell survival. }\end{array}$ & $\begin{array}{l}\text { (Nakano et al. 1995) } \\
\text { (Nakano et al. 1996) } \\
\text { (Fridell et al. 1998) } \\
\text { (Melaragno et al. } \\
\text { 2004) (Son et al. } \\
\text { 2006) (Laurance } \text { et } \\
\text { al. 2012) (Clauser et } \\
\text { al. } \\
\text { 2012) } \\
264\end{array}$ \\
\hline
\end{tabular}

VSMCs synthesize several VKDP calcification inhibitors (Table 1). One of the most potent inhibitors for vascular calcification known in is MGP. ${ }^{187}$ MGP regulates VSMC phenotypic switching through BMP signaling which transdifferentiates VSMC into osteo/chondrogenic phenotype. ${ }^{42,55,202}$ This transdifferentiation, together with loss of VSMC markers; $\alpha$-SMA and SM22 $\alpha$, was found in MGP-deficient mice. ${ }^{203,204}$ MGP also acts locally to inhibit ECM mineralization in calcified vascular lesions. ${ }^{205-207}$ MGP maintains contractility of VSMCs by binding to BMP-2, and thus inhibiting osteo/chondrogenic differentiation. ${ }^{202,208,209}$ MGP also prevents calcification when it is loaded into EVs that are secreted during the process of vascular remodeling. ${ }^{210-212}$ Moreover, intra-section analysis of human coronary arteries $(n=12)$ showed that MGP is associated with microcalcifications in early atherosclerotic lesions ${ }^{213}$, which is associated with increased plaque vulnerability. ${ }^{108,214,215}$ A patient-based proteomic analysis revealed that MGP is increased in calcified AAA $(n=6)$ and TAA $(n=6)$ tissue sample in comparison to the adjacent normal aorta tissues. ${ }^{216}$ It was suggested that upregulation of the calcification inhibitor might be a feedback mechanism to prevent further calcium deposit. ${ }^{216}$ However, circulating MGP has not been studied in the context of AAA and TAA. 


\subsection{Phenotypic switching of VSMCs in aneurysm promotes calcification}

VSMC phenotypic switching, as shown by loss of contractility markers and increases in MMPs, precedes AAA in mice. ${ }^{51}$ Accordingly, synthetic VSMCs and upregulation of OPN was shown in the dilated region of human TAA. ${ }^{139}$

In the context of aneurysm formation, additional specific mechanisms promoting calcification are at play. MMP-mediated elastin degradation and misfolding of elastin were shown to be associated with calcium deposition on elastin fibers and calcification. ${ }^{206,217}$ Additionally, elastic fiber degradation might cause detachment of VSMCs thereby altering their phenotype. ${ }^{93}$ Elastin peptides, which are generated though elastin breaks, upregulate ALP and downregulate MGP expression of human VSMCs in vitro. ${ }^{15}$ Absence of the calcification inhibitory protein MGP also promotes phenotypic switching of VSMCs. ${ }^{205}$ Hence, VSMC phenotypic switching increases both cellular and ECM stiffness. ${ }^{26}$ Elastin-derived peptides and TGF- $\beta 1$ were shown to promote osteo/chondrogenic differentiation of VSMCs, which may lead to calcification. ${ }^{218}$ Indeed, VSMCs of Marfan mice showed enhanced ALP activity and upregulation of osteogenic gene profile including ALP, bone $\gamma$-carboxyglutamic acid-containing protein and RUNX2, in comparison to WT mice. ${ }^{15}$

It was proposed that osteo/chondrogenic differentiation of VSMC is an attempt to prevent vessel wall degeneration by increased ECM production. ${ }^{218}$ Differentiation of macrophages into osteoclast-like cells is also observed in the development of AAAs in both humans and mice. ${ }^{219,220}$ It was shown that pharmacological inhibition of the activity of these osteoclasts (cells involved in resorbing calcification) using bisphosphonate was able to prevent AAA in a $\mathrm{CaCl}_{2}$-induced mouse model of aneurysm. ${ }^{219}$ Furthermore, bisphosphonate attenuated AAA in angiotensin II-induced mouse model of aneurysm through reduction of vascular inflammation. ${ }^{221}$ Conversely, inhibiting osteoclast activity with bisphosphonate failed to prevent aneurysm progression in an animal model of severe Marfan syndrome. ${ }^{222}$ The contradictory outcome may lie upon the different basic pathophysiology between TAA and AAA. ${ }^{221}$

\subsection{Vitamin K antagonists promote and vitamin K rescues calcification}

The importance of vitamin $\mathrm{K}$ status in vascular calcification is supported by studies of $\mathrm{VKAs}^{223}$, which counteract the function of vitamin K by blocking VKOR and subsequently inhibiting vitamin $\mathrm{K}$ recycling. ${ }^{224}$ VKAs, such as warfarin, are widely used as anticoagulants to prevent thromboembolic complications in cardiovascular diseases. ${ }^{225}$ 
In a study in mice, VKA-induced calcification was associated with increased apoptosis and reduced cellularity in the medial vascular layer in mice. ${ }^{26}$ In rats, VKA treatment was shown to rapidly calcify the elastic lamellae of major arteries and aortic heart valves. ${ }^{227}$ This was similar to what has been observed in MGP-deficient mice, suggesting that VKAs induce calcification by inhibiting MGP functionality. ${ }^{205}$ It must be noted that a daily high dose of VKA in combination with high dose vitamin $\mathrm{K} 1$ was used to prevent bleeding and cause arterial calcification of rats $(15 \mathrm{mg}$ warfarin $/ 100 \mathrm{~g}$ of body weight administered twice daily, while typical maintenance dose of VKA for human ranges between 2 and $10 \mathrm{mg} /$ day). ${ }^{227}$ This dosage is required to maintain a constant level of VKA in plasma without oscillation, ${ }^{227}$ because of rapid clearance of warfarin from plasma in rats and considering the half-life of warfarin. ${ }^{228,229}$ However, the authors showed no significant differences in blood chemistry between the VKAtreated and the control groups. Additionally, although observations in animal models are based on much higher doses of VKAs than human dosage, it appears that the international normalized ratio (INR) in these animals falls within the same target INR range for patients. ${ }^{230}$

Ample evidence exists that patients using VKAs have higher levels of vascular calcification than VKA non-users. ${ }^{231,232}$ More than a decade ago it was reported that VKAs are associated with increased valvular calcification in patients. ${ }^{231}$ Since then, this has been verified in many subsequent studies. A large population-based cohort of 15,010 individuals enrolled in the Gutenberg health study, of which 278 patients received VKA treatment, demonstrated an increased arterial stiffness in VKA treated patients. ${ }^{233}$ Interestingly, enhanced inflammation was also observed in VKA users in this study. However, the cross-sectional design of this study does not allow interpretation of cause and effect, and only a limited number of patients received direct-acting anticoagulants for oral anticoagulation therapy for comparison. Another study analyzed atherosclerotic plaques of patients with non-valvular atrial fibrillation, and showed higher coronary calcium score and significantly higher amount of spotty calcification (calcification of $<3 \mathrm{~mm}$ ) in VKA users compared to a matching demographics (age, sex, BMI, family history, etc.) control group ( $\mathrm{n}=101$ per group). ${ }^{234}$ It must be noted that despite the propensity score matching, this study ignored the difference between VKA-treated patients and control with regards to some parameters, including HDL and stroke risk score in patients with atrial fibrillation $\left(\mathrm{CHADS}_{2} \mathrm{VASC}_{2}\right)$, which might contribute to spotty calcification. Serial coronary intravascular ultrasound examinations in a post-hoc analysis of 8 prospective randomized clinical trials showed a significant progression of CAC, independent of changes in atheroma volume in VKA users compared to the propensity matching control group ( $\mathrm{n}=164$ per group). ${ }^{235}$ In a different study, VKA users had significantly more CAC than VKA non- 
users with matching gender and Framingham risk score ( $\mathrm{n}=133$ per group). ${ }^{230}$ A small crosssectional study on long-term VKA treatment showed an association of VKA users with extracoronary calcification. ${ }^{236}$ Recently, small cross-sectional studies conducted in atrial fibrillation patients pointed towards increased prevalence of vascular calcification as compared to nonvitamin $\mathrm{K}$ antagonist oral anticoagulants (NOACs) or no treatment. ${ }^{237}$ Data on vascular calcification from subgroup analyses of large controlled randomized clinical trials comparing warfarin with direct oral anticoagulants for various clinical indications might further clarify the role of vitamin $\mathrm{K}$ in aortic calcification or aneurysm formation. Such results would provide a valuable piece of the puzzle, given the limitations of smaller clinical studies of warfarin and of animal studies that used several log-fold excess of warfarin compared to that used clinically in humans.

In experimental animals, VKA-induced medial calcification was rescued by cotreatment with a high dose of vitamin K2.226 Additionally, regression of arterial calcification was shown in an animal model with high vitamin $\mathrm{K}$ diet. ${ }^{238} \mathrm{In}$ an interventional randomized control trial of 53 long-term end-stage renal disease patients, who had a vitamin $\mathrm{K}$ deficiency, supplementation of vitamin K2 significantly decreased the levels of inactive MGP (dephosphouncarboxylated MGP; dp-ucMGP) in a dose- and time-dependent manner. ${ }^{239}$ This indicates that circulating dp-ucMGP reflects bioavailability of vitamin $\mathrm{K}$ in the vasculature. ${ }^{211,239,240}$ Indeed, low vitamin $\mathrm{K}$ status or intake is linked to vascular calcification in human subjects. ${ }^{241,242}$ A study of 115 patients with suspected coronary artery disease showed reduction of carboxylated MGP correlates with CAC progression. ${ }^{243}$ Recent results from a prospective interventional study of 72 patients with aortic stenosis showed that vitamin K1 supplementation over a 12-month period significantly decelerated the progression of aortic valve calcification. ${ }^{240}$ Hence, the level of dp-ucMGP can be used as a marker for vascular vitamin $\mathrm{K}$ deficiency. As vascular calcification is suggested to increase risk of aneurysm rupture, treatment with vitamin $\mathrm{K}$ could hold promise to decrease this risk.

\subsection{Vitamin $K$ antagonists in aneurysm}

The effect of VKAs on AAA progression has not been fully explored yet. They have been linked to continued AAA expansion of more than $5 \mathrm{~mm}$ in diameter, and increased risk of persistent blood flow in aneurysm sac (endoleak) after endovascular aneurysm repair (EVAR). ${ }^{244,245}$ A few clinical cases have been reported in which the use of anticoagulants induced spontaneous rupture of bronchial artery aneurysms in patients who took heparin and VKAs, and did not have an apparent aortic pathology. ${ }^{246}$ Additionally, VKAs promote many effects similar to what has been observed in aneurysm pathology. In a mouse model of 
atherosclerosis, high dose VKAs induce a vulnerable atherosclerotic plaque phenotype with elastin breaks. ${ }^{230}$ High dose warfarin treatment in rats results in activation of MMP-9, elastin degradation, vascular elastocalcinosis and stiffness. ${ }^{247}$ In addition, impaired vitamin $\mathrm{K}$ status in patients with end-stage renal disease is linked to VSMC phenotypic switching towards senescence-associated secretory phenotype (SASP), thus promoting premature vascular aging. ${ }^{248}$ Taken together, VKAs affect VSMC properties, weaken the vascular media and might thus increase the susceptibility of aneurysms to progress and rupture.

\section{Conclusions}

In summary, in this review we presented what is known about the role of VSMC phenotypic switching in the pathophysiology of aneurysm formation. NOX enzymes in VSMCs are a major source of increased oxidative stress in aneurysms. Oxidative stress induces VSMC phenotypic switching, which results in ECM degradation and weakening of the arterial wall. VSMC phenotypic changes also lead to calcification, which has been recently proposed as a risk factor for aneurysm progression and rupture, as it results in segmental aortic stiffening generating distally increased aortic wall stress. Vitamin $\mathrm{K}$ and VKOR are involved in the regulation of NOX and ROS generation. Vitamin K is known to activate MGP by which it prevents vascular calcification. Moreover, vitamin $\mathrm{K}$ has the ability to scavenge free radicals, reduce oxidative stress and decrease vascular calcification. Therefore, it is tempting to postulate that vitamin $\mathrm{K}$ deficiency plays a role in aneurysm formation. Vitamin $\mathrm{K}$ supplementation holds the potential to lower the risk of aortic aneurysms and improve cardiovascular outcome.

More studies are needed in patients to examine the effects of vitamin $\mathrm{K}$ supplementation on aneurysm progression and risk of rupture. Moreover, shedding light on the effect that vitamin $\mathrm{K}$ has on hallmarks of VSMC phenotype (such as proliferation, migration, contractile protein expression) and the associated mechanisms (oxidative stress, ER stress) would help to fully understand the role of vitamin $\mathrm{K}$ in aneurysm formation.

\section{Acknowledgement}

This project has received funding from the European Union's Horizon 2020 research and innovation programme under the Marie Skłodowska-Curie grant agreement No 675111. 


\section{References}

1. Vorp DA, Raghavan ML, Webster MW. Mechanical wall stress in abdominal aortic aneurysm: Influence of diameter and asymmetry. Journal of Vascular Surgery. 1998;27:632-639.

2. Dua MM, Dalman RL. Hemodynamic Influences on abdominal aortic aneurysm disease: Application of biomechanics to aneurysm pathophysiology. Vascular Pharmacology. 2010;53:11-21.

3. Zamaneh Kassiri RB, Kassiri Z. Extracellular Matrix Remodelling and Abdominal Aortic Aneurysm. Journal of Clinical \& Experimental Cardiology. 2013;04:1-8.

4. Kuivaniemi H, Ryer EJ, Elmore JR, Tromp G. Understanding the pathogenesis of abdominal aortic aneurysms. Expert Review of Cardiovascular Therapy. 2015;13:975987.

5. GBD 2013 Mortality and Causes of Death Collaborators. Global, regional, and national age-sex specific all-cause and cause-specific mortality for 240 causes of death, 19902013: a systematic analysis for the Global Burden of Disease Study 2013. The Lancet. 2015;385:117-171.

6. van Varik BJ, Rennenberg RJMW, Reutelingsperger CP, Kroon AA, de Leeuw PW, Schurgers LJ. Mechanisms of arterial remodeling: lessons from genetic diseases. Frontiers in Genetics. 2012;3:290.

7. Alexander MR, Owens GK. Epigenetic Control of Smooth Muscle Cell Differentiation and Phenotypic Switching in Vascular Development and Disease. Annual Review of Physiology. 2012;74:13-40.

8. Willis AI, Pierre-Paul D, Sumpio BE, Gahtan V. Vascular Smooth Muscle Cell Migration: Current Research and Clinical Implications. Vascular and Endovascular Surgery. 2004;38:11-23.

9. Kapustin AN, Shanahan CM. Emerging roles for vascular smooth muscle cell exosomes in calcification and coagulation. The Journal of Physiology. 2016;594:2905-2914.

10. Schurgers LJ, Akbulut AC, Kaczor DM, Halder M, Koenen RR, Kramann R. Initiation and Propagation of Vascular Calcification Is Regulated by a Concert of Platelet- and Smooth Muscle Cell-Derived Extracellular Vesicles. Frontiers in Cardiovascular Medicine. 2018;5:36.

11. Duer MJ, Friščić T, Proudfoot D, Reid DG, Schoppet M, Shanahan CM, Skepper JN, Wise ER. Mineral Surface in Calcified Plaque Is Like That of Bone. Arteriosclerosis, Thrombosis, and Vascular Biology. 2008;28:2030-2034.

12. Mackey RH, Venkitachalam L, Sutton-Tyrrell K. Calcifications, Arterial Stiffness and Atherosclerosis. In: Atherosclerosis, Large Arteries and Cardiovascular Risk.Vol 44. Basel: KARGER; 2006:234-244.

13. Forsythe RO, Dweck MR, McBride OMB, Vesey AT, Semple SI, Shah ASV, Adamson PD, Wallace WA, Kaczynski J, Ho W, van Beek EJR, Gray CD, Fletcher A, Lucatelli C, Marin A, et al. 18 F-Sodium Fluoride Uptake in Abdominal Aortic Aneurysms. Journal of the American College of Cardiology. 2018;71:513-523.

14. Nakayama A, Morita H, Hayashi N, Nomura Y, Hoshina K, Shigematsu K, Ohtsu H, Miyata T, Komuro I. Inverse Correlation Between Calcium Accumulation and the Expansion Rate of Abdominal Aortic Aneurysms. Circulation Journal. 2016;80:332339.

15. Wanga S, Hibender S, Ridwan Y, van Roomen C, Vos M, van der Made I, van Vliet N, Franken R, van Riel LA, Groenink M, Zwinderman AH, Mulder BJ, de Vries CJ, Essers $\mathrm{J}$, de Waard V. Aortic microcalcification is associated with elastin fragmentation in Marfan syndrome. The Journal of Pathology. 2017;243:294-306.

16. Chowdhury MM, Zieliński LP, Sun JJ, Lambracos S, Boyle JR, Harrison SC, Rudd JHF, 
Coughlin PA. Editor's Choice - Calcification of Thoracic and Abdominal Aneurysms is Associated with Mortality and Morbidity. European Journal of Vascular and Endovascular Surgery. 2018;55:101-108.

17. Geleijnse JM, Vermeer C, Grobbee DE, Schurgers LJ, Knapen MHJ, van der Meer IM, Hofman A, Witteman JCM. Dietary Intake of Menaquinone Is Associated with a Reduced Risk of Coronary Heart Disease: The Rotterdam Study. The Journal of Nutrition. 2004;134:3100-3105.

18. Beulens JWJ, Bots ML, Atsma F, Bartelink M-LEL, Prokop M, Geleijnse JM, Witteman JCM, Grobbee DE, van der Schouw YT. High dietary menaquinone intake is associated with reduced coronary calcification. Atherosclerosis. 2009;203:489-93.

19. Johnston KW, Rutherford RB, Tilson MD, Shah DM, Hollier L, Stanley JC. Suggested standards for reporting on arterial aneurysms. Subcommittee on Reporting Standards for Arterial Aneurysms, Ad Hoc Committee on Reporting Standards, Society for Vascular Surgery and North American Chapter, International Society for Cardiovascular Surgery. Journal of vascular surgery. 1991;13:452-8.

20. Choke E, Cockerill G, Wilson WRW, Sayed S, Dawson J, Loftus I, Thompson MM. A Review of Biological Factors Implicated in Abdominal Aortic Aneurysm Rupture. European Journal of Vascular and Endovascular Surgery. 2005;30:227-244.

21. Henderson EL, Geng YJ, Sukhova GK, Whittemore AD, Knox J, Libby P. Death of smooth muscle cells and expression of mediators of apoptosis by $\mathrm{T}$ lymphocytes in human abdominal aortic aneurysms. Circulation. 99:96-104.

22. Michel J-B, Jondeau G, Milewicz DM. From genetics to response to injury: vascular smooth muscle cells in aneurysms and dissections of the ascending aorta. Cardiovascular Research. 2018;114:578-589.

23. Choke E, Thompson MM, Dawson J, Wilson WRW, Sayed S, Loftus IM, Cockerill GW. Abdominal Aortic Aneurysm Rupture Is Associated With Increased Medial Neovascularization and Overexpression of Proangiogenic Cytokines. Arteriosclerosis, Thrombosis, and Vascular Biology. 2006;26:2077-2082.

24. Raaz U, Zöllner AM, Schellinger IN, Toh R, Nakagami F, Brandt M, Emrich FC, Kayama Y, Eken S, Adam M, Maegdefessel L, Hertel T, Deng A, Jagger A, Buerke M, et al. Segmental Aortic Stiffening Contributes to Experimental Abdominal Aortic Aneurysm Development. Circulation. 2015;131:1783-1795.

25. López-Candales A, Holmes DR, Liao S, Scott MJ, Wickline SA, Thompson RW. Decreased vascular smooth muscle cell density in medial degeneration of human abdominal aortic aneurysms. The American journal of pathology. 1997;150:993-1007.

26. Crosas-Molist E, Meirelles T, López-Luque J, Serra-Peinado C, Selva J, Caja L, Gorbenko del Blanco D, Uriarte JJ, Bertran E, Mendizábal Y, Hernández V, GarcíaCalero C, Busnadiego O, Condom E, Toral D, et al. Vascular Smooth Muscle Cell Phenotypic Changes in Patients With Marfan Syndrome. Arteriosclerosis, Thrombosis, and Vascular Biology. 2015;35:960-972.

27. Elefteriades JA, Pomianowski P. Practical Genetics of Thoracic Aortic Aneurysm. Progress in Cardiovascular Diseases. 2013;56:57-67.

28. Pannu H, Avidan N, Tran-Fadulu V, Milewicz DM. Genetic Basis of Thoracic Aortic Aneurysms and Dissections: Potential Relevance to Abdominal Aortic Aneurysms. Annals of the New York Academy of Sciences. 2006;1085:242-255.

29. Ando M, Okita Y, Morota T, Takamoto S. Thoracic aortic aneurysm associated with congenital bicuspid aortic valve. Cardiovascular surgery (London, England). 1998;6:629-34.

30. Freeze SL, Landis BJ, Ware SM, Helm BM. Bicuspid Aortic Valve: a Review with Recommendations for Genetic Counseling. Journal of genetic counseling. 
2016;25:1171.

31. Guo D-C, Pannu H, Tran-Fadulu V, Papke CL, Yu RK, Avidan N, Bourgeois S, Estrera AL, Safi HJ, Sparks E, Amor D, Ades L, McConnell V, Willoughby CE, Abuelo D, et al. Mutations in smooth muscle $\alpha$-actin (ACTA2) lead to thoracic aortic aneurysms and dissections. Nature Genetics. 2007;39:1488-1493.

32. He R, Guo D-C, Sun W, Papke CL, Duraisamy S, Estrera AL, Safi HJ, Ahn C, Buja LM, Arnett FC, Zhang J, Geng Y-J, Milewicz DM. Characterization of the inflammatory cells in ascending thoracic aortic aneurysms in patients with Marfan syndrome, familial thoracic aortic aneurysms, and sporadic aneurysms. The Journal of thoracic and cardiovascular surgery. 2008;136:922-9, 929.e1.

33. Tang PCY, Yakimov AO, Teesdale MA, Coady MA, Dardik A, Elefteriades JA, Tellides G. Transmural inflammation by interferon- $\gamma$-producing $T$ cells correlates with outward vascular remodeling and intimal expansion of ascending thoracic aortic aneurysms. The FASEB Journal. 2005;19:1528-1530.

34. Wang Y, Ait-Oufella H, Herbin O, Bonnin P, Ramkhelawon B, Taleb S, Huang J, Offenstadt G, Combadière C, Rénia L, Johnson JL, Tharaux P-L, Tedgui A, Mallat Z. TGF- $\beta$ activity protects against inflammatory aortic aneurysm progression and complications in angiotensin II-infused mice. The Journal of Clinical Investigation. 2010;120:422.

35. Schlatmann TJ, Becker AE. Histologic changes in the normal aging aorta: implications for dissecting aortic aneurysm. The American journal of cardiology. 1977;39:13-20.

36. Schurgers LJ, Geleijnse JM, Grobbee DE, Pols HAP, Hofman A, Witteman JCM, Vermeer C. Nutritional Intake of Vitamins K1 (Phylloquinone) and K2 (Menaquinone) in The Netherlands. Journal of Nutritional \& Environmental Medicine. 1999;9:115122.

37. Schurgers LJ, Vermeer C. Determination of Phylloquinone and Menaquinones in Food. Pathophysiology of Haemostasis and Thrombosis. 2000;30:298-307.

38. Schurgers LJ, Teunissen KJF, Hamulyák K, Knapen MHJ, Vik H, Vermeer C. Vitamin K-containing dietary supplements: comparison of synthetic vitamin $\mathrm{K} 1$ and nattoderived menaquinone-7. Blood. 2007;109:3279-83.

39. Schurgers LJ, Vermeer C. Differential lipoprotein transport pathways of K-vitamins in healthy subjects. Biochimica et biophysica acta. 2002;1570:27-32.

40. Shearer MJ, Newman P. Metabolism and cell biology of vitamin K. Thrombosis and haemostasis. 2008;100:530-47.

41. van Gorp R, Schurgers L. New Insights into the Pros and Cons of the Clinical Use of Vitamin K Antagonists (VKAs) Versus Direct Oral Anticoagulants (DOACs). Nutrients. 2015;7:9538-9557.

42. Willems BAG, Vermeer C, Reutelingsperger CPM, Schurgers LJ. The realm of vitamin $\mathrm{K}$ dependent proteins: Shifting from coagulation toward calcification. Molecular Nutrition \& Food Research. 2014;58:1620-1635.

43. Wang Y, Zhen Y, Shi Y, Chen J, Zhang C, Wang X, Yang X, Zheng Y, Liu Y, Hui R. Vitamin K Epoxide Reductase: A Protein Involved in Angiogenesis. Molecular Cancer Research. 2005;3:317-323.

44. Wang Y, Zhang W, Zhang Y, Yang Y, Sun L, Hu S, Chen J, Zhang C, Zheng Y, Zhen Y, Sun K, Fu C, Yang T, Wang J, Sun J, et al. VKORCl Haplotypes Are Associated With Arterial Vascular Diseases (Stroke, Coronary Heart Disease, and Aortic Dissection). Circulation. 2006;113:1615-1621.

45. Parolari A, Tremoli E, Songia P, Pilozzi A, Di Bartolomeo R, Alamanni F, Mestres CA, Pacini D. Biological features of thoracic aortic diseases. Where are we now, where are we heading to: established and emerging biomarkers and molecular pathways. European 
Journal of Cardio-Thoracic Surgery. 2013;44:9-23.

46. Andreas M, Panzenboeck A, Shabanian S, Kocher A, Mannhalter C, Petzl A, Hueblauer J, Wolzt M, Ehrlich M, Lang I. The VKORC1 polymorphism rs9923231 is associated with aneurysms of the ascending aorta in an Austrian population. Thrombosis Research. 2017;152:41-43.

47. Anwar MA, Shalhoub J, Lim CS, Gohel MS, Davies AH. The effect of pressure-induced mechanical stretch on vascular wall differential gene expression. Journal of vascular research. 2012;49:463-78.

48. Owens GK, Kumar MS, Wamhoff BR. Molecular Regulation of Vascular Smooth Muscle Cell Differentiation in Development and Disease. Physiological Reviews. 2004;84:767-801.

49. Owens GK. Regulation of differentiation of vascular smooth muscle cells. Physiological Reviews. 1995;75:487-517.

50. Rzucidlo EM, Martin KA, Powell RJ. Regulation of vascular smooth muscle cell differentiation. Journal of Vascular Surgery. 2007;45:A25-A32.

51. Ailawadi G, Moehle CW, Pei H, Walton SP, Yang Z, Kron IL, Lau CL, Owens GK. Smooth muscle phenotypic modulation is an early event in aortic aneurysms. The Journal of Thoracic and Cardiovascular Surgery. 2009;138:1392-1399.

52. Branchetti E, Poggio P, Sainger R, Shang E, Grau JB, Jackson BM, Lai EK, Parmacek MS, Gorman RC, Gorman JH, Bavaria JE, Ferrari G. Oxidative stress modulates vascular smooth muscle cell phenotype via CTGF in thoracic aortic aneurysm. Cardiovascular Research. 2013;100:316-324.

53. Hao H, Gabbiani G, Bochaton-Piallat M-L. Arterial Smooth Muscle Cell Heterogeneity. Arteriosclerosis, Thrombosis, and Vascular Biology. 2003;23:1510-1520.

54. Chamley-Campbell J, Campbell GR, Ross R. The smooth muscle cell in culture. Physiological Reviews. 1979;59:1-61.

55. Rensen SSM, Doevendans PAFM, van Eys GJJM. Regulation and characteristics of vascular smooth muscle cell phenotypic diversity. Netherlands heart journal : monthly journal of the Netherlands Society of Cardiology and the Netherlands Heart Foundation. 2007;15:100-8.

56. Hao H, Ropraz P, Verin V, Camenzind E, Geinoz A, Pepper MS, Gabbiani G, BochatonPiallat M-L. Heterogeneity of smooth muscle cell populations cultured from pig coronary artery. Arteriosclerosis, thrombosis, and vascular biology. 2002;22:1093-9.

57. Bennett MR, Sinha S, Owens GK. Vascular Smooth Muscle Cells in Atherosclerosis. Circulation research. 2016;118:692-702.

58. Allahverdian S, Chaabane C, Boukais K, Francis GA, Bochaton-Piallat M-L. Smooth muscle cell fate and plasticity in atherosclerosis. Cardiovascular Research. 2018;114:540-550.

59. Durham AL, Speer MY, Scatena M, Giachelli CM, Shanahan CM. Role of smooth muscle cells in vascular calcification: implications in atherosclerosis and arterial stiffness. Cardiovascular research. 2018;114:590-600.

60. Hellström M, Kalén M, Lindahl P, Abramsson A, Betsholtz C. Role of PDGF-B and PDGFR-beta in recruitment of vascular smooth muscle cells and pericytes during embryonic blood vessel formation in the mouse. Development (Cambridge, England). 1999; 126:3047-55.

61. Hautmann MB, Madsen CS, Owens GK. A transforming growth factor beta (TGFbeta) control element drives TGFbeta-induced stimulation of smooth muscle alpha-actin gene expression in concert with two CArG elements. The Journal of biological chemistry. 1997;272:10948-56.

62. Bascands J-L, Girolami J-P, Troly M, Escargueil-Blanc I, Nazzal D, Salvayre R, Blaes 
N. Angiotensin II Induces Phenotype-Dependent Apoptosis in Vascular Smooth Muscle Cells. Hypertension. 2001;38:1294-1299.

63. CLEMPUS R, GRIENDLING K. Reactive oxygen species signaling in vascular smooth muscle cells. Cardiovascular Research. 2006;71:216-225.

64. Nataatmadja M, West J, West M. Overexpression of Transforming Growth Factor- Is Associated With Increased Hyaluronan Content and Impairment of Repair in Marfan Syndrome Aortic Aneurysm. Circulation. 2006;114:I-371-I-377.

65. Reilly CF, Kindy MS, Brown KE, Rosenberg RD, Sonenshein GE. Heparin prevents vascular smooth muscle cell progression through the G1 phase of the cell cycle. The Journal of biological chemistry. 1989;264:6990-5.

66. Beamish JA, Geyer LC, Haq-Siddiqi NA, Kottke-Marchant K, Marchant RE. The effects of heparin releasing hydrogels on vascular smooth muscle cell phenotype. Biomaterials. 2009;30:6286-6294.

67. Mao N, Gu T, Shi E, Zhang G, Yu L, Wang C. Phenotypic switching of vascular smooth muscle cells in animal model of rat thoracic aortic aneurysm. Interactive CardioVascular and Thoracic Surgery. 2015;21:62-70.

68. Milewicz DM, Prakash SK, Ramirez F. Therapeutics Targeting Drivers of Thoracic Aortic Aneurysms and Acute Aortic Dissections: Insights from Predisposing Genes and Mouse Models. Annual review of medicine. 2017;68:51-67.

69. Lindsay ME, Dietz HC. The Genetic Basis of Aortic Aneurysm. Cold Spring Harbor Perspectives in Medicine. 2014;4:a015909-a015909.

70. Zhu L, Vranckx R, Van Kien PK, Lalande A, Boisset N, Mathieu F, Wegman M, Glancy L, Gasc J-M, Brunotte F, Bruneval P, Wolf J-E, Michel J-B, Jeunemaitre X. Mutations in myosin heavy chain 11 cause a syndrome associating thoracic aortic aneurysm/aortic dissection and patent ductus arteriosus. Nature Genetics. 2006;38:343-349.

71. Guo D-C, Pannu H, Tran-Fadulu V, Papke CL, Yu RK, Avidan N, Bourgeois S, Estrera AL, Safi HJ, Sparks E, Amor D, Ades L, McConnell V, Willoughby CE, Abuelo D, et al. Mutations in smooth muscle $\alpha$-actin (ACTA2) lead to thoracic aortic aneurysms and dissections. Nature Genetics. 2007;39:1488-1493.

72. Kim HW, Stansfield BK. Genetic and Epigenetic Regulation of Aortic Aneurysms. BioMed Research International. 2017;2017:1-12.

73. Mallat Z, Tedgui A, Henrion D. Role of Microvascular Tone and Extracellular Matrix Contraction in the Regulation of Interstitial Fluid. Arteriosclerosis, Thrombosis, and Vascular Biology. 2016;36:1742-1747.

74. Ferruzzi J, Murtada S-I, Li G, Jiao Y, Uman S, Ting MYL, Tellides G, Humphrey JD. Pharmacologically Improved Contractility Protects Against Aortic Dissection in Mice With Disrupted Transforming Growth Factor- $\beta$ Signaling Despite Compromised Extracellular Matrix Properties. Arteriosclerosis, thrombosis, and vascular biology. 2016;36:919-27.

75. Chen P, Qin L, Li G, Tellides G, Simons M. Smooth muscle FGF/TGF $\beta$ cross talk regulates atherosclerosis progression. EMBO Molecular Medicine. 2016;8:712-728.

76. Fukui D, Miyagawa S, Soeda J, Tanaka K, Urayama H, Kawasaki S. Overexpression of transforming growth factor $\beta 1$ in smooth muscle cells of human abdominal aortic aneurysm. European Journal of Vascular and Endovascular Surgery. 2003;25:540-545.

77. Nataatmadja M, West J, Prabowo S, West M. Angiotensin II Receptor Antagonism Reduces Transforming Growth Factor Beta and Smad Signaling in Thoracic Aortic Aneurysm. The Ochsner journal. 2013;13:42-8.

78. Doyle JJ, Gerber EE, Dietz HC. Matrix-dependent perturbation of TGF $\beta$ signaling and disease. FEBS Letters. 2012;586:2003-2015.

79. Lindsay ME, Dietz HC. Lessons on the pathogenesis of aneurysm from heritable 
conditions. Nature. 2011;473:308-316.

80. Habashi JP, Judge DP, Holm TM, Cohn RD, Loeys BL, Cooper TK, Myers L, Klein EC, Liu G, Calvi C, Podowski M, Neptune ER, Halushka MK, Bedja D, Gabrielson K, et al. Losartan, an AT1 Antagonist, Prevents Aortic Aneurysm in a Mouse Model of Marfan Syndrome. Science. 2006;312:117-121.

81. Lindsay ME, Schepers D, Bolar NA, Doyle JJ, Gallo E, Fert-Bober J, Kempers MJE, Fishman EK, Chen Y, Myers L, Bjeda D, Oswald G, Elias AF, Levy HP, Anderlid B$\mathrm{M}$, et al. Loss-of-function mutations in TGFB2 cause a syndromic presentation of thoracic aortic aneurysm. Nature genetics. 2012;44:922-7.

82. Wei H, Hu JH, Angelov SN, Fox K, Yan J, Enstrom R, Smith A, Dichek DA. Aortopathy in a Mouse Model of Marfan Syndrome Is Not Mediated by Altered Transforming Growth Factor $\beta$ Signaling. Journal of the American Heart Association. 2017;6.

83. Gallo EM, Loch DC, Habashi JP, Calderon JF, Chen Y, Bedja D, van Erp C, Gerber EE, Parker SJ, Sauls K, Judge DP, Cooke SK, Lindsay ME, Rouf R, Myers L, et al. Angiotensin II-dependent TGF- $\beta$ signaling contributes to Loeys-Dietz syndrome vascular pathogenesis. The Journal of clinical investigation. 2014;124:448-60.

84. Li W, Li Q, Jiao Y, Qin L, Ali R, Zhou J, Ferruzzi J, Kim RW, Geirsson A, Dietz HC, Offermanns S, Humphrey JD, Tellides G. Tgfbr2 disruption in postnatal smooth muscle impairs aortic wall homeostasis. Journal of Clinical Investigation. 2014;124:755-767.

85. Mallat Z, Ait-Oufella H, Tedgui A. The Pathogenic Transforming Growth Factor- $\beta$ Overdrive Hypothesis in Aortic Aneurysms and Dissections: A Mirage? Circulation research. 2017;120:1718-1720.

86. Chen X, Rateri DL, Howatt DA, Balakrishnan A, Moorleghen JJ, Cassis LA, Daugherty A. TGF- $\beta$ Neutralization Enhances AngII-Induced Aortic Rupture and Aneurysm in Both Thoracic and Abdominal Regions. PloS one. 2016;11:e0153811.

87. Angelov SN, Hu JH, Wei H, Airhart N, Shi M, Dichek DA. TGF- $\beta$ (Transforming Growth Factor- $\beta$ ) Signaling Protects the Thoracic and Abdominal Aorta From Angiotensin II-Induced Pathology by Distinct Mechanisms. Arteriosclerosis, Thrombosis, and Vascular Biology. 2017;37:2102-2113.

88. Gao P, Wu W, Ye J, Lu YW, Adam AP, Singer HA, Long X. Transforming growth factor $\beta 1$ suppresses proinflammatory gene program independent of its regulation on vascular smooth muscle differentiation and autophagy. Cellular Signalling. 2018;50:160-170.

89. Zhang Y, Yin J, Ding H, Zhang C, Gao Y-S. Vitamin K 2 Ameliorates Damage of Blood Vessels by Glucocorticoid: a Potential Mechanism for Its Protective Effects in Glucocorticoid-induced Osteonecrosis of the Femoral Head in a Rat Model. Int. J. Biol. Sci. 2016;12:776-785.

90. Wang Z, Wang M, Finn F, Carr BI. The growth inhibitory effects of vitamins K and their actions on gene expression. Hepatology. 1995;22:876-882.

91. Clauser S, Meilhac O, Bièche I, Raynal P, Bruneval P, Michel J-B, Borgel D. Increased secretion of Gas6 by smooth muscle cells in human atherosclerotic carotid plaques. Thrombosis and Haemostasis. 2012;107:140-149.

92. Zhao J, Warburton D. Matrix Gla protein gene expression is induced by transforming growth factor-beta in embryonic lung culture. American Journal of Physiology-Lung Cellular and Molecular Physiology. 1997;273:L282-L287.

93. Bunton TE, Biery NJ, Myers L, Gayraud B, Ramirez F, Dietz HC. Phenotypic alteration of vascular smooth muscle cells precedes elastolysis in a mouse model of Marfan syndrome. Circulation research. 2001;88:37-43.

94. Airhart ND, Arif B, Curci J. Vascular Smooth Muscle Cells From Abdominal Aortic Aneurysms Have Uniquely High Elastolytic Potential Associated With Activation of 
MMP-2. Journal of Surgical Research. 2013;179:282.

95. Silence J, Collen D, Lijnen HR. Reduced Atherosclerotic Plaque but Enhanced Aneurysm Formation in Mice With Inactivation of the Tissue Inhibitor of Metalloproteinase-1 ( TIMP-1 ) Gene. Circulation Research. 2002;90:897-903.

96. Bendeck MP, Irvin C, Reidy MA. Inhibition of matrix metalloproteinase activity inhibits smooth muscle cell migration but not neointimal thickening after arterial injury. Circulation research. 1996;78:38-43.

97. Menashi S, Campa JS, Greenhalgh RM, Powell JT. Collagen in abdominal aortic aneurysm: typing, content, and degradation. Journal of vascular surgery. 1987;6:57882.

98. Tanios F, Gee MW, Pelisek J, Kehl S, Biehler J, Grabher-Meier V, Wall WA, Eckstein $\mathrm{H}-\mathrm{H}$, Reeps C. Interaction of Biomechanics with Extracellular Matrix Components in Abdominal Aortic Aneurysm Wall. European Journal of Vascular and Endovascular Surgery. 2015;50:167-174.

99. Ide Y, Zhang H, Hamajima H, Kawaguchi Y, Eguchi Y, Mizuta T, Yamamoto K, Fujimoto K, Ozaki I. Inhibition of matrix metalloproteinase expression by menatetrenone, a vitamin K2 analogue. Oncology reports. 2009;22:599-604.

100. Ebina K, Shi K, Hirao M, Kaneshiro S, Morimoto T, Koizumi K, Yoshikawa H, Hashimoto J. Vitamin K2 administration is associated with decreased disease activity in patients with rheumatoid arthritis. Modern Rheumatology. 2013;23:1001-1007.

101. Shishavan NG, Gargari BP, Kolahi S, Hajialilo M, Jafarabadi MA, Javadzadeh Y. Effects of Vitamin K on Matrix Metalloproteinase-3 and Rheumatoid Factor in Women with Rheumatoid Arthritis: A Randomized, Double-Blind, Placebo-Controlled Trial. Journal of the American College of Nutrition. 2016;35:392-398.

102. Rowe VL, Stevens SL, Reddick TT, Freeman MB, Donnell R, Carroll RC, Goldman MH. Vascular smooth muscle cell apoptosis in aneurysmal, occlusive, and normal human aortas. Journal of vascular surgery. 2000;31:567-76.

103. Thompson RW, Liao S, Curci JA. Vascular smooth muscle cell apoptosis in abdominal aortic aneurysms. Coronary artery disease. 1997;8:623-31.

104. Rajagopalan S, Meng XP, Ramasamy S, Harrison DG, Galis ZS. Reactive oxygen species produced by macrophage-derived foam cells regulate the activity of vascular matrix metalloproteinases in vitro. Implications for atherosclerotic plaque stability. The Journal of clinical investigation. 1996;98:2572-9.

105. Jia L-X, Zhang W-M, Li T-T, Liu Y, Piao C-M, Ma Y-C, Lu Y, Wang Y, Liu T-T, Qi Y-F, Du J. ER stress dependent microparticles derived from smooth muscle cells promote endothelial dysfunction during thoracic aortic aneurysm and dissection. Clinical Science. 2017;131:1287-1299.

106. Proudfoot D, Skepper JN, Hegyi L, Bennett MR, Shanahan CM, Weissberg PL. Apoptosis regulates human vascular calcification in vitro: evidence for initiation of vascular calcification by apoptotic bodies. Circulation research. 2000;87:1055-62.

107. Nadra I, Mason JC, Philippidis P, Florey O, Smythe CDW, McCarthy GM, Landis RC, Haskard DO. Proinflammatory Activation of Macrophages by Basic Calcium Phosphate Crystals via Protein Kinase C and MAP Kinase Pathways. Circulation Research. 2005;96:1248-1256.

108. Vengrenyuk Y, Carlier S, Xanthos S, Cardoso L, Ganatos P, Virmani R, Einav S, Gilchrist L, Weinbaum S. A hypothesis for vulnerable plaque rupture due to stressinduced debonding around cellular microcalcifications in thin fibrous caps. Proceedings of the National Academy of Sciences of the United States of America. 2006;103:1467883.

109. Nakano T, Higashino K, Kikuchi N, Kishino J, Nomura K, Fujita H, Ohara O, Arita H. 
Vascular smooth muscle cell-derived, Gla-containing growth-potentiating factor for $\mathrm{Ca}(2+)$-mobilizing growth factors. The Journal of biological chemistry. 1995;270:5702-5.

110. Melaragno MG, Cavet ME, Yan C, Tai L-K, Jin Z-G, Haendeler J, Berk BC. Gas6 inhibits apoptosis in vascular smooth muscle: role of Axl kinase and Akt. Journal of Molecular and Cellular Cardiology. 2004;37:881-887.

111. Qiu C, Zheng H, Tao H, Yu W, Jiang X, Li A, Jin H, Lv A, Li H. Vitamin K2 inhibits rat vascular smooth muscle cell calcification by restoring the Gas6/Axl/Akt antiapoptotic pathway. Molecular and Cellular Biochemistry. 2017;433:149-159.

112. Son B-K, Kozaki K, Iijima K, Eto M, Kojima T, Ota H, Senda Y, Maemura K, Nakano T, Akishita M, Ouchi Y. Statins Protect Human Aortic Smooth Muscle Cells From Inorganic Phosphate-Induced Calcification by Restoring Gas6-Axl Survival Pathway. Circulation Research. 2006;98:1024-1031.

113. Melaragno MG, Wuthrich DA, Poppa V, Gill D, Lindner V, Berk BC, Corson MA. Increased expression of Axl tyrosine kinase after vascular injury and regulation by $\mathrm{G}$ protein-coupled receptor agonists in rats. Circulation research. 1998;83:697-704.

114. Ekman C, Site DF, Gottsäter A, Lindblad B, Dahlbäck B. Plasma concentrations of growth arrest specific protein 6 and the soluble form of its tyrosine kinase receptor Axl as markers of large abdominal aortic aneurysms. Clinical Biochemistry. 2010;43:110114.

115. Shanahan CM, Furmanik M. Endoplasmic Reticulum Stress in Arterial Smooth Muscle Cells: A Novel Regulator of Vascular Disease. Current Cardiology Reviews. 2017;13:94-105.

116. Zhao G, Fu Y, Cai Z, Yu F, Gong Z, Dai R, Hu Y, Zeng L, Xu Q, Kong W. Unspliced XBP1 Confers VSMC Homeostasis and Prevents Aortic Aneurysm Formation via FoxO4 Interaction. Circulation Research. 2017;121:1331-1345.

117. Szegezdi E, Logue SE, Gorman AM, Samali A. Mediators of endoplasmic reticulum stress-induced apoptosis. EMBO reports. 2006;7:880-5.

118. Jia L-X, Zhang W-M, Zhang H-J, Li T-T, Wang Y-L, Qin Y-W, Gu H, Du J. Mechanical stretch-induced endoplasmic reticulum stress, apoptosis and inflammation contribute to thoracic aortic aneurysm and dissection. The Journal of Pathology. 2015;236:373-383.

119. Qin Y, Wang Y, Liu O, Jia L, Fang W, Du J, Wei Y. Tauroursodeoxycholic Acid Attenuates Angiotensin II Induced Abdominal Aortic Aneurysm Formation in Apolipoprotein E-deficient Mice by Inhibiting Endoplasmic Reticulum Stress. European Journal of Vascular and Endovascular Surgery. 2017;53:337-345.

120. Wajih N, Hutson SM, Wallin R. Disulfide-dependent Protein Folding Is Linked to Operation of the Vitamin K Cycle in the Endoplasmic Reticulum. Journal of Biological Chemistry. 2007;282:2626-2635.

121. Rutkevich LA, Williams DB. Vitamin K epoxide reductase contributes to protein disulfide formation and redox homeostasis within the endoplasmic reticulum. Molecular biology of the cell. 2012;23:2017-27.

122. Askari B, Khaleqsefat E, Khalafkhani D, Khalaj-Kondori M, Khademvatan K, Soraya $\mathrm{H}$. Study on a novel polymorphism in the VKORC1 promoter region using bioinformatic tools and warfarin dosing data. Thrombosis Research. 2017;158:76-78.

123. Miller FJ, Sharp WJ, Fang X, Oberley LW, Oberley TD, Weintraub NL. Oxidative stress in human abdominal aortic aneurysms: a potential mediator of aneurysmal remodeling. Arteriosclerosis, thrombosis, and vascular biology. 2002;22:560-5.

124. Siu KL, Li Q, Zhang Y, Guo J, Youn JY, Du J, Cai H. NOX isoforms in the development of abdominal aortic aneurysm. Redox Biology. 2017;11:118-125.

125. Konior A, Schramm A, Czesnikiewicz-Guzik M, Guzik TJ. NADPH Oxidases in 
Vascular Pathology. Antioxidants \& Redox Signaling. 2014;20:2794-2814.

126. McCormick ML, Gavrila D, Weintraub NL. Role of Oxidative Stress in the Pathogenesis of Abdominal Aortic Aneurysms. Arteriosclerosis, Thrombosis, and Vascular Biology. 2007;27:461-469.

127. Thomas M, Gavrila D, McCormick ML, Miller FJ, Daugherty A, Cassis LA, Dellsperger KC, Weintraub NL. Deletion of p47 phox Attenuates Angiotensin II-Induced Abdominal Aortic Aneurysm Formation in Apolipoprotein E-Deficient Mice. Circulation. 2006; 114:404-413.

128. Kigawa Y, Miyazaki T, Lei X-F, Nakamachi T, Oguchi T, Kim-Kaneyama J, Taniyama M, Tsunawaki S, Shioda S, Miyazaki A. NADPH Oxidase Deficiency Exacerbates Angiotensin II-Induced Abdominal Aortic Aneurysms in Mice. Arteriosclerosis, Thrombosis, and Vascular Biology. 2014;34:2413-2420.

129. Lu W-W, Jia L-X, Ni X-Q, Zhao L, Chang J-R, Zhang J-S, Hou Y-L, Zhu Y, Guan YF, Yu Y-R, Du J, Tang C-S, Qi Y-F. Intermedin 1- 53 Attenuates Abdominal Aortic Aneurysm by Inhibiting Oxidative Stress. Arteriosclerosis, Thrombosis, and Vascular Biology. 2016;36:2176-2190.

130. Guzik TJ, Chen W, Gongora MC, Guzik B, Lob HE, Mangalat D, Hoch N, Dikalov S, Rudzinski P, Kapelak B, Sadowski J, Harrison DG. Calcium-dependent NOX5 nicotinamide adenine dinucleotide phosphate oxidase contributes to vascular oxidative stress in human coronary artery disease. Journal of the American College of Cardiology. 2008;52:1803-9.

131. Jay DB, Papaharalambus CA, Seidel-Rogol B, Dikalova AE, Lassègue B, Griendling KK. Nox5 mediates PDGF-induced proliferation in human aortic smooth muscle cells. Free radical biology \& medicine. 2008;45:329-35.

132. Guzik B, Sagan A, Ludew D, Mrowiecki W, Chwała M, Bujak-Gizycka B, Filip G, Grudzien G, Kapelak B, Żmudka K, Mrowiecki T, Sadowski J, Korbut R, Guzik TJ. Mechanisms of oxidative stress in human aortic aneurysms - Association with clinical risk factors for atherosclerosis and disease severity. International Journal of Cardiology. 2013;168:2389-2396.

133. Starke RM, Thompson JW, Ali MS, Pascale CL, Martinez Lege A, Ding D, Chalouhi N, Hasan DM, Jabbour P, Owens GK, Toborek M, Hare JM, Dumont AS. Cigarette Smoke Initiates Oxidative Stress-Induced Cellular Phenotypic Modulation Leading to Cerebral Aneurysm Pathogenesis. Arteriosclerosis, Thrombosis, and Vascular Biology. 2018;38:610-621.

134. Xiong W, Mactaggart J, Knispel R, Worth J, Zhu Z, Li Y, Sun Y, Baxter BT, Johanning J. Inhibition of reactive oxygen species attenuates aneurysm formation in a murine model. Atherosclerosis. 2009;202:128-34.

135. Nakahashi TK, Hoshina K, Tsao PS, Sho E, Sho M, Karwowski JK, Yeh C, Yang R-B, Topper JN, Dalman RL. Flow loading induces macrophage antioxidative gene expression in experimental aneurysms. Arteriosclerosis, thrombosis, and vascular biology. 2002;22:2017-22.

136. Gavrila D, Li WG, McCormick ML, Thomas M, Daugherty A, Cassis LA, Miller FJ, Oberley LW, Dellsperger KC, Weintraub NL. Vitamin E Inhibits Abdominal Aortic Aneurysm Formation in Angiotensin II-Infused Apolipoprotein E-Deficient Mice. Arteriosclerosis, Thrombosis, and Vascular Biology. 2005;25:1671-1677.

137. Martinez-Pinna R, Lindholt JS, Blanco-Colio LM, Dejouvencel T, Madrigal-Matute J, Ramos-Mozo P, Vega de Ceniga M, Michel JB, Egido J, Meilhac O, Martin-Ventura JL. Increased levels of thioredoxin in patients with abdominal aortic aneurysms (AAAs). A potential link of oxidative stress with AAA evolution. Atherosclerosis. 2010;212:333-338. 
138. Behr Andersen C, Lindholt JS, Urbonavicius S, Halekoh U, Jensen PS, Stubbe J, Rasmussen LM, Beck HC. Abdominal Aortic Aneurysms Growth Is Associated With High Concentrations of Plasma Proteins in the Intraluminal Thrombus and Diseased Arterial Tissue. Arteriosclerosis, thrombosis, and vascular biology. 2018;38:22542267.

139. Branchetti E, Poggio P, Sainger R, Shang E, Grau JB, Jackson BM, Lai EK, Parmacek MS, Gorman RC, Gorman JH, Bavaria JE, Ferrari G. Oxidative stress modulates vascular smooth muscle cell phenotype via CTGF in thoracic aortic aneurysm. Cardiovascular Research. 2013;100:316-324.

140. Westhofen P, Watzka M, Marinova M, Hass M, Kirfel G, Müller J, Bevans CG, Müller CR, Oldenburg J. Human Vitamin K 2,3-Epoxide Reductase Complex Subunit 1-like 1 (VKORC1L1) Mediates Vitamin K-dependent Intracellular Antioxidant Function. Journal of Biological Chemistry. 2011;286:15085-15094.

141. Mukai K, Morimoto H, Kikuchi S, Nagaoka S. Kinetic study of free-radical-scavenging action of biological hydroquinones (reduced forms of ubiquinone, vitamin $\mathrm{K}$ and tocopherol quinone) in solution. Biochimica et Biophysica Acta (BBA) - General Subjects. 1993;1157:313-317.

142. Vervoort LM, Ronden JE, Thijssen HH. The potent antioxidant activity of the vitamin K cycle in microsomal lipid peroxidation. Biochemical pharmacology. 1997;54:871-6.

143. Li J, Lin JC, Wang H, Peterson JW, Furie BC, Furie B, Booth SL, Volpe JJ, Rosenberg PA. Novel role of vitamin $\mathrm{k}$ in preventing oxidative injury to developing oligodendrocytes and neurons. The Journal of neuroscience : the official journal of the Society for Neuroscience. 2003;23:5816-26.

144. Li J, Wang H, Rosenberg PA. Vitamin K prevents oxidative cell death by inhibiting activation of 12-lipoxygenase in developing oligodendrocytes. Journal of Neuroscience Research. 2009;87:1997-2005.

145. Bridge A, Barr R, Morré DJ. The plasma membrane NADH oxidase of soybean has vitamin $\mathrm{K}(1)$ hydroquinone oxidase activity. Biochimica et biophysica acta. 2000;1463:448-58.

146. Kishi T, Morré DM, Morré DJ. The plasma membrane NADH oxidase of HeLa cells has hydroquinone oxidase activity. Biochimica et biophysica acta. 1999;1412:66-77.

147. Morré DM, Lenaz G, Morré DJ. Surface oxidase and oxidative stress propagation in aging. The Journal of experimental biology. 2000;203:1513-21.

148. Schulman S, Wang B, Li W, Rapoport TA. Vitamin K epoxide reductase prefers ER membrane-anchored thioredoxin-like redox partners. Proceedings of the National Academy of Sciences. 2010;107:15027-15032.

149. Pescatore LA, Bonatto D, Forti FL, Sadok A, Kovacic H, Laurindo FRM. Protein Disulfide Isomerase Is Required for Platelet-derived Growth Factor-induced Vascular Smooth Muscle Cell Migration, Nox1 NADPH Oxidase Expression, and RhoGTPase Activation. Journal of Biological Chemistry. 2012;287:29290-29300.

150. Trevelin SC, Lopes LR. Protein disulfide isomerase and Nox: new partners in redox signaling. Current pharmaceutical design. 2015;21:5951-63.

151. Rutkevich LA, Williams DB. Vitamin K epoxide reductase contributes to protein disulfide formation and redox homeostasis within the endoplasmic reticulum. Molecular biology of the cell. 2012;23:2017-27.

152. Katsuumi G, Shimizu I, Yoshida Y, Minamino T. Vascular Senescence in Cardiovascular and Metabolic Diseases. Frontiers in Cardiovascular Medicine. 2018;5:18.

153. Shanahan CM. Mechanisms of vascular calcification in CKD - evidence for premature ageing? Nature Reviews Nephrology. 2013;9:661-670. 
154. Liao S, Curci JA, Kelley BJ, Sicard GA, Thompson RW. Accelerated Replicative Senescence of Medial Smooth Muscle Cells Derived from Abdominal Aortic Aneurysms Compared to the Adjacent Inferior Mesenteric Artery. Journal of Surgical Research. 2000;92:85-95.

155. Helgadottir A, Thorleifsson G, Magnusson KP, Grétarsdottir S, Steinthorsdottir V, Manolescu A, Jones GT, Rinkel GJE, Blankensteijn JD, Ronkainen A, Jääskeläinen JE, Kyo Y, Lenk GM, Sakalihasan N, Kostulas K, et al. The same sequence variant on 9p21 associates with myocardial infarction, abdominal aortic aneurysm and intracranial aneurysm. Nature Genetics. 2008;40:217-224.

156. Durham AL, Speer MY, Scatena M, Giachelli CM, Shanahan CM. Role of smooth muscle cells in vascular calcification: implications in atherosclerosis and arterial stiffness. Cardiovascular research. 2018;114:590-600.

157. Bennett MR, Clarke MCH. Killing the old: cell senescence in atherosclerosis. Nature Reviews Cardiology. 2017;14:8-9.

158. Michel J-B, Martin-Ventura J-L, Egido J, Sakalihasan N, Treska V, Lindholt J, Allaire E, Thorsteinsdottir U, Cockerill G, Swedenborg J. Novel aspects of the pathogenesis of aneurysms of the abdominal aorta in humans. Cardiovascular Research. 2011;90:1827.

159. Liu Y, Drozdov I, Shroff R, Beltran LE, Shanahan CM. Prelamin A Accelerates Vascular Calcification Via Activation of the DNA Damage Response and SenescenceAssociated Secretory Phenotype in Vascular Smooth Muscle Cells. Circulation Research. 2013;112:e99-109.

160. Malkawi A, Pirianov G, Torsney E, Chetter I, Sakalihasan N, Loftus IM, Nordon I, Huggins C, Charolidi N, Thompson M, Xu XY, Cockerill GW. Increased Expression of Lamin A/C Correlate with Regions of High Wall Stress in Abdominal Aortic Aneurysms. Aorta (Stamford, Conn.). 2015;3:152-66.

161. Liu B, Ghosh S, Yang X, Zheng H, Liu X, Wang Z, Jin G, Zheng B, Kennedy BK, Suh Y, Kaeberlein M, Tryggvason K, Zhou Z. Resveratrol Rescues SIRT1-Dependent Adult Stem Cell Decline and Alleviates Progeroid Features in Laminopathy-Based Progeria. Cell Metabolism. 2012;16:738-750.

162. Potente M, Ghaeni L, Baldessari D, Mostoslavsky R, Rossig L, Dequiedt F, Haendeler J, Mione M, Dejana E, Alt FW, Zeiher AM, Dimmeler S. SIRT1 controls endothelial angiogenic functions during vascular growth. Genes \& Development. 2007;21:26442658.

163. Kida Y, Goligorsky MS. Sirtuins, Cell Senescence, and Vascular Aging. Canadian Journal of Cardiology. 2016;32:634-641.

164. Gorenne I, Kumar S, Gray K, Figg N, Yu H, Mercer J, Bennett M. Vascular Smooth Muscle Cell Sirtuin 1 Protects Against DNA Damage and Inhibits Atherosclerosis. Circulation. 2013;127:386-396.

165. Chen H-Z, Wang F, Gao P, Pei J-F, Liu Y, Xu T-T, Tang X, Fu W-Y, Lu J, Yan Y-F, Wang X-M, Han L, Zhang Z-Q, Zhang R, Zou M-H, et al. Age-Associated Sirtuin 1 Reduction in Vascular Smooth Muscle Links Vascular Senescence and Inflammation to Abdominal Aortic Aneurysm. Circulation Research. 2016;119:1076-1088.

166. Riches K, Clark E, Helliwell RJ, Angelini TG, Hemmings KE, Bailey MA, Bridge KI, Scott DJA, Porter KE. Progressive Development of Aberrant Smooth Muscle Cell Phenotype in Abdominal Aortic Aneurysm Disease. Journal of Vascular Research. 2018;55:35-46.

167. López-Otín C, Blasco MA, Partridge L, Serrano M, Kroemer G. The hallmarks of aging. Cell. 2013;153:1194-217.

168. Bodnar AG, Ouellette M, Frolkis M, Holt SE, Chiu CP, Morin GB, Harley CB, Shay 
JW, Lichtsteiner S, Wright WE. Extension of life-span by introduction of telomerase into normal human cells. Science (New York, N.Y.). 1998;279:349-52.

169. Wilson WRW, Herbert KE, Mistry Y, Stevens SE, Patel HR, Hastings RA, Thompson MM, Williams B. Blood leucocyte telomere DNA content predicts vascular telomere DNA content in humans with and without vascular disease. European Heart Journal. 2008;29:2689-2694.

170. Blunder S, Messner B, Aschacher T, Zeller I, Türkcan A, Wiedemann D, Andreas M, Blüschke G, Laufer G, Schachner T, Bernhard D. Characteristics of TAV- and BAVassociated thoracic aortic aneurysms - Smooth muscle cell biology, expression profiling, and histological analyses. Atherosclerosis. 2012;220:355-361.

171. Aschacher T, Salameh O, Enzmann F, Messner B, Bergmann M. Telomere Biology and Thoracic Aortic Aneurysm. International Journal of Molecular Sciences. 2017;19:3.

172. Yu E, Mercer J, Bennett M. Mitochondria in vascular disease. Cardiovascular Research. 2012;95:173-182.

173. $\mathrm{Yu}$ E, Foote K, Bennett M. Mitochondrial function in thoracic aortic aneurysms. Cardiovascular Research. 2018;114:1696-1698.

174. Yang M, Chadwick AE, Dart C, Kamishima T, Quayle JM. Bioenergetic profile of human coronary artery smooth muscle cells and effect of metabolic intervention. Singh PK, ed. PLOS ONE. 2017;12:e0177951.

175. YUAN K, LIANG W, ZHANG J. A comprehensive analysis of differentially expressed genes and pathways in abdominal aortic aneurysm. Molecular Medicine Reports. 2015;12:2707-2714.

176. Gabrielson M, Vorkapic E, Folkesson M, Welander M, Matussek A, Dimberg J, Länne T, Skogberg J, Wågsäter D. Altered PPAR\&amp;\#x03B3; Coactivator-1 Alpha Expression in Abdominal Aortic Aneurysm: Possible Effects on Mitochondrial Biogenesis. Journal of Vascular Research. 2016;53:17-26.

177. van der Pluijm I, Burger J, van Heijningen PM, IJpma A, van Vliet N, Milanese C, Schoonderwoerd K, Sluiter W, Ringuette L-J, Dekkers DHW, Que I, Kaijzel EL, Te Riet L, MacFarlane EG, Das D, et al. Decreased mitochondrial respiration in aneurysmal aortas of Fibulin-4 mutant mice is linked to PGC1A regulation. Cardiovascular research. 2018;114:1776-1793.

178. Vos M, Esposito G, Edirisinghe JN, Vilain S, Haddad DM, Slabbaert JR, Van Meensel S, Schaap O, De Strooper B, Meganathan R, Morais VA, Verstreken P. Vitamin K2 Is a Mitochondrial Electron Carrier That Rescues Pink1 Deficiency. Science. 2012;336:1306-1310.

179. Swiader A, Nahapetyan H, Faccini J, D’Angelo R, Mucher E, Elbaz M, Boya P, Vindis C. Mitophagy acts as a safeguard mechanism against human vascular smooth muscle cell apoptosis induced by atherogenic lipids. Oncotarget. 2016;7:28821-35.

180. Grootaert MOJ, Moulis M, Roth L, Martinet W, Vindis C, Bennett MR, De Meyer GRY. Vascular smooth muscle cell death, autophagy and senescence in atherosclerosis. Cardiovascular Research. 2018;114:622-634.

181. Kalra SS, Shanahan CM. Vascular calcification and hypertension: Cause and effect. Annals of Medicine. 2012;44:S85-S92.

182. Shanahan CM, Crouthamel MH, Kapustin A, Giachelli CM. Arterial Calcification in Chronic Kidney Disease: Key Roles for Calcium and Phosphate. Towler DA, ed. Circulation Research. 2011;109:697-711.

183. Neven E, Persy V, Dauwe S, De Schutter T, De Broe ME, D'Haese PC. Chondrocyte Rather Than Osteoblast Conversion of Vascular Cells Underlies Medial Calcification in Uremic Rats. Arteriosclerosis, Thrombosis, and Vascular Biology. 2010;30:1741-1750.

184. Jono S, McKee MD, Murry CE, Shioi A, Nishizawa Y, Mori K, Morii H, Giachelli CM. 
Phosphate Regulation of Vascular Smooth Muscle Cell Calcification. Circulation Research. 2000;87.

185. Paloian NJ, Giachelli CM. A current understanding of vascular calcification in CKD. American Journal of Physiology-Renal Physiology. 2014;307:F891-F900.

186. Kapustin AN, Chatrou MLL, Drozdov I, Zheng Y, Davidson SM, Soong D, Furmanik M, Sanchis P, De Rosales RTM, Alvarez-Hernandez D, Shroff R, Yin X, Muller K, Skepper JN, Mayr M, et al. Vascular Smooth Muscle Cell Calcification Is Mediated by Regulated Exosome Secretion. Circulation Research. 2015;116:1312-1323.

187. Schurgers LJ, Uitto J, Reutelingsperger CP. Vitamin K-dependent carboxylation of matrix Gla-protein: a crucial switch to control ectopic mineralization. Trends in Molecular Medicine. 2013;19:217-226.

188. Sugitani H, Wachi H, Mecham RP, Seyama Y. Accelerated calcification represses the expression of elastic fiber components and lysyl oxidase in cultured bovine aortic smooth muscle cells. Journal of atherosclerosis and thrombosis. 2002;9:292-8.

189. Wachi H, Sugitani H, Murata H, Nakazawa J, Mecham RP, Seyama Y. Tropoelastin inhibits vascular calcification via $67-\mathrm{kDa}$ elastin binding protein in cultured bovine aortic smooth muscle cells. Journal of atherosclerosis and thrombosis. 2004;11:15966.

190. Saito E, Wachi H, Sato F, Sugitani H, Seyama Y. Treatment with vitamin k(2) combined with bisphosphonates synergistically inhibits calcification in cultured smooth muscle cells. Journal of atherosclerosis and thrombosis. 2007;14:317-24.

191. Rogers MA, Aikawa M, Aikawa E. Macrophage Heterogeneity Complicates Reversal of Calcification in Cardiovascular Tissues. Circulation Research. 2017;121:5-7.

192. New SEP, Goettsch C, Aikawa M, Marchini JF, Shibasaki M, Yabusaki K, Libby P, Shanahan CM, Croce K, Aikawa E. Macrophage-derived matrix vesicles: an alternative novel mechanism for microcalcification in atherosclerotic plaques. Circulation research. 2013;113:72-7.

193. Allahverdian S, Chehroudi AC, McManus BM, Abraham T, Francis GA. Contribution of Intimal Smooth Muscle Cells to Cholesterol Accumulation and Macrophage-Like Cells in Human Atherosclerosis. Circulation. 2014;129:1551-1559.

194. Vengrenyuk Y, Nishi H, Long X, Ouimet M, Savji N, Martinez FO, Cassella CP, Moore KJ, Ramsey SA, Miano JM, Fisher EA. Cholesterol loading reprograms the microRNA143/145-myocardin axis to convert aortic smooth muscle cells to a dysfunctional macrophage-like phenotype. Arteriosclerosis, thrombosis, and vascular biology. 2015;35:535-46.

195. Chellan B, Rojas E, Zhang C, Hofmann Bowman MA. Enzyme-modified non-oxidized LDL (ELDL) induces human coronary artery smooth muscle cell transformation to a migratory and osteoblast-like phenotype. Scientific reports. 2018;8:11954.

196. Buijs RVC, Willems TP, Tio RA, Boersma HH, Tielliu IFJ, Slart RHJA, Zeebregts CJ. Calcification as a Risk Factor for Rupture of Abdominal Aortic Aneurysm. European Journal of Vascular and Endovascular Surgery. 2013;46:542-548.

197. O'Leary SA, Mulvihill JJ, Barrett HE, Kavanagh EG, Walsh MT, McGloughlin TM, Doyle BJ. Determining the influence of calcification on the failure properties of abdominal aortic aneurysm (AAA) tissue. Journal of the Mechanical Behavior of Biomedical Materials. 2015;42:154-167.

198. Kelly-Arnold A, Maldonado N, Laudier D, Aikawa E, Cardoso L, Weinbaum S. Revised microcalcification hypothesis for fibrous cap rupture in human coronary arteries. Proceedings of the National Academy of Sciences. 2013;110:10741-10746.

199. Forsythe RO, Newby DE, Robson JMJ. Monitoring the biological activity of abdominal aortic aneurysms Beyond Ultrasound. Heart. 2016;102:817-824. 
200. Reeps C, Essler M, Pelisek J, Seidl S, Eckstein H-H, Krause B-J. Increased 18Ffluorodeoxyglucose uptake in abdominal aortic aneurysms in positron emission/computed tomography is associated with inflammation, aortic wall instability, and acute symptoms. Journal of Vascular Surgery. 2008;48:417-423.

201. Chatrou MLL, Winckers K, Hackeng TM, Reutelingsperger CP, Schurgers LJ. Vascular calcification: The price to pay for anticoagulation therapy with vitamin K-antagonists. Blood Reviews. 2012;26:155-166.

202. Malhotra R, Burke MF, Martyn T, Shakartzi HR, Thayer TE, O'Rourke C, Li P, Derwall M, Spagnolli E, Kolodziej SA, Hoeft K, Mayeur C, Jiramongkolchai P, Kumar R, Buys ES, et al. Inhibition of Bone Morphogenetic Protein Signal Transduction Prevents the Medial Vascular Calcification Associated with Matrix Gla Protein Deficiency. Aikawa E, ed. PLOS ONE. 2015;10:e117098.

203. Steitz SA, Speer MY, Curinga G, Yang HY, Haynes P, Aebersold R, Schinke T, Karsenty G, Giachelli CM. Smooth muscle cell phenotypic transition associated with calcification: upregulation of Cbfa1 and downregulation of smooth muscle lineage markers. Circulation research. 2001;89:1147-54.

204. Speer MY, Li X, Hiremath PG, Giachelli CM. Runx2/Cbfa1, but not loss of myocardin, is required for smooth muscle cell lineage reprogramming toward osteochondrogenesis. Journal of Cellular Biochemistry. 2010;110:935-947.

205. Luo G, Ducy P, McKee MD, Pinero GJ, Loyer E, Behringer RR, Karsenty G. Spontaneous calcification of arteries and cartilage in mice lacking matrix GLA protein. Nature. 1997;386:78-81.

206. Murshed M, Schinke T, McKee MD, Karsenty G. Extracellular matrix mineralization is regulated locally; different roles of two gla-containing proteins. The Journal of Cell Biology. 2004; 165:625-630.

207. Schurgers LJ, Teunissen KJF, Knapen MHJ, Kwaijtaal M, van Diest R, Appels A, Reutelingsperger CP, Cleutjens JPM, Vermeer C. Novel Conformation-Specific Antibodies Against Matrix $\gamma$-Carboxyglutamic Acid (Gla) Protein. Arteriosclerosis, Thrombosis, and Vascular Biology. 2005;25:1629-1633.

208. Zebboudj AF, Imura M, Boström K. Matrix GLA Protein, a Regulatory Protein for Bone Morphogenetic Protein-2. Journal of Biological Chemistry. 2002;277:4388-4394.

209. Sweatt A, Sane DC, Hutson SM, Wallin R. Matrix Gla protein (MGP) and bone morphogenetic protein-2 in aortic calcified lesions of aging rats. Journal of thrombosis and haemostasis : JTH. 2003;1:178-85.

210. Kapustin AN, Davies JD, Reynolds JL, McNair R, Jones GT, Sidibe A, Schurgers LJ, Skepper JN, Proudfoot D, Mayr M, Shanahan CM. Calcium Regulates Key Components of Vascular Smooth Muscle Cell-Derived Matrix Vesicles to Enhance Mineralization. Circulation Research. 2011;109.

211. Schurgers LJ, Cranenburg ECM, Vermeer C. Matrix Gla-protein: the calcification inhibitor in need of vitamin K. Thrombosis and haemostasis. 2008;100:593-603.

212. Wallin R, Cain D, Hutson SM, Sane DC, Loeser R. Modulation of the binding of matrix Gla protein (MGP) to bone morphogenetic protein-2 (BMP-2). Thrombosis and haemostasis. 2000;84:1039-44.

213. Chatrou MLL, Cleutjens JP, van der Vusse GJ, Roijers RB, Mutsaers PHA, Schurgers LJ. Intra-Section Analysis of Human Coronary Arteries Reveals a Potential Role for Micro-Calcifications in Macrophage Recruitment in the Early Stage of Atherosclerosis. Gadeau A-P, ed. PLOS ONE. 2015;10:e0142335.

214. Joshi N V, Newby DE, Dweck MR. Identifying high risk plaques prior to heart attack using PET-CT. Future Cardiology. 2014;10:307-310.

215. Ehara S, Kobayashi Y, Yoshiyama M, Shimada K, Shimada Y, Fukuda D, Nakamura 
Y, Yamashita H, Yamagishi H, Takeuchi K, Naruko T, Haze K, Becker AE, Yoshikawa J, Ueda M. Spotty Calcification Typifies the Culprit Plaque in Patients With Acute Myocardial Infarction. Circulation. 2004;110:3424-3429.

216. Matsumoto K-I, Maniwa T, Tanaka T, Satoh K, Okunishi H, Oda T. Proteomic analysis of calcified abdominal and thoracic aortic aneurysms. International Journal of Molecular Medicine. 2012;30:417-429.

217. Basalyga DM, Simionescu DT, Xiong W, Baxter BT, Starcher BC, Vyavahare NR. Elastin Degradation and Calcification in an Abdominal Aorta Injury Model. Circulation. 2004;110:3480-3487.

218. Simionescu A, Philips K, Vyavahare N. Elastin-derived peptides and TGF- $\beta 1$ induce osteogenic responses in smooth muscle cells. Biochemical and Biophysical Research Communications. 2005;334:524-532.

219. Takei Y, Tanaka T, Kent KC, Yamanouchi D. Osteoclastogenic Differentiation of Macrophages in the Development of Abdominal Aortic Aneurysms. Arteriosclerosis, Thrombosis, and Vascular Biology. 2016;36:1962-1971.

220. Tanaka T, Kelly M, Takei Y, Yamanouchi D. RANKL-mediated osteoclastogenic differentiation of macrophages in the abdominal aorta of angiotensin II-infused apolipoprotein E knockout mice. Journal of Vascular Surgery. 2018;68:48S-59S.e1.

221. Tsai S-H, Huang P-H, Peng Y-J, Chang W-C, Tsai H-Y, Leu H-B, Chen J-W, Lin S-J. Zoledronate attenuates angiotensin II-induced abdominal aortic aneurysm through inactivation of Rho/ROCK-dependent $\mathrm{JNK}$ and NF-kB pathway. Cardiovascular Research. 2013;100:501-510.

222. Nistala H, Lee-Arteaga S, Carta L, Cook JR, Smaldone S, Siciliano G, Rifkin AN, Dietz HC, Rifkin DB, Ramirez F. Differential effects of alendronate and losartan therapy on osteopenia and aortic aneurysm in mice with severe Marfan syndrome. Human molecular genetics. 2010;19:4790-8.

223. Moreau C, Bajolle F, Siguret V, Lasne D, Golmard J-L, Elie C, Beaune P, Cheurfi R, Bonnet D, Loriot M-A. Vitamin K antagonists in children with heart disease: height and VKORC1 genotype are the main determinants of the warfarin dose requirement. Blood. 2012;119:861-867.

224. Stafford DW. The vitamin K cycle. Journal of Thrombosis and Haemostasis. 2005;3:1873-1878.

225. Beinema M, Brouwers JRBJ, Schalekamp T, Wilffert B. Pharmacogenetic differences between warfarin, acenocoumarol and phenprocoumon. Thrombosis and haemostasis. 2008;100:1052-7.

226. Krüger T, Oelenberg S, Kaesler N, Schurgers LJ, van de Sandt AM, Boor P, Schlieper G, Brandenburg VM, Fekete BC, Veulemans V, Ketteler M, Vermeer C, JahnenDechent W, Floege J, Westenfeld R. Warfarin Induces Cardiovascular Damage in Mice. Arteriosclerosis, Thrombosis, and Vascular Biology. 2013;33:2618-2624.

227. Price PA, Faus SA, Williamson MK. Warfarin causes rapid calcification of the elastic lamellae in rat arteries and heart valves. Arteriosclerosis, thrombosis, and vascular biology. 1998;18:1400-7.

228. Kekki M, Julkunen RJ, Wahlström B. Distribution pharmacokinetics of warfarin in the rat, a non-linear multicompartment model. Naunyn-Schmiedeberg's archives of pharmacology. 1977;297:61-73.

229. Shepherd AM, Hewick DS, Moreland TA, Stevenson IH. Age as a determinant of sensitivity to warfarin. British journal of clinical pharmacology. 1977;4:315-20.

230. Schurgers LJ, Joosen IA, Laufer EM, Chatrou MLL, Herfs M, Winkens MHM, Westenfeld R, Veulemans V, Krueger T, Shanahan CM, Jahnen-Dechent W, Biessen E, Narula J, Vermeer C, Hofstra L, et al. Vitamin K-Antagonists Accelerate 
Atherosclerotic Calcification and Induce a Vulnerable Plaque Phenotype. Aikawa E, ed. PLoS ONE. 2012;7:e43229.

231. Schurgers LJ, Aebert H, Vermeer C, Bültmann B, Janzen J. Oral anticoagulant treatment: friend or foe in cardiovascular disease? Blood. 2004;104:3231-3232.

232. Weijs B, Blaauw Y, Rennenberg RJMW, Schurgers LJ, Timmermans CCMM, Pison L, Nieuwlaat R, Hofstra L, Kroon AA, Wildberger J, Crijns HJGM. Patients using vitamin $\mathrm{K}$ antagonists show increased levels of coronary calcification: an observational study in low-risk atrial fibrillation patients. European Heart Journal. 2011;32:2555-2562.

233. Eggebrecht L, Prochaska JH, Schulz A, Arnold N, Jünger C, Göbel S, Laubert-Reh D, Binder H, Beutel ME, Pfeiffer N, Blankenberg S, Lackner KJ, Spronk HM, Ten Cate H, Münzel T, et al. Intake of Vitamin K Antagonists and Worsening of Cardiac and Vascular Disease: Results From the Population-Based Gutenberg Health Study. Journal of the American Heart Association. 2018;7:e008650.

234. Plank F, Beyer C, Friedrich G, Stühlinger M, Hintringer F, Dichtl W, Wildauer M, Feuchtner G. Influence of vitamin $\mathrm{K}$ antagonists and direct oral anticoagulation on coronary artery disease: A CTA analysis. International journal of cardiology. 2018;260:11-15.

235. Andrews J, Psaltis PJ, Bayturan O, Shao M, Stegman B, Elshazly M, Kapadia SR, Tuzcu EM, Nissen SE, Nicholls SJ, Puri R. Warfarin Use Is Associated With Progressive Coronary Arterial Calcification. JACC: Cardiovascular Imaging. 2018;11:1315-1323.

236. Rennenberg RJMW, van Varik BJ, Schurgers LJ, Hamulyak K, ten Cate H, Leiner T, Vermeer C, de Leeuw PW, Kroon AA. Chronic coumarin treatment is associated with increased extracoronary arterial calcification in humans. Blood. 2010;115:5121-5123.

237. Peeters F, Dudink E, Kimenai D, Weijs B, Altintas S, Heckman L, Mihl C, Schurgers L, Wildberger J, Meex S, Kietselaer B, Crijns H. Vitamin K Antagonists, Non-Vitamin K Antagonist Oral Anticoagulants, and Vascular Calcification in Patients with Atrial Fibrillation. TH Open. 2018;02:e391-e398.

238. Schurgers LJ, Spronk HM., Soute BA., Schiffers PM, DeMey JG, Vermeer C. Regression of warfarin-induced medial elastocalcinosis by high intake of vitamin $\mathrm{K}$ in rats. Blood. 2006;109:2823-31.

239. Westenfeld R, Krueger T, Schlieper G, Cranenburg ECM, Magdeleyns EJ, Heidenreich S, Holzmann S, Vermeer C, Jahnen-Dechent W, Ketteler M, Floege J, Schurgers LJ. Effect of Vitamin K2 Supplementation on Functional Vitamin K Deficiency in Hemodialysis Patients: A Randomized Trial. American Journal of Kidney Diseases. 2012;59:186-195.

240. Brandenburg VM, Reinartz S, Kaesler N, Krüger T, Dirrichs T, Kramann R, Peeters F, Floege J, Keszei A, Marx N, Schurgers LJ, Koos R. Slower Progress of Aortic Valve Calcification With Vitamin K Supplementation. Circulation. 2017;135:2081-2083.

241. Shea MK, Booth SL, Miller ME, Burke GL, Chen H, Cushman M, Tracy RP, Kritchevsky SB. Association between circulating vitamin K1 and coronary calcium progression in community-dwelling adults: the Multi-Ethnic Study of Atherosclerosis. The American Journal of Clinical Nutrition. 2013;98:197-208.

242. Cranenburg ECM, Schurgers LJ, Uiterwijk HH, Beulens JWJ, Dalmeijer GW, Westerhuis R, Magdeleyns EJ, Herfs M, Vermeer C, Laverman GD. Vitamin K intake and status are low in hemodialysis patients. Kidney International. 2012;82:605-610.

243. Jono S, Ikari Y, Vermeer C, Dissel P, Hasegawa K, Shioi A, Taniwaki H, Kizu A, Nishizawa Y, Saito S. Matrix Gla protein is associated with coronary artery calcification as assessed by electron-beam computed tomography. Thrombosis and Haemostasis. 2004;91:790-794.

244. Bobadilla JL, Hoch JR, Leverson GE, Tefera G. The effect of warfarin therapy on 
endoleak development after endovascular aneurysm repair (EVAR) of the abdominal aorta. Journal of Vascular Surgery. 2010;52:267-271.

245. Seike Y, Tanaka H, Fukuda T, Itonaga T, Morita Y, Oda T, Inoue Y, Sasaki H, Minatoya $\mathrm{K}$, Kobayashi J. Influence of warfarin therapy on the occurrence of postoperative endoleaks and aneurysm sac enlargement after endovascular abdominal aortic aneurysm repair. Interactive CardioVascular and Thoracic Surgery. 2017;24:ivw383.

246. Wang Z, Xu C, Ding X, Chen J, Xin H. Spontaneous Rupture of a Mediastinal Bronchial Artery Aneurysm Induced by Anticoagulant Agent. The Thoracic and cardiovascular surgeon reports. 2016;5:18-20.

247. Bouvet C, Moreau S, Blanchette J, de Blois D, Moreau P. Sequential Activation of Matrix Metalloproteinase 9 and Transforming Growth Factor $\beta$ in Arterial Elastocalcinosis. Arteriosclerosis, Thrombosis, and Vascular Biology. 2008;28:856862.

248. Stenvinkel P, Luttropp K, McGuinness D, Witasp A, Qureshi AR, Wernerson A, Nordfors L, Schalling M, Ripsweden J, Wennberg L, Söderberg M, Bárány P, Olauson $\mathrm{H}$, Shiels PG. CDKN2A/p16INK4a expression is associated with vascular progeria in chronic kidney disease. Aging. 2017;9:494-507.

249. Danziger J. Vitamin K-dependent Proteins, Warfarin, and Vascular Calcification. Clinical Journal of the American Society of Nephrology. 2008;3:1504-1510.

250. Kapustin AN, Schoppet M, Schurgers LJ, Reynolds JL, McNair R, Heiss A, JahnenDechent W, Hackeng TM, Schlieper G, Harrison P, Shanahan CM. Prothrombin Loading of Vascular Smooth Muscle Cell-Derived Exosomes Regulates Coagulation and Calcification. Arteriosclerosis, Thrombosis, and Vascular Biology. 2017;37:e22e32.

251. Borissoff JI, Spronk HMH, ten Cate H. The Hemostatic System as a Modulator of Atherosclerosis. Schwartz RS, ed. New England Journal of Medicine. 2011;364:17461760 .

252. Schurgers L, Spronk H. Differential cellular effects of old and new oral anticoagulants: consequences to the genesis and progression of atherosclerosis. Thrombosis and Haemostasis. 2014;112:909-917.

253. Matsuzaka T, Tanaka H, Fukuda M, Aoki M, Tsuji Y, Kondoh H. Relationship between vitamin $\mathrm{K}$ dependent coagulation factors and anticoagulants (protein $\mathrm{C}$ and protein $\mathrm{S}$ ) in neonatal vitamin K deficiency. Archives of disease in childhood. 1993;68:297-302.

254. Esmon CT, Vigano-D'Angelo S, D'Angelo A, Comp PC. Anticoagulation proteins C and S. Advances in experimental medicine and biology. 1987;214:47-54.

255. Han X, Fiehler R, Broze GJ, Jr. Isolation of a protein Z-dependent plasma protease inhibitor. Proceedings of the National Academy of Sciences of the United States of America. 1998;95:9250-5.

256. Neve A, Corrado A, Cantatore FP. Osteocalcin: Skeletal and extra-skeletal effects. Journal of Cellular Physiology. 2013;228:1149-1153.

257. IYEMERE VP, PROUDFOOT D, WEISSBERG PL, SHANAHAN CM. Vascular smooth muscle cell phenotypic plasticity and the regulation of vascular calcification. Journal of Internal Medicine. 2006;260:192-210.

258. Viegas CSB, Cavaco S, Neves PL, Ferreira A, João A, Williamson MK, Price PA, Cancela ML, Simes DC. Gla-Rich Protein Is a Novel Vitamin K-Dependent Protein Present in Serum That Accumulates at Sites of Pathological Calcifications. The American Journal of Pathology. 2009;175:2288-2298.

259. Viegas CSB, Rafael MS, Enriquez JL, Teixeira A, Vitorino R, Luís IM, Costa RM, Santos S, Cavaco S, Neves J, Macedo AL, Willems BAG, Vermeer C, Simes DC. GlaRich Protein Acts as a Calcification Inhibitor in the Human Cardiovascular System. 
Arteriosclerosis, Thrombosis, and Vascular Biology. 2015;35:399-408.

260. Willems BA, Furmanik M, Caron MMJ, Chatrou MLL, Kusters DHM, Welting TJM, Stock M, Rafael MS, Viegas CSB, Simes DC, Vermeer C, Reutelingsperger CPM, Schurgers LJ. Ucma/GRP inhibits phosphate-induced vascular smooth muscle cell calcification via SMAD-dependent BMP signalling. Scientific reports. 2018;8:4961.

261. Viegas CSB, Santos L, Macedo AL, Matos AA, Silva AP, Neves PL, Staes A, Gevaert K, Morais R, Vermeer C, Schurgers L, Simes DC. Chronic Kidney Disease Circulating Calciprotein Particles and Extracellular Vesicles Promote Vascular Calcification. Arteriosclerosis, Thrombosis, and Vascular Biology. 2018;38:575-587.

262. Nakano T, Kawamoto K, Higashino K, Arita H. Prevention of growth arrest-induced cell death of vascular smooth muscle cells by a product of growth arrest-specific gene, gas6. FEBS letters. 1996;387:78-80.

263. Fridell YW, Villa J, Attar EC, Liu ET. GAS6 induces Axl-mediated chemotaxis of vascular smooth muscle cells. The Journal of biological chemistry. 1998;273:7123-6.

264. Laurance S, Lemarié CA, Blostein MD. Growth Arrest-Specific Gene 6 (gas6) and Vascular Hemostasis. Advances in Nutrition. 2012;3:196-203. 


\section{Chapter 4}

Vascular smooth muscle cells from abdominal aortic aneurysm are characterised by a dysregulated inflammatory pho otyp and oxidative stress with increased extracellular $v$ icle rele se, accelerated senescenc and ca vific ion

Ploingarm Petsophonsakul ${ }^{1}$, Barend Mees ${ }^{2,3}$, Paul Shiels ${ }^{4}$ Nikola Panar orou ${ }^{4}$, Sarah Buchanan $^{4}$, Sylvia Oggero ${ }^{5}$, Michael Jacobs ${ }^{2,3}$, Rafael Kram nn $^{6}$, Mals zat urmanik ${ }^{1}$, Leon Schurgers ${ }^{1,6}$

In preparation

1. Department of Biochemistry, Cardic scular caarch Institute Maastricht, Maastricht University, The Netherlands

2. Department of Vascular Su Maastric University Medical Center (MUMC), Maastricht, the Netherlands

3. European Vascular Aache Maastricht, Maastricht, the Netherlands.

4. Institute of $\mathrm{Ca}$ r Scir and on Wohl Translational Research Centre, University of Glasgow, Bearsden,

5. William Har stitute, Barts and the London School of Medicine, Queen Mary University of 2 , Lo lon, $\mathrm{K}$.

6 Divist of lon logy, RWTH Aachen University, 52074 Aachen, Germany. 


\title{
Chapter
}

\section{Nicotine promotes vascular calcification via intracellular $\mathrm{Ca}^{2+}$-mediated, Nox5-induced oxidative stress and extracellular vesicle release in vascular smooth muscle cells}

\author{
Ploingarm Petsophonsakul ${ }^{1^{*}}$, Mathias Burgmaier $^{1,2^{*}}$, Brecht Willems ${ }^{1}$, Sylvia \\ Heeneman $^{3}$, Nadina Stadler ${ }^{3}$, Felix Gremse ${ }^{4}$, Sebastian Reith ${ }^{1}$, Kathrin Burgmaier ${ }^{5}$, Florian \\ Kahles $^{2}$, Nikolaus Marx², Ehsan Natour6,8, Elham Bidar ${ }^{6,8}$, Michael Jacobs ${ }^{7,8}$, Barend Mees ${ }^{7,8}$, \\ Chris Reutelingsperger ${ }^{1}$, Malgorzata Furmanik ${ }^{1}$, Leon Schurgers ${ }^{1}$
}

Submitted, under review

1. Department of Biochemistry, Cardiovascular Research Institute Maastricht, Maastricht University, The Netherlands

2. Department of Cardiology, Medical Clinic I, University Hospital of the RWTH Aachen, Germany

3. Department of Pathology, Cardiovascular Research Institute Maastricht, Maastricht University, The Netherlands

4. Experimental Molecular Imaging, University Hospital of the RWTH Aachen, Germany

5. Department of Pediatrics, University Hospital of Cologne, Cologne, Germany

6. Department of Cardiovascular Surgery, Maastricht University Medical Center (MUMC), Maastricht, the Netherlands

7. Department of Vascular Surgery, Maastricht University Medical Center (MUMC), Maastricht, the Netherlands

8. European Vascular Center Aachen-Maastricht, Maastricht, the Netherlands.

*These authors contributed equally 


\begin{abstract}
Aims

Smokers are at increased risk of cardiovascular events. However, the exact mechanisms through which smoking influences cardiovascular disease resulting in accelerated atherosclerosis and vascular calcification are unknown. The aim of this study was to investigate effects of nicotine on initiation of vascular smooth muscle cell (VSMC) calcification and to elucidate underlying mechanisms.
\end{abstract}

\title{
Methods and results:
}

We assessed vascular calcification of 62 carotid lesions of both smoking and non-smoking patients using ex vivo micro-computed-tomography ( $\mu \mathrm{CT})$-scanning. Calcification was present more often in carotid plaques of smokers ( $n=22$ of $30,73.3 \%$ ) compared to non-smokers ( $n=11$ of 32, 34.3\%; $\mathrm{p}<0.001$ ), confirming higher atherosclerotic burden. The difference was particularly profound for microcalcifications, which was 17-fold higher in smokers compared to non-smokers. In vitro, nicotine induced human primary VSMC calcification, increased osteogenic gene expression (Runx2, Osx, BSP and OPN), and extracellular vesicle (EV) secretion. The pro-calcifying effects of nicotine were mediated by $\mathrm{Ca}^{2+}$-dependent Nox5. SiRNA knock-down of Nox5 inhibited nicotine-induced EV release and calcification. Moreover, pre-treatment of hVSMCs with vitamin K2 ameliorated nicotine-induced intracellular oxidative stress, EV secretion, and calcification. Using nicotinic acetylcholine receptor (nAChR) blockers $\alpha$-bungarotoxin and hexamethonium bromide we found that the effects of nicotine on intracellular $\mathrm{Ca}^{2+}$ and oxidative stress were mediated by $\alpha 7$ and $\alpha 3$ nAChR. Finally, we showed that Nox 5 expression was higher in carotid arteries of smokers and correlated with calcification levels in these vessels.

\section{Conclusion}

In this study we provide evidence that nicotine induces Nox5-mediated pro-calcific processes as novel mechanism of increased atherosclerotic calcification. We identified that activation of $\alpha 7$ and $\alpha 3 \mathrm{nAChR}$ by nicotine increases intracellular $\mathrm{Ca}^{2+}$ and initiates calcification of hVSMCs through increased Nox5 activity, leading to oxidative stress-mediated EV release. Identifying the role of Nox5-induced oxidative stress opens novel avenues for diagnosis and treatment of smoking-induced cardiovascular disease.

Key Words: nicotine, vascular calcification, vascular smooth muscle cell phenotypic switching, Nox5, vitamin K2. 


\section{Introduction}

Cigarette smoking is a major cause of coronary heart disease and cardiovascular diseases (CVD). According to the 2014 Surgeon General's Report on smoking and health, smoking is responsible for approximately one of every four deaths from CVD. ${ }^{1}$ Smoking has been shown to be associated with increased cardiovascular morbidity and mortality in a dosedependent manner. ${ }^{2,3}$ Because of its detrimental effect, smoking remains the most important modifiable risk factor for CVD outcome. ${ }^{4}$

Vascular calcification is a strong and independent risk factor of CVD and used as a parameter to detect atherosclerotic burden in patients. ${ }^{5}$ Vascular calcification is the deposition of hydroxyapatite crystals in the vasculature which can be categorized by size. ${ }^{6}$ Microcalcification is an active dynamic process caused by vesicle-mediated mineralization, apoptotic bodies, and osteogenic differentiation. ${ }^{7,8}$ It precedes macrocalcification and is considered detrimental. ${ }^{9}$ Vascular calcification is commonly observed in atherosclerosis, aortic aneurysm, chronic kidney disease, and diabetes. ${ }^{10,11}$ Arterial intimal calcification is associated with arterial obstruction and atherosclerotic plaque rupture, whereas arterial medial calcification is associated with arterial stiffness, systolic hypertension, and aortic aneurysm. ${ }^{12}$ Vascular calcification is an active process driven by vascular smooth muscle cells (VSMCs), which are the major cell type in the vessel wall and are located in the tunica media. ${ }^{13}$ Vascular calcification arises from differentiation of VSMC, VSMC apoptosis, and mineralization of extracellular vesicles $(\mathrm{EV}) .^{12,14-16}$ Lineage-tracing studies reveal that VSMCs undergo phenotypic switching and give rise to a variety of cells, including osteogenic-like cells, which contribute to vascular calcification. ${ }^{17,18}$ Thus, VSMCs are well recognized as key player in atherogenesis and atherosclerotic plaque calcification. ${ }^{19}$

Cigarette smoking is strongly associated with (sub-)clinical atherosclerosis including coronary artery, peripheral artery, and aortic calcification. ${ }^{20-23}$ A growing body of evidence suggests that nicotine, a major constituent of cigarette smoke ${ }^{24}$, accounts for impaired vascular function and vascular calcification. ${ }^{25}$ In this study, we aimed to unravel the mechanistic link between nicotine and VSMC-induced vascular calcification. We investigate the effect of smoking on calcification in human carotid plaques and explore the effect of nicotine on VSMC processes that lead to vascular calcification in vitro. 


\section{Methods}

\section{Quantification of microcalcifications in patients}

Human carotid artery lesion specimen were obtained from 30 patients autopsied at the University Hospital Maastricht, Maastricht, the Netherlands via the Maastricht Pathology Tissue Collection as previously described. ${ }^{26}$ The collection, storage and processing of tissue and patient data are in accordance with the "Code for Proper Use of Secondary Human Tissue in the Netherlands" and the Declaration of Helsinki. ${ }^{26}$ Informed written consent was given prior to the inclusion of subject material in the study. Micro-computed tomography $(\mu \mathrm{CT})$ images were captured using a $\mu \mathrm{CT}$ scanner (Tomoscope DUO, CT-Imaging, Erlangen, Germany). Sources of the $\mu \mathrm{CT}$ were operated with voltage of $65 \mathrm{kV}$ and current of $0.5 \mathrm{~mA}$. 720 projections with 1032 x 1012 pixels were acquired during one revolution with duration of 90 seconds. Volumetric images were reconstructed using a Feldkamp Reconstruction at voxel size $35 \mu \mathrm{m}$ using a medium sharp reconstruction kernel (T60). Volumetric images were visualized and analyzed using the Imalytics Preclinical Software. ${ }^{27}$ Calcifications were interactively segmented and counted using a fixed threshold (100 HU) and connected component analysis. ${ }^{27}$ In order to show differences in calcification according to calcification size, segmented components were grouped into small, medium and large classes based on their volumes $(<0.01$ $\mathrm{mm}^{3},<0.1 \mathrm{~mm}^{3}$, and $>0.1 \mathrm{~mm}^{3}$ ). Due to the lack of previous studies using this design and set up, these cut-offs were chosen based on the scanners resolution, specimen size and distribution of calcification size. Volumes were determined based on the segmentation size, i.e. proportional to the number of segmented voxels. Calcification amount per voxel was assumed to be proportional to the voxel intensity and the amount of calcification per plaque was computed as the sum of the corresponding voxels.

\section{VSMC culture and treatments}

Human primary VSMCs were isolated from a non-diseased region of aortic tissue obtained from patients undergoing aortic aneurysm surgical repair in agreement with the Dutch Code for Proper Secondary Use of Human Tissue. This study complies with the Declaration of Helsinki. VSMCs were cultured in DMEM (Gibco) supplemented with 20\% FBS (Gibco) and $1 \%$ penicillin/streptomycin (PS) (Gibco). VSMCs were passaged when $90 \%$ confluent and used for experiments at passage 3-10. VSMCs were stimulated with nicotine $(150 \mathrm{nM}, 1 \mu \mathrm{M}$, $1 \mathrm{mM}, 5 \mathrm{mM}, 10 \mathrm{mM}$, Sigma, N3876) or vehicle control (ethanol). Inhibitor treatments were carried out prior nicotine stimulation: GKT136901 $(1 \mu \mathrm{M}, 5 \mu \mathrm{M}$, Cayman chemical, 17764), $\alpha-$ 
Bungarotoxin $(1 \mu \mathrm{M}, 10 \mu \mathrm{M}$, Life Technologies, B1601), N-acetyl-cysteine (0.5 $\mu \mathrm{M}$, Sigma, A7250), Vitamin K (Menaquinone-7, $10 \mu \mathrm{M}$, Nattopharma ASA), Stattic (1 $\mu \mathrm{M}$, Abcam, ab120952), SU6656-SrcFK inhibitor (2 $\mu$ M, Sigma, S9692), GSK2656157-pERK inhibitor ( $2 \mu \mathrm{M}$, ApexBio, B2175), BAPTA-AM (1 $\mu \mathrm{M}$, Molecular probes \#d1207).

\section{Statistical analysis}

Data are shown as mean \pm SD and were obtained in three or more independent experiments. Normality of all data was tested using the Shapiro-Wilk test. If data was not normally distributed, the Man-Whitney and Kruskal-Wallis tests were used, otherwise, statistical significance was tested with t-test, one sample-test and 1-way ANOVA with Bonferroni post hoc for experiments with 2 and more groups, respectively. Statistical analysis was carried out using GraphPad Prism 8.2.0. All clinical data were analysed on a per lesion basis and the statistical test did not account for the correlation of multiples lesions within patients. Clinical data computations were performed using SPSS (IBM Corp., Armonk, NY, USA). The exact test used for each data set is mentioned in figure legends. * denotes $\mathrm{p}<0.05, * * \mathrm{p}<0.01, * * *$ $\mathrm{p}<0.001$.

(Extended methods are provided in Supplemental material)

\section{Results}

\section{Smoking increases the incidence of calcification in human atherosclerotic plaques}

Smoking has been shown to correlate with higher incidence of vascular calcification. ${ }^{38}$ We assessed calcifications in 30 carotid artery atherosclerotic plaques of 15 smokers and compared to 32 plaques of 15 non-smokers using $\mu \mathrm{CT}$ scanning (Figure 1A and 1B). We divided the observed calcifications into 3 groups based on size and quantified their number and volume. Results show that, overall, calcification was present in $73.3 \%$ smokers and $34.4 \%$ nonsmokers ( $\mathrm{p}=0.002$, Table 1 ). Smoking was associated with a significantly higher prevalence of plaque calcifications of all size categories (microcalcifications were present in 21 lesions $(70.0 \%)$ of smokers vs. 8 lesions $(25.0 \%)$ of non-smokers, $\mathrm{p}<0.001$; intermediate calcifications in 20 lesions $(77.7 \%)$ vs. 7 lesions $(21.9 \%)$, p $<0.001$; macrocalcifications in 18 lesions $(60.0 \%)$ vs. 4 lesions $(12.5 \%), \mathrm{p}<0.001$; Table 1). Additionally, smokers had significantly more calcifications of all sizes (Figure 1C-E). The total volume of microcalcifications and intermediate calcifications, but not macrocalcifications, was also higher in smokers than in non-smokers (Figure 1F-H). These results suggest that smoking predisposes the formation of 
microcalcifications as well as calcification progression resulting in increased numbers of intermediate and macrocalcification.

Table 1: Characteristics of patients, whose lesions were used for the study.

\begin{tabular}{|c|c|c|c|}
\hline Clinical data & $\begin{array}{l}\text { Smoking } \\
\mathrm{n}=\mathbf{3 0}\end{array}$ & $\begin{array}{l}\text { Non-Smoking } \\
\mathrm{n}=32\end{array}$ & p-value \\
\hline Age (years) & $74.5 \pm 11.5$ & $75.2 \pm 10.4$ & NS \\
\hline Male (n, \%) & $14(46.7)$ & $17(53.1)$ & NS \\
\hline Diabetes (n, \%) & $14(46.7)$ & $14(43.8)$ & NS \\
\hline Glucose (mmol/L) & $8.8 \pm 3.6$ & $9.1 \pm 3.4$ & NS \\
\hline $\mathrm{CRP}(\mathrm{mg} / \mathrm{L})$ & $155.1 \pm 149$ & $113.4 \pm 112.2$ & NS \\
\hline Calcification (n, \%) & $22(73.3)$ & $11(34.4)$ & 0.002 \\
\hline Overall NOC (n) & $921.5 \pm 1305.5$ & $54.3 \pm 146.2$ & 0.001 \\
\hline \multicolumn{4}{|l|}{ Microcalcification } \\
\hline Present (n, \%) & $21(70.0)$ & $8(25.0)$ & $<0.001$ \\
\hline NOC (n) & $917.7 \pm 1303.7$ & $53.7 \pm 145.8$ & 0.001 \\
\hline Volume $\left(\mathrm{mm}^{2}\right)$ & $0.180 \pm 0.235$ & $0.018 \pm 0.045$ & 0.001 \\
\hline Total calcification (AU) & $207.8 \pm 268.7$ & $22.5 \pm 55.3$ & 0.001 \\
\hline \multicolumn{4}{|c|}{ Intermediate size calcification } \\
\hline Present $(\mathrm{n}, \%)$ & $20(66.7)$ & $7(21.9)$ & $<0.001$ \\
\hline NOC (n) & $2.43 \pm 2.40$ & $0.38 \pm 1.10$ & $<0.001$ \\
\hline Volume $\left(\mathrm{mm}^{2}\right)$ & $0.069 \pm 0.068$ & $0.011 \pm 0.034$ & $<0.001$ \\
\hline Total calcification (AU) & $89.55 \pm 91.97$ & $15.79 \pm 45.59$ & $<0.001$ \\
\hline \multicolumn{4}{|l|}{ Macrocalcification } \\
\hline Present $(\mathrm{n}, \%)$ & $18(60.0)$ & $4(12.5)$ & $<0.001$ \\
\hline NOC (n) & $1.37 \pm 1.38$ & $0.31 \pm 1.00$ & 0.001 \\
\hline Volume $\left(\mathrm{mm}^{2}\right)$ & $2.47 \pm 4.07$ & $1.28 \pm 6.77$ & NS \\
\hline Total calcification (AU) & $4610.8 \pm 9766.4$ & $2360.9 \pm 12654.4$ & NS \\
\hline
\end{tabular}

The data are presented as mean $\pm \mathrm{SD}$ or $\mathrm{n}(\%)$. Data were analysed on a per lesion basis and the statistical test did not account for the correlation of multiples lesions within patients.

Abbreviations: $\mathrm{NOC}=$ number of calcifications; $\mathrm{AU}=$ arbitrary units. 


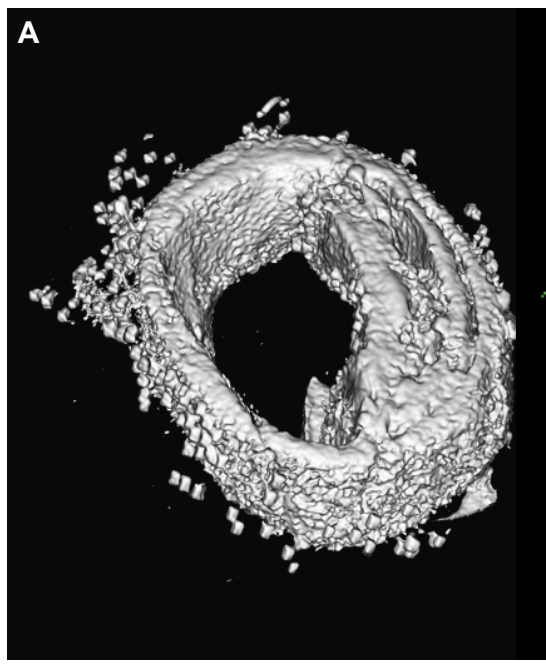

C

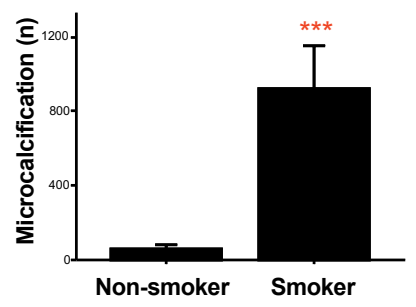

$\mathbf{F}$

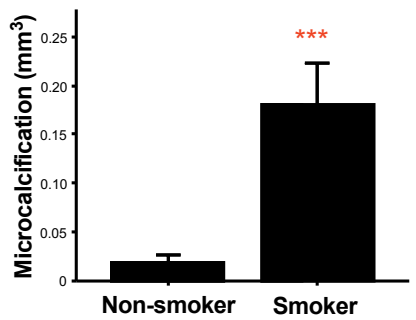

D

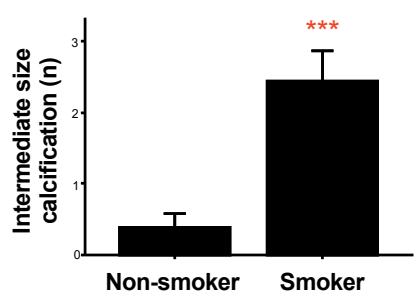

G

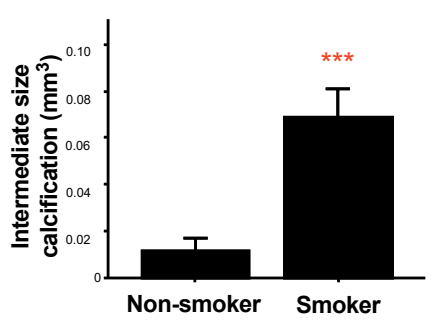

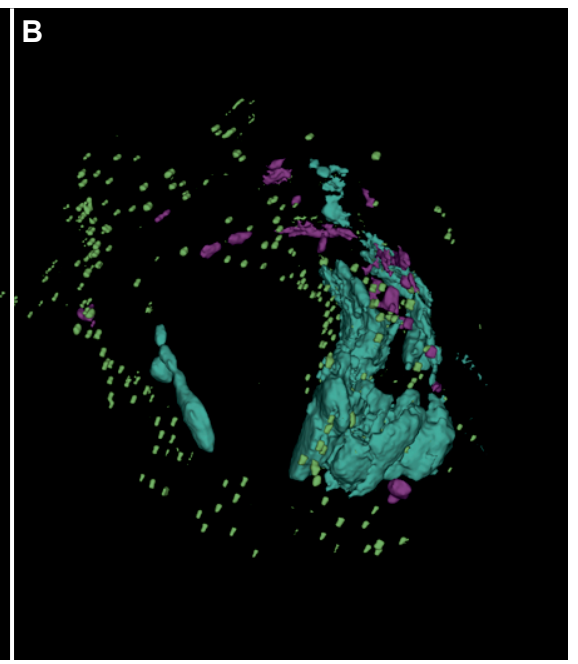

E

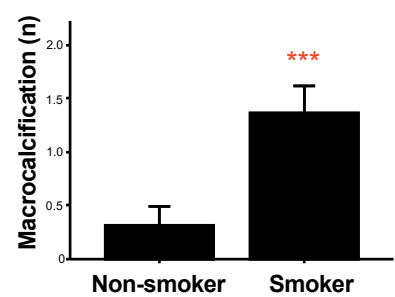

H

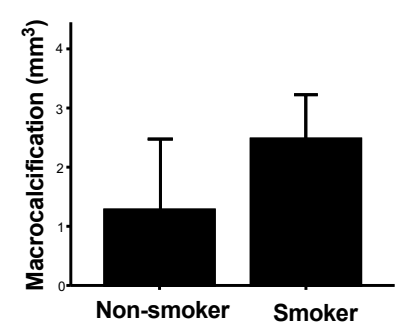

Figure 1. Smoking increases the incidence and amount of calcification in human atherosclerotic plaques. (A) Representative $\mu \mathrm{CT}$ image of carotid plaque from a non-smoker. Carotid plaque including soft tissue and (B) the same plaque without soft tissue displaying compartmentation of microcalcification in green, intermediate size calcification in magenta, and macrocalcification in turquoise. (C) Number of microcalcifications, (D) intermediate size calcifications and (E) macrocalcifications in carotid artery atherosclerotic plaques from smokers and non-smokers quantified by $\mu \mathrm{CT}$. (F) Volume of microcalcifications, (G) intermediate size calcifications, and (H) from the same analysis. Statistical significance was tested using $\mathrm{t}$-test, $\mathrm{n}=30$ plaques for smokers, $\mathrm{n}=32$ plaques for non-smokers. All graphs show mean and SEM. 


\section{Nicotine increases VSMC calcification in vitro}

To investigate the mechanisms underlying increased calcification observed with smoking, we investigated effects of nicotine, a major component of cigarette smoke, on human primary VSMC calcification in vitro. Nicotine increased calcification of VSMCs (Figure 2A), as well as other hallmarks of active mineralisation processes. Expression of some osteogenic markers was increased: transcription factors Runx 2 and Osx and downstream targets OCN, BSP and OPN (Figure 2B-2F), however others did not show a consistent pattern of upregulation (Supplemental figure 1A-1D). Increased osteogenic gene expression was accompanied by a decrease in expression of some contractile markers: SM22 $\alpha$ mRNA (Figure $2 \mathrm{G}$ ) and $\alpha \mathrm{SMA}, \mathrm{CNN} 1, \mathrm{p}-\mathrm{MLC}$ on protein level (Figure $2 \mathrm{H}-\mathrm{K}$ ). Expression of other contractile markers did not show a consistent pattern of regulation (Supplemental Figure 1E-1I). We also examined expression of markers characteristic of the dedifferentiated (synthetic) phenotype (KLF4, S100A4) and found it not to be changed by nicotine (Supplemental Figure 1J, 1K). 
A

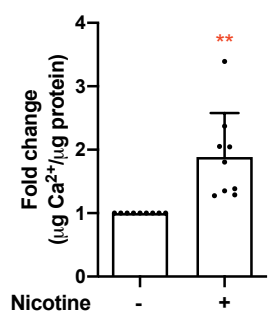

E

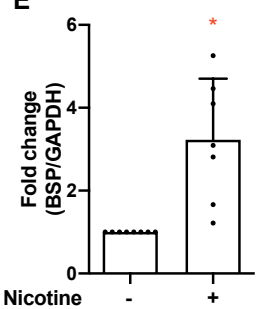

B

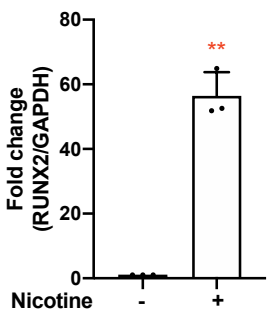

$\mathbf{F}$

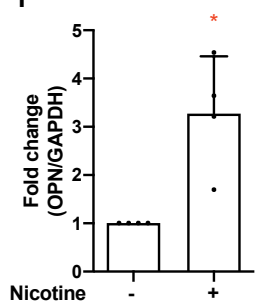

C

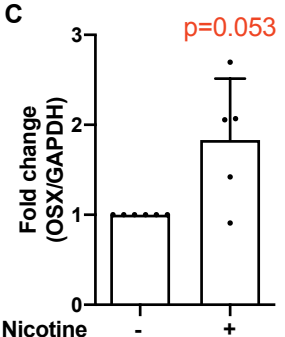

G

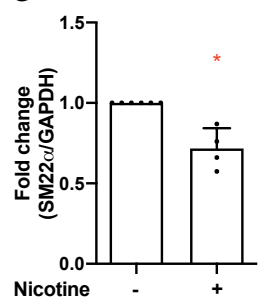

D

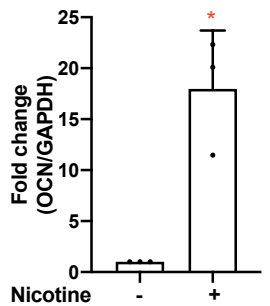

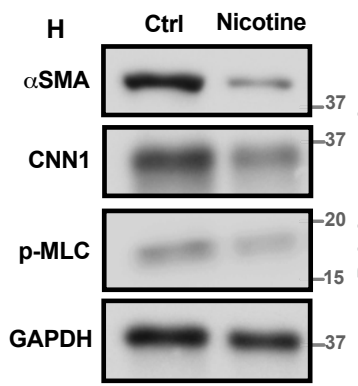

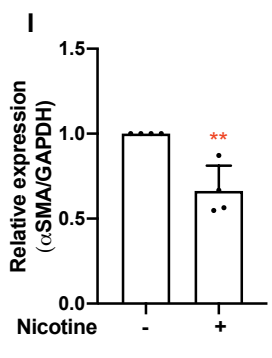

J
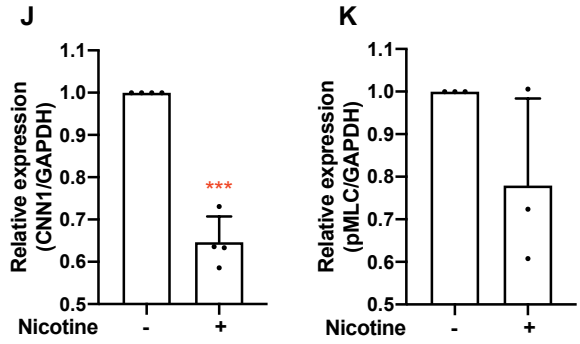

N

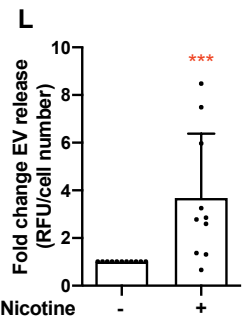

M

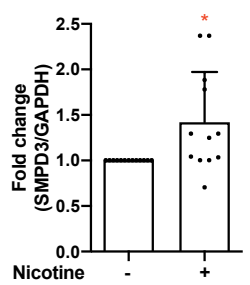

Figure 2. Nicotine increases VSMC calcification in vitro. (A) Calcification was induced with elevated $\mathrm{Ca}^{2+}$ concentrations $(5.4 \mathrm{mM})$ in DMEM with $2.5 \% \mathrm{FBS}$ in the presence of nicotine (1 mM, 5-7 days) and quantified using an o-cresolphthalein colorimetric assay. Statistical significance was tested with one sampletest. (B-F) qPCR analysis of osteogenic genes RUNX2, Osx, OCN, BSP, OPN, and (G) contractile marker SM22 $\alpha$ in VSMCs treated with nicotine $(1 \mu \mathrm{M}$ or $1 \mathrm{mM}, 7$ days in DMEM with $20 \%$ FBS). Statistical significance was tested with one sample-test. Each of the genes were tested at least 3 times with a different set of samples ( $\mathrm{n} \geq 3$ independent experiments) in duplicate. In case of borderline significance, more samples were added to rule in/rule out the genes that are involved in nicotine-induced changes in VSMCs. (H-K) Western blotting and quantification of contractile markers aSMA, CNN1, p-MLC in VSMCs treated with nicotine (1mM, 7days in DMEM with 20\% FBS). Labels show protein standard (kDa). Statistical 
significance was tested with one sample-test. (L) VSMCs treated with nicotine (1mM, 24 hours) in DMEM with $0.5 \%$ FBS secrete more EVs than VSMCs treated with vehicle control. EVs were captured with antiCD63-coulped beads, detected with a fluorescently labelled anti-CD81 antibody and quantified using flow cytometry. Statistical significance was tested with one sample-test. (M-N) qPCR analysis of EV-related genes; CD63 and SMPD3 mRNA expression treated with nicotine (1mM, 7days in DMEM with 20\% FBS). Statistical significance was tested with one sample-test. All graphs show data from $n \geq 3$ independent experiments.

Calcifying EVs play an important role in the initiation and development of vascular calcification. ${ }^{39}$ We found that EV release was increased by nicotine (Figure 2L, Supplemental Figure 1L), as was expression of EV-related genes (Figure 2M, 2N). Surprisingly, we observed that VSMCs treated with nicotine showed decreased proliferation rates compared to control (Supplemental Figure 2A). Nicotine at the concentration and timepoint used for these assays did not affect VSMC viability at the time points the cells were collected for analysis (Supplemental Figure 2B, 2C). Taken together, these results suggest dedifferentiation of VSMCs and activation of some calcification-promoting mechanisms as a result of exposure to nicotine.

\section{Nicotine induces ROS production in VSMCs}

As nicotine is a known inducer of oxidative stress ${ }^{40,41}$ and increased reactive oxygen species (ROS) are an important risk factor for atherosclerosis and calcification ${ }^{24,42}$, we investigated the effect of nicotine on ROS production in VSMCs. We found that nicotine induced ROS production in VSMCs (Figure 3A). Further to that, nicotine-induced ROS and EV production could be blocked by antioxidant vitamin K2 (Figure 3B, 3C), and this leads to decreased calcification (Figure 3D). The same effect was observed for antioxidant Nacetylcysteine (NAC, Figure 3E). This suggests that the calcification-promoting effects of nicotine are mediated by increased ROS production. 
A

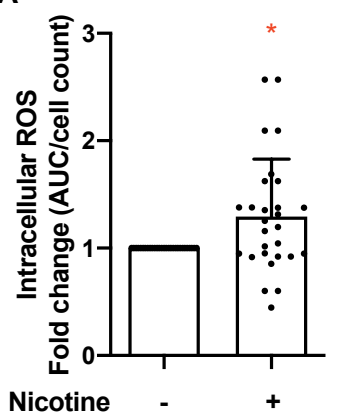

D

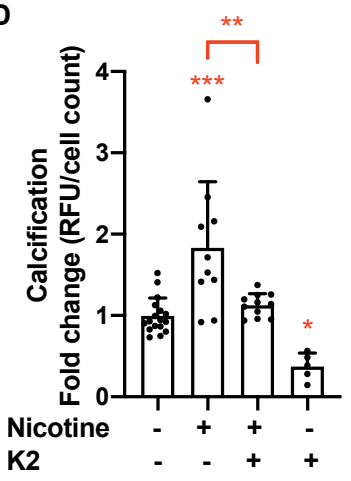

B

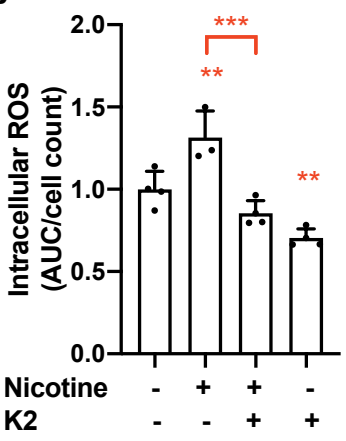

E

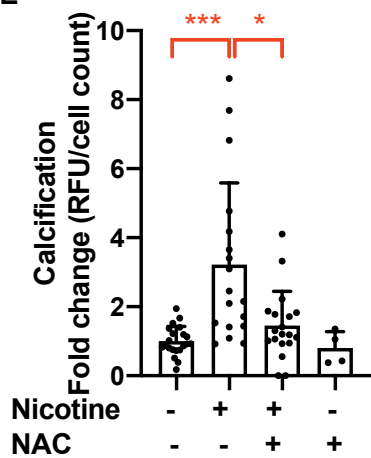

C

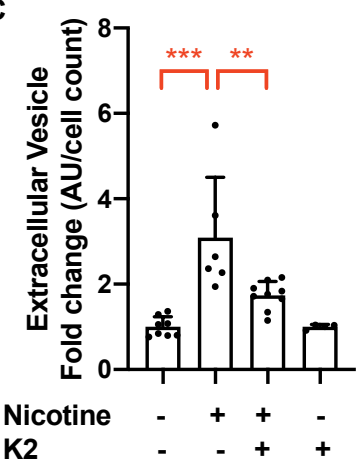

Figure 3. Nicotine-induced ROS production leads to VSMC calcification. (A) Stimulation of nicotine ( $1 \mathrm{mM}, 40$ minutes) induces intracellular ROS of VSMCs compared to vehicle control. ROS production was measured using a fluorescent assay with DCFDA. Statistical significance was tested with one sample-test. Pre-treatment of VSMCs with vitamin $\mathrm{K}(10 \mu \mathrm{M}, 1$ hour) prior to stimulation with nicotine reduces (B) intracellular ROS (1 $\mathrm{mM}$ nicotine, 40 minutes), (C) EV secretion (1 $\mathrm{mM}$ nicotine in DMEM with $0.5 \% \mathrm{FBS}$, 24 hours), and (D) VSMC calcification ( $1 \mathrm{mM}$ nicotine in DMEM with $2.5 \% \mathrm{FBS}$ and $3.6 \mathrm{mM} \mathrm{Ca}^{2+}, 3-5$ days). Statistical significance was tested with ANOVA (B-D). (E) Pre-treatment with NAC ( $0.5 \mu \mathrm{M}, 1$ hour) prior to nicotine stimulation reduces VSMC calcification induced by DMEM with $2.5 \%$ FBS and $3.6 \mathrm{mM}$ $\mathrm{Ca}^{2+}$ (3-5 days). Calcification was detected using Fetuin A-Alexa-546. Statistical significance was tested with Kruskal-Wallis test. All graphs show data from $\mathrm{n} \geq 3$ independent experiments.

\section{Nox5 mediates pro-calcific effects of nicotine}

To reveal the source of increased ROS, we examined the expression of Nox 4 and Nox 5 , two enzymes strongly implicated in oxidative stress in vascular disease. ${ }^{43}$ Expression of neither enzyme was consistently changed by nicotine treatment (Figure 4A-D). However, pan-Nox inhibitor GKT136901 significantly blocked nicotine-induced ROS production suggesting a potential role for a Nox enzymes in these processes (Figure 4E). Pan-Nox inhibitor 
GKT136901 was not sufficient to reduce nicotine-induced calcification (Figure 4F). Nox5 activity is known to be mediated by $\mathrm{Ca}^{2+}$ binding to this enzyme ${ }^{43}$ and we have previously shown that increased intracellular $\mathrm{Ca}^{2+}$ mediates increased ROS production by Nox5. ${ }^{44}$ Therefore, we wanted to investigate whether nicotine induces changes in intracellular $\mathrm{Ca}^{2+}$. First, we showed that nicotine did induce an increase in intracellular $\mathrm{Ca}^{2+}$ (Figure $4 \mathrm{G}$ ). Further to that, intracellular $\mathrm{Ca}^{2+}$ chelator BAPTA-AM attenuated nicotine-induced ROS production in VSMCs (Figure 4H). To confirm that this effect is mediated by Nox5, we performed siRNA knockdown of Nox5 (Figure 4I, 4J). Results show that Nox5 siRNA significantly lowered nicotine-induced ROS production (Figure 4K), EV release (Figure 4L) and calcification (Figure 4M). 
A

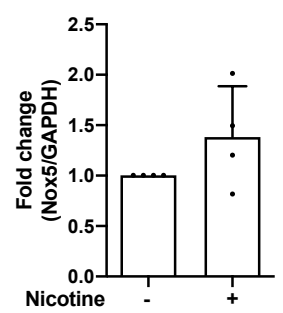

E

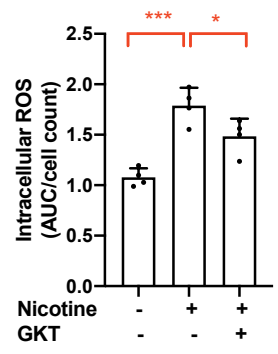

B

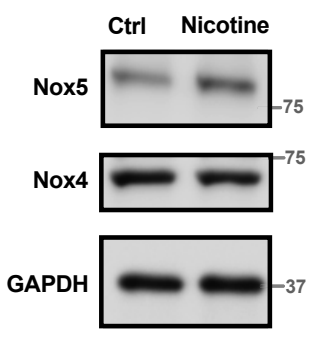

$\mathbf{F}$

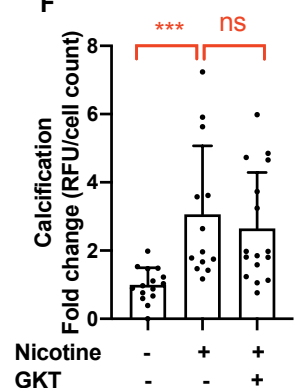

C

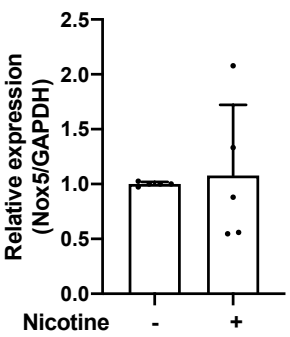

G

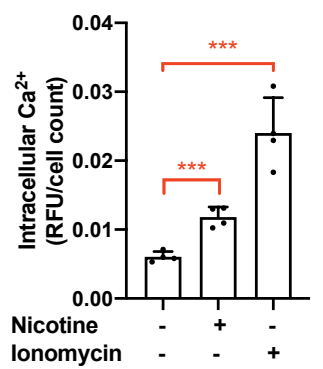

D

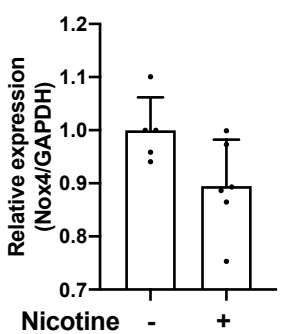

H

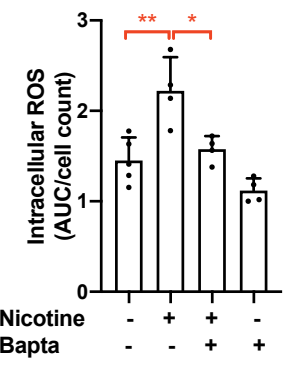

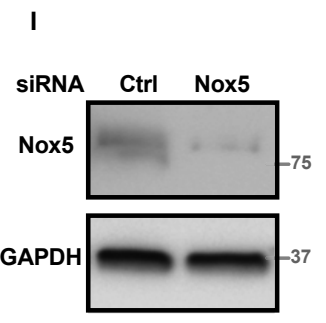

$\mathbf{J}$

K
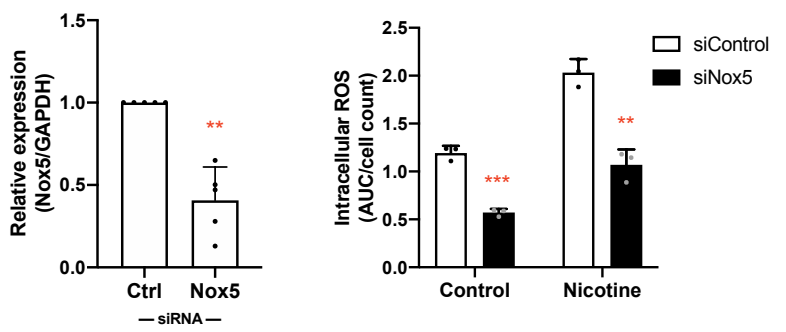

$\mathbf{L}$

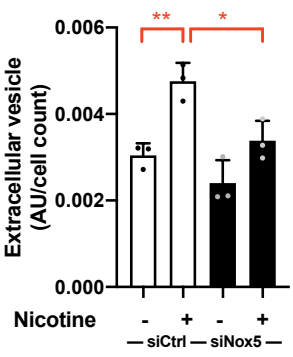

M

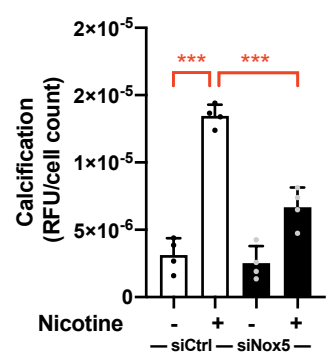

Figure 4. Nox5 mediates pro-calcific effects of nicotine. (A) qPCR analysis of NOX5 mRNA expression in VSMCs treated with nicotine (1 mM, 7days in DMEM with 20\% FBS). (B-D) Western blotting and quantification of Nox 4 and Nox 5 protein in VSMCs treated with nicotine ( $1 \mathrm{mM}, 7$ days in DMEM with $20 \%$ FBS). Labels show protein standard $(\mathrm{kDa})$. Statistical significance was tested with t-test. (E) Pre-treatment of VSMCs with GKT136901 (1 1 M, 1 hour) prior nicotine stimulation ( $1 \mathrm{mM}, 40$ minutes) reduces nicotineinduced intracellular ROS. Statistical significance was tested with ANOVA. (F) VSMC calcification was induced with calcification medium $\left(2.5 \% \mathrm{FBS}, 3.6 \mathrm{mM} \mathrm{Ca}^{2+}\right)$ in the presence of nicotine $(1 \mathrm{mM})$, with or 
without pre-treatment with GKT ( $1 \mu \mathrm{M}, 1$ hour), for 3 to 5 days. Calcification was detected using Fetuin AAlexa-546. Statistical significance was tested with Kruskal-Wallis test. (G) Nicotine (10 mM, 5 minutes) induces an increase in intracellular $\mathrm{Ca}^{2+}$ (measured using Fluo-4-AM). Statistical significance was tested with t-test. (H) Pre-treament of VSMCs with BAPTA-AM $(1 \mu \mathrm{M}, 1$ hour) reduces nicotine-induced intracellular $\mathrm{Ca}^{2+}$ (10 mM nicotine, 5 minutes). Statistical significance was tested with ANOVA. (I-J) Western blot showing that siRNA knock-down (24 hours) decreased Nox5 protein expression. Labels show protein standard $(\mathrm{kDa})$. Statistical significance was tested with one sample-test (K) SiRNA knock-down of Nox5 (24 hours) decreased VSMC intracellular ROS, (L) EV secretion, and (M) VSMC calcification $(2.5 \%$ FBS, $3.6 \mathrm{mM} \mathrm{Ca}^{2+}$, 3-5 days). Statistical significance was tested with ANOVA (K-M). All graphs are representative of data from $n \geq 3$ independent experiments.

In order to examine alternative mechanisms leading to oxidative stress-mediated calcification and phenotype changes of VSMCs we investigated the SrcFK/JAK-STAT3/ERK pathways (Supplemental Figure 3A). ${ }^{45}$ While we observed a trend towards increased STAT3 phosphorylation $(p=0.051)$ after nicotine treatment (Supplemental Figure 3B, 3C), inhibition of STAT3 phosphorylation with Stattic did not consistently change EV release and calcification (Supplemental Figure 3D-E). Additionally, inhibition of SrcFK with SU6656 and ERK phosphorylation with GSK2656157 did not change nicotine-induced EV release or calcification (Supplemental Figure 3D, 3E). Taken together, these results suggest that these pathways do not play a role in mediating nicotine-induced EV release and calcification.

\section{Nicotine mediates its effects through interaction with $\alpha 3$ and $\alpha 7$ nicotinic acetylcholine receptors}

Subsequently, we investigated which nicotinic acetylcholine receptor (nAchR) subunit mediates the effects of nicotine in VSMCs. We used two nAchR inhibitors, hexamethonium bromide and $\alpha$-Bungarotoxin, which inhibit $\alpha 3$, and $\alpha 7-9$ nAchR subunits, respectively. ${ }^{46,47}$ VSMCs do not express $\alpha 8$ and $\alpha 9$ subunits. ${ }^{46}$ Both hexamethonium bromide and $\alpha$ Bungarotoxin reduced nicotine-induced intracellular ROS production (Figure 5A). While hexamethonium bromide significantly decreased VSMC calcification, $\alpha$-Bungarotoxin did so only slightly (Figure 5B). However, $\alpha$-Bungarotoxin reduced nicotine-induced raise in intracellular $\mathrm{Ca}^{2+}$ (Figure 5C), but not EV release (Figure 5D) or expression of Nox 5 and EVrelated genes (Figure 5E-G). This data suggests that both $\alpha 3$ and $\alpha 7 \mathrm{nAchR}$ are involved in mediating effects of nicotine in VSMCs. 
A

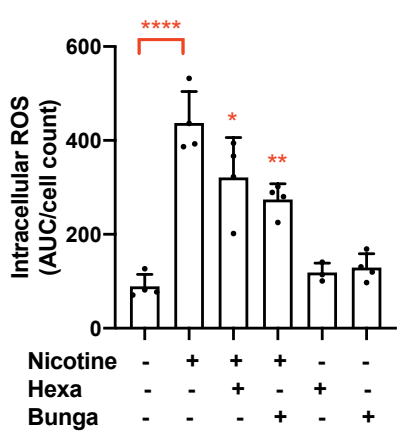

D

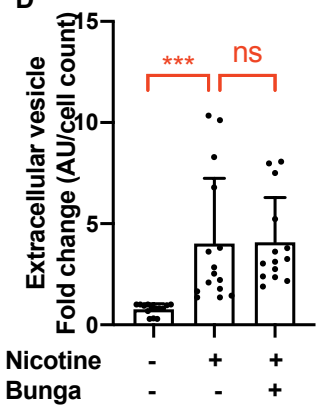

G

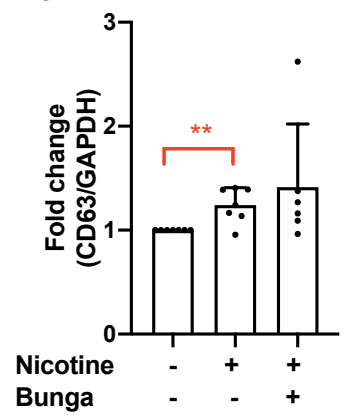

B

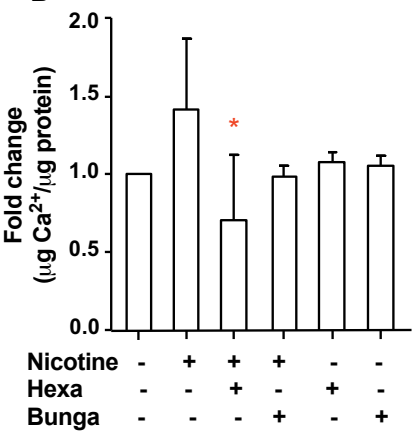

E

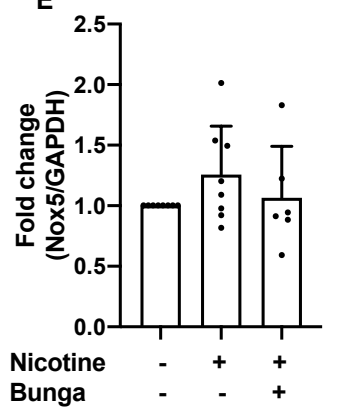

C

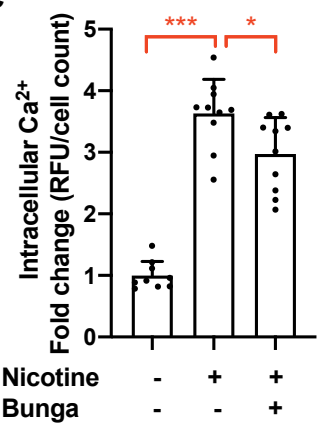

$\mathbf{F}$

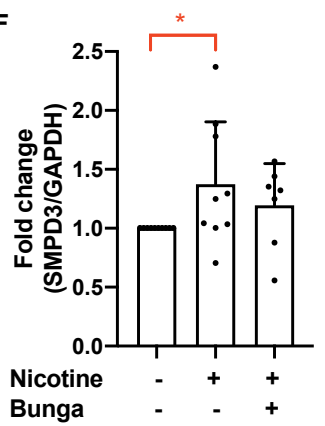

Figure 5. Nicotine mediates its effects through interaction with $\alpha 3$ and $\alpha 7$ nicotinic acetylcholine receptor. (A) Pre-treatment with $\alpha$-Bungarotoxin $(1 \mu \mathrm{M}, 1$ hour $)$ and hexamethonium bromide $(100 \mu \mathrm{M}, 1$ hour) reduced nicotine-induced intracellular ROS (1 mM nicotine, 40 minutes) and (B) VSMC calcification ( $1 \mathrm{mM}$ nicotine in DMEM with 2.5\% FBS, $3.6 \mathrm{mM} \mathrm{Ca}^{2+}, 3-5$ days). Calcification was detected using Fetuin A-Alexa-546. Statistical significance was tested with ANOVA (A-B). (C) Pre-treatment with $\alpha$ Bungarotoxin ( $1 \mu \mathrm{M}, 1$ hour) prior to nicotine stimulation ( $1 \mathrm{mM}, 5$ minutes) reduces intracellular $\mathrm{Ca}^{2+}$. Statistical significance was tested with ANOVA. (D) VSMCs were treated with nicotine ( $1 \mathrm{mM}, 24$ hours) with or without pre-treatment with $\alpha$-Bungarotoxin $(1 \mu \mathrm{M}, 1$ hour) in DMEM with $0.5 \%$ FBS. EVs were captured with anti-CD63-coulped beads, detected with a fluorescently labelled anti-CD81 antibody and quantified using flow cytometry. Statistical significance was tested with Kruskal-Wallis test. (E) qPCR analysis of Nox5 and (F-G) EV-related gene CD63 and SMPD3 expression in VSMCs treated with nicotine ( $1 \mathrm{mM}, 7$ days in DMEM with $20 \% \mathrm{FBS}$ ) with or without $\alpha$-Bungarotoxin pre-treatment ( $1 \mu \mathrm{M}, 1$ hour). 
Statistical significance was tested with ANOVA (E) and Kruskal-Wallis test (F-G). All graphs show representative data from $\mathrm{n} \geq 3$ independent experiments.

\section{6. expression correlates with the amount of calcification in human atherosclerotic plaques}

Finally, to examine whether our findings have relevance in vivo, we examined expression of Nox5 as well as contractile marker CNN1, synthetic marker S100A4 and EV marker CD63 in human carotid arteries 15 smokers and 15 non-smokers, whose arteries were previously examined by $\mu \mathrm{CT}$ (Figure 1). Immunohistochemistry showed markedly increased expression of Nox 5 in smokers compared to non-smokers, while levels of CNN1, S100A4 and CD63 were not changed (Figure 6A-6E). Interestingly, we found a positive correlation $(\mathrm{r}=0.8187, \mathrm{p}<0.0001)$ between calcification (measured by $\mu \mathrm{CT})$ and Nox 5 expression (score) in both smokers and non-smokers (Figure 6E). Taken together, these data suggest that smoking is associated with increased Nox 5 expression and that Nox 5 promotes calcification in vivo. 
A

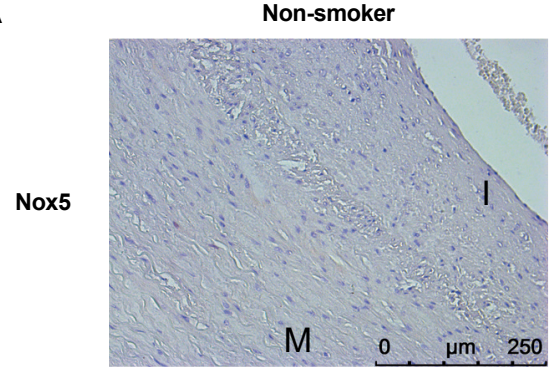

CNN1

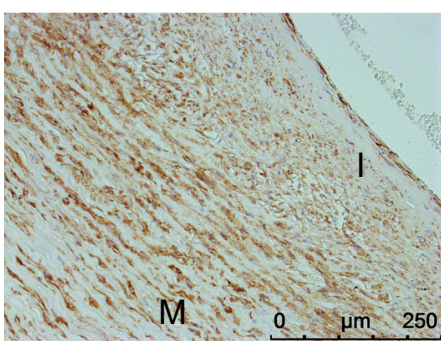

M

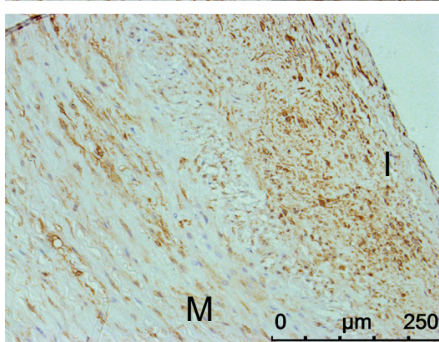

B

C

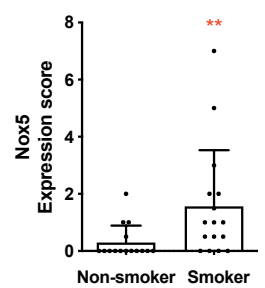

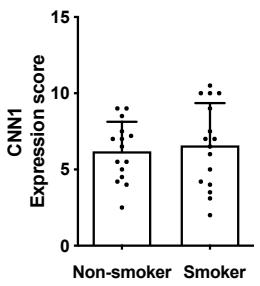

Smoker
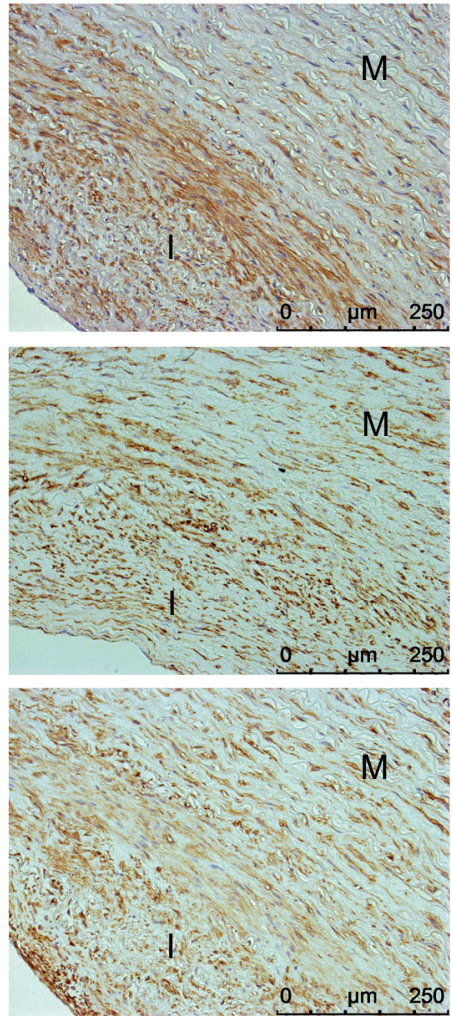

D

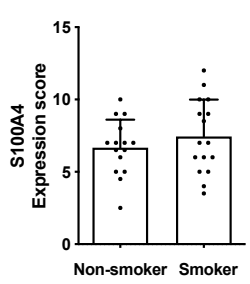

E

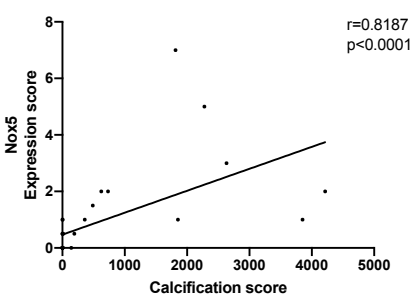

Figure 6. Smoking and calcification are associated with increased carotid artery Nox5 expression. (A) Immunohistochemical analysis of Nox5, CNN and S100A4 expression in carotid artery samples from human donors. I and $\mathrm{M}$ indicates intima and media, respectively. Scale bars are $250 \mu \mathrm{m}$. Figure shows representative images from 32 carotid artery samples that were stained ( 15 smokers, 15 non-smokers). (B-D) Quantification of protein expression scores. Statistical significance was tested with Mann-Whitney test. Dots denote individual data points. (E) Nox 5 expression positively correlates with calcification $(\mathrm{P}<0.001, \mathrm{r}=0.8187$ and $\mathrm{P}<0.0001, \mathrm{r}=0.794$, when outliers are removed). Nox 5 expression scores were plotted against $\mu \mathrm{CT}$ total calcification scores for each patient. Graph shows individual data points (both smokers and non-smokers). Linear regression was plotted, and a two-tailed Pearson correlation test was carried out. 


\section{Discussion}

In this study we demonstrated that smoking is associated with a significant increase in both micro- and macrocalcification in human carotid artery atherosclerotic plaques. We showed through in vitro studies that nicotine directly affects human VSMCs through $\alpha 3$ and $\alpha 7 \mathrm{nAChR}$ and induces all the major hallmarks of calcification. We uncovered a novel mechanism by which nicotine induces an increase in intracellular $\mathrm{Ca}^{2+}$, resulting in Nox5-mediated intracellular oxidative stress providing the perfect storm for VSMC calcification (Figure 7).

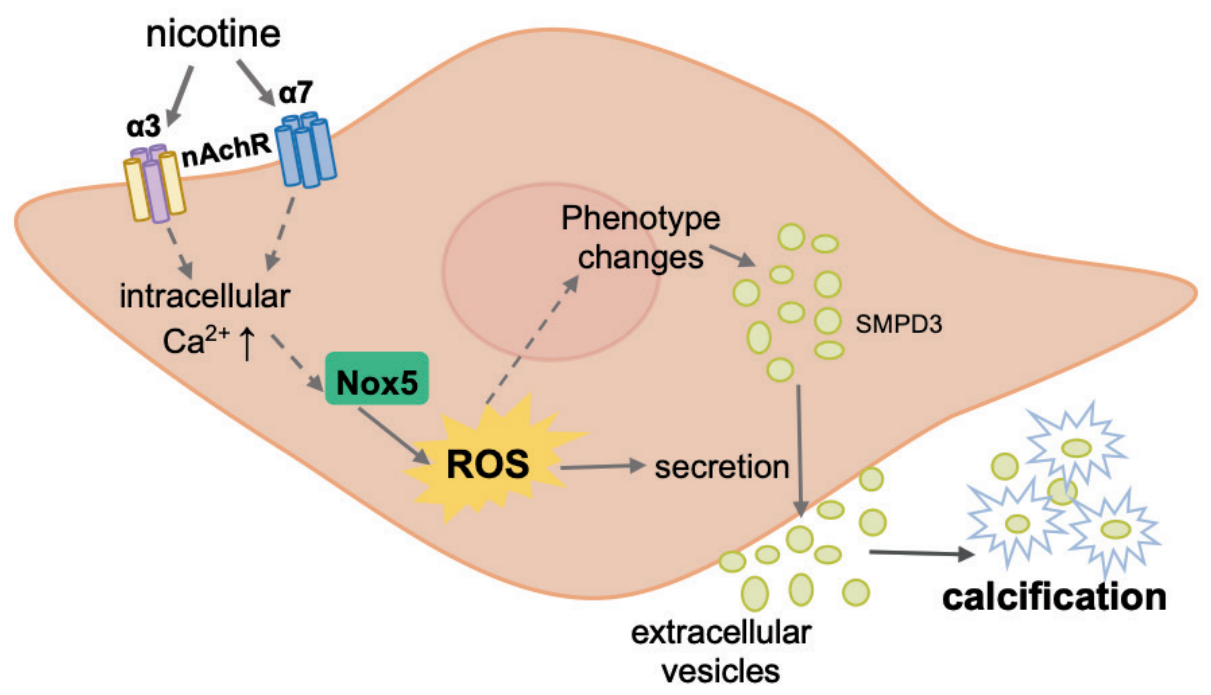

Figure 7. Mechanism of nicotine-induced VSMC calcification. Nicotine induces changes in VSMCs that initiate their calcification. First, nicotine binds to $\alpha 3$ and $\alpha 7 \mathrm{nAchR}$ on VSMCs, which rapidly raises intracellular $\mathrm{Ca}^{2+}$ levels. Nox5, whose activity is dependent on $\mathrm{Ca}^{2+}$, is then activated and subsequently increases production of intracellular ROS. Oxidative stress induces VSMC phenotypic switching and promotes transdifferentiation of VSMCs towards an osteogenic phenotype. Phenotypic switching of VMSC also results in higher secretion of EVs, which mineralize and contribute to calcification.

\section{Smoking is associated with vascular microcalcification and vulnerable plaque phenotype}

We show that calcification is significantly more present in smokers than non-smokers. Our data support previous studies which reported a significant association between smoking and coronary artery as well as aortic calcification. ${ }^{20,48}$ While smoking has recently been shown to be an independent risk factor for carotid artery plaque calcification ${ }^{49}$, calcifications have not been analysed with respect to their size. It has been shown that microcalcifications affect atherosclerotic plaque stability. ${ }^{50}$ We extend the current knowledge and show that smoking is associated with 17 -fold increase in microcalcifications within atherosclerotic lesions. Since 
microcalcifications are biologically active and are an important feature of vulnerable plaques $^{9,50-52}$, our data suggest that smoking may be associated with a more vulnerable plaque phenotype. Indeed, studies have shown that cigarette smoke impacts the composition of the plaque, which contributes to plaque vulnerability and increased risk of plaque rupture. ${ }^{53,54}$

\section{Nicotine induces phenotypic switching of VSMCs and initiates calcification}

In this study, we elucidate the mechanism by which nicotine initiates vascular calcification in VSMCs. First, we show that nicotine downregulates VSMC contractile markers (SM22 $\alpha, \alpha \mathrm{SMA}, \mathrm{CNN} 1$, and p-MLC) and upregulates bone-specific markers (Runx2, Osx, OCN, BSP and OPN). This is in line with previous studies showing that nicotine decreased expression of $\alpha$ SMA, SM22 $\alpha$ and increased expression of OPN in murine VSMCs ${ }^{55}$ and OPN and inflammatory cytokines in human VSMCs. ${ }^{56}$ Another study reported that nicotine differentiated VSMCs to a synthetic phenotype, demonstrated by a reduction in SM22 $\alpha$ and hcaldesmon, and increased in myosin-II 10 and $\beta$-actin gene expression. ${ }^{57}$ Unexpectedly, the observed decrease in contractile markers in our experiments was not accompanied by a nicotine-induced increase in synthetic phenotype markers. This could be explained by the heterogeneity of VSMCs and sub-clonal population of VSMCs ${ }^{17,58}$, which do not uniformly express specific markers at specific time points. ${ }^{58}$ More recent understanding points to the notion that VSMCs exhibit co-expression of genes rather than a two-end spectrum: contractile and synthetic phenotype, and that intrinsic and extrinsic factors as well as the developmental phase of the aorta should be taken into account. ${ }^{59,60}$

Phenotypic switching of VSMCs can be caused by various stimuli, including oxidized cholesterol, inflammatory cytokines, PDGF, and oxidative stress. ${ }^{61,62} \mathrm{We}$ found that nicotine mainly acts via increasing oxidative stress, as it markedly induced intracellular ROS production and ROS mediated nicotine-induced calcification. It is well documented that nicotine induces ROS generation both in animal studies ${ }^{63-65}$ and in murine and rat VSMCs (as cigarette smoke extract). ${ }^{55,66}$ However, our study is the first to show a causative link between ROS, nicotine and VSMC calcification.

We also show that ROS production induced by nicotine leads to increased EV release from VSMCs. Both quantification using a CD63/CD81 bead capture assay and NTA suggest a role for exosomes, however, we cannot exclude a role for larger microvesicles, which were also present in VSMC culture supernatants. EVs are a well-known inducer of calcification and it is known that phenotypic switching of VSMCs results in increased secretion of EVs. ${ }^{39,67}$ Pathological conditions induce release of EVs with distinct composition, which may affect 
cellular phenotypes. ${ }^{68}$ Indeed, release of EVs from osteogenic VSMCs promotes mineralization. ${ }^{67,69}$ Nicotine (as cigarette smoke extract) has been shown to affect the composition of EVs in lung cancer and bronchial epithelial cells ${ }^{70,71}$ and higher levels of local site EVs were found in lungs of smokers. ${ }^{72}$ Interestingly, nicotine reduced monocyte-derived EV release. ${ }^{73}$ However, to our knowledge, there is no previous data on the effect of nicotine on EV release from VSMCs.

\section{nAchR and Nox5 mediate pro-calcific processes induced by nicotine}

We investigated the intracellular source of increased ROS and, through pharmacological inhibition and knockdown experiments, we identified Nox 5 as a key regulator of nicotine-induced ROS generation and calcification in human VSMCs. Nox enzymes are a major source of ROS in vascular diseases ${ }^{74}$, however the mechanism linking nicotine and oxidative stress in VSMCs is not well described in the literature. The effect of cigarette smoke on inducing vascular Nox activity has mainly been studied in endothelial cells. ${ }^{75,76}$ Cigarette smoke extract induced endothelial CXCL16-dependent leukocyte arrest via Nox $5 .{ }^{77}$ Some data using rat and rabbit VSMCs suggest the involvement of Nox2 after nicotine induction. ${ }^{64,78}$ Despite the lack of increased Nox 5 expression in VSMCs exposed to nicotine in our study, we found that siRNA knock-down of Nox5 attenuated nicotine-induced ROS production, EV release and calcification. This indicates that although Nox 5 levels are not altered, activity of Nox 5 is increased. Nox 5 is a unique Nox, as it does not require other subunits for activity, but does require $\mathrm{Ca}^{2+}$ binding. ${ }^{43,79}$ We found that nicotine significantly raises intracellular $\mathrm{Ca}^{2+}$ within VSMCs, thereby contributing to increased Nox5 activity without increasing Nox5 expression. Our data are in line with a previous study showing that nicotine increases intracellular $\mathrm{Ca}^{2+}$ levels in human VSMCs. ${ }^{57}$

We also investigated an alternative mechanism leading to oxidative stress-mediated phenotypic switching of VSMCs and calcification, involving Janus kinase (JAK)/Signal transducers and activator of transcription (STAT) signalling, a critical pathway that regulates cell proliferation, differentiation, and apoptosis. ${ }^{80}$ Our data show that nicotine induces STAT3 phosphorylation in VSMCs. However, inhibiting STAT3, SrcFK, and ERK phosphorylation did not reduce nicotine-induced EV release and calcification, which was consistent with decreased proliferation rate of VSMCs treated with nicotine. This data merits caution as in vitro experimental time-points models more accurately interpret acute smoking than habitual smoking, which might involve activation of different signaling pathways. ${ }^{81}$ The STAT3/SrcFK pathway was shown to be only activated during 24 hour nicotine exposure of rat VSMCs but 
not after 48 hour nicotine exposure. ${ }^{81}$ The fact that we did not see nicotine-induced changes in EV release and VSMC calcification when inhibiting STAT3 after 7 days of treatment might be explained by a transient involvement of STAT3 phosphorylation at only the initial exposure to nicotine. As a result of this, STAT3 might not necessarily participate in the mechanisms of EV release and calcification of VSMCs. In line with our results, cholesteryl ester-transfer protein inhibitor treatment of rat VSMCs showed that STAT3 phosphorylation was unaffected by oxidative stress inhibitor NAC and Nox inhibitor GKT137831, suggesting that these two pathways are independent from each other. ${ }^{82}$ With the data obtained in our study, we conclude that nicotine-mediated VMSC calcification does not depend on SrcFK/JAK-STAT3/ERK pathways.

In this study we show that nicotine affects VSMCs at least in part through binding of $\alpha 3$ and $\alpha 7 \mathrm{nAchR}$. We show that inhibition of $\alpha 3$ and $\alpha 7 \mathrm{nAchR}$ results in decreased intracellular ROS. Inhibition of $\alpha 3 \mathrm{nAchR}$ reduces nicotine-induced VSMC calcification whereas inhibition of $\alpha 7 \mathrm{nAchR}$ reduces nicotine-induced intracellular $\mathrm{Ca}^{2+}$. Indeed, others have shown that nicotine increases intracellular $\mathrm{Ca}^{2+}$ of rat airway smooth muscle cells through $\alpha 7 \mathrm{nAchR} .{ }^{83}$ However, the connection between $\alpha 7 \mathrm{nAchR}$ and Nox5-mediated oxidative stress in VSMCs has not been made before. Although a previous study has shown that $\alpha 7 \mathrm{nAchr}$ is the most abundantly expressed subunit in human $\mathrm{VSMCs}^{84}$, we did not observe a significant reduction of nicotine-induced EV secretion when inhibiting $\alpha 7 \mathrm{nAchR}$. Therefore, we conclude that other nAchRs may also play roles in VSMC phenotypic switching.

To confirm our in vitro findings, we show that carotid arteries of patients who smoked have higher Nox 5 expression levels than arteries of non-smokers. Because we did not observe Nox5 expression consistently elevated in nicotine-induced VSMCs, the elevated expression in carotid arteries could be attributed to the length and amount of cigarette that smokers were exposed to, or other chemical constituents in the cigarette which also induce oxidative stress via Nox activity. ${ }^{85}$ More interestingly, Nox5 expression positively correlates with degree of calcification in these patients. Specifically, the correlation of Nox 5 and calcification is the strongest at lower scores of calcifications. This observation may imply an involvement of Nox 5 in initiating calcification after being induced by nicotine. Once calcification is present, it induces more changes in the vasculature that lead to more calcification. ${ }^{86-89}$ While the presence of Nox 5 in the atherosclerotic plaques of human carotid arteries is $\mathrm{known}^{90-92}$, a direct association between smoking and Nox 5 expression has not been described. Amongst vascular diseases, smoking is known as one of the strongest life-style risk factors for development and calcification of abdominal aortic aneurysm (AAA). ${ }^{93-96}$ Interestingly, Nox5 expression was 
significantly increased in aortic aneurysm segments compared to matched non-dilated aortic specimens. ${ }^{97}$ Additionally, increased oxidative stress was significantly associated with smoking in the aortic aneurysm segments. ${ }^{97}$ Our in vivo data put forward Nox5 as a key mediator of vascular calcification caused by smoking.

\section{Vitamin K ameliorates effects of nicotine on VSMCs}

Given the role of oxidative stress in the pathogenesis of vascular calcification, antioxidant therapy may represent a viable therapeutic approach. We found that pre-treatment of VSMCs with vitamin K attenuates nicotine-induced intracellular ROS generation, reduces EV release, and subsequently inhibits calcification. However, we have not excluded that vitamin $\mathrm{K}$ could decrease calcification by its direct effect on $\gamma$-glutamylcarboxylation. Vitamin $\mathrm{K}$ is involved in multiple cellular processes and has important implications in cardiovascular and bone diseases. ${ }^{98}$ The primary role of vitamin $\mathrm{K}$ is to serve as a cofactor in the activation of coagulations factors and vitamin K-dependent calcification inhibitors such as matrix Glaprotein $^{99}$, however vitamin $\mathrm{K}$ also exerts antioxidative properties, as several studies have demonstrated. ${ }^{100-104}$ It has also been shown that vitamin $\mathrm{K}$ can serve as an electron donor for the plasma membrane Nox of soybean plant, which may implicate protection of plasma membranes against ROS. ${ }^{105}$ Nicotine administration in rats fed with a high-fat diet was shown to lower scavenging activity of antioxidant enzymes. ${ }^{106}$ It is therefore tempting to speculate that vitamin $\mathrm{K}$ may be a useful agent to counteract the development of nicotine-induced vascular pathologies.

Taken together, we propose a novel mechanism by which nicotine induces VSMC calcification, via a sequence of events involving a raise in intracellular $\mathrm{Ca}^{2+}$ via the $\alpha 7 \mathrm{nAchR}$, increasing ROS production by $\mathrm{Ca}^{2+}$-dependent Nox5 and increase EV release. We show that smoking is associated with increased vascular microcalcification in atherosclerotic plaques and that both smoking and degree of calcification correlated with increased Nox5 expression. Finally, we show that reducing oxidative stress using vitamin $\mathrm{K}$ ameliorates effects of nicotine on VSMCs. Nicotine is the primary agent in both cigarettes and e-cigarettes. Our findings add to the current literatures that vaping may not be a healthier choice when it comes to vascular health. Our study contributes to the understanding of how nicotine not only affects atherosclerotic plaque calcification, but possibly also other VSMC-mediated vascular diseases, such as hypertension ${ }^{107,108}$ and aortic aneurysm. ${ }^{109,110}$ 


\section{Limitation of the study}

(i) Detail characterization of the study cohort is not available. We have included all parameters we were able to access, but did not have information about further patient characteristics such as cardiovascular risk factors (e.g. family history, hypertension), laboratory values (LDL, HDL, cholesterol, triglycerides, hsCRP), and medication. (ii) The discrepancy between VSMC markers in vitro and in vivo observations could be attributed to the length and amount of cigarette that smokers were exposed to. In vivo data from vascular tissue of a smoker represents years of cigarette exposure, and possibly vascular repair and remodeling as compensation. In vitro data represents direct effect of nicotine and the immediate consequences that lead to VSMC pathology. We did not observe differences in S100A4 expression both on mRNA level in vitro and by immunohistochemistry in vivo. This is consistent with previous findings that S100A4, while associated with VSMC phenotype in certain conditions ${ }^{111}$, does not increase with increased Nox 5 activity. The tissue analysed by immunohistochemistry might represent various stages of atherosclerosis and various locations in the plaque, which we could not control for. It is possible that active synthetic differentiation occurs only at certain stages and locations of the vessel and thus any differences in expression are obscured, even though they may have been present. Additionally, the lack of correlation of S100A4 with Nox 5 expression confirms our previous findings that overexpression of Nox 5 or $\mathrm{H} 2 \mathrm{O} 2$-induced oxidative stress downregulates expression of S100A4 in VSMCs. Therefore, we cannot unequivocally conclude the nature of S100A4 regulation because of the interaction between nicotine treatment and oxidative stress. Further to that, we saw no difference in CNN1 expression in smokers vs non-smokers by immunohistochemistry, which. could be attributed to similar reasons. (iii) $\mathrm{We}$ have not investigated the involvement of other members of the Nox family in mediating nicotine-induced effects on VSMCs. However, we have previously investigated the involvement of Nox 1 and Nox4 in VSMC differentiation and calcification and found that they were not involved. ${ }^{44}$ While literature shows that Nox 2 is involved in mediated oxidative stress in VSMCs ${ }^{12,113}$, it has not been examined whether this leads to increased calcification.

\section{Funding}

This project has received funding from the European Union's Horizon 2020 research and innovation programme under the Marie Skłodowska-Curie grant agreement No 675111 and 722609. This study was partly funded by NWO ZonMw (MKMD 40-42600-98-13007) grant to $\mathrm{CR}$ and LS. 


\section{Authors' contributions}

P.P., M.B., B.W, N.S., S.H., and M.F. performed the experiments and analysed the data; P.P., M.B., M.F, and L.S. wrote the manuscript; P.P., M.B., B.W., B.M., M.F., and L.S. designed the study; F.G., S.R., K.B., F.K., N.M., E.N., E.B., M.J., C.R., B.M., M.F., and L.S. provided patient material and discussed the study; P.P., M.B., M.F., and L.S. edited the manuscript and all authors approved the final manuscript; P.P and M.B. contributed equally to this work.

\section{Acknowledgments}

We would like to thank Cecile Maassen and Peter Leenders for excellent technical support.

\section{Conflict of interest}

Dr. Schurgers is an unpaid consultant to Immunodiagnostic systems (IDS) and receives research grants from Nattopharma, Bayer, Boehringer Ingelheim and Daiichi Sankyo. Dr. Gremse is the owner of Gremse-IT GmbH.

\section{Translational Perspective}

Our findings reveal that smoking causes vascular calcification through VSMC Nox-5 mediated pro-calcific processes. We elucidate the molecular effects of nicotine on VSMC phenotype and provide novel insights into mechanisms of nicotine-induced vascular calcification. Nicotine binding to the $\mathrm{nAChR}$ results in increased intracellular calcium and secretion of extracellular vesicles, providing potential targets for pharmacological intervention. The use of vitamin $\mathrm{K} 2$, besides being a cofactor for the carboxylation of matrix Gla-protein, is an effective antioxidant ameliorating nicotine-induced oxidative stress and extracellular vesicle release, and has the potential to open new avenues for the treatment of vascular disease. 


\section{References}

1. HHS, CDC. SMOKING AND CARDIOVASCULAR DISEASE.

2. White WB. Smoking-related morbidity and mortality in the cardiovascular setting. Preventive cardiology. 2007;10(2 Suppl 1):1-4.

3. Willett WC, Green A, Stampfer MJ, Speizer FE, Colditz GA, Rosner B, Monson RR, Stason W, Hennekens CH. Relative and Absolute Excess Risks of Coronary Heart Disease among Women Who Smoke Cigarettes. New England Journal of Medicine. 1987;317(21):1303-1309.

4. McEvoy JW, Blaha MJ, Defilippis AP, Lima JAC, Bluemke DA, Gregory Hundley W, Min JK, Shaw LJ, Lloyd-Jones DM, Graham Barr R, Budoff MJ, Blumenthal RS, Nasir K. Cigarette Smoking and Cardiovascular Events: Role of Inflammation and Infclinical Atherosclerosis from the Multiethnic Study of Atherosclerosis. Arteriosclerosis, Thrombosis, and Vascular Biology. 2015;35(3):700-709.

5. Wang Y, Osborne MT, Tung B, Li M, Li Y. Imaging cardiovascular calcification. Journal of the American Heart Association. 2018;7(13).

6. Kelly-Arnold A, Maldonado N, Laudier D, Aikawa E, Cardoso L, Weinbaum S. Revised microcalcification hypothesis for fibrous cap rupture in human coronary arteries. Proceedings of the National Academy of Sciences. 2013;110(26):10741-10746.

7. Shioi A, Ikari Y. Plaque calcification during atherosclerosis progression and regression. Journal of Atherosclerosis and Thrombosis. 2018;25(4):294-303.

8. Chatrou MLL, Cleutjens JP, van der Vusse GJ, Roijers RB, Mutsaers PHA, Schurgers LJ. Intra-Section Analysis of Human Coronary Arteries Reveals a Potential Role for Micro-Calcifications in Macrophage Recruitment in the Early Stage of Atherosclerosis. PLOS ONE. 2015;10(11):e0142335.

9. Hutcheson JD, Maldonado N, Aikawa E. Small entities with large impact: Microcalcifications and atherosclerotic plaque vulnerability. Current Opinion in Lipidology. 2014;25(5):327-332.

10. Nicoll R, Henein M. Arterial calcification: A new perspective? International Journal of Cardiology. 2017;228:11-22.

11. Forsythe RO, Dweck MR, McBride OMB, Vesey AT, Semple SI, Shah ASV, Adamson PD, Wallace WA, Kaczynski J, Ho W, van Beek EJR, Gray CD, Fletcher A, Lucatelli C, Marin A, et al. 18 F-Sodium Fluoride Uptake in Abdominal Aortic Aneurysms. Journal of the American College of Cardiology. 2018;71(5):513-523.

12. Durham AL, Speer MY, Scatena M, Giachelli CM, Shanahan CM. Role of smooth muscle cells in vascular calcification: implications in atherosclerosis and arterial stiffness. Cardiovascular research. 2018;114(4):590-600.

13. Cecchettini A, Rocchiccioli S, Boccardi C, Citti L. Vascular Smooth-Muscle-Cell Activation. Proteomics Point of View. In: International Review of Cell and Molecular Biology. Vol 288. Elsevier Inc.; 2011:43-99.

14. Kapustin AN, Shanahan CM. Calcium Regulation of Vascular Smooth Muscle CellDerived Matrix Vesicles. Trends in Cardiovascular Medicine. 2012;22(5):133-137. 
15. Kapustin AN, Shanahan CM. Emerging roles for vascular smooth muscle cell exosomes in calcification and coagulation. The Journal of Physiology. 2016;594(11):2905-2914.

16. Byon CH, Javed A, Dai Q, Kappes JC, Clemens TL, Darley-Usmar VM, McDonald JM, Chen Y. Oxidative stress induces vascular calcification through modulation of the osteogenic transcription factor Runx2 by AKT signaling. The Journal of biological chemistry. 2008;283(22):15319-27.

17. Liu M, Gomez D. Smooth Muscle Cell Phenotypic Diversity. Arteriosclerosis, thrombosis, and vascular biology. 2019;39(9):1715-1723.

18. Basatemur GL, Jørgensen HF, Clarke MCH, Bennett MR, Mallat Z. Vascular smooth muscle cells in atherosclerosis. Nature Reviews Cardiology. 2019;16(12):727-744.

19. Libby P. Current concepts of the pathogenesis of the acute coronary syndromes. Circulation. 2001;104(3):365-372.

20. Hisamatsu T, Miura K, Arima H, Kadota A, Kadowaki S, Torii S, Suzuki S, Miyagawa N, Sato A, Yamazoe M, Fujiyoshi A, Ohkubo T, Yamamoto T, Murata K, Abbott RD, et al. Smoking, Smoking Cessation, and Measures of Subclinical Atherosclerosis in Multiple Vascular Beds in Japanese Men. Journal of the American Heart Association. 2016;5(9).

21. McEvoy JW, Nasir K, Defilippis AP, Lima JAC, Bluemke DA, Hundley WG, Barr RG, Budoff MJ, Szklo M, Navas-Acien A, Polak JF, Blumenthal RS, Post WS, Blaha MJ. Relationship of cigarette smoking with inflammation and subclinical vascular disease: The multi-ethnic study of atherosclerosis. Arteriosclerosis, Thrombosis, and Vascular Biology. 2015;35(4):1002-1010.

22. Kronmal RA, McClelland RL, Detrano R, Shea S, Lima JA, Cushman M, Bild DE, Burke GL. Risk factors for the progression of coronary artery calcification in asymptomatic subjects: Results from the Multi-Ethnic Study of Atherosclerosis (MESA). Circulation. 2007;115(21):2722-2730.

23. Rasmussen T, Frestad D, Køber L, Pedersen JH, Thomsen LH, Dirksen A, Kofoed KF. Development and progression of coronary artery calcification in long-term smokers: Adverse effects of continued smoking. Journal of the American College of Cardiology. 2013;62(3):255-257.

24. Benowitz NL, Burbank AD. Cardiovascular Toxicity of Nicotine: Implications for Electronic Cigarette Use. Trends in cardiovascular medicine. 2016;26(6):515.

25. Babic M, Schuchardt M, Tölle M, van der Giet M. In times of tobacco-free nicotine consumption: The influence of nicotine on vascular calcification. European Journal of Clinical Investigation. 2019;49(4):e13077.

26. Stadler N, Heeneman S, Vöö S, Stanley N, Giles GI, Gang BP, Croft KD, Mori TA, Vacata V, Daemen MJAP, Waltenberger J, Davies MJ. Reduced metal ion concentrations in atherosclerotic plaques from subjects with Type 2 diabetes mellitus. Atherosclerosis. 2012;222(2):512-518.

27. Gremse F, Stärk M, Ehling J, Menzel JR, Lammers T, Kiessling F. Imalytics preclinical: Interactive analysis of biomedical volume data. Theranostics. 2016;6(3):328-341. 
28. Chomczynski P, Sacchi N. The single-step method of RNA isolation by acid guanidinium thiocyanate-phenol-chloroform extraction: Twenty-something years on. Nature Protocols. 2006;1(2):581-585.

29. Reynolds JL, Joannides AJ, Skepper JN, Mcnair R, Schurgers LJ, Proudfoot D, JahnenDechent W, Weissberg PL, Shanahan CM. Human vascular smooth muscle cells undergo vesicle-mediated calcification in response to changes in extracellular calcium and phosphate concentrations: A potential mechanism for accelerated vascular calcification in ESRD. Journal of the American Society of Nephrology. 2004;15(11):2857-2867.

30. Kapustin AN, Chatrou MLL, Drozdov I, Zheng Y, Davidson SM, Soong D, Furmanik M, Sanchis P, De Rosales RTM, Alvarez-Hernandez D, Shroff R, Yin X, Muller K, Skepper JN, Mayr M, et al. Vascular Smooth Muscle Cell Calcification Is Mediated by Regulated Exosome Secretion. Circulation Research. 2015;116(8):1312-1323.

31. Jahnen-Dechent W, Heiss A, Schäfer C, Ketteler M. Fetuin-A regulation of calcified matrix metabolism. Circulation research. 2011;108(12):1494-509.

32. Price PA, Lim JE. The inhibition of calcium phosphate precipitation by fetuin is accompanied by the formation of a fetuin-mineral complex. Journal of Biological Chemistry. 2003;278(24):22144-22152.

33. Schinke T, Amendt C, Trindl A, Pöschke O, Müller-Esterl W, Jahnen-Dechent W. The serum protein $\alpha 2-\mathrm{HS}$ glycoprotein/fetuin inhibits apatite formation in vitro and in mineralizing calvaria cells. A possible role in mineralization and calcium homeostasis. Journal of Biological Chemistry. 1996;271(34):20789-20796.

34. Rochette CN, Rosenfeldt S, Heiss A, Narayanan T, Ballauff M, Jahnen-Dechent W. A Shielding Topology Stabilizes the Early Stage Protein-Mineral Complexes of Fetuin-A and Calcium Phosphate: A Time-Resolved Small-Angle X-ray Study. ChemBioChem. 2009;10(4):735-740.

35. Smith ER, Ford ML, Tomlinson LA, Rajkumar C, Mcmahon LP, Holt SG. Phosphorylated fetuin-A-containing calciprotein particles are associated with aortic stiffness and a procalcific milieu in patients with pre-dialysis CKD. Nephrol Dial Transplant. 2012;27:1957-1966.

36. Smith ER, Hewitson TD, Cai MMX, Aghagolzadeh P, Bachtler M, Pasch A, Holt SG. A novel fluorescent probe-based flow cytometric assay for mineral-containing nanoparticles in serum. Scientific Reports. 2017;7(1):1-17.

37. Vermes I, Haanen C, Steffens-Nakken H, Reutellingsperger C. A novel assay for apoptosis Flow cytometric detection of phosphatidylserine expression on early apoptotic cells using fluorescein labelled Annexin V. Journal of Immunological Methods. 1995;184(1):39-51.

38. Hirooka N, Kadowaki T, Sekikawa A, Ueshima H, Choo J, Miura K, Okamura T, Fujiyoshi A, Kadowaki S, Kadota A, Nakamura Y, Maegawa H, Kashiwagi A, Masaki $\mathrm{K}$, Sutton-Tyrrell K, et al. Influence of cigarette smoking on coronary artery and aortic calcium among random samples from populations of middle-aged Japanese and Korean men. Journal of epidemiology and community health. 2013;67(2):119-24. 
39. Bakhshian Nik A, Hutcheson JD, Aikawa E. Extracellular Vesicles As Mediators of Cardiovascular Calcification. Frontiers in Cardiovascular Medicine. 2017;4:78.

40. Khademi F, Totonchi H, Mohammadi N, Zare R, Zal F. Nicotine-Induced Oxidative Stress in Human Primary Endometrial Cells. International Journal of Toxicology. 2019;38(3):202-208.

41. Barr J, Sharma CS, Sarkar S, Wise K, Dong L, Periyakaruppan A, Ramesh GT. Nicotine induces oxidative stress and activates nuclear transcription factor kappa B in rat mesencephalic cells. Molecular and Cellular Biochemistry. 2007;297(1-2):93-99.

42. Liu C-C, Yeh H-I. Nicotine: A Double-Edged Sword in Atherosclerotic Disease. Acta Cardiologica Sinica. 2014;30(2):108-13.

43. Sirker A, Zhang M, Shah AM. NADPH oxidases in cardiovascular disease: Insights from in vivo models and clinical studies. Basic Research in Cardiology. 2011;106(5):735-747.

44. Furmanik M, Chatrou M, van Gorp RH, Akbulut A, Willems B, Schmidt HH, van Eys G, Bochaton-Piallat ML, Proudfoot D, Biessen E Al, Hedin U, Matic L, Mees B, Shanahan CM, Reutelingsperger $\mathrm{C}$, et al. Reactive Oxygen-Forming Nox5 Links Vascular Smooth Muscle Cell Phenotypic Switching and Extracellular VesicleMediated Vascular Calcification. Circulation research. 2020;127(7):911-927.

45. Mackay CE, Knock GA. Control of vascular smooth muscle function by Src-family kinases and reactive oxygen species in health and disease. Journal of Physiology. 2015;593(17):3815-3828.

46. Colquhoun LM, Patrick JW. Pharmacology of Neuronal Nicotinic Acetylcholine Receptor Subtypes. Advances in Pharmacology. 1997;39(C):191-220.

47. Nelson ME, Lindstrom J. Single channel properties of human $\alpha 3$ AChRs: Impact of $\beta 2$, $\beta 4$ and $\alpha 5$ subunits. Journal of Physiology. 1999;516(3):657-678.

48. Jöckel KH, Lehmann N, Jaeger BR, Moebus S, Möhlenkamp S, Schmermund A, Dragano N, Stang A, Grönemeyer D, Seibel R, Mann K, Volbracht L, Siegrist J, Erbel R. Smoking cessation and subclinical atherosclerosis-Results from the Heinz Nixdorf Recall Study. Atherosclerosis. 2009;203(1):221-227.

49. Xu X, Hua Y, Wang L, Hou W, Xia M. Correlation between risk factors of cerebrovascular disease and calcified plaque characteristics in patients with atherosclerotic severe carotid stenosis. Neurological Research. 2020;42(1):83-89.

50. Ehara S, Kobayashi Y, Yoshiyama M, Shimada K, Shimada Y, Fukuda D, Nakamura Y, Yamashita H, Yamagishi H, Takeuchi K, Naruko T, Haze K, Becker AE, Yoshikawa J, Ueda M. Spotty Calcification Typifies the Culprit Plaque in Patients With Acute Myocardial Infarction. Circulation. 2004;110(22):3424-3429.

51. Yun YS, Choi SJ, Lee JY, Kim YS, Yoon SA, Park SC, Shin OR, Jang EJ, Kim YO. Impact of arterial microcalcification of the vascular access on cardiovascular mortality in hemodialysis patients. Hemodialysis International. 2014;18(1):54-61.

52. Jia H, Abtahian F, Aguirre AD, Lee S, Chia S, Lowe H, Kato K, Yonetsu T, Vergallo $\mathrm{R}, \mathrm{Hu} \mathrm{S}$, Tian J, Lee H, Park SJ, Jang YS, Raffel OC, et al. In vivo diagnosis of plaque 
erosion and calcified nodule in patients with acute coronary syndrome by intravascular optical coherence tomography. Journal of the American College of Cardiology. 2013;62(19):1748-1758.

53. Kumagai S, Amano T, Takashima H, Waseda K, Kurita A, Ando H, Maeda K, Ito Y, Ishii H, Hayashi M, Yoshikawa D, Suzuki S, Tanaka A, Matsubara T, Muroharab T. Impact of cigarette smoking on coronary plaque composition. Coronary Artery Disease. 2015;26(1):60-65.

54. Ambrose JA, Barua RS. The pathophysiology of cigarette smoking and cardiovascular disease: An update. Journal of the American College of Cardiology. 2004;43(10):17311737.

55. Wang Z, Liu B, Zhu J, Wang D, Wang Y. Nicotine-mediated autophagy of vascular smooth muscle cell accelerates atherosclerosis via $\mathrm{nAChRs/ROS/NF- \kappa B}$ signaling pathway. Atherosclerosis. 2019;284:1-10.

56. Wang Y, Zhang F, Yang W, Xue S. Nicotine Induces Pro-inflammatory Response in Aortic Vascular Smooth Muscle Cells Through a NFkB/Osteopontin Amplification Loop-Dependent Pathway. Inflammation. 2012;35(1):342-349.

57. Yoshiyama S, Chen Z, Okagaki T, Kohama K, Nasu-Kawaharada R, Izumi T, Ohshima N, Nagai T, Nakamura A. Nicotine exposure alters human vascular smooth muscle cell phenotype from a contractile to a synthetic type. Atherosclerosis. 2014;237(2):464-470.

58. Rensen SSM, Doevendans PAFM, van Eys GJJM. Regulation and characteristics of vascular smooth muscle cell phenotypic diversity. Netherlands heart journal : monthly journal of the Netherlands Society of Cardiology and the Netherlands Heart Foundation. 2007;15(3):100-8.

59. Lacolley P, Regnault V, Nicoletti A, Li Z, Michel JB. The vascular smooth muscle cell in arterial pathology: A cell that can take on multiple roles. Cardiovascular Research. 2012;95(2):194-204.

60. Shanahan CM, Weissberg PL. Smooth muscle cell heterogeneity: Patterns of gene expression in vascular smooth muscle cells in vitro and in vivo. Arteriosclerosis, Thrombosis, and Vascular Biology. 1998;18(3):333-338.

61. Gomez D, Owens GK. Smooth muscle cell phenotypic switching in atherosclerosis. Cardiovascular Research. 2012;95(2):156-164.

62. Mody N, Parhami F, Sarafian TA, Demer LL. Oxidative stress modulates osteoblastic differentiation of vascular and bone cells. Free Radical Biology and Medicine. 2001;31(4):509-519.

63. Mayhan WG, Sharpe GM. Superoxide dismutase restores endothelium-dependent arteriolar dilatation during acute infusion of nicotine. Journal of Applied Physiology. 1998;85(4):1292-1298.

64. Xiao D, Huang X, Yang S, Zhang L. Antenatal nicotine induces heightened oxidative stress and vascular dysfunction in rat offspring. British Journal of Pharmacology. 2011;164(5):1400-1409.

65. Li J, Liu S, Cao G, Sun Y, Chen W, Dong F, Xu J, Zhang C, Zhang W. Nicotine induces 
endothelial dysfunction and promotes atherosclerosis via GTPCH1. Journal of Cellular and Molecular Medicine. 2018;22(11):5406-5417.

66. Starke RM, Thompson JW, Ali MS, Pascale CL, Martinez Lege A, Ding D, Chalouhi N, Hasan DM, Jabbour P, Owens GK, Toborek M, Hare JM, Dumont AS. Cigarette Smoke Initiates Oxidative Stress-Induced Cellular Phenotypic Modulation Leading to Cerebral Aneurysm Pathogenesis. Arteriosclerosis, Thrombosis, and Vascular Biology. 2018;38(3):610-621.

67. Schurgers LJ, Akbulut AC, Kaczor DM, Halder M, Koenen RR, Kramann R. Initiation and Propagation of Vascular Calcification Is Regulated by a Concert of Platelet- and Smooth Muscle Cell-Derived Extracellular Vesicles. Frontiers in Cardiovascular Medicine. 2018;5:36.

68. Aikawa E. Extracellular vesicles in cardiovascular disease: Focus on vascular calcification. Journal of Physiology. 2016;594(11):2877-2880.

69. Hutcheson JD, Goettsch C, Rogers MA, Aikawa E. Revisiting cardiovascular calcification: A multifaceted disease requiring a multidisciplinary approach. Seminars in Cell and Developmental Biology. 2015;46:68-77.

70. Xu L, Deng X. Tobacco-specific nitrosamine 4-(methylnitrosamino)-1-(3-pyridyl)-1butanone induces phosphorylation of $\mu$ - and $\mathrm{m}$-calpain in association with increased secretion, cell migration, and invasion. Journal of Biological Chemistry. 2004;279(51):53683-53690.

71. Fujita Y, Araya J, Ito S, Kobayashi K, Kosaka N, Yoshioka Y, Kadota T, Hara H, Kuwano K, Ochiya T. Suppression of autophagy by extracellular vesicles promotes myofibroblast differentiation in COPD pathogenesis. Journal of Extracellular Vesicles. $2015 ; 4: 28388$.

72. Wu F, Yin Z, Yang L, Fan J, Xu J, Jin Y, Yu J, Zhang D, Yang G. Smoking Induced Extracellular Vesicles Release and Their Distinct Properties in Non-Small Cell Lung Cancer. Journal of Cancer. 2019;10(15):3435-3443.

73. Haque S, Sinha N, Ranjit S, Midde NM, Kashanchi F, Kumar S. Monocyte-derived exosomes upon exposure to cigarette smoke condensate alter their characteristics and show protective effect against cytotoxicity and HIV-1 replication. Scientific Reports. 2017;7(1):1-14.

74. Burtenshaw D, Hakimjavadi R, Redmond EM, Cahill PA. Nox, reactive oxygen species and regulation of vascular cell fate. Antioxidants. 2017;6(4):90.

75. Jaimes EA, DeMaster EG, Tian R-X, Raij L. Stable Compounds of Cigarette Smoke Induce Endothelial Superoxide Anion Production via NADPH Oxidase Activation. Arteriosclerosis, Thrombosis, and Vascular Biology. 2004;24(6):1031-1036.

76. Steffen Y, Vuillaume G, Stolle K, Roewer K, Lietz M, Schueller J, Lebrun S, Wallerath T. Cigarette smoke and LDL cooperate in reducing nitric oxide bioavailability in endothelial cells via effects on both eNOS and NADPH oxidase. Nitric Oxide. 2012;27(3):176-184.

77. Marques P, Collado A, Escudero P, Rius C, González C, Servera E, Piqueras L, Sanz 
MJ. Cigarette smoke increases endothelial CXCL16-leukocyte CXCR6 adhesion in vitro and in vivo. Potential consequences in chronic obstructive pulmonary disease. Frontiers in Immunology. 2017;8:1766.

78. Hotston MR, Jeremy JY, Bloor J, Koupparis A, Persad R, Shukla N. Sildenafil inhibits the up-regulation of phosphodiesterase type 5 elicited with nicotine and tumour necrosis factor-? in cavernosal vascular smooth muscle cells: mediation by superoxide. $B J U$ International. 2007;99(3):612-618.

79. Jagnandan D, Church JE, Banfi B, Stuehr DJ, Marrero MB, Fulton DJR. Novel mechanism of activation of NADPH oxidase 5: Calcium sensitization via phosphorylation. Journal of Biological Chemistry. 2007;282(9):6494-6507.

80. Kiu H, Nicholson SE. Biology and significance of the JAK/STAT signalling pathways. Growth Factors. 2012;30(2):88-106.

81. Wada T, Naito M, Kenmochi H, Tsuneki H, Sasaoka T. Chronic nicotine exposure enhances insulin-induced mitogenic signaling via up-regulation of $\alpha 7$ nicotinic receptors in isolated rat aortic smooth muscle cells. Endocrinology. 2007;148(2):790-799.

82. Rios FJ, Lopes RA, Neves KB, Camargo LL, Montezano AC, Touyz RM. Off-target vascular effects of cholesteryl ester transfer protein inhibitors involve redox-sensitive and signal transducer and activator of transcription 3-dependent pathwayss. Journal of Pharmacology and Experimental Therapeutics. 2016;357(2):415-422.

83. Jiang Y, Dai A, Zhou Y, Peng G, Hu G, Li B, Sham JSK, Ran P. Nicotine elevated intracellular $\mathrm{Ca} 2+$ in rat airway smooth muscle cells via activating and up-regulating a7-nicotinic acetylcholine receptor. Cellular Physiology and Biochemistry. 2014;33(2):389-401.

84. Nakamura A. Effects of Nicotine Contained in Tobacco Mainstream Smoke on Vascular Smooth Muscle Cells. In: Atherosclerosis - Yesterday, Today and Tomorrow. InTech; 2018.

85. Mai Y, Higashi T, Terada K, Hatate C, Nepal P, Horiguchi M, Harada T, Miwa S, Horinouchi T. Nicotine- and tar-free cigarette smoke extract induces cell injury via intracellular Ca2+-dependent subtype-specific protein kinase $\mathrm{C}$ activation. Journal of Pharmacological Sciences. 2012;120(4):310-314.

86. Ewence AE, Bootman M, Roderick HL, Skepper JN, McCarthy G, Epple M, Neumann M, Shanahan CM, Proudfoot D. Calcium Phosphate Crystals Induce Cell Death in Human Vascular Smooth Muscle Cells. Circulation Research. 2008;103(5):e28-34.

87. Sage AP, Lu J, Tintut Y, Demer LL. Hyperphosphatemia-induced nanocrystals upregulate the expression of bone morphogenetic protein-2 and osteopontin genes in mouse smooth muscle cells in vitro. Kidney International. 2011;79(4):414-422.

88. Lei Y, Sinha A, Nosoudi N, Grover A, Vyavahare N. Hydroxyapatite and calcified elastin induce osteoblast-like differentiation in rat aortic smooth muscle cells. Experimental Cell Research. 2014;323(1):198-208.

89. Nadra I, Boccaccini AR, Philippidis P, Whelan LC, McCarthy GM, Haskard DO, Landis RC. Effect of particle size on hydroxyapatite crystal-induced tumor necrosis factor alpha 
secretion by macrophages. Atherosclerosis. 2008;196(1):98-105.

90. Guzik TJ, Chen W, Gongora MC, Guzik B, Lob HE, Mangalat D, Hoch N, Dikalov S, Rudzinski P, Kapelak B, Sadowski J, Harrison DG. Calcium-Dependent NOX5 Nicotinamide Adenine Dinucleotide Phosphate Oxidase Contributes to Vascular Oxidative Stress in Human Coronary Artery Disease. Journal of the American College of Cardiology. 2008;52(22):1803-1809.

91. Manea A, Manea SA, Gan AM, Constantin A, Fenyo IM, Raicu M, Muresian H, Simionescu M. Human monocytes and macrophages express NADPH oxidase 5; A potential source of reactive oxygen species in atherosclerosis. Biochemical and Biophysical Research Communications. 2015;461(1):172-179.

92. Vlad M-L, Manea S-A, Lazar A-G, Raicu M, Muresian H, Simionescu M, Manea A. Histone Acetyltransferase-Dependent Pathways Mediate Upregulation of NADPH Oxidase 5 in Human Macrophages under Inflammatory Conditions: A Potential Mechanism of Reactive Oxygen Species Overproduction in Atherosclerosis. Oxidative Medicine and Cellular Longevity. 2019;2019:3201062.

93. Kent KC, Zwolak RM, Egorova NN, Riles TS, Manganaro A, Moskowitz AJ, Gelijns $\mathrm{AC}$, Greco G. Analysis of risk factors for abdominal aortic aneurysm in a cohort of more than 3 million individuals. Journal of Vascular Surgery. 2010;52(3):539-548.

94. Norman PE, Curci JA. Understanding the effects of tobacco smoke on the pathogenesis of aortic aneurysm. Arteriosclerosis, thrombosis, and vascular biology. 2013;33(7):1473-7.

95. Aune D, Schlesinger S, Norat T, Riboli E. Tobacco smoking and the risk of abdominal aortic aneurysm: a systematic review and meta-analysis of prospective studies. Scientific reports. 2018;8(1):14786.

96. Jung JG, Wu LT, Kim JS, Kim E Du, Yoon SJ. Relationship between smoking and abdominal aorta calcification on computed tomography. Korean Journal of Family Medicine. 2019;40(4):248-253.

97. Guzik B, Sagan A, Ludew D, Mrowiecki W, Chwała M, Bujak-Gizycka B, Filip G, Grudzien G, Kapelak B, Żmudka K, Mrowiecki T, Sadowski J, Korbut R, Guzik TJ. Mechanisms of oxidative stress in human aortic aneurysms - Association with clinical risk factors for atherosclerosis and disease severity. International Journal of Cardiology. 2013;168(3):2389-2396.

98. Halder M, Petsophonsakul P, Akbulut AC, Pavlic A, Bohan F, Anderson E, Maresz K, Kramann R, Schurgers L. Vitamin K: Double bonds beyond coagulation insights into differences between vitamin $\mathrm{K} 1$ and $\mathrm{K} 2$ in health and disease. International Journal of Molecular Sciences. 2019;20(4):896.

99. Schurgers LJ, Uitto J, Reutelingsperger CP. Vitamin K-dependent carboxylation of matrix Gla-protein: a crucial switch to control ectopic mineralization. Trends in Molecular Medicine. 2013;19(4):217-226.

100. Mukai K, Morimoto H, Kikuchi S, Nagaoka S. Kinetic study of free-radical-scavenging action of biological hydroquinones (reduced forms of ubiquinone, vitamin $\mathrm{K}$ and tocopherol quinone) in solution. Biochimica et Biophysica Acta (BBA) - General 
Subjects. 1993;1157(2):313-317.

101. Vervoort LM, Ronden JE, Thijssen HH. The potent antioxidant activity of the vitamin K cycle in microsomal lipid peroxidation. Biochemical pharmacology. 1997;54(8):8716.

102. Li J, Lin JC, Wang H, Peterson JW, Furie BC, Furie B, Booth SL, Volpe JJ, Rosenberg PA. Novel role of vitamin $\mathrm{k}$ in preventing oxidative injury to developing oligodendrocytes and neurons. The Journal of neuroscience : the official journal of the Society for Neuroscience. 2003;23(13):5816-26.

103. Li J, Wang H, Rosenberg PA. Vitamin K prevents oxidative cell death by inhibiting activation of 12-lipoxygenase in developing oligodendrocytes. Journal of Neuroscience Research. 2009;87(9):1997-2005.

104. Dai L, Schurgers LJ, Shiels PG, Stenvinkel P. Early vascular ageing in chronic kidney disease: impact of inflammation, vitamin K, senescence and genomic damage. Neprol Dial Transplant. 2020;35(Suppl 2):ii31-ii37.

105. Bridge A, Barr R, Morré DJ. The plasma membrane NADH oxidase of soybean has vitamin $\mathrm{K}(1)$ hydroquinone oxidase activity. Biochimica et biophysica acta. 2000;1463(2):448-58.

106. Ashakumary L, Vijayammal PL. Effect of Nicotine on Antioxidant Defence Mechanisms in Rats Fed a High-Fat Diet. Pharmacology. 1996;52(3):153-158.

107. Touyz RM, Alves-Lopes R, Rios FJ, Camargo LL, Anagnostopoulou A, Arner A, Montezano AC. Vascular smooth muscle contraction in hypertension. Cardiovascular Research. 2018;114(4):529-539.

108. Jaminon A, Reesink K, Kroon A, Schurgers L. The role of vascular smooth muscle cells in arterial remodeling: Focus on calcification-related processes. International Journal of Molecular Sciences. 2019;20(22):5694.

109. Kuivaniemi H, Ryer EJ, Elmore JR, Tromp G. Understanding the pathogenesis of abdominal aortic aneurysms. Expert Review of Cardiovascular Therapy. 2015;13(9):975-987.

110. Petsophonsakul P, Furmanik M, Forsythe R, Dweck M, Schurink GW, Natour E, Reutelingsperger C, Jacobs M, Mees B, Schurgers L. Role of Vascular Smooth Muscle Cell Phenotypic Switching and Calcification in Aortic Aneurysm Formation. Arteriosclerosis, Thrombosis, and Vascular Biology. 2019;39(7):1351-1368.

111. Chaabane C, Heizmann CW, Bochaton-Piallat ML. Extracellular S100A4 induces smooth muscle cell phenotypic transition mediated by RAGE. Biochimica et Biophysica Acta - Molecular Cell Research. 2015;1853(9):2144-2157.

112. Konior A, Schramm A, Czesnikiewicz-Guzik M, Guzik TJ. NADPH oxidases in vascular pathology. Antioxidants and Redox Signaling. 2014;20(17):2794-2814.

113. Briones AM, Tabet F, Callera GE, Montezano AC, Yogi A, He Y, Quinn MT, Salaices M, Touyz RM. Differential regulation of Nox1, Nox2 and Nox4 in vascular smooth muscle cells from WKY and SHR. Journal of the American Society of Hypertension. 2011;5(3):137-153. 


\section{Supplemental Figures and Table}

A

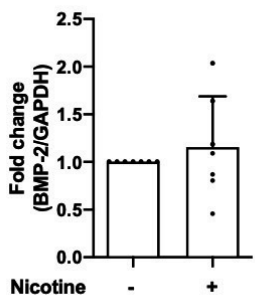

E

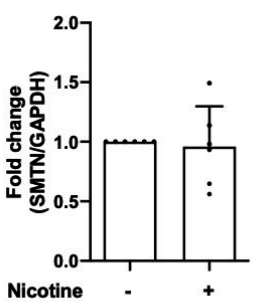

B

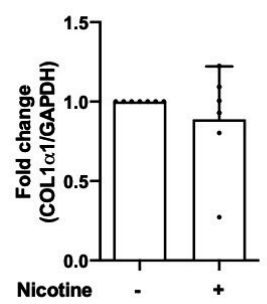

F

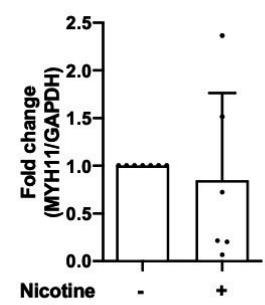

J

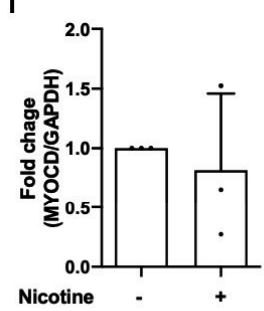

C

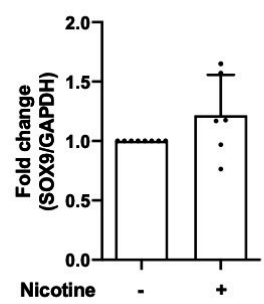

G

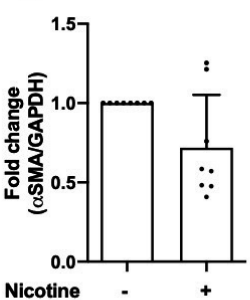

$\mathbf{K}$

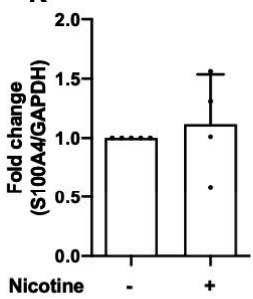

D

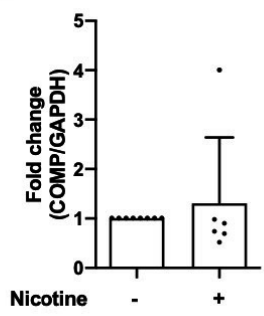

H

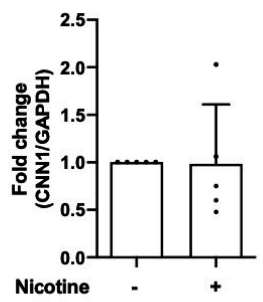

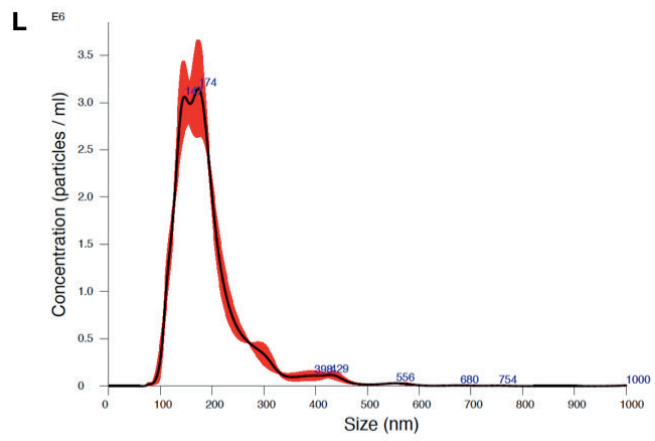

Supplemental Figure 1. Phenotype-related gene expression in VSMCs in response to nicotine. $\mathrm{qPCR}$ analysis of (A-D) osteogenic (BMP-2, COL1 $\alpha 1$, SOX9, COMP), (E-I) contractile (SMTN, MYH11, $\alpha$ SMA, CNN1, MYOCD), and (J-K) differentiation/synthetic (KLF4 and S100A) gene expression in VSMCs treated with nicotine (1 mM, 7 days in DMEM with 20\% FBS). (L) Nanoparticle tracking analysis shows size distribution of the EVs in VSMC culture supernatants. Statistical significance was tested with one sampletest (A-K). All graphs show data from $n \geq 3$ independent experiments. 
A

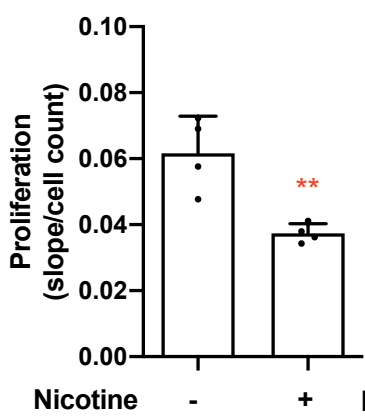

B

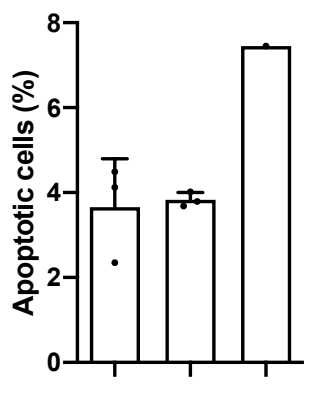

C

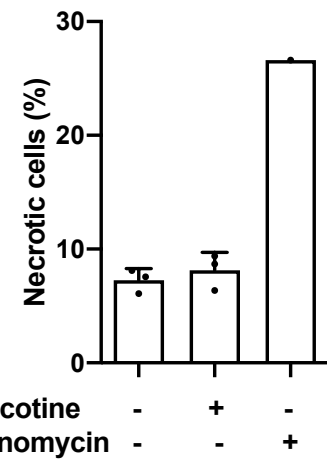

Supplemental Figure 2. Effect of nicotine on VSMC proliferation and viability. (A) VSMCs treated with nicotine $(1 \mathrm{mM})$ proliferated at a decreased rate over 5-7 days in DMEM with 20\% FBS. Proliferation rate of VSMCs was measured in vitro using xCELLigence. Statistical significance was tested with t-test. (B-C) Nicotine at $1 \mathrm{mM}$ concentration and timepoint used for all experiments did not affect viability of VSMCs. Ionomycin was added 15 minutes before measurement at $1 \mu \mathrm{M}$ concentration. Statistical significance was tested with t-test. 
A

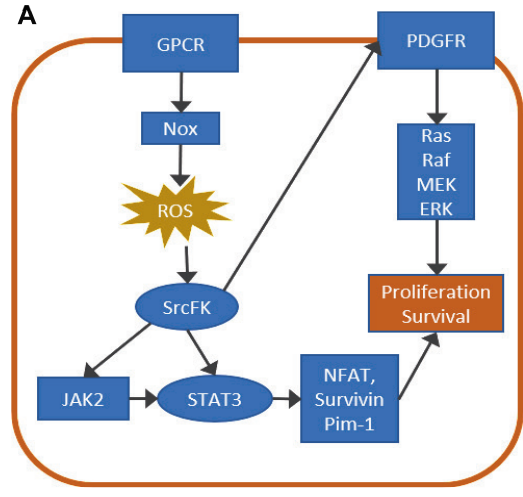

D

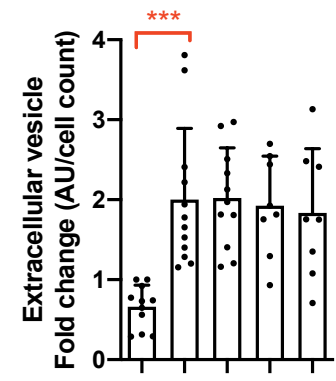

Nicotine

Stattic

GSK2656157 - - + +

SU6656 - - . - +
B

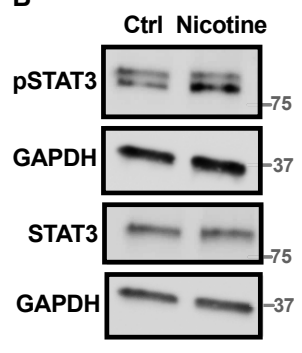

C

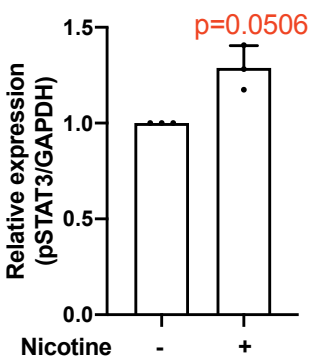

Supplemental Figure 3. Effect of nicotine on SrcFK/JAK-STAT3/ERK pathways in VSMCs. (A) An alternative mechanism of nicotine-induced VSMC effects through the SrcFK/JAK-STAT3/ERK pathways. (B-C) Western blotting and quantification of pSTAT3 and STAT3 in VSMCs treated with nicotine (1 mM in DMEM with $20 \%$ FBS, 15 minutes). Statistical significance was tested with one sample-test. (D) VSMCs treated with nicotine ( $1 \mathrm{mM}, 24$ hours) with or without pre-treatment with Stattic $(1 \mu \mathrm{M}, 1$ hour), SU6656 ( $2 \mu \mathrm{M}, 1$ hour), GSK2656157 ( $2 \mu \mathrm{M}, 1$ hour) prior to nicotine stimulation in DMEM with $0.5 \% \mathrm{FBS}$. EVs were captured with anti-CD63-coulped beads, detected with a fluorescently labelled anti-CD81 antibody and quantified using flow cytometry. Statistical significance was tested with ANOVA. (E) VSMC calcification was induced with calcification medium $\left(2.5 \% \mathrm{FBS}, 3.6 \mathrm{mM} \mathrm{Ca}^{2+}\right)$ in the presence of nicotine $(1 \mathrm{mM})$, with or without pre-treatment with Stattic ( $1 \mu \mathrm{M}, 1$ hour), SU6656 ( $2 \mu \mathrm{M}, 1$ hour), GSK2656157 ( $2 \mu \mathrm{M}, 1$ hour) prior nicotine stimulation for 3 to 5 days. Calcification was detected using Fetuin A-Alexa-546. Statistical significance was tested with ANOVA. All graphs show data from $n \geq 3$ independent experiments. 
A

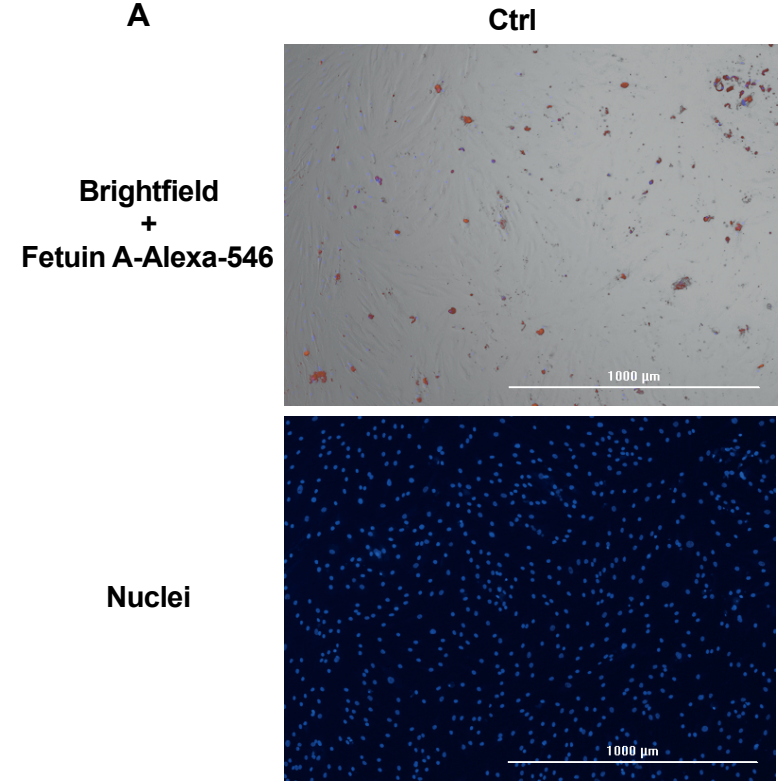

Nicotine
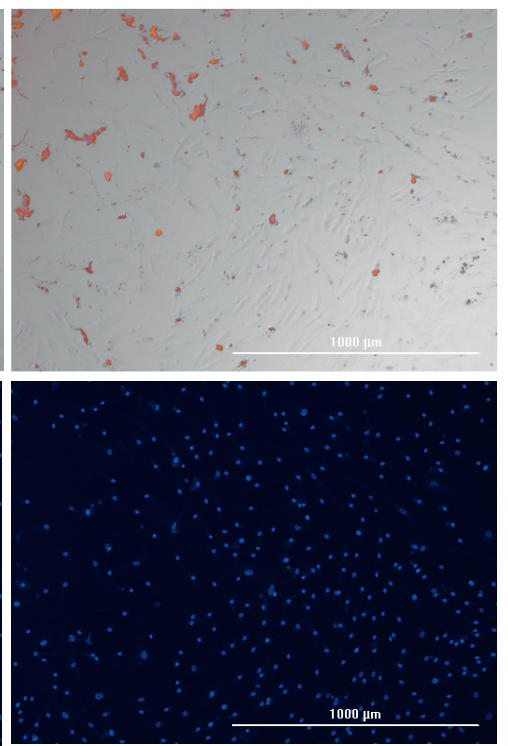

Supplemental Figure 4. Effect of nicotine on VSMC calcification. (A) Representative images of VMSC calcification. VSMC calcification was induced with calcification medium (DMEM with 2.5\% FBS and 3.6 $\mathrm{mM} \mathrm{Ca}{ }^{2+}$ ) in the presence of vehicle control $(\mathrm{EtOH})$ or $1 \mathrm{mM}$ nicotine. Nicotine increases VSMC calcification within 3-5 days. Calcification was detected using Fetuin A-Alexa-546. VSMC nuclei were stained with Hoechst. Fluorescence signal were analysed and normalized to the number of cells. 


\section{Supplemental table 1. List of primers used for qPCR.}

\begin{tabular}{|c|c|c|}
\hline Primer & Forward & Reverse \\
\hline$\alpha$-SMA & 5' AAG TAC CCA ATA GAA CAC GGC ATC 3' & 5' CCA GGT CCA GAC GCA TGA T 3' \\
\hline $\operatorname{Sm} 22 \mathrm{a}$ & 5' TTG AAG GCA AAG ACA TGG CAG CAG 3' & 5' TCC ACG GTA GTG CCC ATC ATT CTT 3' \\
\hline SMTN & 5' GAG TAT GAG GAG CGC AAG C 3' & 5' AAC CTC CCA GCC AAG GTG 3' \\
\hline MYH11 & 5' AGA AGC CAG GGA GAA GGA AAC CAA 3' & 5' TGG AGC TGA CCA GGT CTT CCA TTT 3' \\
\hline MyoCD & 5' TGC AGC TCC AAA TCC TCA GC 3' & 5' TCA GTG GCG TTG AAG AAG AGT T 3' \\
\hline CNN1 & 5' GCT GGA GAA CAT CGG CAA CTT CAT CAA G 3' & 5' GCT CCT GCT TCT CTG CGT ACT TCA CTC 3' \\
\hline KLF4 & 5' AGA GGA GCC CAA GCCAAA 3' & 5' AGC CGT CCC AGT CAC AGT 3' \\
\hline S100A4 & 5' TCA TCT GTC CTT TTC CCC AAG A 3' & 5' AGT TCA AGC TCA ACA AGT CAG AAC TAA 3' \\
\hline NOX5 & 5' TCT TCG AGG CTG CGG ACA AG 3' & 5' GCC TGG AGC GCA AAG TTT ACT ACA T 3' \\
\hline NOX4 & 5' CCC AGT GTG TCC GCG TTA GA 3' & 5' ACG GTT TCC AGT CAT CCA GCA 3' \\
\hline BMP-2 & 5' GCA GCT TCC ACC ACG AAG AAT C 3' & 5' TCT CCT GTG TCT GCT CCC GA 3' \\
\hline Runx2 & 5' TTA ATC TCC GCA GGT CAC TAC CAG 3' & 5' CGG GTG GTC AGC GAT GAT CT 3' \\
\hline Osx & 5' TGC TTG AGG AGG AAG TTC AC 3' & 5' AGG TCA CTG CCC ACA GAG TA 3' \\
\hline $\mathrm{OCN}$ & 5' GGC AGC GAG GTA GTG AAG AG 3' & 5' CGA TAG GCC TCC TGA AAG C 3' \\
\hline OPN & 5' TTG CAG CCT TCT CAG CCA A 3' & 5' GGA GGC AAA AGC AAA TCA CTG 3' \\
\hline BSP & 5' AGT TTC GCA GAC CTG ACA TCC AGT 3' & 5' TTC ATA ACT GTC CTT CCC ACG GCT 3' \\
\hline Collal & 5' TGT GGC CCA GAA GAA CTG GTA CAT 3' & 5' ACT GGA ATC CAT CGG TCA TGC TCT 3' \\
\hline SOX9 & 5' AGC TCT GGA GAC TTC TGA ACG AGA 3' & 5' ACT TGT AAT CCG GGT GGT CCT TCT 3' \\
\hline COMP & 5' GCA GAT GGA GCA AAC GTA TTG GCA 3' & 5' AGG ACT TCT TGT CCT TCC AAC CCA 3' \\
\hline SMPD3 & 5' GCC TAT CAC TGT TAC CCC AAC 3' & 5' GAC GAT TCT TTG GTC CTG AGG 3' \\
\hline CD63 & 5' CGG TGG AAG GAG GAA TGA AAT GT 3' & 5' GAC ACC CAC GGC AAT CAG T 3' \\
\hline GAPDH & 5' AAC GGA TTT GGT CGT ATT GGG C 3' & 5' CTT GAC GGT GCC ATG GAA TTT G 3' \\
\hline
\end{tabular}




\section{Supplemental Methods}

\section{cDNA synthesis and real-time PCR}

VSMCs were incubated with nicotine $(150 \mathrm{nM}, 1 \mu \mathrm{M}$ or $1 \mathrm{mM})$ or ethanol for 7 days in culture medium. After incubation, total RNA was extracted using a phenol-chloroform method as previously described by Chomczynski et al. ${ }^{28}$ RNA concentration was quantified spectrophotometrically at $260 \mathrm{~nm}$. $250 \mathrm{ng}$ of total RNA was reverse transcribed into cDNA using Moloney Murine Leukemia Virus Reverse Transcriptase (M-MLV RT), RNAse Out, dNTPs, dithiothreitol (all Invitrogen), and an oligo(dT) adapter (Eurogentec) for 1 hour at $37^{\circ} \mathrm{C}$. Gene expression levels were quantified by real-time quantitative PCR (qPCR) on a LightCycler 480 (Roche Applied Science). Amplification reactions were carried out in a volume of $10 \mu 1$ including 100ng of total cDNA, $5 \mu 1$ QuantiTect SYBR Green PCR Kit (Qiagen) and $0.5 \mu \mathrm{M}$ of each primer (Supplemental Table 1.) An initial denaturation step $\left(15\right.$ minutes at $95^{\circ} \mathrm{C}$ ) was followed by 50 cycles of amplification (denaturation: 15 seconds at $95^{\circ} \mathrm{C}$, annealing: 30 seconds at $57^{\circ} \mathrm{C}$, extension: 45 seconds at $72^{\circ} \mathrm{C}$ ). The specificity of amplification products was controlled by melting curve genotyping. Fluorescence curves were analyzed with LinRegPCR software and relative quantification by plotting N0 ratios. All samples were assayed in triplicate.

\section{Western blotting}

VSMCs were lysed in RIPA lysis buffer (ThermoFisher Scientific) with MS-SAFE (Sigma). Protein concentrations were determined using DC protein assay kit (Bio-Rad) and lysates were separated on Any kD Mini-PROTEAN TGX Precast Protein Gels (BioRad). Samples were transferred to a nitrocellulose membrane (BioRad) and incubated overnight with anti-calponin1 (1:2000, Abcam, ab46794), anti- $\alpha$ SMA (1:2000, Dako, M0851), anti-p-MLC (1:500, Cell Signalling, 3675S), anti-Nox4 (1:1000, Abcam, ab133303), anti-Nox5 (1:500, Abcam, ab191010) anti-GAPDH (1:10000, Milipore, MAB374), anti-STAT3 (1:2000, Cell Signalling, 49045), anti-pSTAT3 (1:1000, Cell Signalling, 91345). Protein was then detected using HRPconjugated secondary antibodies (anti-mouse: p0447, Dako; anti-rabbit: 7074S, Cell Signalling) and visualized by enhanced chemiluminescence (Pierce ECL Western Blotting Substrate, ThermoFisher Scientific).

\section{Calcification detection}

Cells were seeded into 48 -well plates at 15000 cells/well. The next day, media were replaced with calcification medium (DMEM, 2.5\% FBS, 1\% PS and $3.6 \mathrm{mM}$ or $5.4 \mathrm{mM} \mathrm{Ca}^{2+}$ ) with 
nicotine for 3 to 5 days. The lower concentration of FBS in the vitro model of VSMC calcification is similar to what has been used in past studies. ${ }^{29,30} \mathrm{Cells}$ were preincubated with inhibitors one hour prior to nicotine stimulation. Calcification was quantified using either of the following methods; 1.Cresolphtalein method (Randox, London, United Kingdom) and normalized to protein content determined by BCA assay (Thermo Scientific, Bleiswijk, the Netherlands), 2.Calcification was detected using fluorescence probe (Fetuin A-Alexa-546, 3 $\mu \mathrm{g} / \mathrm{ml}$ in calcification medium). VSMC nuclei were stained with Hoechst 33342 (Thermo Fisher). The fluorescence signal was analysed with Cytation ${ }^{\mathrm{TM}} 3$ (Biotek) (Supplemental Figure 4) and normalized to the number of cells. Fetuin A is a potent inhibitor of ectopic mineralization and calcification. ${ }^{31,32}$ Monomeric form of fetuin A has a high affinity to small clusters of calcium and phosphate and binds the mineral surface without influencing formation of mineral nuclei. ${ }^{31,33,34}$ Fetuin A has been used as a surrogate marker for mineral containing particles and calcifcation. ${ }^{35,36}$

\section{Quantification of extracellular vesicle release}

Cells were seeded in 48-well plates at 15000 cells/well and incubated with nicotine for 24 hours. Exosomes were quantified using a bead-capture assay. ${ }^{30}$ Anti-human CD63 antibody (BD Bioscience, 556019) was immobilized on aldehyde-sulphate functionalized beads (Invitrogen). Human primary VSMC culture media was incubated with anti-CD63-coated beads on a shaker overnight at $4{ }^{\circ} \mathrm{C}$. VSMC nuclei were stained with Hoechst 33342 (Thermo Fisher) and counted using a Cytation ${ }^{\mathrm{TM}} 3$ (Biotek). Beads were washed and incubated with anti-CD81-APC antibodies (BD Bioscience, 551112) for $1 \mathrm{~h}$ at room temperature. Then beads were washed with PBS with 2\% BSA and analyzed by flow cytometry (Accuri C6, BD). Arbitrary units (AU) were calculated as mean fluorescence unit times percentage of positive beads and normalized to the number of cells.

\section{Nanoparticle Tracking Analysis}

VSMC culture supernatant was collected and centrifuged at $4400 \mathrm{~g}$ for 15 minutes, and 13000 g for 2 minutes at $4{ }^{\circ} \mathrm{C}$ to remove cells and apoptotic bodies, respectively. Suspension of extracellular vesicles was loaded into the sample chamber of an NS300 (Nanosight, Amesbury, UK) and three videos of 60 seconds were recorded of each sample. Samples were analyzed using basic control setting (shutter speed 50 millisecond, camera gains 280-560). Data analysis was performed with NTA 2.1 software (Nanosight). Data are presented as the average and standard deviation of the video recording. 


\section{Oxidative stress measurement}

Cells were seeded in 96-well black plates at 8000 cells/well and stimulated with $1 \mathrm{mM}$ nicotine at times of measurement. Inhibitors were preincubated 1 hour. Subsequently, VSMCs were stimulated with nicotine for 40 minutes. Intracellular reactive oxygen species were measured using cell permeant reagent 2',7'-dichlorofluorescin diacetate (DCFDA), a fluorogenic dye that measures hydroxyl, peroxyl and other reactive oxygen species (ROS) activity within the cell. The fluorescence intensity was detected with Cytation ${ }^{\mathrm{TM}} 3$ (Biotek) for $40 \mathrm{~min}$ and analyzed by calculating area under the curve (AUC) and normalized to the number of cells.

\section{Intracellular $\mathrm{Ca}^{2+}$ assay}

Cells were seeded in 96-well plates at 8000 cells/well. The next day, growth medium were replaced with medium (DMEM, 20\% FBS, 1\% PS) supplemented with $5 \mu \mathrm{M}$ Fluo-4-AM (Invitrogen \# F14201), $0.4 \mathrm{mg} / \mathrm{ml}$ Pluronic, and Hoechst for 30 minutes at $37^{\circ} \mathrm{C}$. Cells were washed twice with PBS and replaced with Krebs-Ringer phosphate glucose (KRPG) buffer supplemented with green quencher (Cell Signalling \#12388) and stimulus (nicotine 10mM, abungarotoxin $10 \mu \mathrm{M}$ ). Positive control contained $3.6 \mathrm{mM} \mathrm{CaCl}_{2}$ and $500 \mu \mathrm{M}$ Ionomycin. Intracellular $\mathrm{Ca}^{2+}$ was detected and quantified with Cytation ${ }^{\mathrm{TM}} 3$ (Biotek) and normalized to the number of cells.

\section{Proliferation assay}

To measure the proliferation rate of VSMCs, we used an in vitro xCELLigence RTCA (realtime cell analysis) platform. Cells were seeded into 96-well electronic microtiter plates (EPlate ${ }^{\circledR)}$ at 2000 cells/well in growth medium and observed over 5-7 days. Adhesion of cells to the gold microelectrodes in the wells impedes the flow of electric current between electrodes and impedance value is plotted as a unitless parameter (Cell Index) over course of time. The rate of cell growth was determined by calculating the slope of the line curve between two given time points.

\section{Cell death assay}

VSMCs were plated into a $12-w e l l$ plate, 30000 cells/well. The next day they were treated with $1 \mathrm{mM}$ nicotine in DMEM with 20\% FBS for 7 days. After that cells were trypsinised and pelleted together with cells from the culture supernatant, in order to include dead cells. Cells were then resuspended in binding buffer with $0.3 \mathrm{ng} / \mu 1$ AnnexinA5-FITC, ${ }^{37}$ and $3 \mathrm{ng} / \mu \mathrm{l}$ propidium iodide (Sigma). After 15 min cells were analyzed using flow cytometry (Accuri C6, $\mathrm{BD})$. 


\section{Immunohistochemistry}

Sequential $4 \mu \mathrm{m}$ paraffin sections of human carotid artery lesions (15 smokers and 15 nonsmokers analysed using a $\mu \mathrm{CT}$, as described above) were cut and used for immunohistochemical staining as previously described ${ }^{8}$, using the following primary antibodies: Nox5 (Sc-67006, Santa Cruz, 1:500), calponin (1:200, Abcam, ab46794), S100A4 (1:100, Bioconnect, LS-B2520), HRP conjugated secondary antibodies (anti-mouse, Dako, P0447; anti-rabbit, Dako, P0217, both at 1:250) and DAB or Nova-RED substrate (Vector Labs, Amsterdam, the Netherlands). Sections were counterstained with haematoxylin (Klinipath, Duiven, the Netherlands) and mounted in entellan (Merck, Amsterdam, the Netherlands). Pictures were taken with a Leica DM2000 widefield microscope (Leica Microsystems). The protein expression in the stained tissue sections was quantified using scores from 0 to 5 for intima, media and plaque. The 3 scores for each vessel sample were summed and these values were used for analysis. The scoring was carried out blinded. 


\section{Chapter 6}

\section{Vitamin K inhibits vascular smooth muscle cell induced calcification via reduced oxidative stress and extracellular vesicle secretion}

RH. van Gorp ${ }^{1}$, P Petsophonsakul ${ }^{1}$, AM Jaminon ${ }^{1}$, P Leenders $^{2}$, W Jahnen-Dechent ${ }^{3}$, CP Reutelingsperger $^{1}$, LJ Schurgers ${ }^{1}$.

In preparation

1. Department of Biochemistry, Cardiovascular Research Institute Maastricht, Maastricht University, Maastricht, The Netherlands

2. Department of Pharmacology-Toxicology, Cardiovascular Research Institute Maastricht, Maastricht University, Maastricht, The Netherlands

3. Department of Biomedical Engineering, RWTH Aachen University, Germany 


\begin{abstract}
Introduction: Vascular calcification is a strong predictor of cardiovascular outcome. Vascular calcification is in part mediated via loss of vitamin $\mathrm{K}$ dependent calcification inhibitor matrix Gla protein (MGP). Vitamin K supplementation has been shown to protect development of medial calcification and thus provides a promising intervention potential. However, the effect of vitamin $\mathrm{K}$ on intimal calcification remains unknown. Therefore, we questioned whether vitamin $\mathrm{K}$ supplementation holds progression of atherosclerotic plaque calcification.

Method: Female Apoe $^{-/-}$mice were placed on western type diet (WTD) or WTD supplemented with warfarin (Warfarin) for 18 weeks. Additionally, after 6 weeks of initial warfarin supplementation diet was substituted to WTD without (Ctrl) or with vitamin K2 (MK7). Aortic arches were used to assess effects of vitamin $\mathrm{K}$ on atherosclerotic plaque development and calcification by (immuno)histochemical analyses. Moreover, in vitro effects of warfarin and MK7 on vascular smooth muscle cells (VSMC) were determined.
\end{abstract}

Results: Warfarin induced local vitamin $\mathrm{K}$ deficiency as shown by significant elevated vascular uncarboxylated MGP, which was accompanied by significantly increased intimal atherosclerotic plaque size and calcification compared to WTD. Substituting warfarin to Ctrl or MK7 significantly attenuated atherosclerotic calcification. Moreover, switching to MK7 significantly reduced plaque size and oxidative stress compared to continuing warfarin, while increasing collagen content of atherosclerotic plaques compared to Ctrl. Exogenous injected fetuin-A-alexa488, a fluorescent calcification binding probe, showed significant reduced atherosclerotic plaque uptake after MK7 compared to warfarin and Ctrl. In vitro, MK7 reduced and attenuated warfarin induced VSMC oxidative stress and extracellular vesicle release and subsequent calcification.

Conclusion: VKA induces vitamin $\mathrm{K}$ deficiency and aggravates atherosclerosis and calcification. Stopping VKA treatment resulted in less atherosclerosis and calcification. Switching to MK7 supplementation reduced atherosclerotic plaque progression and improved markers of plaque stability. The beneficial effects of restoring vitamin $\mathrm{K}$ status in the vessel wall are probably mediated by direct effects on VSMC. Our data support clinical trials testing the hypothesis that vitamin $\mathrm{K}$ treatment can hold progression of atherosclerosis and vascular calcification. 


\section{Introduction}

Vascular calcification is associated with increased risk of all-cause cardiovascular mortality (1). Coronary artery calcification (CAC) develops with atherosclerosis and is measured to predict cardiovascular events (2). In an observational study of 25,253 asymptomatic patients, a CAC score higher than 1,000 was correlated with a $16 \%$ lower 10 year survival rate, even after the adjustments for risk factors, such as age, hypercholesterolemia, diabetes, smoking, hypertension, and a family history of premature coronary heart disease (3). Additionally, annual increase of vascular calcification predicts cardiovascular events $(4,5)$. Location, size and activity of vascular calcification determine to worsening cardiovascular outcome. Micro- and metabolic active calcification increase plaque vulnerability and thus risk on myocardial infarction and stroke (6).

While initially thought of as a passive process, vascular calcification is now accepted to be highly regulated by vascular smooth muscle cells (VSMC) and calcification inhibitory proteins. Vitamin $\mathrm{K}$ antagonist (VKA), used as antithrombotic agent, is associated with increased vascular calcification (7). VKA induce vascular calcification in part by loss of vitamin K-dependent calcification inhibitor matrix Gla protein (MGP) (8). The function of MGP was highlighted in MGP deficient mice, which developed severe vascular calcification leading to death by ruptured vessels within 6 weeks of birth (9). In vivo mutagenesis experiments showed that the calcification inhibitory function of MGP requires the Gla-residues (10), which are formed with the aid of vitamin $\mathrm{K}$ and thus inhibited by VKA. Elevated uncarboxylated MGP (ucMGP) is localized around areas of vascular calcification, suggesting lack of inhibition (11). Also increased circulating levels of inactive MGP have been shown to correlate with vascular calcification $(12,13)$ and cardiovascular mortality $(14,15)$.

An extensive list of potential medications that address vascular calcification has been compiled (16). However, most of these have only been studied in preclinical models, lack clinical research or have serious side effects. Of all enlisted drugs, vitamin $\mathrm{K}$ seem to have great potential considering that it is safe and cost-effective for inhibiting vascular calcification. MGP requires vitamin K unequivocally for its activity. Indeed, high vitamin K supplementation has been shown to stabilize or inhibit medial calcification in pre-clinical models of VKAinduced calcification $(8,17)$. Data from epidemiological studies have pointed out an important role of vitamin $\mathrm{K}$ as a potentially protective factor for cardiovascular health. People with the highest intake of food rich in vitamin $\mathrm{K} 2$ had a significantly reduces cardiovascular risk and vascular calcification (18-20). 
Increasing dietary vitamin $\mathrm{K}$ intake or oral vitamin $\mathrm{K}$ supplementation is relatively easy and cost effective and thus it is intriguing to speculate about a favorable risk-benefit ratio. Vitamin K supplementation appears to be safe and the WHO has set no upper tolerance level for vitamin $\mathrm{K}$ intake (21). Indeed, vitamin $\mathrm{K}$ has been shown to hold progression of vascular (22) and valvular (23) calcification. Vitamin K2 subtype menaquinone-7 (MK7) has been shown to dose-dependently reduce inactive MGP concentrations $(24,25)$. Currently, several clinical trials are testing the hypothesis whether MK7 supplementation holds progression of CAC (VitaK-CAC (NCT01002157) and BASIK2 (NCT02917525)). Here, we studied the effect of vitamin K (MK7) supplementation on atherosclerotic plaque development and calcification.

\title{
Materials and methods
}

\begin{abstract}
Animals
All animal studies were performed under an approved protocol by the ethics committee for animal experiments of Maastricht University. Twelve-week-old female C57BL6 Apoe $^{-/-}$mice were purchased from Charles River (Den Bosch, The Netherlands) and housed in climatecontrolled spaces under 12-hour day/night cycle with ad libitum access to food and water. All mice were fed an irradiated (0.9Mrad) vitamin K-deficient Western Type Diet (WTD: 0.25\% cholesterol and 15\% cocoa butter, derived from Altromin, Germany). WTD was supplemented with in corn oil dissolved vitamin K1 ( $5 \mu \mathrm{g} / \mathrm{g}$; Merck KGaA, Darmstadt, Germany) for control, warfarin (3 mg/g warfarin, Merck KGaA, Darmstadt, Germany) and vitamin K1 (1.5 mg/g) for VKA treatment or vitamin K2 (MK7; $100 \mu \mathrm{g} / \mathrm{g}$, kindly supplied by Nattopharma, Oslo, Norway) for vitamin K supplementation. Vitamin K1, antagonises the effect of warfarin in liver, yet has little to no effect in extrahepatic tissue (26). Therefore, vitamin K1 is coadministered with warfarin to prevent bleedings, yet introducing vitamin K-deficiency in the vasculature (27).

Mice were randomly assigned to receive WTD without (WTD) or with warfarin (Warfarin) for 18 weeks. After 6 weeks of warfarin diet, part of the animals was placed on WTD (Ctrl) or WTD supplemented with MK7 (MK7) for another 12 weeks of treatment (Figure 1A). Mice that received warfarin were intraperitoneally injected with fetuin-A-Alexa488 24 hours before sacrificing.
\end{abstract}

After treatment periods, mice were sacrificed and blood was collected via the portal vein in $105 \mathrm{mM}$ trisodium citrate and plasma aliquots were frozen at $-80^{\circ} \mathrm{C}$ until analysis. Next, the 
vasculature was washed with a sterile binding buffer (40mM Hepes, $150 \mathrm{mM} \mathrm{NaCl}, 5 \mathrm{mM} \mathrm{KCl}$, $1 \mathrm{mM} \mathrm{MgCl}_{2}$ and $2.5 \mathrm{mM} \mathrm{CaCl}_{2}, \mathrm{pH} 7.3$ ) via the left ventricle. The aortic arch was dissected and fixated overnight in $1 \%(\mathrm{v} / \mathrm{v})$ HEPES-buffered formaldehyde containing $150 \mathrm{mM}$ saline at $4^{\circ} \mathrm{C}$ before being embedded in paraffin. Sections were cut at $4 \mu \mathrm{m}$ thickness.

\section{Blood analysis}

Total plasma cholesterol was assessed with the Synchron LX20 (Beckman Coulter, Brea, USA). Vitamin K concentration in plasma was determined using HPLC as described previously (28).

\section{Histochemical analysis}

Plaque size was determined by hematoxyline and eosine (HE) stain and analysed using ImageJ software. Plaques were analysed for calcification (alizarin Red S), collagen (picro Sirius red), necrotic core (Toluidine blue) and number of elastin breaks (Elastica von Gieson). Elastin breaks found in the medial layer beneath the atherosclerotic plaque were scored using a scoring system ranging from 0 to 4 ; 0 , no breaks; 1 , one-three breaks; 2, four-six breaks; 3, seven-nine breaks and $4,9>$ breaks.

Immunohistochemistry was used to further examine plaque phenotype. Plaques were assessed for uncarboxylated matrix Gla protein (ucMGP, 1:400; IDS, Boldon, UK), carboxylated MGP (cMGP, 1:400; IDS, Boldon, UK), oxidative stress (8-hydroxyguanisine 1:300; Meridian Life Science, Tennessee, USA), alpha-SMA (1:400, Merck KGaA, Darmstadt, Germany), MAC3 (1:50, Biosciences, San Jose, United States) and to visualize injected fetuin-A-488 (antiAlexa488 1:5000; Invitrogen, California, USA). HRP conjugated secondary antibodies were visualized with Nova-RED substrate (Vector Labs, Amsterdam, the Netherlands). 2D analysis quantification was performed using Leica Application Suite X (Leica Microsystems, Wetzlar, Germany).

\section{Vascular smooth muscle cells}

Human primary vascular smooth muscle cells (VSMC) were obtained from human aortic tissue explants obtained from males and females aged between 18 and 65 years of age. VSMCs were cultured in DMEM medium (Gibco, Thermo Fisher Scientific Inc, Paisley, Scotland, UK) supplemented with $20 \%$ fetal bovine serum (FBS), $100 \mathrm{U} / \mathrm{mL}$ penicillin and $100 \mu \mathrm{g} / \mathrm{mL}$ streptomycin. Cells were used between passage 5 and 10 . 


\section{qPCR}

RNA extraction, cDNA synthesis and qPCR were performed as described previously (29). The following primers were used: Nrf2 (F) 5'CAGCGACGGAAAGAGTATGA3', Nrf2 (R) 5'TGGGCAACCTGGGAGTAG3',GAPDH(F) 5'AACGGATTTGGTCGTATTGGGC 3', GAPDH (R) 5'CTTGACGGTGCCATGGAATTTG 3'.

\section{In vitro calcification measurement}

VSMC were plated in a 24 well plates to adhere overnight in culture medium. Next, VSMC were placed in calcifying medium consisting of DMEM supplemented with 2.5\% FBS, 100 $\mathrm{U} / \mathrm{mL}$ penicillin, and $100 \mu \mathrm{g} / \mathrm{mL}$ streptomycin in the presence of an additional $1.8 \mathrm{mmol} / \mathrm{L}$ calcium in addition of stimulus. Calcium deposits were assessed by O-cresolphthalein and calcium content was normalized for protein content (micro BSA protein kit, Thermo Fisher Scientific Inc, Paisley, Scotland, UK).

\section{Extracellular oxidative stress in VSMC}

To determine oxidative stress, we measured extracellular ROS using Amplex Red, which detects hydrogen peroxide or peroxidase activity. VSMC were seeded in a 96-well which were allowed to adhere overnight. After 24 hours of treatment, cells were washed twice and placed in the presence of stimulus in Krebs-Ringer Phosphate Glucose buffer (KRPG; 145mM NaCl, $5.7 \mathrm{mM}$ sodium phosphate, $4.86 \mathrm{mM} \mathrm{KCl}, 0.54 \mathrm{mM} \mathrm{CaCl} 2,1.22 \mathrm{mM} \mathrm{MgSO} 4,5.5 \mathrm{mM}$ glucose, pH 7.4) mixed 1:1 with Amplex Red mixture (50 $\mu \mathrm{M}$ Amplex Red (Thermo Fisher Scientific Inc, Waltham, MA, USA) and 0.1 U/ml HRP. Fluorescence (excitation wavelength 544nm; emission wavelength 590nm) was measured using the Cytation 3 Cell Imaging Multi-Mode Reader (BioTek Instruments Inc., Winooski, VT, USA). To normalize for cell number, total protein content was measured using a micro BCA protein assay kit from Thermo Scientific (Thermo Fisher Scientific Inc, Waltham, MA, USA) according to the manufacturer's instructions.

\section{Intracellular VSMC hydrogen peroxide}

To identify intracellular ROS, we used the cell permeable fluoregenic substrate 2,7 dichlorofluorescein diacetate (DCFDA, Merck KGaA, Darmstadt, Germany) which is oxidized to 2,7 -dichlorofluorescein in the presence of reactive oxidants. 
VSMC were seeded in a 96-well plate and left to adhere overnight. Next, culture medium was replaced by Krebs-Ringer Phosphate Glucose buffer (KRPG; 145mM NaCl, 5.7mM sodium phosphate, $4.86 \mathrm{mM} \mathrm{KCl}, 0.54 \mathrm{mM} \mathrm{CaCl} 2,1.22 \mathrm{mM} \mathrm{MgSO} 4,5.5 \mathrm{mM}$ glucose, $\mathrm{pH} 7.4)$ in the presence of $20 \mu \mathrm{M}$ DCFDA for $60 \mathrm{~min}$ in the dark at $37^{\circ} \mathrm{C}$ and $5 \% \mathrm{CO}$. After washing, cells were incubated with stimulus in combination with $1 \mu \mathrm{g} / \mathrm{mL}$ Hoechst and fluorescence was measured (Excitation 485, Emission 529) with a Cytation 3 Cell Imaging Multi-Mode Reader (BioTek Instruments Inc., Winooski, VT, USA) for a total of 30 minutes. Fluorescence intensity was corrected for background and normalized to cell count.

\section{Extracellular vesicle quantification}

VSMC cells were seeded in a 12-well plate and allowed to adhere overnight. Next, VSMC were placed in low serum conditions $(0.5 \%$ FBS $)$ with stimulus for 24 hours, after which medium was collected. Medium was centrifuged at $3000 \mathrm{x}$ g for 15 minutes and incubated with CD-63 (BD Bioscience, San Jose, United States) coupled beads overnight. After washing with PBS-2\% BSA, beads were incubated with a secondary antibody anti-CD-81-APC (1:50, BD Bioscience, San Jose, United States) and incubated for 60 minutes in the dark. After washing, beads were placed in Hepes buffer with additional $2.5 \mathrm{mM} \mathrm{Ca}^{2+}$ and $250 \mathrm{ng} / \mathrm{mL}$ Alexa-647 labelled AnnexinA5. Hereafter, extracellular vesicles were detected by flow cytometry (Accuri C6, BD bioscience, San Jose, United States). Exosome secretion is expressed as arbitrary units, which were calculated as follow: median fluorescence was multiplied by percentage positive beads and this was normalized for cell number, as described before (29).

\section{Statistical analyses}

In vivo data are presented as median with interquartile range or stated otherwise. All in vitro data were obtained in three or more independent experiments in triplicates or more wells and data are expressed as mean with SD. Data were analysed using Mann-Whitney T-test or Kruskal-Wallis One-way ANOVA as indicated using PRISM software (GraphPad 8.3.0, San Diego, US). Values of $\mathrm{p}<0.05$ were considered statistically significant. 


\section{Results}

Mice were fed a western type diet (WTD) or WTD supplemented with warfarin (Warfarin) for 18 weeks. Additionally, mice were fed a warfarin diet for 6 weeks, after which the diet was substituted to WTD supplemented without (Ctrl) or with MK7 supplementation (MK7) (Figure 1A, schematic experimental overview). Weight and cholesterol levels were unaltered between groups after 18 weeks of treatment (Table 1). MK7 supplementation was confirmed in plasma of mice. Here, mice receiving MK7 supplementation showed a mean of $69 \mu \mathrm{g} / \mathrm{L}$ MK7 and 2 $\mu \mathrm{g} / \mathrm{L}$ of MK4 levels in blood plasma, while both forms of vitamin K2 were absent in treatment without MK7 supplementation (Table 1).

Table 1. Model validation.

\begin{tabular}{|c|c|c|c|c|}
\hline & WTD & Warfarin & Ctrl & MK7 \\
\hline Weight $(\mathbf{g})$ & $23.82 \pm 1.6$ & $22.5 \pm 1.93$ & $23.87 \pm 0.99$ & $23.28 \pm 1.81$ \\
\hline $\begin{array}{c}\text { Cholesterol } \\
(\mathbf{m M})\end{array}$ & $21.27 \pm 3.34$ & $20.56 \pm 4.26$ & $19.23 \pm 4.75$ & $19.91 \pm 5.84$ \\
\hline MK7 $(\boldsymbol{\mu g} / \mathbf{L})$ & - & - & - & $69 \pm 11$ \\
\hline MK4 $(\boldsymbol{\mu g} / \mathbf{L})$ & - & - & - & $2 \pm 0.8$ \\
\hline
\end{tabular}

\section{Vitamin $\mathrm{K}$ metabolism in atherogenesis and calcification.}

First, we tested effect of long term warfarin treatment on the vasculature. After 18 weeks of treatment, calcification was significantly increased in warfarin treated animals compared to WTD control (median of $66 \%$ and $21 \%$ of plaque area, respectively; Figure 1B). Moreover, 18 weeks of warfarin treatment resulted in a significant increase in plaque size compared to WTD (median of $0.40 \mathrm{~mm}^{2}$ vs $0.57 \mathrm{~mm}^{2} ; \mathrm{p}<0.05$; Figure $1 \mathrm{C}$ ).

Next, we treated animals for 6 weeks with warfarin, after which mice were split and put on control or MK7 diet for another 12 weeks (Figure 1A). In animals treated for 6 weeks with warfarin, no calcification could be detected histochemically using Alizarin Red S stain (data not shown). Substitution to Ctrl and MK7 showed significant reduction in amount of calcification compared to warfarin and same calcification area as compared to WTD $(\mathrm{p}<0.05$; Figure 1B). Switching from warfarin diet to $\mathrm{Ctrl}$ or MK7 resulted in a plaque size similar to WTD $\left(0.38 \mathrm{~mm}^{2}\right.$ plaque size $)$, with a significant attenuation in plaque size of MK7 compared to warfarin $\left(0.33 \mathrm{~mm}^{2}\right.$ plaque size; Figure $\left.1 \mathrm{C}\right)$. 


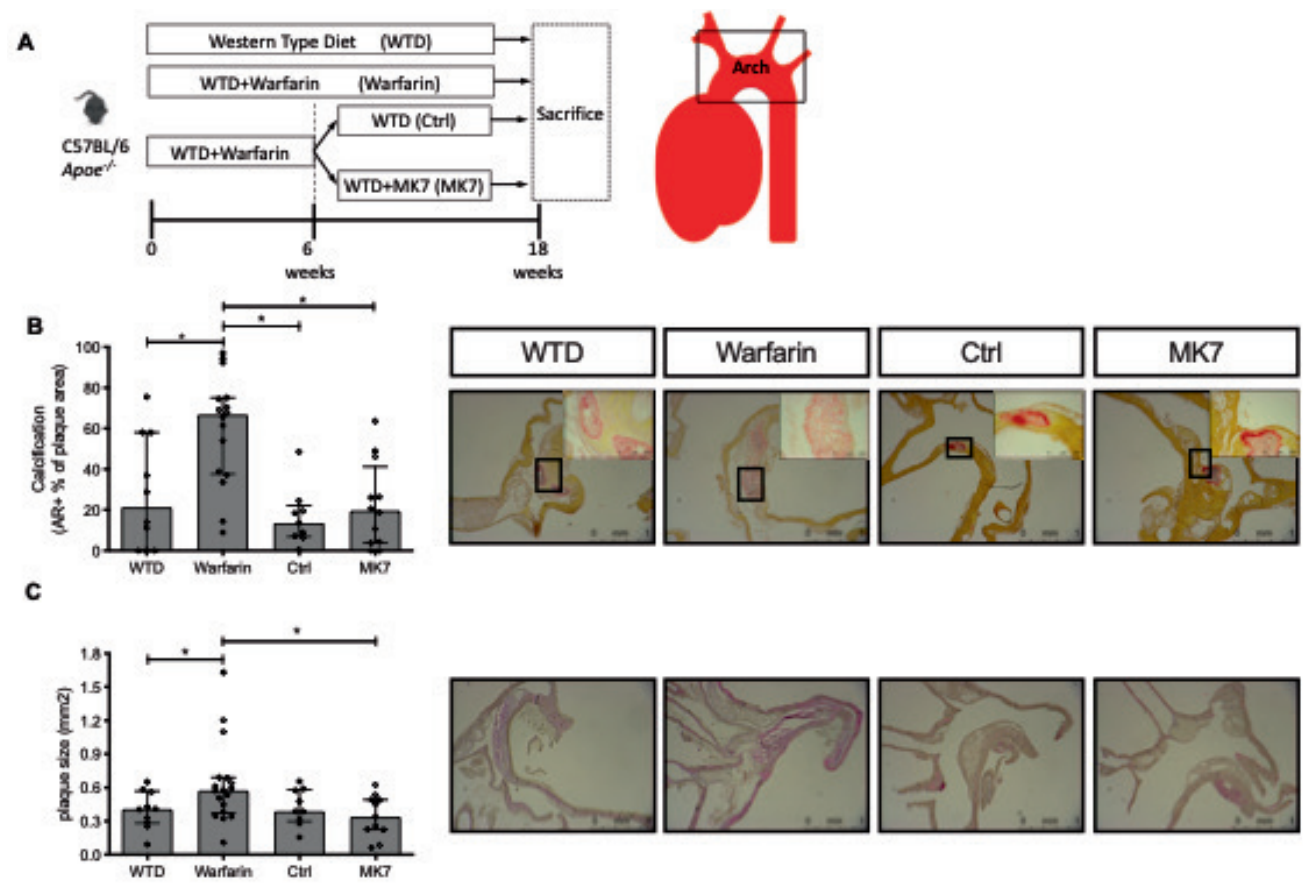

Figure 1. Warfarin increase atherosclerotic calcification and progression after 18 weeks of treatment. A) Schematic overview of animal experiment. B) Warfarin treatment significantly increased calcification compared to WTD treatment. Switching from warfarin to Ctrl or MK7 supplementation significantly reduced calcification to similar levels are WTD. C) Plaque size $\left(\mathrm{mm}^{2}\right)$ was significantly increased after warfarin treatment compared to control. MK7 supplementation significantly reduced plaque size compared to warfarin. Data is presented as median with interquartile range. Statistical significance was assed using Kruskal-Wallis test, $* \mathrm{p}<0.05, * *$.

To test for local vitamin K deficiency, uncarboxylated MGP (ucMGP) in the atherosclerotic plaque was determined. Warfarin treatment for 18 weeks significantly increased ucMGP positivity in the atherosclerotic plaque compared to WTD ( $p<0.001$; Figure 2A). Although switching from warfarin to either control or MK7 reduced ucMGP, no significant difference was found (Figure 2A). In contrast, MK7 significantly increased cMGP in atherosclerotic plaque compared to $\mathrm{Ctrl}(2.9 \%$ vs $0.5 \%$ of plaque area; Figure $2 \mathrm{~B})$. No significant difference in cMGP was observed between warfarin and WTD or Ctrl. 
A
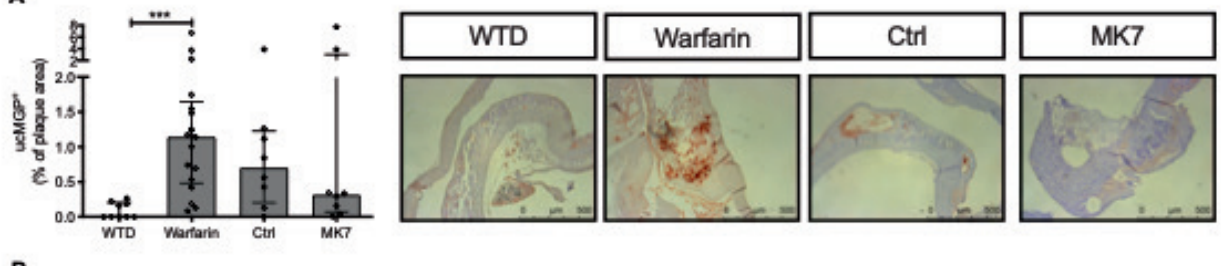

B
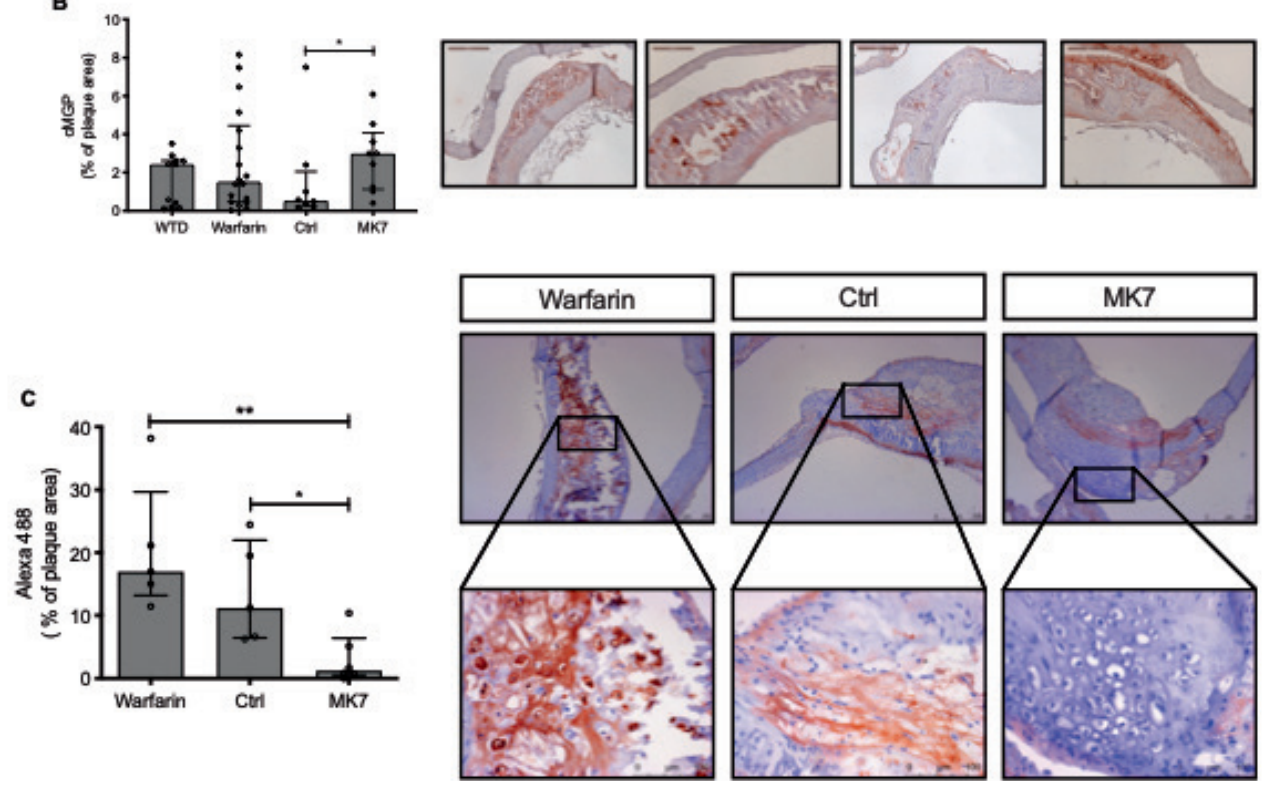

Figure 2. Vitamin K metabolism in atherosclerotic plaques. A) 18 weeks of warfarin treatment significantly increased uncarobxylated MGP (ucMGP) presence compared to control. No significant difference was found in ucMGP presence after switching to Ctrl or MK7 in atherosclerotic plaques. B) MK7 supplementation significantly increased presence of carboxylated MGP (cMGP) in atherosclerotic plaques compared to Ctrl. C) Visualization of intraperitoneal injected fetuin-A-Alexa488 demonstrated a significant reduction after MK7 supplementation compared to warfarin and Ctrl treatment. Data is presented as median with interquartile range. Statistical significance was assed using Kruskal-Wallis test, ${ }^{*} \mathrm{p}<0.05,{ }^{* *} \mathrm{p}<0.01,{ }^{* * *} \mathrm{p}<0.001$.

Warfarin treated animals received an intraperitoneal injection of fluorescently labelled fetuin-A-Alexa488, 24 hours before sacrifice. Fetuin-A is a calcification inhibitor with strong affinity for calcium-crystals (30). Moreover, fetuin-A is internalized and secreted by VSMC vesicles $(29,31)$. Fetuin-A-Alexa488 was detected by an HRP-labelled antibody directed against the fluorophore Alexa488. Visualization revealed high presence of fetuin-A-Alexa488 in atherosclerotic plaques after warfarin treatment $(20.5 \%$ of plaque volume; Figure $2 \mathrm{C})$. Switching to MK7 showed a significant reduction of fetuin-A presence in atherosclerotic plaques $(1.2 \%$ of plaque volume $)$ compared to warfarin $(\mathrm{p}<0.01)$ and $\mathrm{Ctrl}(11.2 \%$ of plaque 
volume; $\mathrm{p}<0.05$; Figure $2 \mathrm{C}$ ). Fetuin-A was also present in the medial and adventitial layer, however this was similar between all treatment.

\section{MK7 promotes plaque stability}

MK7 substitution significantly reduced oxidative stress (as measured by positive 8-OHdG stain) in the plaque compared to 18 weeks of warfarin treatment $\left(23 \% \mathrm{vs} 57 \%\right.$ of $8-\mathrm{OHdG}^{+}$ cells for MK7 and warfarin respectively; Figure 3A). No difference was observed in intraplaque oxidative stress between WTD and warfarin treated groups after 6 weeks of treatment (data not shown), but was significantly increased in warfarin treated mice after 18 weeks of treatment (Figure 3A). Additionally, elastin breaks in the medial layer under the plaque and collagen content of the plaque were measured as markers of plaque vulnerability.
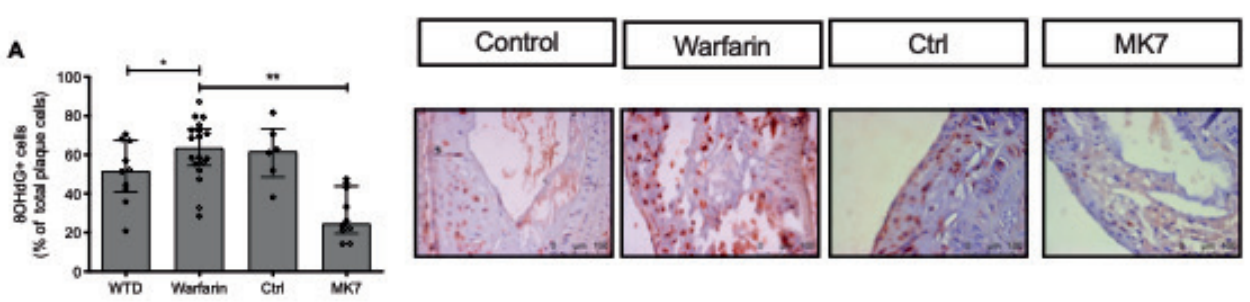

B
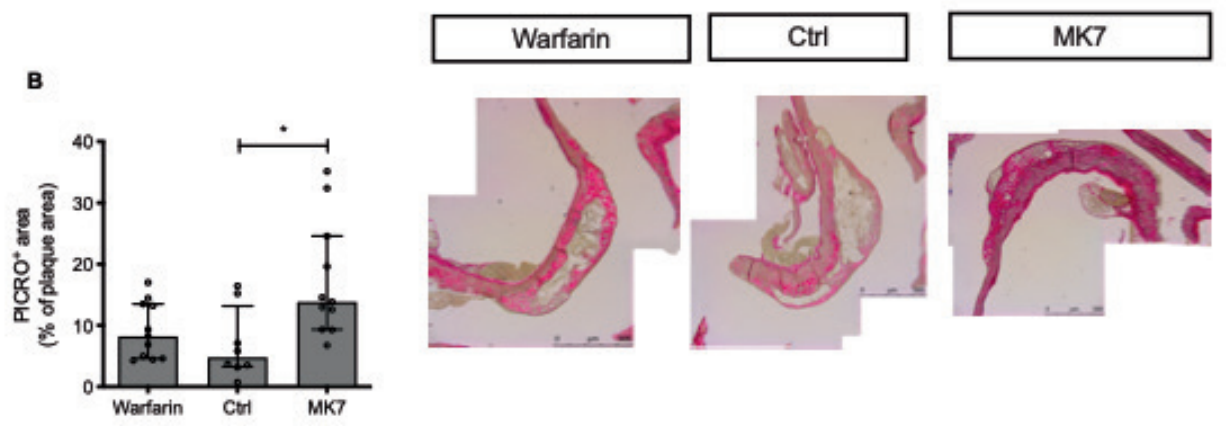

Figure 3. MK7 promotes plaque stability. A) Warfarin significantly increased oxidative stress in the atherosclerotic plaque, as visualized by $8-\mathrm{OhDG}$, compared to control. MK7 significantly reduced oxidative stress in atherosclerotic plaques compared to 18 weeks of warfarin treatment. B) MK7 treatment significantly increased collagen in atherosclerotic plaques compared to warfarin treatment. Data is presented as median with interquartile range. Statistical significance was assed using Kruskal-Wallis test, ${ }^{*} \mathrm{p}<0.05, * * \mathrm{p}<0.01$.

No difference in medial elastin breaks was observed after 6 weeks of treatment between WTD and warfarin treatment (data not shown). However, 18 weeks warfarin treatment significantly increased elastin breaks compared to control $(\mathrm{p}<0.01$; Table 2$)$. No significant difference was observed after switching from warfarin diet to either Ctrl or MK7 supplemented 
diet. No difference was observed between warfarin and $\mathrm{Ctrl}$ in collagen content of atherosclerotic plaques (Figure 3B). Switching to MK7 supplementation increased collagen content in atherosclerotic plaques compared to warfarin $(\mathrm{p}=0.099)$ and was significantly increased compared to $\mathrm{Ctrl}(9.1 \%, 6.9 \%$ and $17.4 \%$ of plaque volume for warfarin, $\mathrm{Ctrl}$ and MK7 treated groups respectively; Figure 2B). Plaque parameters of necrotic core size, $\alpha$ SMA+ and MAC3+ cells showed no significant difference between any groups (Table 2).

Table 2. Plaque characteristics after 18 weeks of treatment.

\begin{tabular}{|c|c|c|c|c|}
\hline \multicolumn{2}{|c}{ WTD } & Warfarin & Ctrl & MK7 \\
\hline Elastin breaks (score) & $1.56 \pm 0.77$ & $2.5 \pm 0.57 *$ & $2.07 \pm 0.44$ & $2.2 \pm 0.6$ \\
\hline $\begin{array}{c}\text { Necrotic core (\% of } \\
\text { plaque) }\end{array}$ & $5.8 \pm 4.38$ & $7.91 \pm 10$ & $17.18 \pm 17.1$ & $9.97 \pm 8.48$ \\
\hline $\begin{array}{c}\text { aSMA+ cells (\% of } \\
\text { plaque) }\end{array}$ & $1.82 \pm 1.32$ & $1.46 \pm 1.26$ & $1.48 \pm 1.31$ & $1.11 \pm 0.6$ \\
\hline $\begin{array}{c}\text { MAC3+ cells (\% of } \\
\text { plaque) }\end{array}$ & $5.37 \pm 4.1$ & $5.33 \pm 5.28$ & $5.89 \pm 3.98$ & $10.66 \pm 7$ \\
\hline
\end{tabular}

\section{Warfarin treatment of human vascular smooth muscle cells increases calcification.}

VSMC have been shown to be pivotal players in vascular calcification and atherogenesis development. Therefore, we tested the effect of warfarin and MK7 on VSMC in vitro. Warfarin significantly increased calcification of VSMC compared to vehicle control (Figure 4A). To test whether warfarin induced calcification is vitamin $\mathrm{K}$ dependent, warfarin was cotreated with an equal dose of MK7. Warfarin induced VSMC calcification was completely prevented by MK7 (Figure 4A). 

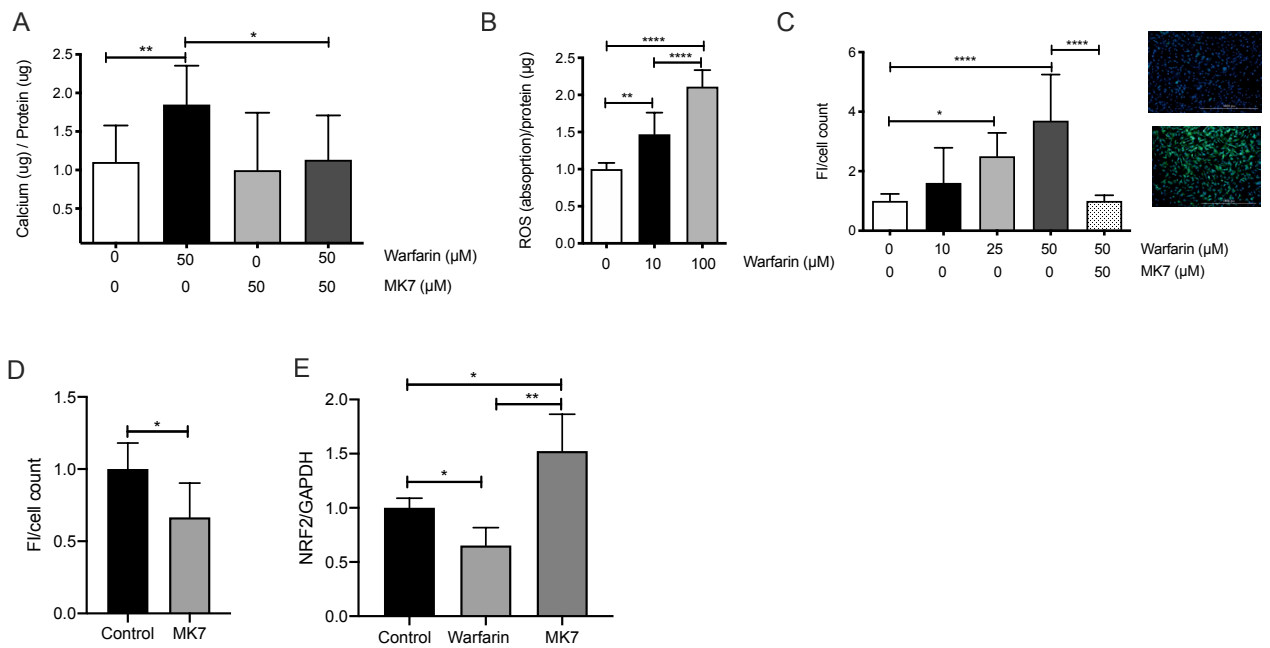

Figure 4. Antioxidant properties of Vitamin $K$ in vascular smooth muscle cells. A) Warfarin treatment increased calcification of VSMC and warfarin induced calcification can be blocked by co-stimulation with MK7. B) Warfarin treatment increased extracellular oxidative stress in a dose dependent manner after 24 hours of stimulation C) Direct warfarin stimulation induced dose-dependent intracellular oxidative stress, which is blocked by co-stimulation with MK7. D) Direct MK7 stimulation reduced intracellular oxidative stress in VSMC compared to control. E) Stimulation of VSMC with warfarin and MK7 reduced and increased Nrf2 mRNA levels, respectively. Data is presented as mean $\pm \mathrm{SD}$. Statistical significance was assed using t-test or Kruskal-Wallis test when applicable, ${ }^{*} \mathrm{p}<0.05, * * \mathrm{p}<0.01, * * * * \mathrm{p}<0.0001$.

\section{MK7 reduces oxidative stress and protects from warfarin induced ROS}

Switching diet from warfarin to MK7 reduced oxidative stress in atherosclerotic plaques. Therefore, we examined the role of warfarin and MK7 on VSMC oxidative stress. Incubating VSMC for 24 hours with warfarin significantly increased extracellular peroxide levels in a dose dependent manner compared to control treated VSMC (1.4 and 2.1-fold increase for 10 and $100 \mu \mathrm{M}$ warfarin, respectively; Figure 4B). Moreover, incubation of VSMC with warfarin induced a significant dose dependent increase in intracellular ROS (2.5-fold; $p$ $<0.05$ and 3.7-fold; $\mathrm{p}<0.001$ for $25 \mu \mathrm{M}$ and $50 \mu \mathrm{M}$ of warfarin, respectively; Figure 4C). Stimulation of VSMC with a combination of warfarin and MK7 prevented increased intracellular ROS levels ( $\mathrm{p}<0.001$; Figure 4C). Moreover, MK7 significantly reduced intracellular ROS levels compared to control ( $66 \%$ of control levels, $\mathrm{p}<0.05$; Figure 4D). The master transcription regulator of oxidative stress is nuclear factor erythroid 2-related factor 2 (Nrf2). Therefore, we assessed the impact of vitamin K and warfarin on mRNA level of nuclear factor Nrf2. Warfarin stimulation significantly reduced Nrf2 levels compared to control (0.65- 
fold; $\mathrm{p}<0.05$ ), whereas MK7 significantly increased Nrf2 mRNA levels compared to both control $(1.5$-fold; $\mathrm{p}<0.05))$ and warfarin $(\mathrm{p}<0.01)$, respectively (Figure $4 \mathrm{E})$.

\section{MK7 counteracts warfarin induced extracellular vesicle release}

Extracellular vesicles have been associated with vascular calcification by forming a nidus for calcification (29). Reduced fetuin-A presence in plaques of MK7 treated mice might be a result of altered extracellular vesicle uptake or secretion. Presence of fetuin-A in vesicles promotes vesicles phagocytosis and blocks vesicle-mediated VSMC calcification. Therefore, we determined quantity of extracellular vesicles secreted by VSMC when incubated with either warfarin or MK7. After 24 hours of stimulation, warfarin significantly increased extracellular vesicle number in culture medium $(2.2$-fold; $\mathrm{p}<0.01)$, which was inhibited by simultaneous stimulus of MK7 ( $<<0.05$; Figure 5A). MK7 treatment significantly reduced extracellular vesicle number compared to control (0.86-fold of control; Figure $5 \mathrm{~B})$. To test whether phagocytosis potential would be affected, we detected phosphatidylserine on extracellular vesicles using AnxA5-FITC. Warfarin treatment significantly increased phosphatidylserine exposure on extracellular vesicles compared to control and MK7 treatment, while no difference was present between control and MK7 (Figure 5C).

A

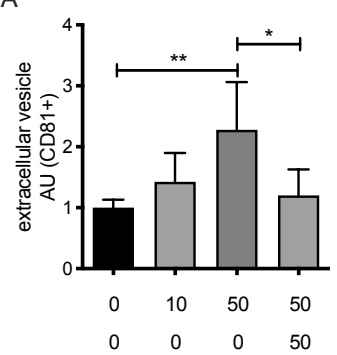

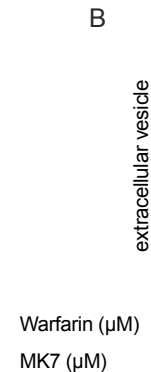

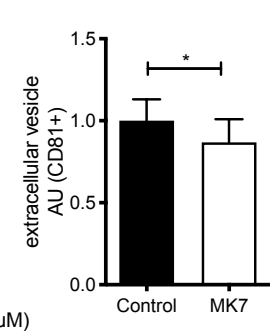

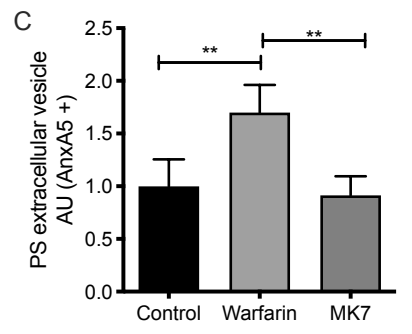

Figure 5. Vitamin K metabolism and extracellular vesicles in vascular smooth muscle cells. A) 24 hours of warfarin treatment increased extracellular vesicles in the medium. Warfarin increased extracellular vesicles numbers was blocked by co-stimulation with MK7. B) MK7 reduced extracellular vesicle numbers compared to control, after 24 hours. C) Warfarin significantly increased phosphatidylserine (PS) exposure on extracellular vesicles compared to control and MK7. Data is presented as mean \pm SD. Statistical significance was assed using t-test or Kruskal-Wallis test when applicable, ${ }^{*} \mathrm{p}<0.05,{ }^{* *} \mathrm{p}<0.01$.

\section{Discussion}

In this paper we show that warfarin aggravates atherosclerosis and calcification and that discontinuing warfarin treatment results in attenuation of both atherosclerosis progression and 
calcification. Supplementation of MK7 improves plaque stability, in part via direct effects on VSMC by reducing oxidative stress and extracellular vesicle release. Our data support clinical trials that test the hypothesis whether MK7 supplementation has beneficial effects on the cardiovascular system.

Long term warfarin treatment results in increased calcification and plaque progression. In patients, VKA duration is associated with more vascular calcification $(8,32,33)$ and increased intraplaque haemorrhages (34). Additionally, duration of VKA treatment is associated with a negative outcome in subclinical phenotypes of cardiovascular disease and promoting of disease development $(32,35)$. VKA treatment negatively influences atherosclerosis by increasing atherosclerotic plaque vulnerability $(8,36)$. Although it is generally accepted that long term VKA treatment induces vascular calcification, short term treatment of VKA is regarded as safe without detrimental side-effects. Therefore, we tested whether discontinuation of VKA treatment would prevent long term detrimental vascular effects. Discontinuing VKA prevented long term detrimental effects on vascular calcification and atherosclerosis progression. Additional MK7 supplementation did not further attenuate atherosclerosis progression and calcification, likely because of sufficient vitamin $\mathrm{K}$ intake in control treated animals (37).

Previous reports have shown that high vitamin K2 intake prevents medial calcification $(17,38,39)$. In our study we specifically focussed on atherosclerotic plaque calcification, which is distinct from medial calcification (40). Intimal calcification is linked to vitamin $\mathrm{K}$ deficiency (8) but also to inflammation and increased oxidative stress $(41,42)$. This corroborates our findings of ucMGP presence in atherosclerotic plaques, highlighting the large variation in vitamin K-status in both control and MK7 treated animals. High vitamin $\mathrm{K}$ has been shown to have limited effects on ucMGP levels but significantly increases carboxylated MGP levels (43). Indeed, MK7 significantly increased presence of cMGP in atherosclerotic plaques compared to discontinuing of warfarin.

MK7 treated animals displayed reduced levels of oxidative stress in the atherosclerotic plaques. We provide in vitro evidence that warfarin rapidly increased intracellular VSMC oxidative stress and subsequent extracellular vesicle release. It has been shown that both oxidative stress and extracellular vesicle release are features of synthetic VSMCs (44) and involved in atherosclerosis progression and calcification $(42,45,46)$. Cellular oxidative stress is under the control of the master regulator Nrf2, which has been associated with VSMC calcification (47) and Nrf2 activation in VSMC has been shown to have protective effects on atherosclerosis (48). Downstream of Nrf2 is NAD(P)H Quinone Dehydrogenase 1 (NQO1), also termed DT-diaphorase, which is involved in recycling of vitamin K (49). NQO1 is, like 
vitamin $\mathrm{K}$ epoxide reductase (VKOR), inhibited by VKA. Thus, warfarin could increase oxidative stress via both inhibition of VKOR and NQO1, which could be counteracted by additional vitamin K. Decreased Nrf2 promotes oxidative stress which has been associated with increased cellular senescence (50). Cellular senescence contributes to vascular aging and is associated with elevated inflammation (50) and vascular calcification (51). It has been proposed that vitamin $\mathrm{K}$ is linked to senescence, as a strong inverse correlation was observed between $C D K N 2 A / p 16 I N K 4 a$ expression and carboxylated osteocalcin levels. Thus, vitamin $\mathrm{K}$ deficiency may contribute to premature vascular senescence (52).

Oxidative stress is linked to increased extracellular vesicle release, which is a known nidus for vascular calcification $(53,54)$. Warfarin induces a dose-dependent increased secretion of extracellular vesicles, via a vitamin K-dependent mechanism since vitamin $\mathrm{K}$ could abolish secretion of extracellular vesicles. Extracellular vesicles from warfarin treated VSMCs exhibited increased phosphatidylserine (PS) exposure, which is known to promote recognition and clearance via phagocytosis. Extracellular vesicles exposing PS have been observed in human atherosclerotic plaques and contribute to plaque thrombogenicity (55). Gla-residues from gamma-carboxylated vitamin K-dependent proteins can bind to the negatively charged PS $(56,57)$, thereby preventing the formation of a nucleation site. Moreover, calcification and inflammation result in decreased presence of MGP and fetuin-A in extracellular vesicles while enriching PS exposure (46). Fetuin-A is a systemic calcification inhibitor that is internalized and secreted by VSMC derived vesicles $(29,31)$. While fetuin-A is not expressed by VSMC, it is efficiently loaded into VSMC secreted vesicles (31). We injected fluorescently labelled fetuin-A as novel imaging probe. Warfarin treatment resulted in significant uptake of fluorescently labelled fetuin-A in the atherosclerotic plaques. MK7 treated animals had significantly less labelled fetuin-A present in atherosclerotic lesions, suggesting a decreased nidus for calcification. In addition, in vitro MK7 reduced VSMC extracellular vesicle presence.

In conclusion, discontinuation of short term warfarin use prevents long term detrimental effect on atherosclerosis progression and calcification. MK7 supplementation attenuates atherosclerotic plaque progression by supporting an environment with reduced oxidative stress and increased collagen deposition. These effects of vitamin $\mathrm{K}$ are suggested via controlling VSMC mediated oxidative stress and subsequently could reduce vascular senescence of VSMC. 


\section{References}

1. Rennenberg RJMW, Kessels AGH, Schurgers LJ, van Engelshoven JMA, de Leeuw PW, Kroon AA. Vascular calcifications as a marker of increased cardiovascular risk: a meta-analysis. Vasc Health Risk Manag. 2009;5(1):185-97.

2. Budoff MJ, Young R, Burke G, Jeffrey Carr J, Detrano RC, Folsom AR, et al. Ten-year association of coronary artery calcium with atherosclerotic cardiovascular disease (ASCVD) events: the multi-ethnic study of atherosclerosis (MESA). Eur Heart J. 2018 Jul 1;39(25):2401-8.

3. Budoff MJ, Shaw LJ, Liu ST, Weinstein SR, Mosler TP, Tseng PH, et al. Long-term prognosis associated with coronary calcification: observations from a registry of 25,253 patients. J Am Coll Cardiol. 2007 May 8;49(18):1860-70.

4. Raggi P, Callister TQ, Shaw LJ. Progression of coronary artery calcium and risk of first myocardial infarction in patients receiving cholesterol-lowering therapy. Arterioscler Thromb Vasc Biol. American Heart Association, Inc; 2004 Jul;24(7):1272-7.

5. Virmani R, Kolodgie FD, Burke AP, Farb A, Schwartz SM. Lessons from sudden coronary death: a comprehensive morphological classification scheme for atherosclerotic lesions. Arterioscler Thromb Vasc Biol. 2000 May;20(5):1262-75.

6. Joshi NV, Vesey AT, Williams MC, Shah ASV, Calvert PA, Craighead FHM, et al. 18Ffluoride positron emission tomography for identification of ruptured and high-risk coronary atherosclerotic plaques: a prospective clinical trial. Lancet. 2014 Feb 22;383(9918):705-13.

7. van Gorp RH, Schurgers LJ. New Insights into the Pros and Cons of the Clinical Use of Vitamin K Antagonists (VKAs) Versus Direct Oral Anticoagulants (DOACs). Nutrients. 2015;7(11):9538-57.

8. Schurgers LJ, Joosen IA, Laufer EM, Chatrou MLL, Herfs M, Winkens MHM, et al. Vitamin K-antagonists accelerate atherosclerotic calcification and induce a vulnerable plaque phenotype. PLoS ONE. 2012;7(8):e43229.

9. Luo G, Ducy P, McKee MD, Pinero GJ, Loyer E, Behringer RR, et al. Spontaneous calcification of arteries and cartilage in mice lacking matrix GLA protein. Nature. 1997 Mar 6;386(6620):78-81.

10. Murshed M, Schinke T, McKee MD, Karsenty G. Extracellular matrix mineralization is regulated locally; different roles of two gla-containing proteins. J Cell Biol. 2004 Jun 7;165(5):625-30.

11. Schurgers LJ, Teunissen KJF, Knapen MHJ, Kwaijtaal M, van Diest R, Appels A, et al. Novel conformation-specific antibodies against matrix gamma-carboxyglutamic acid (Gla) protein: undercarboxylated matrix Gla protein as marker for vascular calcification. Arterioscler Thromb Vasc Biol. 2005 Aug;25(8):1629-33.

12. Dalmeijer GW, van der Schouw YT, Magdeleyns EJ, Vermeer C, Verschuren WMM, Boer JMA, et al. Circulating desphospho-uncarboxylated matrix $\gamma$-carboxyglutamate protein and the risk of coronary heart disease and stroke. J Thromb Haemost. John Wiley \& Sons, Ltd (10.1111); 2014 Jul;12(7):1028-34.

13. Schurgers LJ, Barreto DV, Barreto FC, Liabeuf S, Renard C, Magdeleyns EJ, et al. The circulating inactive form of matrix gla protein is a surrogate marker for vascular calcification in chronic kidney disease: a preliminary report. Clin J Am Soc Nephrol. American Society of Nephrology; 2010 Apr;5(4):568-75.

14. Ueland T, Dahl CP, Gullestad L, Aakhus S, Broch K, Skårdal R, et al. Circulating levels of non-phosphorylated undercarboxylated matrix Gla protein are associated with disease severity in patients with chronic heart failure. Clin Sci. 2011 Aug;121(3):119-27. 
15. Parker BD, Schurgers LJ, Brandenburg VM, Christenson RH, Vermeer C, Ketteler M, et al. The associations of fibroblast growth factor 23 and uncarboxylated matrix Gla protein with mortality in coronary artery disease: the Heart and Soul Study. Ann Intern Med. American College of Physicians; 2010 May 18;152(10):640-8.

16. Wu M, Rementer C, Giachelli CM. Vascular calcification: an update on mechanisms and challenges in treatment. Calcif Tissue Int. Springer US; 2013 Oct;93(4):365-73.

17. Krüger T, Oelenberg S, Kaesler N, Schurgers LJ, van de Sandt AM, Boor P, et al. Warfarin induces cardiovascular damage in mice. Arterioscler Thromb Vasc Biol. 2013 Nov;33(11):2618-24.

18. Geleijnse JM, Vermeer C, Grobbee DE, Schurgers LJ, Knapen MHJ, van der Meer IM, et al. Dietary intake of menaquinone is associated with a reduced risk of coronary heart disease: the Rotterdam Study. J Nutr. 2004 Nov;134(11):3100-5.

19. Beulens JWJ, Bots ML, Atsma F, Bartelink M-LEL, Prokop M, Geleijnse JM, et al. High dietary menaquinone intake is associated with reduced coronary calcification. Atherosclerosis. 2009 Apr;203(2):489-93.

20. Gast GCM, de Roos NM, Sluijs I, Bots ML, Beulens JWJ, Geleijnse JM, et al. A high menaquinone intake reduces the incidence of coronary heart disease. Nutr Metab Cardiovasc Dis. 2009 Sep;19(7):504-10.

21. Trumbo P, Yates AA, Schlicker S, Poos M. Dietary reference intakes: vitamin A, vitamin $\mathrm{K}$, arsenic, boron, chromium, copper, iodine, iron, manganese, molybdenum, nickel, silicon, vanadium, and zinc. J Am Diet Assoc. 2001 Mar;101(3):294-301.

22. Shea MK, O'Donnell CJ, Hoffmann U, Dallal GE, Dawson-Hughes B, Ordovas JM, et al. Vitamin K supplementation and progression of coronary artery calcium in older men and women. Am J Clin Nutr. 2009 Jun;89(6):1799-807.

23. Brandenburg VM, Reinartz S, Kaesler N, Krüger T, Dirrichs T, Kramann R, et al. Slower Progress of Aortic Valve Calcification With Vitamin K Supplementation. Circulation. 2017 May 23;135(21):2081-3.

24. Westenfeld R, Krueger T, Schlieper G, Cranenburg ECM, Magdeleyns EJ, Heidenreich $\mathrm{S}$, et al. Effect of Vitamin K2 Supplementation on Functional Vitamin K Deficiency in Hemodialysis Patients: A Randomized Trial. YAJKD. Elsevier Inc; 2012 Feb 1;59(2):186-95.

25. Dalmeijer GW, van der Schouw YT, Magdeleyns E, Ahmed N, Vermeer C, Beulens JWJ. The effect of menaquinone-7 supplementation on circulating species of matrix Gla protein. Atherosclerosis. 2012 Dec;225(2):397-402.

26. Wallin R, Martin LF. Warfarin poisoning and vitamin $\mathrm{K}$ antagonism in rat and human liver. Design of a system $<\mathrm{i}>\mathrm{in}$ vitro $</ \mathrm{i}>$ that mimics the situation $<\mathrm{i}>$ in vivo $</ \mathrm{i}>$. Biochem J. Portland Press Limited; 1987 Jan 15;241(2):389-96.

27. Price PA, Faus SA, Williamson MK. Warfarin causes rapid calcification of the elastic lamellae in rat arteries and heart valves. Arterioscler Thromb Vasc Biol. 1998 Sep;18(9):1400-7.

28. Schurgers LJ, Vermeer C. Determination of phylloquinone and menaquinones in food. Effect of food matrix on circulating vitamin K concentrations. Haemostasis. 2000 Oct;30(6):298-307.

29. Kapustin AN, Chatrou MLL, Drozdov I, Zheng Y, Davidson SM, Soong D, et al. Vascular smooth muscle cell calcification is mediated by regulated exosome secretion. Circ Res. Lippincott Williams \& Wilkins; 2015 Apr 10;116(8):1312-23.

30. Terkeltaub RA, Santoro DA, Mandel G, Mandel N. Serum and plasma inhibit neutrophil stimulation by hydroxyapatite crystals. Evidence that serum alpha 2-HS glycoprotein is a potent and specific crystal-bound inhibitor. Arthritis Rheum. John Wiley \& Sons, Ltd; 1988 Sep;31(9):1081-9. 
31. Reynolds JL, Skepper JN, McNair R, Kasama T, Gupta K, Weissberg PL, et al. Multifunctional roles for serum protein fetuin-a in inhibition of human vascular smooth muscle cell calcification. Journal of the American Society of Nephrology. American Society of Nephrology; 2005 Oct;16(10):2920-30.

32. Weijs B, Blaauw Y, Rennenberg RJMW, Schurgers LJ, Timmermans CCMM, Pison L, et al. Patients using vitamin $\mathrm{K}$ antagonists show increased levels of coronary calcification: an observational study in low-risk atrial fibrillation patients. Eur Heart J. 2011 Oct;32(20):2555-62.

33. Peeters F, Dudink E, Kimenai D, Weijs B, Altintas S, Heckman L, et al. Vitamin K Antagonists, Non-Vitamin K Antagonist Oral Anticoagulants, and Vascular Calcification in Patients with Atrial Fibrillation. TH Open. Georg Thieme Verlag KG; 2018 Oct 1;02(04):e391-8.

34. Mujaj B, Bos D, Muka T, Lugt AVD, Ikram MA, Vernooij MW, et al. Antithrombotic treatment is associated with intraplaque haemorrhage in the atherosclerotic carotid artery: a cross-sectional analysis of The Rotterdam Study. Eur Heart J. 2018 Jul 27.

35. Eggebrecht L, Prochaska JH, Schulz A, Arnold N, Jünger C, Göbel S, et al. Intake of Vitamin K Antagonists and Worsening of Cardiac and Vascular Disease: Results From the Population-Based Gutenberg Health Study. J Am Heart Assoc. 2018 Sep 4;7(17):1396-25.

36. Plank F, Beyer C, Friedrich G, Stühlinger M, Hintringer F, Dichtl W, et al. Influence of vitamin $\mathrm{K}$ antagonists and direct oral anticoagulation on coronary artery disease: A CTA analysis. International Journal of Cardiology. Elsevier B.V; 2018 Jun 1;260(C):11-5.

37. Harshman SG, Fu X, Karl JP, Barger K, Lamon-Fava S, Kuliopulos A, et al. Tissue Concentrations of Vitamin K and Expression of Key Enzymes of Vitamin K Metabolism Are Influenced by Sex and Diet but Not Housing in C57B16 Mice. J Nutr. 2016 Aug;146(8):1521-7.

38. Schurgers LJ, Teunissen KJF, Hamulyák K, Knapen MHJ, Vik H, Vermeer C. Vitamin K-containing dietary supplements: comparison of synthetic vitamin $\mathrm{K} 1$ and nattoderived menaquinone-7. Blood. 2007 Apr 15;109(8):3279-83.

39. McCabe KM, Booth SL, Fu X, Shobeiri N, Pang JJ, Adams MA, et al. Dietary vitamin $\mathrm{K}$ and therapeutic warfarin alter the susceptibility to vascular calcification in experimental chronic kidney disease. Kidney Int. 2013 May;83(5):835-44.

40. Amann K. Media calcification and intima calcification are distinct entities in chronic kidney disease. Clin J Am Soc Nephrol. American Society of Nephrology; 2008 Nov;3(6):1599-605.

41. Shanahan CM. Inflammation ushers in calcification: a cycle of damage and protection? Circulation. Lippincott Williams \& Wilkins; 2007 Dec 11;116(24):2782-5.

42. Byon CH, Chen Y. Molecular Mechanisms of Vascular Calcification in Chronic Kidney Disease: The Link between Bone and the Vasculature. Curr Osteoporos Rep. 2015 May 7.

43. Schurgers LJ, Spronk HMH, Soute BAM, Schiffers PM, DeMey JGR, Vermeer C. Regression of warfarin-induced medial elastocalcinosis by high intake of vitamin $\mathrm{K}$ in rats. Blood. 2007 Apr 1;109(7):2823-31.

44. Branchetti E, Poggio P, Sainger R, Shang E, Grau JB, Jackson BM, et al. Oxidative stress modulates vascular smooth muscle cell phenotype via CTGF in thoracic aortic aneurysm. Cardiovasc Res. 2013 Nov 1;100(2):316-24.

45. Byon CH, Javed A, Dai Q, Kappes JC, Clemens TL, Darley-Usmar VM, et al. Oxidative stress induces vascular calcification through modulation of the osteogenic transcription factor Runx2 by AKT signaling. J Biol Chem. 2008 May 30;283(22):15319-27. 
46. Kapustin AN, Shanahan CM. Emerging roles for vascular smooth muscle cell exosomes in calcification and coagulation. J Physiol (Lond). 2016 Jun 1;594(11):2905-14.

47. Wei R, Enaka M, Muragaki Y. Activation of KEAP1/NRF2/P62 signaling alleviates high phosphate-induced calcification of vascular smooth muscle cells by suppressing reactive oxygen species production. Sci Rep. Nature Publishing Group; 2019 Jul 17;9(1):10366-13.

48. Bozaykut P, Karademir B, Yazgan B, Sozen E, Siow RCM, Mann GE, et al. Effects of vitamin $\mathrm{E}$ on peroxisome proliferator-activated receptor $\gamma$ and nuclear factor-erythroid 2-related factor 2 in hypercholesterolemia-induced atherosclerosis. Free Radical Biology and Medicine. 2014 May;70:174-81.

49. Ingram BO, Turbyfill JL, Bledsoe PJ, Jaiswal AK, Stafford DW. Assessment of the contribution of NAD(P)H-dependent quinone oxidoreductase 1 (NQO1) to the reduction of vitamin K in wild-type and NQO1-deficient mice. Biochem J. 2013 Nov $15 ; 456(1): 47-54$.

50. Ungvari Z, Tarantini S, Nyúl-Tóth Á, Kiss T, Yabluchanskiy A, Csipo T, et al. Nrf2 dysfunction and impaired cellular resilience to oxidative stressors in the aged vasculature: from increased cellular senescence to the pathogenesis of age-related vascular diseases. Geroscience. Springer International Publishing; 2019 Oct 26;133(5):446-12.

51. Ragnauth CD, Warren DT, Liu Y, McNair R, Tajsic T, Figg N, et al. Prelamin A acts to accelerate smooth muscle cell senescence and is a novel biomarker of human vascular aging. Circulation. Lippincott Williams \& Wilkins; 2010 May 25;121(20):2200-10.

52. Stenvinkel P, Luttropp K, McGuinness D, Witasp A, Qureshi AR, Wernerson A, et al. $\mathrm{CDKN} 2 \mathrm{~A} / \mathrm{p} 16 \mathrm{INK} 4 \mathrm{a}$ expression is associated with vascular progeria in chronic kidney disease. Aging (Albany NY). 2017 Feb 9;9(2):494-507.

53. Kapustin AN, Davies JD, Reynolds JL, McNair R, Jones GT, Sidibe A, et al. Calcium regulates key components of vascular smooth muscle cell-derived matrix vesicles to enhance mineralization. Circ Res. 2011 Jun 24;109(1):e1-12.

54. Goettsch C, Hutcheson JD, Aikawa M, Iwata H, Pham T, Nykjaer A, et al. Sortilin mediates vascular calcification via its recruitment into extracellular vesicles. J Clin Invest. 2016 Mar 7.

55. Mallat Z, Hugel B, Ohan J, Lesèche G, Freyssinet JM, Tedgui A. Shed membrane microparticles with procoagulant potential in human atherosclerotic plaques: a role for apoptosis in plaque thrombogenicity. Circulation. 1999 Jan 26;99(3):348-53.

56. Kapustin AN, Schoppet M, Schurgers LJ, Reynolds JL, McNair R, Heiss A, et al. Prothrombin Loading of Vascular Smooth Muscle Cell-Derived Exosomes Regulates Coagulation and CalcificationHighlights. Arterioscler Thromb Vasc Biol. American Heart Association, Inc; 2017 Mar 1;37(3):e22-e32.

57. Schurgers LJ, Spronk HMH, Skepper JN, Hackeng TM, Shanahan CM, Vermeer C, et al. Post-translational modifications regulate matrix Gla protein function: importance for inhibition of vascular smooth muscle cell calcification. J Thromb Haemost. 2007 Dec;5(12):2503-11. 


\section{Chapter}

General discussion 


\section{Key findings in perspective}

Aortic aneurysm is an emerging cardiovascular disease that mainly affects the older population. Untreated aneurysm leads to aortic rupture, hemorrhage, and death. Aortic aneurysm at different anatomical sites associates with different causes. Whereas aortic aneurysm in the ascending aorta is mainly associated with genetic diseases such as Marfan and Loey-Dietz syndrome, abdominal aortic aneurysm is associated with aging, gender, and lifestyle risk factor such as smoking. Both pathologies involve depletion of VSMCs and ECM degradation, which leads to weakening of the vessel wall resulting in dilation. However, what causes aortic aneurysm and the pathophysiology of aneurysm formation has not been elucidated. Recent data has shown that active microcalcification takes place in aortic aneurysm, as demonstrated by an increased uptake of the bone PET tracer $\mathrm{NaF}^{18}$. The increase of $\mathrm{NaF}^{18}$ uptake in aortic aneurysm also correlates with the progression of the disease. We hypothesized that VSMCs play an important role in the pathogenesis of aneurysm since it is the most abundant cell type within the vascular bed playing a key role in vascular calcification. In this thesis we investigated the role of VSMCs in the pathophysiology of vascular diseases such as aneurysm and atherosclerosis.

In chapter 4, we compared VSMCs isolated from aneurysm tissue to VSMCs isolated from healthy tissue from the same patient. We investigated the characteristics of aneurysm VSMCs and their involvement in aortic aneurysm formation and progression. In chapter 5, we studied the effect of smoking, the most important life-style risk factor of aneurysm, on vascular calcification and effects of nicotine on VSMCs in vitro. In chapter 6, we used an animal model to elaborate on the effect of vitamin $\mathrm{K}$ supplementation on atherosclerotic plaque progression and calcification.

Key findings in this thesis are

1. VSMCs isolated from aneurysm tissue exhibit a distinct phenotype to VSMCs isolated from healthy tissue (Chapter 4)

2. Nicotine initiates vascular calcification through calcium-dependent NOX5 signaling (chapter 5)

3. Vitamin $\mathrm{K}$ ameliorate nicotine-induced oxidative stress, extracellular vesicles, and calcification (chapter 5)

4. Vitamin K2 supplementation holds atherosclerotic plaque progression and rescues intimal calcification in a preclinical experimental animal model (chapter 6). 


\section{Aneurysm VSMC exhibit a distinct phenotype from healthy VSMC}

Calcification in AAA increases risk of aortic rupture and is associated with higher overall and cardiovascular mortality. ${ }^{1,2}$ Vascular remodelling and calcification are mediated by vascular smooth muscle cells. However, the underlying mechanisms of VSMC involvement in aneurysm formation is not completely clear. In this study, we examined phenotype differences of VSMCs isolated from aneurysmal aorta compared non-aneurysmal vascular tissue of the same patient and how these differences affect VSMC calcification.

In this thesis, we demonstrated that AAA VSMCs exhibit a phenotype distinct from VSMCs isolated from non-aneurysmal vascular tissue from the same patient. AAA VSMCs undergo phenotypic switching, lose contractility and assume a synthetic phenotype. AAA VSMCs showed pro-inflammatory differentiation by increased expression of Galectin 3 and CD68, markers generally expressed by inflammatory cells, implicating macrophage-like VSMCs. Interestingly, increased Galectin-3 expression was observed in differentiated osteoblastic cells and osteochondrogenic VSMCs. ${ }^{3,4}$ Indeed, macrophage-like human VSMCs have a genetic profile associated with calcification and showed higher propensity to calcify. ${ }^{5}$ We further showed that phenotypic switching of AAA VSMC is accompanied by alterations in VSMC oxidative stress and EV release, which are important VSMC features that drive microcalcification. To date, there is no data on the role of VSMCs-derived EVs in patients with AAA. Furthermore, we showed that AAA VSMCs exhibit senescence associated secretory phenotype (SASP) at earlier passages compared to non-AAA VSMCs. These early passage AAA VSMCs secrete IL6 which induced inflammatory responses in ECs. Ultimately, we showed that AAA VSMCs from all analysed patients calcify faster and deposited significantly more calcium-crystals compared to non-AAA VSMCs. It has been shown that senescent human VSMCs overexpress inflammatory and pro-calcific genes associated with medial calcification. 6,7 Taken together, our results suggest that VSMC senescence and resulting inflammation contribute to vascular microcalcification observed in AAA.

We also explored potential markers for early AAA detection. AAA tissue showed significantly higher expression of inactive vitamin K-dependent MGP (ucMGP), a strong inhibitor of vascular calcification. We hypothesize that the distinct AAA VSMC features, together with an inactive calcification inhibitor (ucMGP) status, favours initiation of microcalcification. Our findings provide novel insight into the mechanisms of AAA development, and thus the potential for new avenues of treatment. 


\section{Nicotine initiate vascular calcification through calcium-dependent Nox5}

Smoking is an important risk factor of cardiovascular morbidity and mortality and is known to associate with increased vascular calcification. ${ }^{8}{ }^{9}$ However, the molecular mechanism how smoking initiates vascular calcification has not been fully understood. Nicotine is a major constituent of smoking. ${ }^{10}$ It has been shown that nicotine acts via the nicotinic acetyl choline receptor (nAchr) in neuronal cells. ${ }^{11}$ In human VSMCs, expression of $\alpha 2, \alpha 6, \alpha 7, \beta 1 \mathrm{nAch}$ has been reported. ${ }^{12}$ In this study we investigated the correlation between smoking and vascular calcification in atherosclerotic plaques. Furthermore, we investigated the direct effect of nicotine on VSMCs in vitro to unravel the mechanism underlying nicotine-induced vascular calcification.

In this thesis, we showed that smokers have a higher degree of calcification of atherosclerotic plaques compared to non-smokers. This is in line with previous studies which reported a significant association between smoking and coronary and aortic calcification. ${ }^{13,14}$ However, the size of calcification areas has not been studied before. We extended the current knowledge and demonstrate that smokers have higher total volume of microcalcification compared to non-smokers. Microcalcification is a known feature of the vulnerable plaque phenotype. ${ }^{15-18}$ This suggest that smoking may cause detrimental effects by promoting the vulnerable plaque to rupture via microcalcification.

We further investigated the direct effect of nicotine on VSMC in vitro. We found that nicotine induces major hallmarks of calcification including phenotypic switching of VSMCs to an osteochondrogenic phenotype, oxidative stress, and secretion of EVs. We showed that the effects of nicotine were in part through binding to $\alpha 3$ and $\alpha 7 \mathrm{nAch}$. The association of smoking-induced oxidative stress has been reported before, however the exact mechanism has not been elucidated. We showed that nicotine-induced VSMC calcification is mediated - in part - through Nox5, an enzyme producing ROS. We further showed that nicotine increased the activity of Nox 5 by inducing a rapid increase of intracellular calcium. Increased calcium influx through $\alpha 7 \mathrm{nAch}$ by nicotine has only been described in neuronal cells. ${ }^{11}$ To the best of our knowledge, this is the first study to reveal a connection between nicotine and Nox 5 in VSMCs. We identified a mechanism by which nicotine induced Nox5-mediated oxidative stress, EV release, and subsequently VSMC calcification. Finally, we showed that our in vitro findings are relevant in vivo by demonstrating that aortic tissue from patients who smoked has higher level expression of Nox 5 than non-smokers. The increase expression of Nox 5 is also positively correlate with the degree of calcification in these patients. Thus, our findings add to 
the current knowledge that smoking causes vascular calcification through VSMC-mediated pathways.

\section{Vitamin $K$ ameliorates nicotine-induced oxidative stress, extracellular vesicles, and calcification}

Vitamin $\mathrm{K}$ is a fat-soluble vitamin. Natural occurring vitamin $\mathrm{K}$ includes vitamin $\mathrm{K} 1$ and vitamin $\mathrm{K} 2$. Whereas vitamin $\mathrm{K} 1$ is found in green vegetables, vitamin $\mathrm{K} 2$ is synthesized by bacteria and it can be found in fermented food. ${ }^{19}$ The main function of vitamin $\mathrm{K}$ is to act as a cofactor in the posttranslational carboxylation of vitamin $\mathrm{K}$ dependent proteins (VKDPs). ${ }^{20}$ VKDPs are localized throughout the human body. Hepatic VKDPs include coagulation factors and anticoagulant proteins. Hence, they are involved in the long-known function of vitamin $\mathrm{K}$ in regulating blood coagulation. ${ }^{20}$ Extrahepatic VKDPs include matrix Gla protein (MGP), Osteocalcin, and Gla rich protein (GRP) which are involved in regulating bone hemostasis and ectopic calcification. ${ }^{21}$ Specifically, MGP is expressed by VSMCs and is known to inhibit extracellular matrix mineralization and vascular calcification. ${ }^{22}$ Vitamin $\mathrm{K}$ supplementation has shown to decrease aortic valve calcification. ${ }^{23}$ Vitamin $\mathrm{K}$ may also be involved in an alternative vitamin $\mathrm{K}$ route, which is associated with its function as antioxidant and production of ATP. ${ }^{24}$ However, data on these non-canonical functions are yet not conclusive.

In this thesis, we showed that vitamin $\mathrm{K}$ has beneficial effect at the cellular level. We showed that vitamin K2 (MK-7) was able to prevent nicotine-induced VSMC calcification. This is in line with a previous study showing that vitamin $\mathrm{K}$ prevents aortic valve calcification. ${ }^{23} \mathrm{We}$ further explored the non-canonical role of vitamin $\mathrm{K}$ as an antioxidant and found that vitamin $\mathrm{K}$ reduces nicotine-induced oxidative stress and subsequently reduces secretion of EVs from VSMCs. Thus far, vitamin K has been reported to protect against oxidative stress and oxidative stress-induced cell death in primary oligodendrocytes and immature cortical neurons. ${ }^{25,26}$ The mechanism of action has not been fully elucidated. However, vitamin $\mathrm{K}$ has also been shown to directly modulate Nox activity in soybean plant. ${ }^{27}$ Indeed, we showed that Nox5 mediates nicotine-induced ROS, EV secretion and calcification of VSMCs. Therefore, it is likely that vitamin K scavenges ROS which is generated by Nox5, thereby lowering the secretion of EVs which form the nidus of calcification. 


\section{Vitamin K2 supplementation holds atherosclerotic plaque progression and rescues intimal calcification in a preclinical animal model.}

Vitamin $\mathrm{K}$ antagonist (VKA), such as warfarin, are widely used as anticoagulants to prevent thromboembolic complications. ${ }^{28}$ VKAs counteract the function of vitamin $\mathrm{K}$ by blocking VKOR and subsequently inhibit vitamin $\mathrm{K}$ recycling. ${ }^{29}$ Thus, VKA may indirectly impact activity of VKDPs. ${ }^{21,30}$ Ample evidence exists that patient using VKA have higher level of valvular and vascular calcification than VKA non-users. ${ }^{31-34}$ Analysis of atherosclerotic plaques from patients showed higher coronary calcium score and significantly higher amount of spotty calcification in VKA users compared to VKA non-users. ${ }^{34}$ Indeed, vascular calcification reflects atherosclerotic plaque burden and is a strong predictor for cardiovascular mortality. ${ }^{35}$ However, medical treatment for vascular calcification has not been established to date. $^{36}$ In experimental animals, VKA-induced medial calcification was rescued by cotreatment with a high dose of vitamin K2. ${ }^{37}$ We further investigated the effect of VKA and vitamin K2 (MK-7) supplementation on intimal calcification and atherosclerotic plaque development in an apoe ${ }^{-/-}$mouse model of atherosclerosis.

In this thesis, long-term warfarin treatment induces vascular intima calcification and increased atherosclerotic plaque size in mice. We showed that long-term warfarin treatment increases the inactive form of the calcification inhibitor ucMGP, supporting the notion that VKA might induce calcification by inhibiting MGP functionality. ${ }^{38} \mathrm{We}$ further demonstrated that discontinuing warfarin treatment and replacing the treatment by vitamin $\mathrm{K} 2$ prevents longterm effect of vitamin $\mathrm{K}$ deficiency on atherosclerosis plaque progression and intimal calcification. Specifically, vitamin K2 supplementation significantly increased the activated form of MGP (cMGP), reduced oxidative stress and increased amount of collagen in atherosclerotic plaques. Using an in vitro experimental setup, we showed that the effect of VKA and vitamin K2 on atherosclerotic plaque development is regulated, at least in part, via VSMCs. Finally, using a novel fluorescently labelled fetuin-A probe, which has high affinity to mineral nuclei, we demonstrated that vitamin $\mathrm{K} 2$ reduced the presence of calcification nidus in atherosclerotic plaques. This supports our in vitro findings that vitamin $\mathrm{K} 2$ reduces EV release from VSMCs, hence vitamin K2 might help to limit the nidus for the initiation of calcification. Taken together, our research suggests that vitamin K2 supplementation has clinical potential for the treatment of vascular calcification. 


\section{Concluding remarks and future perspectives}

The research described in this thesis aims to unravel mechanisms underlying aortic aneurysm formation. We revealed that aneurysm VSMCs display a distinct phenotype compared to healthy VSMCs. Our research emphasizes the importance of VSMC phenotypic switching and VSMC calcification in the pathogenesis of abdominal aortic aneurysm. As smoking is one of the strongest life-style risk factors for AAA, we demonstrate a mechanism by which nicotine induces pro-calcific traits of VSMCs through Nox5. We provide evidence that vitamin $\mathrm{K}$ reduces oxidative stress and calcification and ameliorates VSMC pathologies. Finally, we translated the cardiovascular promoting effect of vitamin $\mathrm{K}$ to the pre-clinical setting. 


\section{Reference}

1. Chowdhury MM, Zieliński LP, Sun JJ, Lambracos S, Boyle JR, Harrison SC, Rudd JHF, Coughlin PA. Editor's Choice - Calcification of Thoracic and Abdominal Aneurysms is Associated with Mortality and Morbidity. European Journal of Vascular and Endovascular Surgery. 2018;55(1):101-108.

2. Buijs RVC, Willems TP, Tio RA, Boersma HH, Tielliu IFJ, Slart RHJA, Zeebregts CJ. Calcification as a Risk Factor for Rupture of Abdominal Aortic Aneurysm. European Journal of Vascular and Endovascular Surgery. 2013;46(5):542-548.

3. Simon D, Derer A, Andes FT, Lezuo P, Bozec A, Schett G, Herrmann M, Harre U. Galectin-3 as a novel regulator of osteoblast-osteoclast interaction and bone homeostasis. Bone. 2017;105:35-41.

4. Iacobini C, Fantauzzi CB, Pugliese G, Menini S. Role of Galectin-3 in Bone Cell Differentiation, Bone Pathophysiology and Vascular Osteogenesis. International journal of molecular sciences. 2017;18(11).

5. Chellan B, Rojas E, Zhang C, Hofmann Bowman MA. Enzyme-modified non-oxidized LDL (ELDL) induces human coronary artery smooth muscle cell transformation to a migratory and osteoblast-like phenotype. Scientific reports. 2018;8(1):11954.

6. Nakano-Kurimoto R, Ikeda K, Uraoka M, Nakagawa Y, Yutaka K, Koide M, Takahashi T, Matoba S, Yamada H, Okigaki M, Matsubara H. Replicative senescence of vascular smooth muscle cells enhances the calcification through initiating the osteoblastic transition. American Journal of Physiology-Heart and Circulatory Physiology. 2009;297(5):H1673-H1684.

7. Burton DGA, Giles PJ, Sheerin ANP, Smith SK, Lawton JJ, Ostler EL, Rhys-Williams W, Kipling D, Faragher RGA. Microarray analysis of senescent vascular smooth muscle cells: A link to atherosclerosis and vascular calcification. Experimental Gerontology. 2009;44(10):659-665.

8. White WB. Smoking-related morbidity and mortality in the cardiovascular setting. Preventive cardiology. 2007;10(2 Suppl 1):1-4.

9. Willett WC, Green A, Stampfer MJ, Speizer FE, Colditz GA, Rosner B, Monson RR, Stason W, Hennekens CH. Relative and Absolute Excess Risks of Coronary Heart Disease among Women Who Smoke Cigarettes. New England Journal of Medicine. 1987;317(21):1303-1309.

10. Benowitz NL, Burbank AD. Cardiovascular Toxicity of Nicotine: Implications for Electronic Cigarette Use. Trends in cardiovascular medicine. 2016;26(6):515.

11. Dajas-Bailador FA, Mogg AJ, Wonnacott S. Intracellular Ca $2+$ signals evoked by stimulation of nicotinic acetylcholine receptors in SH-SY5Y cells: Contribution of voltage-operated $\mathrm{Ca} 2+$ channels and $\mathrm{Ca} 2+$ stores. Journal of Neurochemistry. 2002;81(3):606-614.

12. Nakamura A. Effects of Nicotine Contained in Tobacco Mainstream Smoke on Vascular Smooth Muscle Cells. In: Atherosclerosis - Yesterday, Today and Tomorrow. InTech; 2018 .

13. Hisamatsu T, Miura K, Arima H, Kadota A, Kadowaki S, Torii S, Suzuki S, Miyagawa N, Sato A, Yamazoe M, Fujiyoshi A, Ohkubo T, Yamamoto T, Murata K, Abbott RD, et al. Smoking, Smoking Cessation, and Measures of Subclinical Atherosclerosis in Multiple Vascular Beds in Japanese Men. Journal of the American Heart Association. 2016;5(9).

14. Jöckel KH, Lehmann N, Jaeger BR, Moebus S, Möhlenkamp S, Schmermund A, Dragano N, Stang A, Grönemeyer D, Seibel R, Mann K, Volbracht L, Siegrist J, Erbel R. Smoking cessation and subclinical atherosclerosis-Results from the Heinz Nixdorf Recall Study. Atherosclerosis. 2009;203(1):221-227. 
15. Ehara S, Kobayashi Y, Yoshiyama M, Shimada K, Shimada Y, Fukuda D, Nakamura Y, Yamashita H, Yamagishi H, Takeuchi K, Naruko T, Haze K, Becker AE, Yoshikawa J, Ueda M. Spotty calcification typifies the culprit plaque in patients with acute myocardial infarction: An intravascular ultrasound study. Circulation. 2004;110(22):3424-3429.

16. Yun YS, Choi SJ, Lee JY, Kim YS, Yoon SA, Park SC, Shin OR, Jang EJ, Kim YO. Impact of arterial microcalcification of the vascular access on cardiovascular mortality in hemodialysis patients. Hemodialysis International. 2014;18(1):54-61.

17. Jia H, Abtahian F, Aguirre AD, Lee S, Chia S, Lowe H, Kato K, Yonetsu T, Vergallo $\mathrm{R}$, Hu S, Tian J, Lee H, Park SJ, Jang YS, Raffel OC, et al. In vivo diagnosis of plaque erosion and calcified nodule in patients with acute coronary syndrome by intravascular optical coherence tomography. Journal of the American College of Cardiology. 2013;62(19):1748-1758.

18. Hutcheson JD, Maldonado N, Aikawa E. Small entities with large impact: Microcalcifications and atherosclerotic plaque vulnerability. Current Opinion in Lipidology. 2014;25(5):327-332.

19. Schurgers LJ, Geleijnse JM, Grobbee DE, Pols HAP, Hofman A, Witteman JCM, Vermeer C. Nutritional Intake of Vitamins K1 (Phylloquinone) and K2 (Menaquinone) in The Netherlands. Journal of Nutritional \& Environmental Medicine. 1999;9(2):115122.

20. Halder M, Petsophonsakul P, Akbulut AC, Pavlic A, Bohan F, Anderson E, Maresz K, Kramann R, Schurgers L. Vitamin K: Double Bonds beyond Coagulation Insights into Differences between Vitamin K1 and K2 in Health and Disease. International journal of molecular sciences. 2019;20(4).

21. Willems BAG, Vermeer C, Reutelingsperger CPM, Schurgers LJ. The realm of vitamin $\mathrm{K}$ dependent proteins: Shifting from coagulation toward calcification. Molecular Nutrition \& Food Research. 2014;58(8):1620-1635.

22. Schurgers LJ, Uitto J, Reutelingsperger CP. Vitamin K-dependent carboxylation of matrix Gla-protein: a crucial switch to control ectopic mineralization. Trends in Molecular Medicine. 2013;19(4):217-226.

23. Brandenburg VM, Reinartz S, Kaesler N, Krüger T, Dirrichs T, Kramann R, Peeters F, Floege J, Keszei A, Marx N, Schurgers LJ, Koos R. Slower Progress of Aortic Valve Calcification With Vitamin K Supplementation. Circulation. 2017;135(21):2081-2083.

24. Vos M, Esposito G, Edirisinghe JN, Vilain S, Haddad DM, Slabbaert JR, Van Meensel S, Schaap O, De Strooper B, Meganathan R, Morais VA, Verstreken P. Vitamin K2 Is a Mitochondrial Electron Carrier That Rescues Pink1 Deficiency. Science. 2012;336(6086):1306-1310.

25. Li J, Lin JC, Wang H, Peterson JW, Furie BC, Furie B, Booth SL, Volpe JJ, Rosenberg PA. Novel role of vitamin $\mathrm{k}$ in preventing oxidative injury to developing oligodendrocytes and neurons. The Journal of neuroscience: the official journal of the Society for Neuroscience. 2003;23(13):5816-26.

26. Li J, Wang H, Rosenberg PA. Vitamin K prevents oxidative cell death by inhibiting activation of 12-lipoxygenase in developing oligodendrocytes. Journal of Neuroscience Research. 2009;87(9):1997-2005.

27. Bridge A, Barr R, Morré DJ. The plasma membrane NADH oxidase of soybean has vitamin $\mathrm{K}(1)$ hydroquinone oxidase activity. Biochimica et biophysica acta. 2000;1463(2):448-58.

28. Beinema M, Brouwers JRBJ, Schalekamp T, Wilffert B. Pharmacogenetic differences between warfarin, acenocoumarol and phenprocoumon. Thrombosis and haemostasis. 2008;100(6):1052-7. 
29. STAFFORD DW. The vitamin K cycle. Journal of Thrombosis and Haemostasis. 2005;3(8):1873-1878.

30. Chatrou MLL, Winckers K, Hackeng TM, Reutelingsperger CP, Schurgers LJ. Vascular calcification: The price to pay for anticoagulation therapy with vitamin K-antagonists. Blood Reviews. 2012;26(4):155-166.

31. Schurgers LJ, Aebert H, Vermeer C, Bültmann B, Janzen J. Oral anticoagulant treatment: friend or foe in cardiovascular disease? Blood. 2004;104(10):3231-3232.

32. Weijs B, Blaauw Y, Rennenberg RJMW, Schurgers LJ, Timmermans CCMM, Pison L, Nieuwlaat R, Hofstra L, Kroon AA, Wildberger J, Crijns HJGM. Patients using vitamin $\mathrm{K}$ antagonists show increased levels of coronary calcification: an observational study in low-risk atrial fibrillation patients. European Heart Journal. 2011;32(20):2555-2562.

33. Eggebrecht L, Prochaska JH, Schulz A, Arnold N, Jünger C, Göbel S, Laubert-Reh D, Binder H, Beutel ME, Pfeiffer N, Blankenberg S, Lackner KJ, Spronk HM, Ten Cate H, Münzel T, et al. Intake of Vitamin K Antagonists and Worsening of Cardiac and Vascular Disease: Results From the Population-Based Gutenberg Health Study. Journal of the American Heart Association. 2018;7(17): $\mathrm{e} 008650$.

34. Plank F, Beyer C, Friedrich G, Stühlinger M, Hintringer F, Dichtl W, Wildauer M, Feuchtner G. Influence of vitamin $\mathrm{K}$ antagonists and direct oral anticoagulation on coronary artery disease: A CTA analysis. International journal of cardiology. 2018;260:11-15.

35. Demer LL, Tintut Y. Vascular calcification: Pathobiology of a multifaceted disease. Circulation. 2008;117(22):2938-2948.

36. Liu W, Zhang Y, Yu CM, Ji QW, Cai M, Zhao YX, Zhou YJ. Current understanding of coronary artery calcification. Journal of Geriatric Cardiology. 2015;12(6):668-675.

37. Krüger T, Oelenberg S, Kaesler N, Schurgers LJ, van de Sandt AM, Boor P, Schlieper G, Brandenburg VM, Fekete BC, Veulemans V, Ketteler M, Vermeer C, JahnenDechent W, Floege J, Westenfeld R. Warfarin Induces Cardiovascular Damage in Mice. Arteriosclerosis, Thrombosis, and Vascular Biology. 2013;33(11):2618-2624.

38. Luo G, Ducy P, McKee MD, Pinero GJ, Loyer E, Behringer RR, Karsenty G. Spontaneous calcification of arteries and cartilage in mice lacking matrix GLA protein. Nature. 1997;386(6620):78-81. 


\section{Chapter 8}

Summary 
Chapter 1 provides fundamental knowledge on current understanding of aortic aneurysm and vascular calcification. Abdominal aortic aneurysm is a dilation of the aortic vessel wall and is most commonly found among men, older age population, and smokers. The underlying mechanism how aneurysm is formed has not been elucidated in detail. Current management relies exclusively on surgical repair in order to prevent rupture and there is no pharmacotherapy is yet recommended thus far. Vascular calcification is an active process of calcium-phosphate crystal deposition and is associated with cardiovascular diseases including aortic aneurysm. Numerous processes have been proposed as pathological mechanism for the initiation of vascular calcification including loss of calcification inhibitors and osteochondrogenic-like cells. VSMCs are the major cell type in the vessel and play an important role in vascular pathology and vascular remodeling. VSMC elicits a remarkable phenotypic plasticity and they are important mediators of vascular calcification through differentiation in osteochondrogenic phenotype. Moreover, VSMCs harbor MGP - a vitamin $\mathrm{K}$ dependent protein (VKDP) which is an important calcification inhibitor. Chapter 2 describes the role of vitamin $\mathrm{K}$ in depth. Vitamin $\mathrm{K}$ is an essential bioactive compound which acts as a cofactor for the carboxylation of hepatic and extrahepatic vitamin $\mathrm{K}$ dependent proteins. We elaborated on the different functions and implications in diseases of vitamin $\mathrm{K}$ beyond its well-established role in coagulation. There are two naturally occurring vitamin $\mathrm{K}$ : Phylloquinone (K1) and Menaquinones (K2), both of which facilitate hepatic VKDPs activation and coagulation processes. Specifically, we highlight the role of vitamin K2 which is more able to redistribute to the circulation and assist extrahepatic VKDPs in maintaining bone hemostasis as well as inhibiting ectopic calcification. Vitamin K2, specifically MK-7, has the longest bioavailability and is most efficiently absorbed. We summarized the current implications of vitamin $\mathrm{K}$ in different clinical settings including osteoporosis, atherosclerosis, cancer, and inflammatory diseases.

Chapter 3 elaborates on what is currently known about the role of VSMC phenotypic switching in pathophysiology of aortic aneurysm formation. We highlight that calcification of the vessel wall is involved in the initiation and progression of both thoracic and abdominal aortic aneurysms. Thus, early detection of microcalcification may help to hold aortic aneurysm progression. VSMCs actively mediate changes in aortic wall structure that lead to aneurysm formation and vascular calcification through a process called phenotypic switching. This phenotypic switching can be triggered by various stimuli including oxidative stress which is an important factor underlies the pathology of aortic aneurysm. In our review, we extend on current knowledge by providing an insight of the involvement of vitamin K-dependent 
processes in aortic aneurysm. Vitamin $\mathrm{K}$ helps decrease vascular calcification through facilitation of MGP, a VKDP which is synthesized by VSMCs. Moreover, vitamin K and vitamin K-oxidoreductase are involved in the regulation of Nox and ROS generation. We shed light on potential treatment mechanisms with vitamin $\mathrm{K}$ to prevent vascular calcification induced aortic aneurysm formation and progression.

In Chapter 4, we characterized human AAA VSMCs and compared them to VSMCs from a non-aneurysm region of the same patient. AAA VSMCs undergo phenotypic switching, activating several mechanisms leading to vascular calcification. AAA VSMCs lose contractility and assume the synthetic phenotype. This is accompanied by alterations in VSMC oxidative stress and EV release. AAA VSMCs further differentiate towards macrophage-like and osteo/chondrogenic-like VSMCs displaying a SASP phenotype. Pro-inflammatory AAA VSMCs secrete IL6 which induces inflammatory responses in ECs. We hypothesized that these AAA VSMC features, together with an increase in ucMGP (inactive calcification inhibitor), induces microcalcification. Microcalcification is known to cause destructive changes in the surrounding extracellular matrix and leads to weakening of the vessel wall. Macrocalcification develops over time and further aggravates the dilation of the vessel.

In Chapter 5, we investigate how smoking affects vascular calcification. Calcification, specifically microcalcification, was found at a higher level in atherosclerotic plaques of smokers compared to non-smokers. We unraveled the mechanism how nicotine initiates VSMC calcification. Nicotine directly affects VSMCs by increasing intracellular calcium, oxidative stress, EV release, and subsequently calcification through binding of $\alpha 3$ and $\alpha 7 \mathrm{nACh}$ receptor. Binding of nicotine to $\mathrm{nACh}$ resulted in a rapid increase of calcium influx and induced calcium dependent-Nox 5 activation generating ROS. We identified Nox 5 as a key mediator in inducing pro-calcific processes of VSMCs by nicotine. Finally, we showed that vitamin K2 (MK-7) ameliorates nicotine-induced VSMC pathologies including reduced oxidative stress, EV release and calcification.

In Chapter 6, we used a preclinical animal model to demonstrate the effect of vitamin $\mathrm{K} 2$ on atherosclerotic plaque development and calcification. We report that discontinuation of VKA prevents vascular calcification in atherosclerotic plaques compared to long-term VKA treatment. Supplementation of vitamin K2 not only prevents vascular intima calcification, but also reduces atherosclerotic plaque progression and improves plaque stability by reducing oxidative stress and increasing collagen content. These findings support a potential use of vitamin K2 supplementation for treatment of atherosclerosis and calcification in the clinical settings. 



\section{Appendix}

Valorisation 


\section{Valorisation}

Aortic aneurysm is a life-threatening, pathological condition characterized by permanent dilation of the aorta. Aortic aneurysm is associated with male gender, advanced age, hypertension, genetic diseases and lifestyle factors such as smoking. Because of lack of understanding of the pathology underlying aneurysm formation, no pharmacotherapy is yet recommended to reduce risk of aortic aneurysm progression and rupture. Current management of aneurysms relies exclusively on surgical repair in order to prevent rupture. Decision for the type of repair requires careful assessment of rupture risk, specific feature or anatomy, lifeexpectancy, and patient's preference. Although medical advancement enables less invasive surgical treatments such as Endovascular aneurysm repair (EVAR) over the previous decade. EVAR comes with higher reintervention rate and cost.

Better knowledge of basic mechanisms underlying aortic aneurysm will open up novel avenues for intervention and disease management. Key areas which offer great opportunities to advance knowledge regarding aneurysm formation have been proposed by medical experts in the field and include the following topics: 1. definition of etiologic factors responsible for development of aortic aneurysm, with an emphasis on elucidating biological mechanisms by which specific risk factors might act to promote aortic disease such as atherosclerosis and hypertension; 2. elucidation of genetic loci for an inherited predisposition; 3. better definition of the cellular and molecular pathophysiology of aneurysms, with emphasis on the mechanisms underlying progressive destruction of aortic wall. This includes the role of specific proteinases, nature of immune response, and better understanding of the role of VSMC in disease initiation and progression. ${ }^{5}$

The research described in this thesis aims to unravel mechanisms underlying aortic aneurysm formation. We characterized VSMCs from aortic aneurysm tissue with specific focus on the involvement of vascular calcification in the pathogenesis of abdominal aortic aneurysm. Moreover, we studied the effect of smoking, the strongest life-style risk factor for development of aneurysm, on VSMCs and explored the role of vitamin $\mathrm{K}$ as potential anti-calcific and antioxidant therapy in vascular pathologies.

Current implications of vitamin $\mathrm{K}$ and vitamin $\mathrm{K}$ dependent proteins in cardiovascular diseases are described in Chapter 2. The importance of VSMCs in vascular pathologies, with a focus on aortic aneurysm, is emphasized in Chapter 3. In this chapter, we extended on current knowledge by providing an insight in the involvement of vitamin K-dependent processes in 
aortic aneurysm and shed light on potential treatment mechanisms with the nutraceutical vitamin $\mathrm{K}$ to prevent vascular calcification induced aortic aneurysm formation and progression.

In Chapter 4, we characterized VSMCs from aneurysm patients and compared apparently healthy VSMCs and VSMCs from the abdominal aneurysm of the same patient. Understanding the basic pathologies of aortic aneurysm promote emergence of new approaches that would result in a better disease management. The findings in this chapter extend the current knowledge of aneurysmal VSMCs characteristic and morphology which has mainly been described based on studies in animal models. Importantly, we report that aneurysmal VSMCs are less contractile, increase extracellular vesicle release, and calcified more than control VSMCs. Our findings emphasize the importance of VSMCs in aortic aneurysm and its significant role in mediating vascular microcalcification which is observed during aortic aneurysm progression. Indeed, use of ${ }^{18} \mathrm{~F}-\mathrm{NaF}$ to detect microcalcification recently became a promising additive tool to predict aneurysm progression and clinical events. It is particularly useful for patients in which the decision to intervene is challenging. We put forward (micro) calcification as an important risk factor amendable for intervention in AAA. Thus, targeting of VSMCs and extracellular vesicles may prevent vascular microcalcification and thus reduce aggravation of aortic diseases.

In a pilot study, we showed that aneurysmal tissue is positive for (inactive) ucMGP, a marker used for indication of vascular vitamin $\mathrm{K}$ deficiency. Vascular vitamin $\mathrm{K}$ deficiency is associated with increased vascular calcification. Future studies in aneurysm patients measuring plasma inactive ucMGP as biomarker might provide insight on aortic aneurysm risk, hence provide a novel treatment area using vitamin $\mathrm{K}$ to improve vitamin $\mathrm{K}$ status.

Nicotine is known for its devastating effects on the vasculature. It increases risk of atherosclerotic calcification and abdominal aortic aneurysm. In Chapter $\mathbf{5}$ we investigated the molecular mechanisms how nicotine potentially affects the vasculature. We revealed that smoking is associated with higher degree of microcalcification in atherosclerotic plaques and unravel a potential mechanism by which nicotine affects VSMC via Nox5-mediated procalcific processes. We demonstrated the involvement of $\alpha 3$ and $\alpha 7$ nicotine acetylcholine receptor in nicotine-induced VSMC pathologies which thus serve as potential targets for pharmacological intervention. Moreover, we show that downstream of nicotine binding to the nAChr induces oxidative stress and causes extracellular vesicle mediated calcification. Our data contribute to the understanding of how nicotine not only affects atherosclerotic plaque calcification, but possibly also other VSMC-mediated vascular diseases, such as hypertension and aortic aneurysm. Because nicotine is the primary agent in both cigarettes and e-cigarettes, 
our findings also add to the current knowledge that vaping may not be a better and healthier choice for vascular health.

In chapter 5, we provide evidence that vitamin K2, besides being a cofactor for the carboxylation of matrix Gla-protein to inhibit vascular calcification, is an effective antioxidant ameliorating nicotine-induced oxidative stress and extracellular vesicle release, subsequently inhibiting calcification of VSMCs. Vitamin K2 is naturally present in fermented food and is also available as supplement. The use of vitamin K2 is an easy, safe and cost-effective way to maintain vascular health and prevent vascular disease. In chapter 6, we further provide evidence on cardiovascular promoting effects of vitamin $\mathrm{K} 2$ in vivo. Using an animal model of atherosclerosis, we show that discontinuation of VKA and switch to supplementation with vitamin $\mathrm{K} 2$ prevents vascular calcification and reduces atherosclerotic plaque progression. Our findings emphasized an adequate status of vitamin $\mathrm{K} 2$ for vascular health and put forward clinical implications of vitamin K2 supplementation to treat cardiovascular diseases. 


\section{Reference}

1. O'Leary SA, Mulvihill JJ, Barrett HE, Kavanagh EG, Walsh MT, McGloughlin TM, Doyle BJ. Determining the influence of calcification on the failure properties of abdominal aortic aneurysm (AAA) tissue. Journal of the Mechanical Behavior of Biomedical Materials. 2015;42:154-167.

2. Buijs RVC, Willems TP, Tio RA, Boersma HH, Tielliu IFJ, Slart RHJA, Zeebregts CJ. Calcification as a Risk Factor for Rupture of Abdominal Aortic Aneurysm. European Journal of Vascular and Endovascular Surgery. 2013;46(5):542-548.

3. Speelman L, Bohra A, Bosboom EMH, Schurink GWH, Van De Vosse FN, Makaorun MS, Vorp DA. Effects of wall calcifications in patient-specific wall stress analyses of abdominal aortic aneurysms. Journal of Biomechanical Engineering. 2007;129(1):105109.

4. Forsythe RO, Dweck MR, McBride OMB, Vesey AT, Semple SI, Shah ASV, Adamson PD, Wallace WA, Kaczynski J, Ho W, van Beek EJR, Gray CD, Fletcher A, Lucatelli C, Marin A, et al. 18 F-Sodium Fluoride Uptake in Abdominal Aortic Aneurysms. Journal of the American College of Cardiology. 2018;71(5):513-523.

5. Wassef M, Upchurch GR, Kuivaniemi H, Thompson RW, Tilson MD. Challenges and opportunities in abdominal aortic aneurysm research. Journal of Vascular Surgery. 2007;45(1):192-198. 



\section{Appendix}

About the author 



\section{About the author}

Ploingarm Petsophonsakul was born on 18th March 1990 in Würzburg, Germany. At the age of five, she moved to Thailand and completed high school education from the Prince' Royals College in Chiang Mai. During her high school, she received a one-year student exchange scholarship from the AFS Intercultural programs to study in Finland. In 2009, she started her Bachelor education in Medical Technology at the Faculty of Associated Medical Sciences, Chiang Mai University, Thailand. She performed her Bachelor thesis in cancer research and received a student exchange scholarship from Yamauchi University School of Medicine, Japan, in order to research at the Department of Laboratory Sciences, Faculty of Health Sciences. She was awarded entrance into the Bachelor's degree program with the highest entrance exam score and obtained a Bachelor of Science degree with First Class Honors in 2013. After graduation, she was offered a position as a Clinical Marketing Specialist at Roche Diagnostic (Thailand) Ltd. where she specialized in innovative biomarkers, and served as a scientific contact linking the Key Opinion Leaders (KOL) with the company, and scientifically supporting sales representatives. In 2014, she was accepted into the Master program of Molecular Bioengineering at the Technische Universität Dresden, Germany. During her Master study, she worked as a research assistant at Max Planck Institute of Molecular Cell Biology and Genetics (MPI-CBG) and performed her internship at the Center for Regenerative Therapies Dresden (CRTD). She received an ERASMUS grant and a PROMOS scholarship of the Deutscher Akademischer Austauschdienst (DAAD) to perform her Master thesis in the Structural Biophysics group at the Institute of Pharmacology and Structural Biology (iPBS), Toulouse, France, where she contributed to research in the field of Drug discovery. In 2016, she was accepted into a 3-year doctoral training program by the European Vascular Interventions and Therapeutic Innovation Network (EVOluTION) -a Marie Sklodowska-Curie Actions Innovative Training Network, and a $\mathrm{PhD}$ position at the department of Biochemistry under the supervision of Prof. Dr. Leon Schurgers. During her PhD training, she was on an industrial secondment at NattoPharma in Krakow, Poland, where she implemented scientific research into product development and commercialization; and a research secondment at Queen Mary University of London, United Kingdom, where her research was focused on vascular inflammation. The aim of her $\mathrm{PhD}$ project was to investigate the role of vascular remodeling in atherosclerosis and aortic aneurysm, with a specific focus on the involvement of vascular calcification. 



\section{Appendix}

Publications 


\section{Publications}

Akbulut AC*, Pavlic A*, Petsophonsakul P*, Halder M*, Maresz K, Kramann R, Schurgers L. Vitamin K2 Needs an RDI Separate from Vitamin K1. Nutrients. 2020 Jun 21;12(6):1852.

Petsophonsakul P, Furmanik M, Forsythe R, Dweck M, Schurink GW, Natour E, Reutelingsperger C, Jacobs M, Mees B, Schurgers L. Role of Vascular Smooth Muscle Cell Phenotypic Switching and Calcification in Aortic Aneurysm Formation. Arterioscler Thromb Vasc Biol. 2019 Jul;39(7):1351-1368.

Halder M*, Petsophonsakul P*, Akbulut AC*, Pavlic A*, Bohan F, Anderson E, Maresz K, Kramann R, Schurgers L. Vitamin K: Double Bonds beyond Coagulation Insights into Differences between Vitamin K1 and K2 in Health and Disease. Int J Mol Sci. 2019 Feb 19;20(4):896.

Petsophonsakul P, Pompimon W, Banjerdpongchai R. Apoptosis induction in human leukemic promyelocytic HL-60 and monocytic U937 cell lines by goniothalamin. Asian Pac J Cancer Prev. 2013;14(5):2885-9.

\section{Publications in Preparation}

Petsophonsakul P*, Burgmaier M*, Willems B, Heeneman S, Stadler N, Gremse F, Reith S, Burgmaier K, Kahles F, Marx N, Natour E, Bidar E, Jacobs M, Mees B, Reutelingsperger C, Furmanik M, Schurgers L. Nicotine promotes vascular calcification via intracellular $\mathrm{Ca} 2+-$ mediated, Nox5-induced oxidative stress and extracellular vesicle release in vascular smooth muscle cells. (submitted)

Petsophonsakul P, Mees B, Shiels P, Panagiotou N, Buchanan S, Oggero S, Jacobs M, Kramann R, Furmanik M, Schurgers L. Vascular smooth muscle cells from abdominal aortic aneurysm are characterised by a dysregulated inflammatory phenotype and oxidative stress with increased extracellular vesicle release, accelerated senescence and calcification. (in preparation)

van Gorp R, Petsophonsakul P, Jaminon A, Leenders P, Jahnen-Dechent W, Reutelingsperger $\mathrm{C}$, Schurgers L.Vitamin $\mathrm{K}$ inhibits vascular smooth muscle cell induced calcification via reduced oxidative stress and extracellular vesicle secretion. (in preparation)

Oral Presentation

\section{Oral and Poster presentation}

Petsophonsakul P, Furmanik M, Mees B, Schurgers L. Vitamin K ameliorates nicotineinduced calcification of VSMCs by inhibiting oxidative stress and extracellular vesicle secretion. European Atherosclerosis Society (EAS) congress, May 2019, Maastricht, the Netherlands 
Petsophonsakul P, Furmanik M, Mees B, Schurgers L. Nutraceutical modulating the vascular vitamin K system. European Vascular Interventions and Therapeutic Innovation Network (EVOluTION) congress, September 2019, Munich, Germany.

Petsophonsakul P, Furmanik M, Mees B, Schurgers L. Vitamin K ameliorates nicotineinduced calcification of VSMCs by inhibiting oxidative stress and extracellular vesicle secretion. British Pharmacological Society (BPS), December 2018, London, United Kingdom. 



\section{Appendix}

Acknowledgement 


\section{Acknowledgement}

The completion of this thesis represents four years of my academic adventure towards a doctoral degree. This incredible milestone has been greatly influenced by many people to whom I would like to acknowledge and extend my heartfelt gratitude.

My deepest gratitude goes firstly to my supervisors, Prof. Dr. Leon Schurgers, Prof. Dr. Chris Reutelingsperger and Dr. Barend Mees, who played a central role in my achieving this thesis. Dear Leon, you gave me the great opportunity of obtaining the Marie-Curie fellowship and a $\mathrm{PhD}$ position within your group, for which I will be forever grateful. The initial proposal of my project was broad, but with your positive outlook and confidence, it evolved into a great research, of which I am very proud. Rather than handing me a written plan during the past four years, you chose to encourage us in how to think and do research in ways that come naturally to us, which are built on our own individual strength. Thank you for giving me the time and space to grow as a researcher and the freedom to explore my research interest. Your drive and enthusiasm have always been contagious. They influenced me greatly and my intellectual horizon truly broadened through what I learnt from you. Dear Chris, once in a while I had the chance to present my work to you during group meetings. Each time, I was captivated by your immense knowledge and constructive comments. Everything you mentioned had a hint of philosophical wisdom, which will always remind me of why we do science. Your insights helped to improve the quality of this thesis. You made me think beyond research and for this I am very grateful. Dear Barend, you continuously supported my project and provided all the material we needed for the research. Through your generous help and connections, I was able to retrieve some of the most important data, which seemed impossible to acquire. It was always a pleasant surprise when I received confirmation to attend those amazing conferences, to which you anonymously registered my name. Thank you for exposing me to the clinical aspects and allowing me to witness your AAA operation, which was surreal. Your energy was inspirational and led me to believe that my research could be translated and meaningful for patients.

Herewith, I would like to extend my sincere appreciation to the assessment committee, Prof. Dr. Tilman Hackeng, Prof. Dr. Jos Maessen, Prof. Dr. Guido Haenen, Dr. Alexander Gombert and Dr. Kak Khee Yeung for the valuable time they took to review this thesis and their acceptance of the invitation to judge my defense. 
I would like to acknowledge the European Vascular Interventions and Therapeutic Innovation Network (EVOluTION), which, next to interdisciplinary and cross-cutting research, provided a multidisciplinary training program throughout my $\mathrm{PhD}$ training. I am grateful to Prof. Dr. Mauro Perretti, who coordinated the innovative training network (ITN) and supervised me during my research secondment at Queen Mary University of London. I am also grateful to our collaborators at NattoPharma; Dr. Kate Quackenbush, Dr. Hogne Vik and Eric Anderson, who guided my industrial secondment and provided fantastic training in entrepreneurial and commercial aspects of the sciences. The work in this thesis was supported by the European Union's Horizon 2020 research and innovation programme under the Marie Skłodowska-Curie grant, Agreement No 675111.

My most special thanks go to Rick and Armand, my paranymphs. I was amazed how sharing the tiniest office in the department with both of you created so many beautiful memories. Screaming in the office seemed ordinary, but hard feelings never lasted longer than a day. Lab work together could also get a little bit silly, but more importantly it was never boring. These two senior PhDs, who taught me all of the lab assays when I started, never failed to criticize, and were behind the greatest ideas. Both of you were there since the first day of my $\mathrm{PhD}$ and it is very meaningful that you are going to stand with me on the last day of this $\mathrm{PhD}$ journey. Dear Rick, I was fascinated by your curiosity and the way you always came up with the strangest questions, which tended to speed up a dull afternoon effortlessly. In fact, I missed my reserved culture slots a couple of times because I was enjoying our frank discussions so much. Your honest thoughts were always refreshing to hear and your encouragement on my dreaded days helped me more than you probably realized. I am grateful for those wonderful years, during which I got to know you. Thank you for all your support, smart input in many experimental set-ups, and of course, all of the guaranteed-success protocols you passed on. Dear Armand, I am indebted to you for all the food from your lunch box and overripe fruits you shared with me daily. I appreciated your openness and drop-in texts from time to time to check whether I was still alive (especially during my holiday). You are one of the most reliable and selfless persons I know, who also took on a great deal of responsibility for the group. The amount of time you helped me seemed infinite, and each time you were there to ensure everything ran smoothly from start to end. The red chair next to your desk, where people kept bumping their head on the shelf, stood there for a reason - you are always open to others and welcoming. 
I would like to mention other special colleagues and researchers who played an important role in my PhD years. P' Bird (Kanin), you are a person I admire tremendously and have incredible respect for, both professionally and personally. You gave me the strongest moral support during my $\mathrm{PhD}$, and your sharp vision always got me through complex situations. Long multi-course dinner on Sunday nights tells a lot about this friendship. Funnily enough, it was never Thai food and never too spicy, which can involve sweat and tears. Thank you for being like my family and keeping my Thai fluency in check. Wishing you a lot of success in whatever path you choose to take in the future. Gosia, when I first arrived in Maastricht, we were the only two international colleagues in the group. I remember that our first email was a Maastricht survival guide. I always enjoyed our conversations, which were followed occasionally by a plant swap. I would like to acknowledge that your contribution to the work in this thesis was extremely important. Thank you for your help in shaping and guiding me with my manuscript and response to the reviewers in the smartest and wittiest way. What I learned from you as a scientist is invaluable and I was grateful for the chance to work with you. Petra, you were the one who kept our lab running smoothly, ensured that we had the best workspace and equipment, and saved us from all the lady inspectors. Thank you for being the expert and best source of solutions in the area where I totally lost connection. I will always remember the warm welcome you gave me at your home and allowing me to learn a whole new science of astronomy from your son, Twan. Cecile, you brought in so much positivity into our group and you are my own definition of 'gezelligheid'. Everything in the lab was achievable and so much fun when you were there. Tuesday and Wednesday were certainly more special than the rest of the week and I am thankful that you always kept cool every time I came in with a last-minute lab purchase. Niko D, Peter, and Liset, you made up this amazing group and I will definitely miss the fruitful daily lunchtime chats we had. Thank you for always guiding us and demonstrating great laboratory practice. Maurice, Cengiz and Angelina, it was never my idea to spend a month living together in a four-bedroom apartment in Krakow, but it turned out to be the most memorable work trip and a fine summer. With countless cafehoppings to get the work done, we achieved 2 reviews, which have now been published. That was great collaboration between two ITNs and I am grateful that we shared the experience together. Greg, I could never have enough of your genuineness and optimism. It's amazing how you always brought that into the lab and meetings. All the best with finishing the PhD. To our growing group members, Niko R, Rogier, Vanessa and Anxhela, good luck with your $\mathrm{PhD}$ project and enjoy the exciting years ahead. Special thanks go to Trees for always dropping by to check that everything was all right, share her stories and help me with making contracts, 
sorting out visas, and submitting this thesis. I would like to thank my Biochemistry colleagues and the Biochemistry Department. I have been a part of many laboratory environments and there's nowhere quite like yours. This department is made up of amazing and genuine people and will always be a very special place for me.

I would like to acknowledge other fellow Early Stage Researchers (ESRs) within the EVOluTION ITN, Bim, Jan, Laura, Monika, Silvia, Antonino, Becci, Sanne and Chiara. Although we were scattered around in different places, we shared similar burdens, which were resolved every time we traveled together. Best of luck and success to all of them in their $\mathrm{PhD}$ projects and exciting chapters to come. Very special thanks go to Stravros and Annabelle, our managers, for their attentive virtual care and swift email responses.

Spending years away from home can be rough, but I was fortunate to meet a wonderful community of Thai students in Maastricht; Nac, P'Pui, P'Lek, P'Por (and P'Martin), Poan, Ice, P'SomO, Yada, Beau, Jul, and Boost, and Family Pieters; P'Nok, Khun Paul, and N'Than, who provided a happy distraction from my research. Thank you for making me laugh so hard my stomach hurt every time we met, for the adventurous trips, and for many authentic home-cooked meals that helped me not to miss home. I was well fed on every occasion.

Very special gratitude goes to all of my mentors who had known me for over twenty years and significantly influenced my life and career. I will never forget what they taught me. Bob, our weekly English lesson turned into hours of discussion about sales, psychology and human dynamics, which equipped me with valuable skills that set me off for career advancement. Khun Eugen, my family's dearest friend, who helped me on my troublesome days. Words cannot express how much I am thankful for his help and infinite generosity. My sincere appreciation goes next to Kru Ked Jittamas, Assoc Prof. Dr. Ratana Banjerdpongchai, Dr. Heiner Grandel and Dr. Lionel Mourey, who believed in me and gave me amazing opportunities in my career path. Hanna, Eero and Laura, who I cherish and fortunately have them as my second family in Finland.

Dear Brecht, the final draft of this thesis was fueled with delicious pancakes and lunches you made when I was too stressed to leave my laptop. Thank you for always being there for me, understanding, giving advice, and taking care of me. I'm lucky to be with a person who is not only super determined in his goals and choices, which is such an inspiration, but also very warm and caring. Your sense of humor is the most comforting thing and I am grateful for having you with me on this journey and on those to come. A special message goes to Maria and Martin, thank you for being an incredible advocate in my journey to finish my $\mathrm{PhD}$ and job search. Your warm welcome and endless supplies from your garden were most fulfilling. 
Lastly, I am most grateful to my family. There are no words that can describe how much I love them. Petnoi, my sister, who spent a few minutes every day before her toddler woke up around 5 am to design this beautiful thesis cover for me. She and my brother-in-law, Bene, have kept their door open for me during the last 6 years while I roamed around Germany, France, the Netherlands and UK. Thank you both for reminding me that family is not so far away. You stood by me and gave me the utmost in family support during this journey. This career path would not have been possible without both of you. To my nearest and dearest, Agu Hong, Agu Cheng, Agim Nat, Agim Luang, J'Meaw, J'Ngek and H'Ieng, thank you for your care and love through calls, visits and welfare packages that you sent while I was overseas. I appreciate you all so much for being close to my parents when I'm away. My final and most important thanks go to my parents who are the strongest foundation of my life, and made me who I am today. They have been my role models for learning, working and dealing with life successfully. Dear Papa and Mae, I cannot imagine how courageous you were to send us, and let us spend summer learning abroad every year on our own, since I was 6 years old. I believe this to be the most powerful form of education. I am grateful for the way you have raised me, guided me by examples, and how you have always treated me like an adult. Nothing would have been achieved without your encouragement in whatever direction I chose. Thank you for your endless support, even while I pursue my career and explore new paths on the other side of the world. The achievement of this doctoral degree is dedicated to you. 